Portland State University

PDXScholar

$5-2009$

\title{
Environmental Durability of Reinforced Concrete Deck Girders Strengthened for Shear with Surface Bonded Carbon Fiber-Reinforced Polymer
}

\author{
Christopher Higgins \\ Oregon State University \\ Matthew R. Dawson \\ Oregon State University \\ Mikal M. Mitchell \\ Oregon State University \\ Gautam Sopal \\ Oregon State University \\ A. Ekin Senturk \\ Oregon State University \\ Follow this and additional works at: https://pdxscholar.library.pdx.edu/trec_reports \\ Part of the Civil and Environmental Engineering Commons, and the Transportation Commons \\ Let us know how access to this document benefits you.
}

\section{Recommended Citation}

Higgins, Christopher, Matthew R. Dawson, Mikal M. Mitchell, Gautam Sopal,and A. Ekin Senturk. Environmental Durability of Reinforced Concrete Deck Girders Strengthened for Shear with Surface Bonded Carbon Fiber-Reinforced Polymer. Portland, OR: Transportation Research and Education Center (TREC), 2009. http://dx.doi.org/10.15760/trec.21

This Report is brought to you for free and open access. It has been accepted for inclusion in TREC Final Reports by an authorized administrator of PDXScholar. Please contact us if we can make this document more accessible: pdxscholar@pdx.edu. 

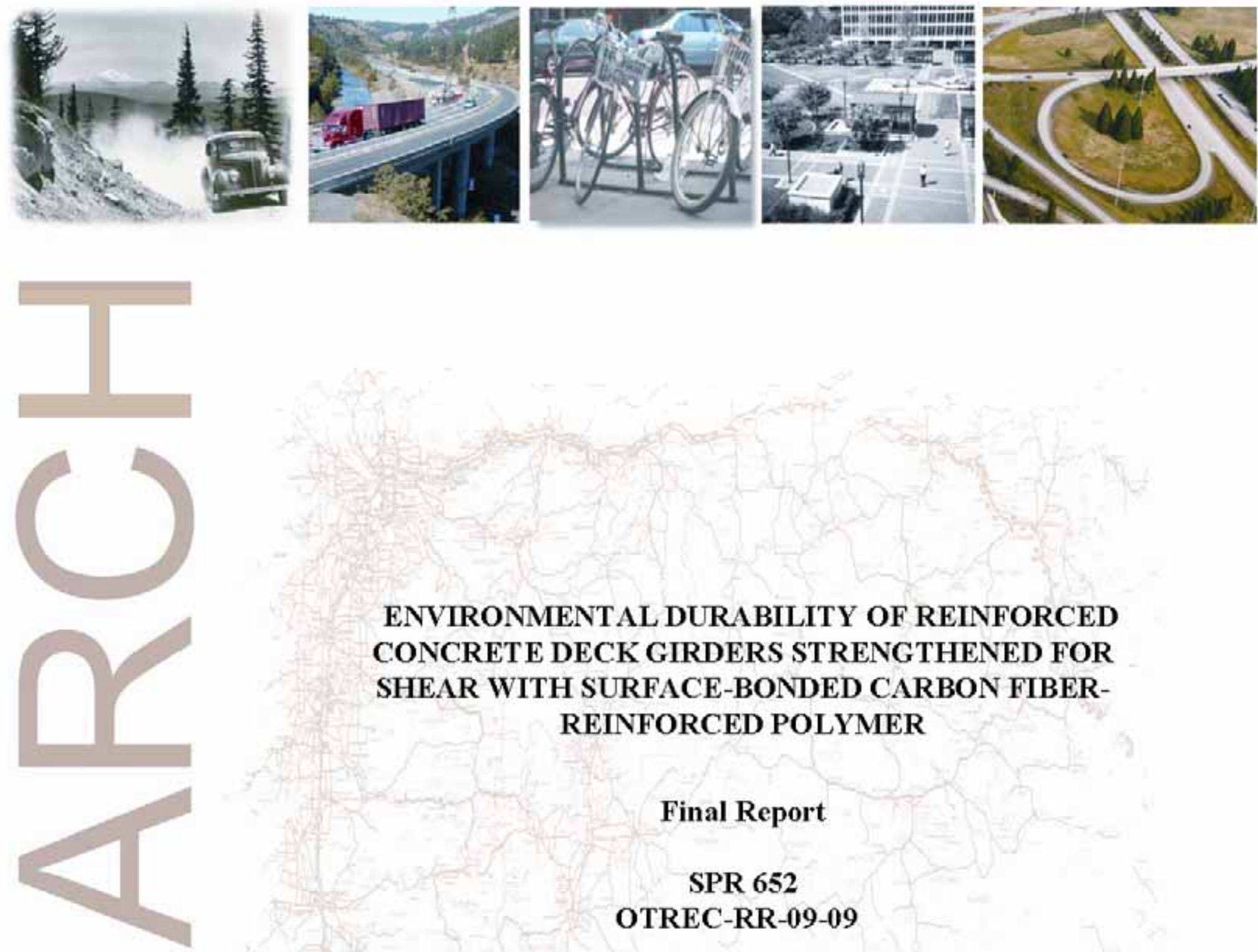

\title{
ENVIRONMENTAL DURABILITY OF REINFORCED CONCRETE DECK GIRDERS STRENGTHENED FOR SHEAR WITH SURFACE-BONDED CARBON FIBER- REINFORCED POLYMER
}

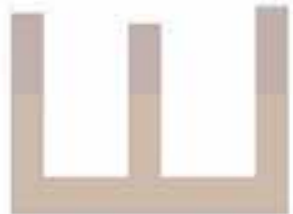

\author{
Final Report
}

SPR 652

OTREC-RR-09-09
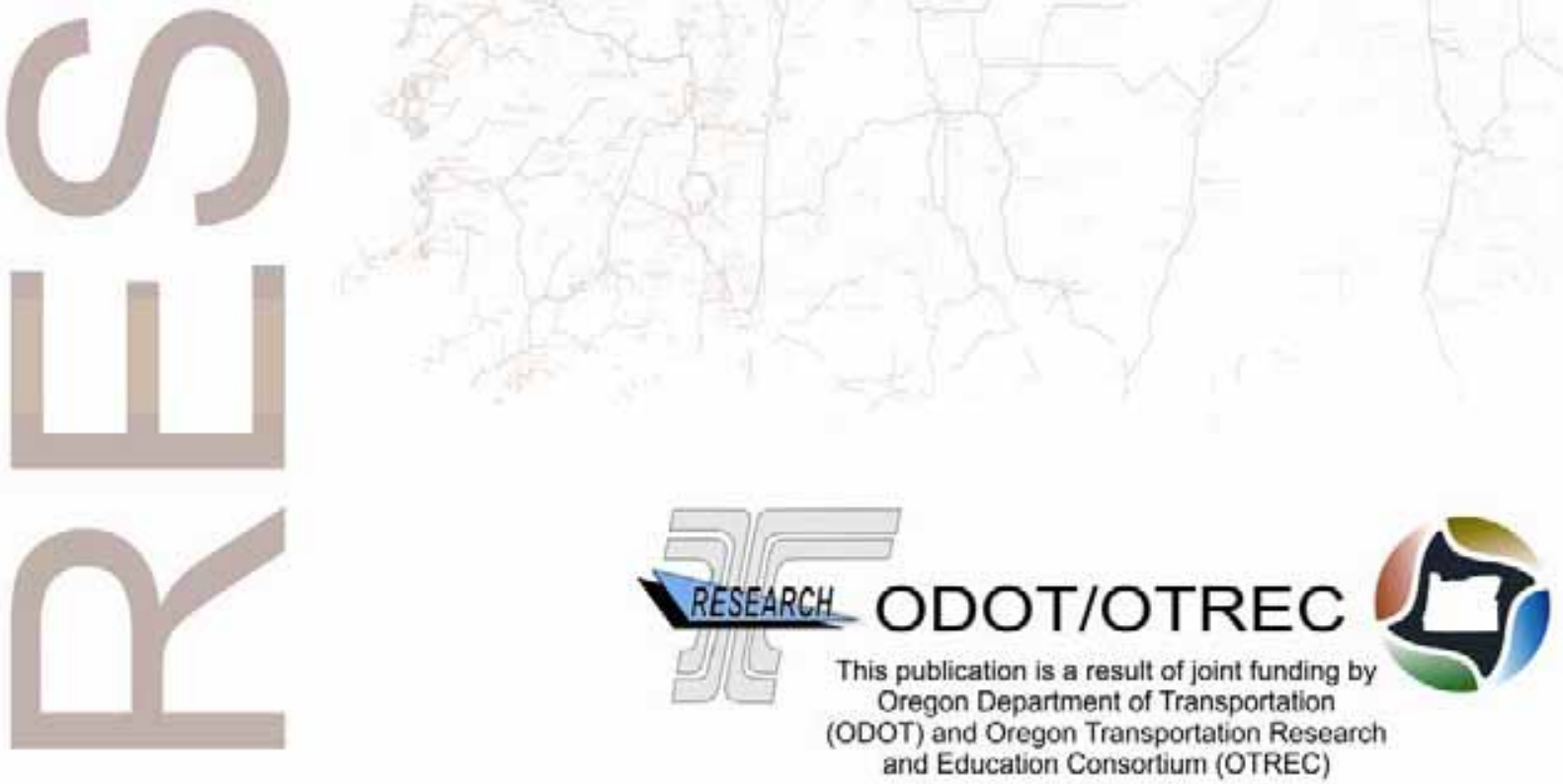



\title{
ENVIRONMENTAL DURABILITY OF REINFORCED CONCRETE DECK GIRDERS STRENGTHENED FOR SHEAR WITH SURFACE-BONDED CARBON FIBER-REINFORCED POLYMER
}

\author{
Final Report \\ SPR 652 \\ OTREC-RR-09-09
}

by

Christopher Higgins, Assistant Professor Matthew R. Dawson, Graduate Research Assistant Mikal M. Mitchell, Graduate Research Assistant

Gautam Sopal, Graduate Research Assistant

A. Ekin Senturk, Post-Doctoral Faculty Research Associate

\author{
School of Civil and Construction Engineering \\ Oregon State University \\ Corvallis, OR 97331 \\ for \\ Oregon Department of Transportation \\ Research Unit \\ 200 Hawthorne Ave. SE, Suite B-240 \\ Salem OR 97301-5192 \\ and \\ Federal Highway Administration \\ 400 Seventh Street, SW \\ Washington, DC 20590-0003 \\ and \\ Oregon Transportation Research \\ and Education Consortium \\ P.O. Box 751 \\ Portland, OR 97207
}

May 2009 

Technical Report Documentation Page

\begin{tabular}{|c|c|c|}
\hline $\begin{array}{l}\text { 1. Report No. } \\
\text { FHWA-OR-RD-09-17 }\end{array}$ & 2. Government Accession No. & 3. Recipient's Catalog No. \\
\hline \multicolumn{2}{|l|}{ 4. Title and Subtitle } & $\begin{array}{l}\text { 5. Report Date } \\
\text { May } 2009\end{array}$ \\
\hline \multicolumn{2}{|c|}{$\begin{array}{l}\text { Environmental Durability of Reinforced Concrete Deck Girders Strengthened } \\
\text { for Shear with Surface Bonded Carbon Fiber-Reinforced Polymer }\end{array}$} & 6. Performing Organization Code \\
\hline \multicolumn{3}{|c|}{$\begin{array}{l}\text { Christopher Higgins, PhD; Matthew R. Dawson, MS; Mikal M. Mitchell, MS; } \\
\text { Gautam Sopal, MS; A. Ekin Senturk, PhD }\end{array}$} \\
\hline \multicolumn{2}{|l|}{ 9. Performing Organization Name and Address } & 10. Work Unit No. (TRAIS) \\
\hline \multicolumn{2}{|c|}{$\begin{array}{l}\text { School of Civil and Construction Engineering } \\
\text { Oregon State University } \\
\text { Corvallis, OR } 97331\end{array}$} & $\begin{array}{l}\text { 11. Contract or Grant No. } \\
\text { SPR } 652 \\
\text { OTREC RR-09-09 }\end{array}$ \\
\hline \multicolumn{2}{|l|}{ 12. Sponsoring Agency Name and Address } & 13. Type of Report and Period Covered \\
\hline $\begin{array}{l}\text { Oregon Department of Transportation } \\
\text { Research Unit } \\
200 \text { Hawthorne Ave. SE, Suite B-240 } \\
\text { Salem, OR } 97301-5192\end{array}$ & \multirow{2}{*}{$\begin{array}{l}\text { Oregon Transportation Resea } \\
\text { and Education Consortium (C } \\
\text { P.O. Box } 751 \\
\text { Portland, Oregon } 97207\end{array}$} & Final Report \\
\hline $\begin{array}{l}\text { Salem, OR 97301-5192 } \\
\text { Federal Highway Administration } \\
400 \text { Seventh Street SW } \\
\text { Washington, DC 20590-0003 }\end{array}$ & & 14. Sponsoring Agency Code \\
\hline
\end{tabular}

15. Supplementary Notes

\section{Abstract}

This research investigated the durability of carbon fiber-reinforced polymer composites (CFRP) used for shear strengthening reinforced concrete deck girders. Large beams were used to avoid accounting for size effects in the data analysis. The effort included determining the role of freeze-thaw, moisture, and fatigue on structural performance and developing analytical design procedures that account for durability.

The results showed that moisture infiltration behind the CFRP, combined with freeze-thaw, was critical in reducing shear panel stiffness and shear capacity. Long-term moisture exposure alone produced only a minor decrease in shear capacity. Freeze-thaw, combined with fatigue, had little effect on shear capacity if water infiltration was minimized. Fatigue caused some debonding, but the debonding was not significant enough to affect capacity.

Use of ACI-318 with ACI 440 provided conservative predicted shear strengths after environmental exposure. However, the ACI approach did not provide uniform levels of safety because the observed conservatism was built into the prediction for the unstrengthened base specimens but not for the CFRP contribution. Consequently, a recommendation of the research is to apply the environmental exposure factor at the final design step to limit the effective CFRP stress/strain. For locations with very large numbers of wet freeze-thaw cycles and extended exposure to continuous moisture, the environmental reduction factors should be reduced even further. To better predict the CFRP bond strength demands that can occur due to shear-moment interaction, a further check of the design should be made beyond those required by ACI-440.

\section{Key Words}

CFRP; CARBON FIBER; COMPOSITE; STRENGTH; SHEAR; REINFORCED CONCRETE; BEAMS; GIRDERS; FREEZETHAW; FATIGUE; MOISTURE; ENVIRONMENT; DURABILITY; DESIGN

\section{Distribution Statement}

Copies available from NTIS, and online at http://www.oregon.gov/ODOT/TD/TP_RES/ and http://www.otrec.us

\begin{tabular}{|l|l|l|l|}
\hline $\begin{array}{l}\text { 19. Security Classification (of this report) } \\
\text { Unclassified }\end{array}$ & $\begin{array}{c}\text { 20. Security Classification (of this page) } \\
\text { Unclassified }\end{array}$ & $\begin{array}{c}21 . \text { No. of Pages } \\
210\end{array}$ & 22. Price \\
\hline
\end{tabular}




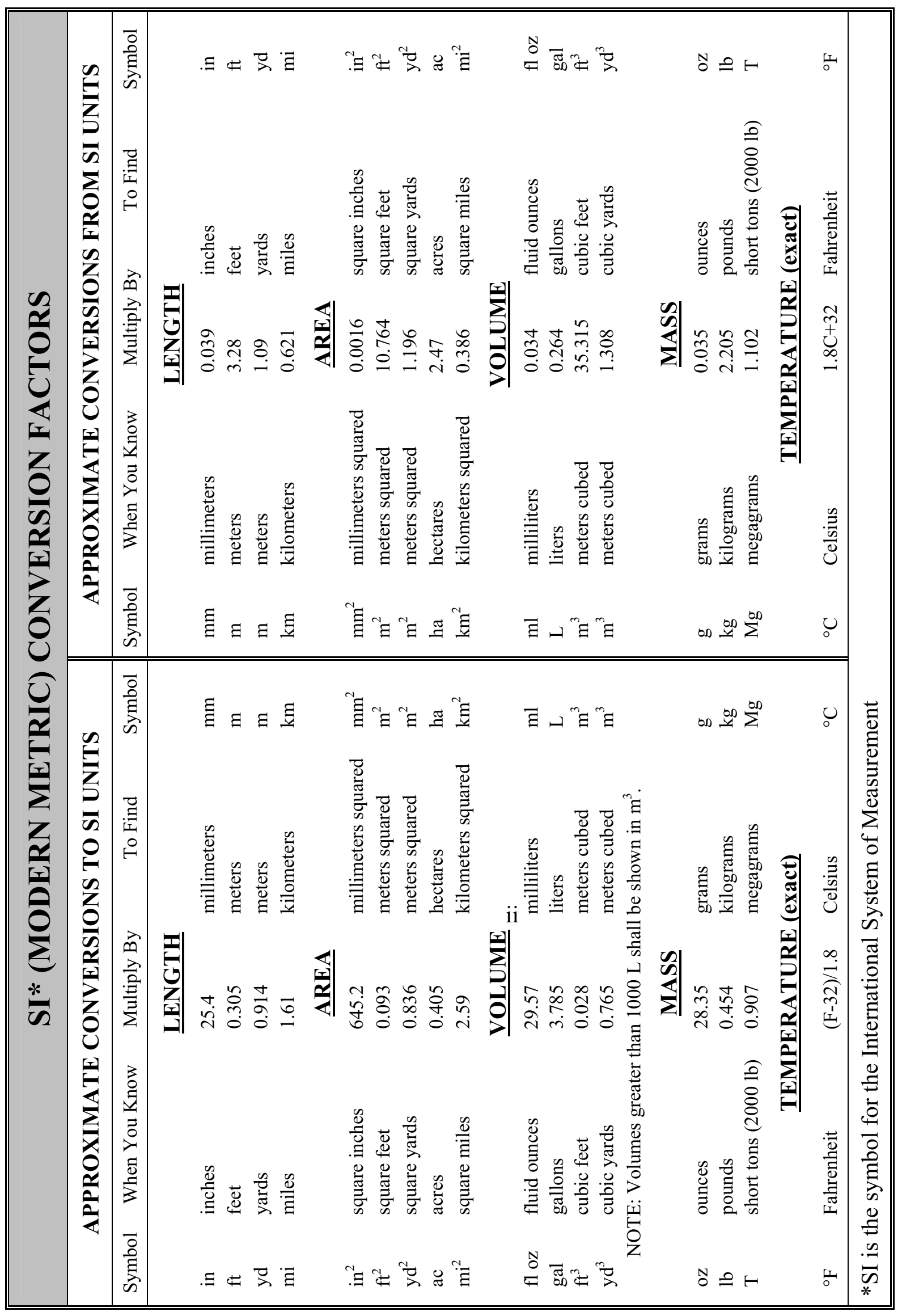




\section{ACKNOWLEDGEMENTS}

This research was funded by the Oregon Transportation Research and Education Consortium (OTREC) and the Oregon Department of Transportation (ODOT) as part of a larger study on the environmental durability of carbon fiber-reinforced polymers (CFRP). Mr. Steven Soltesz of ODOT coordinated the research project and his assistance is gratefully acknowledged. CFRP repair materials were donated by the BASF Corporation, Edge Structural Composites, Fyfe Co. LLC., and Sika Corporation. The authors would also like to thank Ms. Kate Bradbury and Ms. Laurel Senger for their assistance in experimental testing and data reduction. The findings and conclusions are those of the writers and do not necessarily reflect those of the project sponsors or the individuals acknowledged.

\section{DISCLAIMER}

This document is disseminated under the sponsorship of the Oregon Department of Transportation and the United States Department of Transportation in the interest of information exchange. The State of Oregon and the United States Government assume no liability of its contents or use thereof.

The contents of this report reflect the view of the authors who are solely responsible for the facts and accuracy of the material presented. The contents do not necessarily reflect the official views of the Oregon Department of Transportation or the United States Department of Transportation.

The State of Oregon and the United States Government do not endorse products of manufacturers. Trademarks or manufacturers' names appear herein only because they are considered essential to the object of this document.

This report does not constitute a standard, specification, or regulation. 


\title{
ENVIRONMENTAL DURABILITY OF REINFORCED CONCRETE DECK GIRDERS STRENGTHENED FOR SHEAR WITH SURFACE-BONDED CARBON FIBER-REINFORCED POLYMER
}

\author{
TABLE OF CONTENTS
}

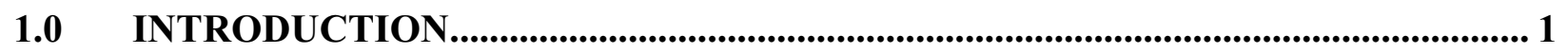

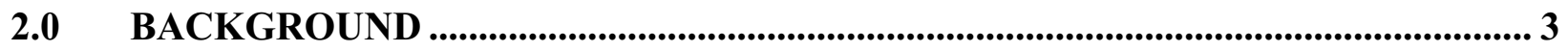

2.1 ACI 440.2R-08 DESIGN PROVISIONS ............................................................... 3

2.2 TEMPERATURE EFFECTS ON SURFACE BONDED FRP ….......................................... 4

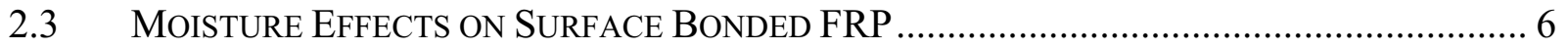

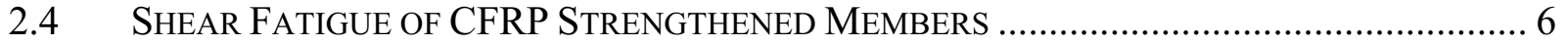

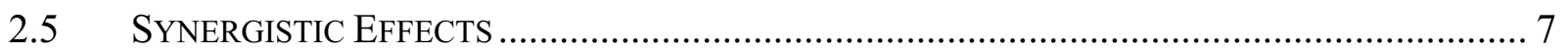

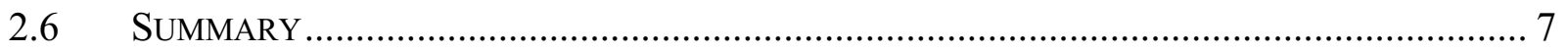

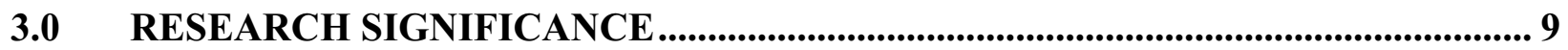

4.0 EXPERIMENTAL PROGRAM......................................................................... 11

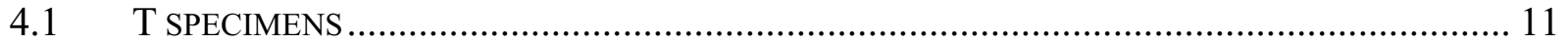

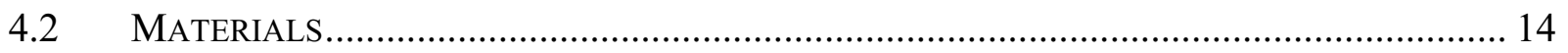

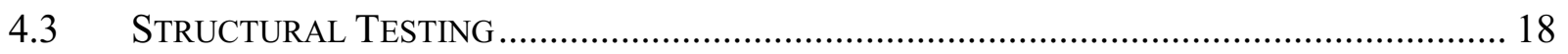

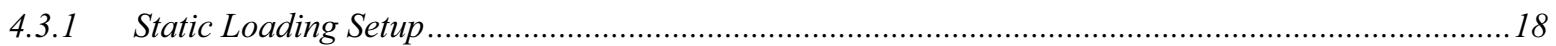

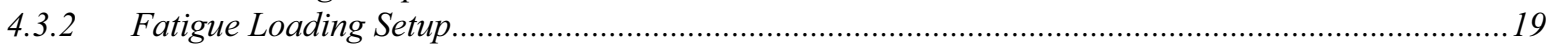

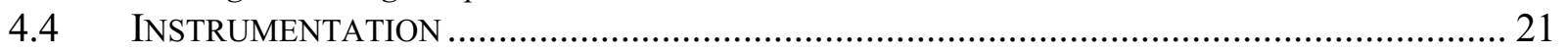

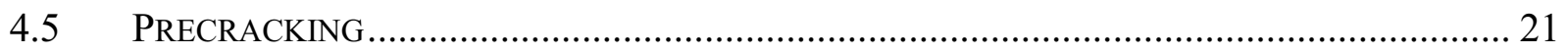

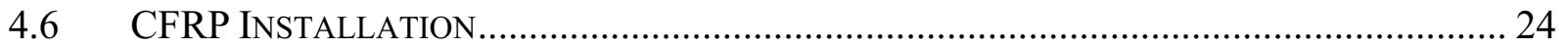

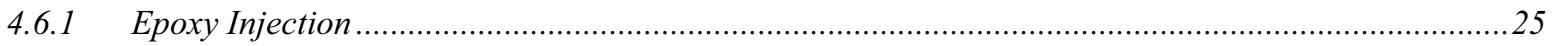

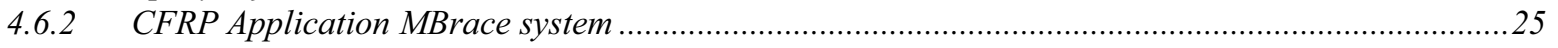

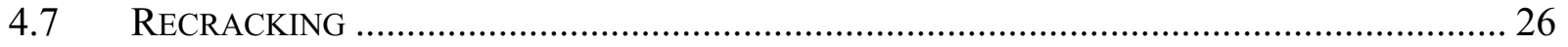

ENVIRONMENTAL EXPOSURE

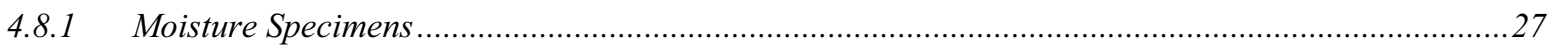

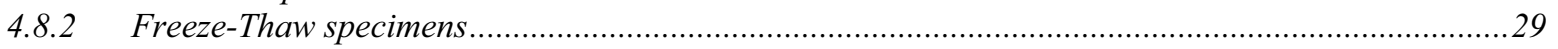

5.0 EXPERIMENTAL RESULTS............................................................................. 33

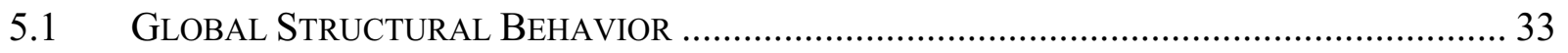

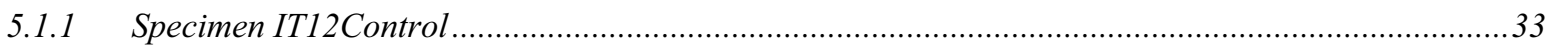

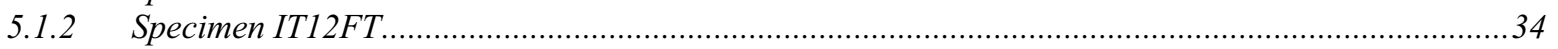

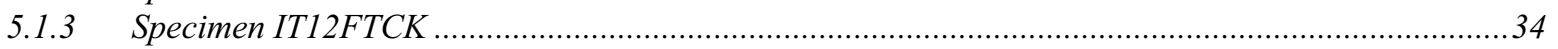

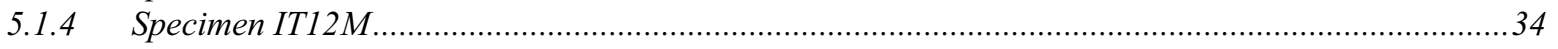

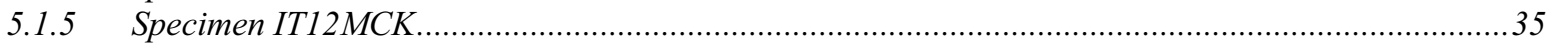

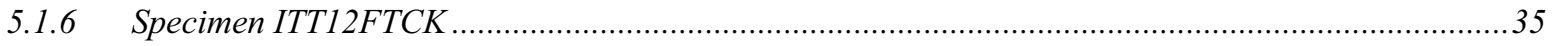

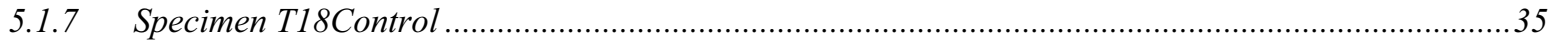

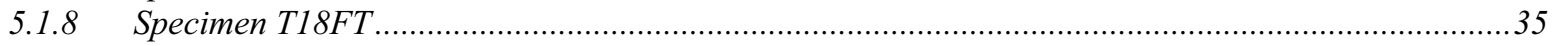

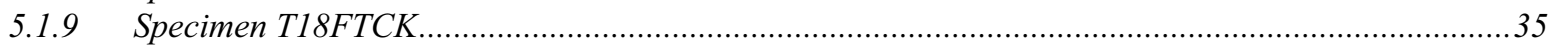

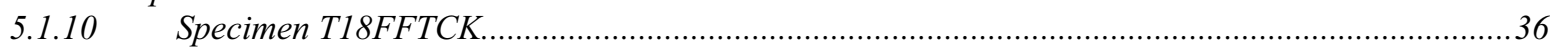


5.2 Comparison of Pre-Strengthening - Post-Strengthening ResPonses ............. 47

5.3 COMPARISON OF PRE-EXPOSURE AND POST-EXPOSURE RESPONSES ............................ 50

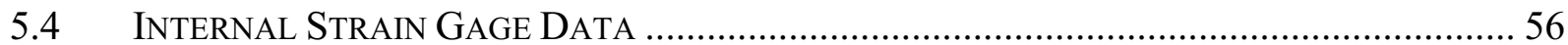

5.5 CFRP FLEXURAL STRAIN FROM DEBONDING …....................................................... 56

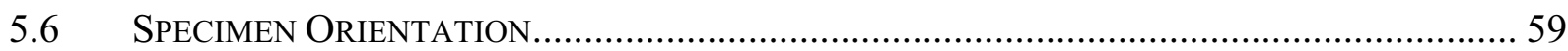

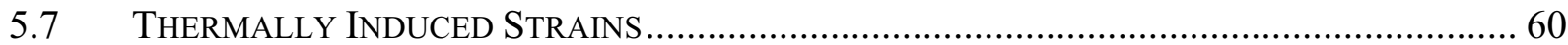

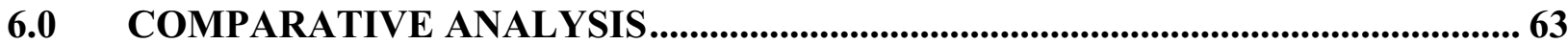

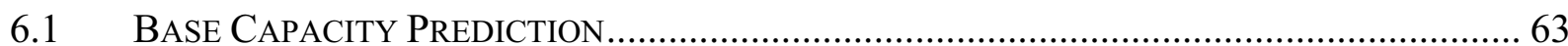

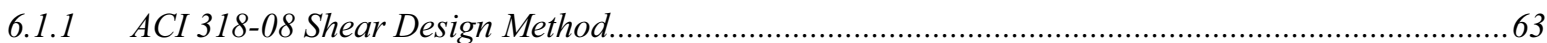

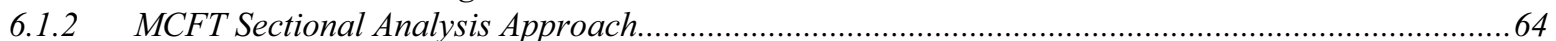

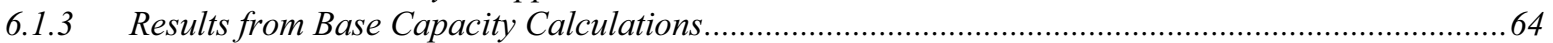

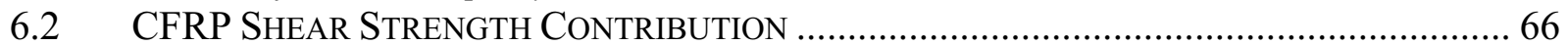

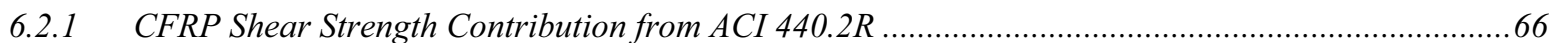

6.2.2 CFRP Shear Strength Contribution Estimates ........................................................................... 70

6.3 CFRP SHEAR STRENGTH DEMANDS ESTIMATED WITH SHEAR-MOMENT INTERACTION 71

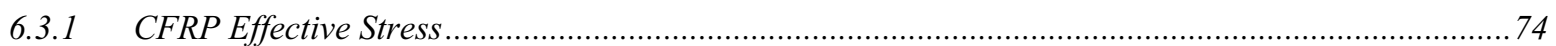

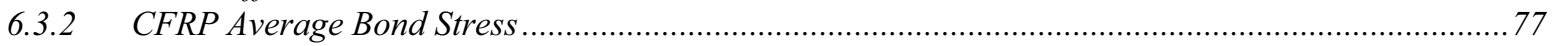

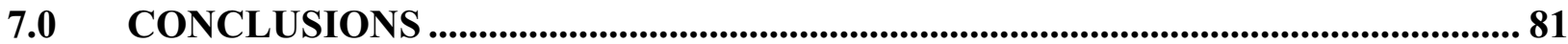

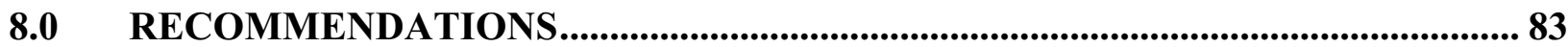

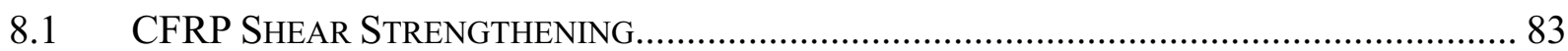

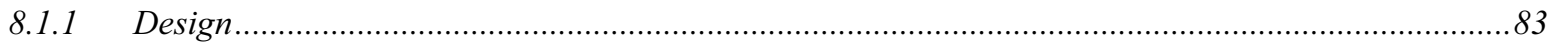

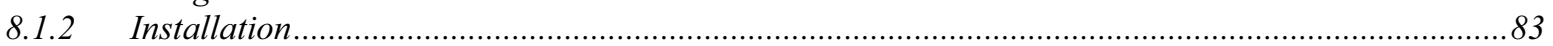

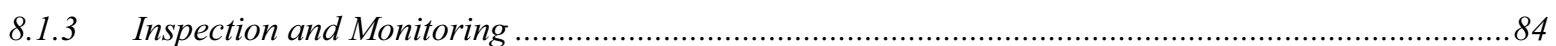

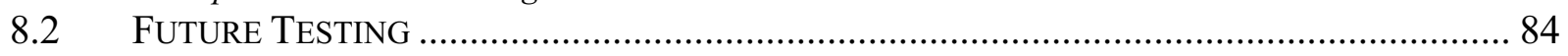

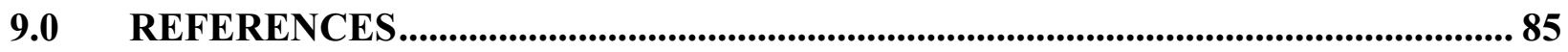

\section{APPENDICES}

APPENDIX A: RESULTS OF BEAM TESTS

APPENDIX B: SCALE EFFECTS ON REINFORCED CONCRETE BEAMS STRENGTHENED FOR SHEAR WITH DISCRETE EXTERNALLY BONDED CARBON FIBER-REINFORCED POLYMER U-WRAPS

APPENDIX C: CFRP SHEAR STRENGTHENING DESIGN OF A T-GIRDER

\section{LIST OF TABLES}

Table 2.1: ACI-440 Reduction factors for various FRP systems subjected to environmental exposure conditions (ACI 2008).

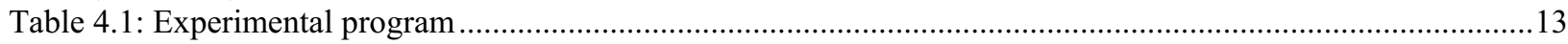

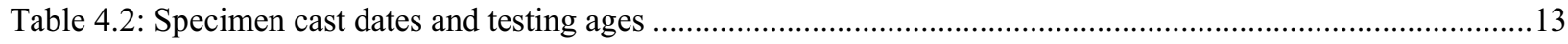

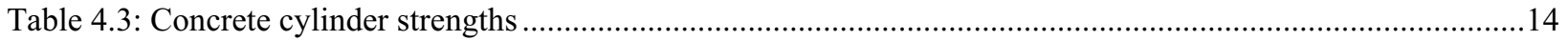

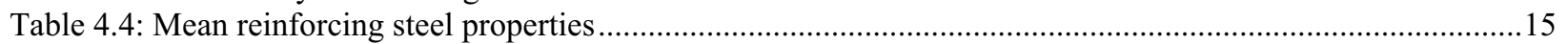

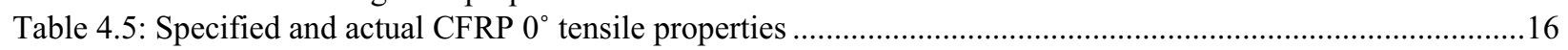

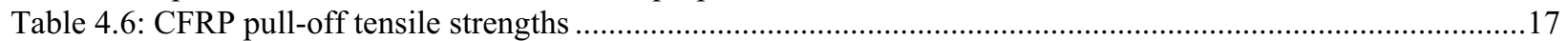

Table 4.7: Pull-off tensile strengths for Different CFRP systems ...............................................................17 


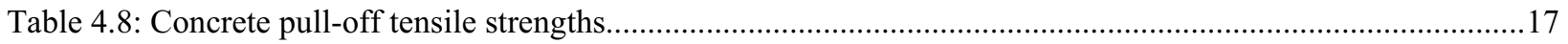

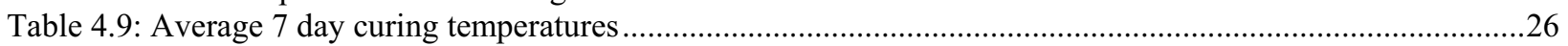

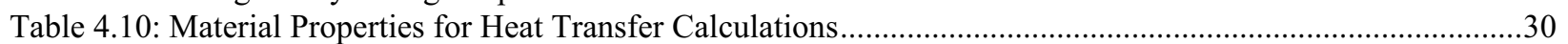

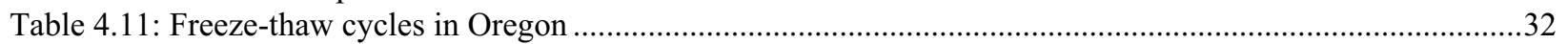

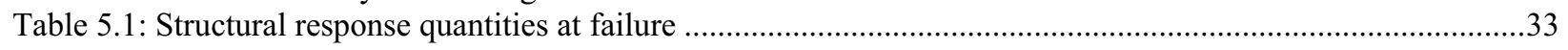

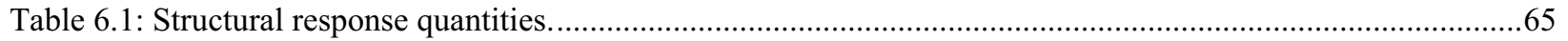

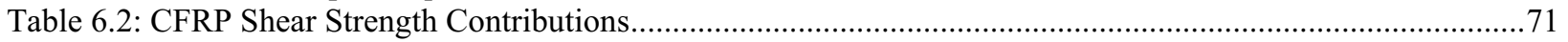

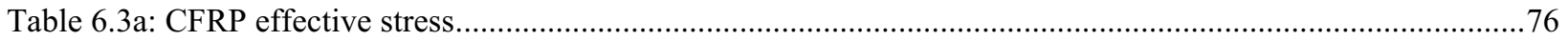

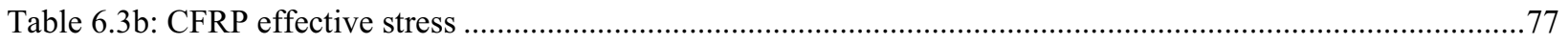

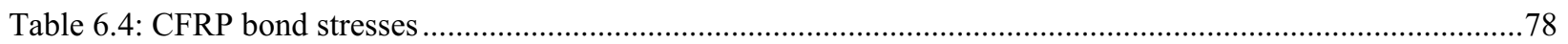

\section{LIST OF FIGURES}

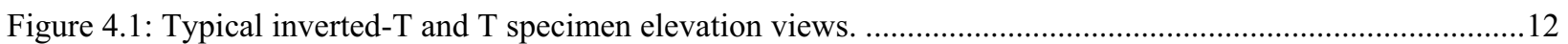

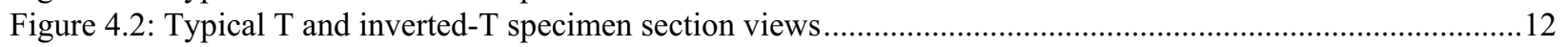

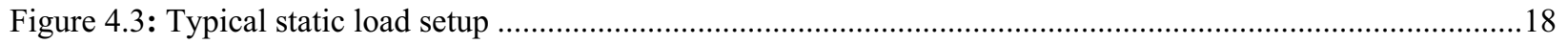

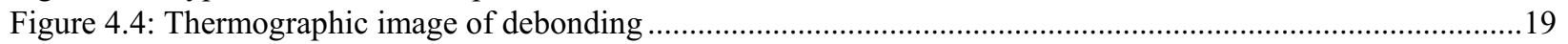

Figure 4.5: Fatigue + Freeze-Thaw Loading Setup (Side View) .....................................................................20

Figure 4.6: Fatigue + Freeze-Thaw Loading Setup (South View) ...................................................................2

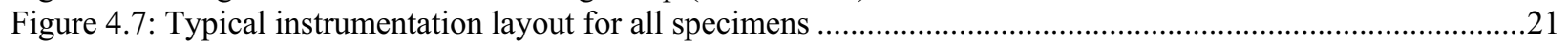

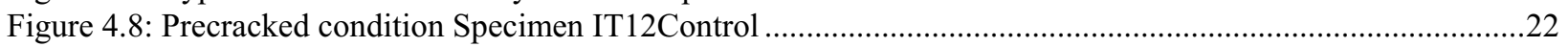

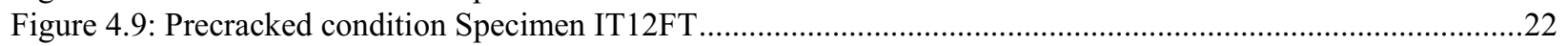

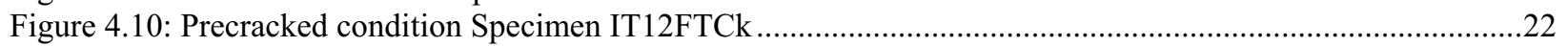

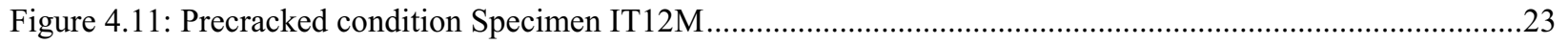

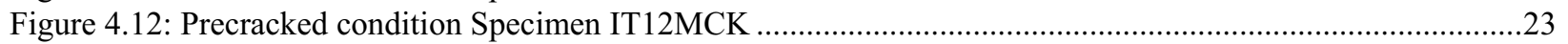

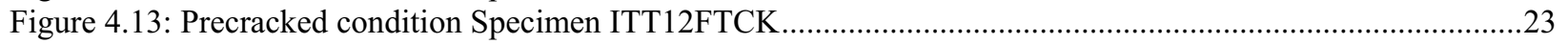

Figure 4.14: Precracked condition Specimen T18 Control .............................................................................23

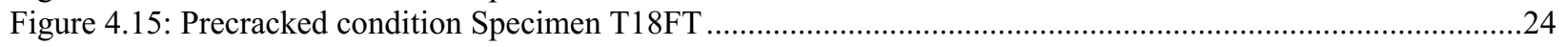

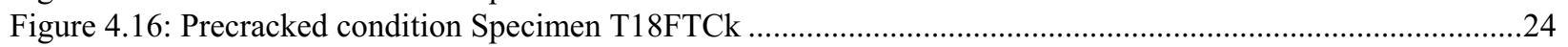

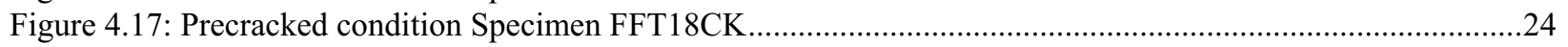

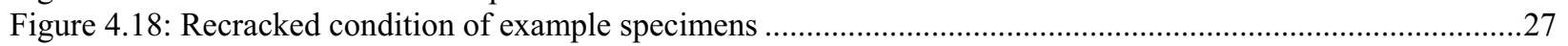

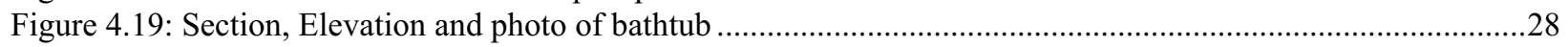

Figure 4.20: Typical temperature cycles for exposure conditions of moisture specimens ......................................28

Figure 4.21: Typical temperature measurements during freeze-thaw cycling ........................................................29

Figure 4.22: Typical surface and air temperature response for Stayton site............................................................31

Figure 4.23: Predicted and measured temperatures during experimental freeze-thaw exposure.................................32

Figure 5.1: Specimen IT12Control Midspan shear - deflection curves at failure ........................................................36

Figure 5.2: Specimen IT12FT Midspan shear - deflection curves at failure..........................................................37

Figure 5.3: Specimen IT12FTCk Midspan shear - deflection curves at failure .......................................................37

Figure 5.4: Specimen IT12M Midspan shear - deflection curves at failure.........................................................38

Figure 5.5: Specimen IT12MCK Midspan shear - deflection curves at failure ......................................................38

Figure 5.6: Specimen ITT12FTCK Midspan shear - deflection curves at failure.....................................................39

Figure 5.7: Specimen T18Control Midspan shear - deflection curves at failure .......................................................39

Figure 5.8: Specimen T18FT Midspan shear - deflection curves at failure ......................................................40

Figure 5.9: Specimen T18FTCk Midspan shear - deflection curves at failure ....................................................40

Figure 5.10: Specimen FFT18CK Midspan shear - deflection curves at failure..................................................4

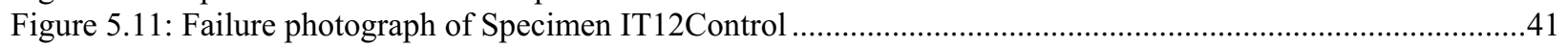

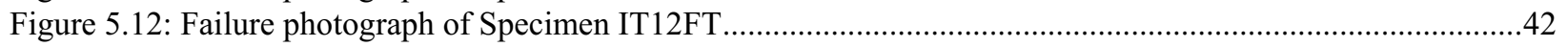

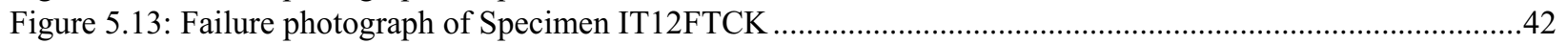

Figure 5.14: Failure photograph of Specimen IT12M.....................................................................................

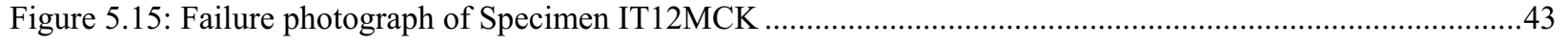


Figure 5.16: Failure photograph of Specimen IT12FTCK ……….................................................................

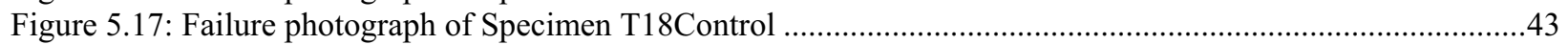

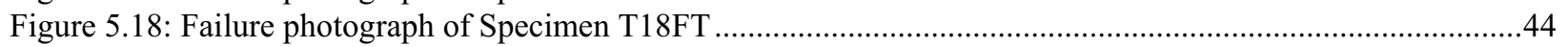

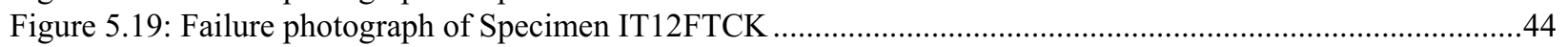

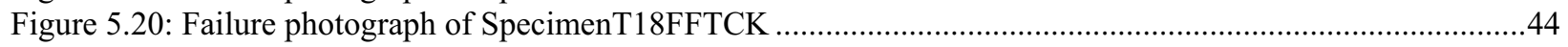

Figure 5.21: Cracked and debonded condition at load step prior to failure for Specimen IT 12 Control ..................45

Figure 5.22: Cracked and debonded condition at load step prior to failure for Specimen IT12FT ............................45

Figure 5.23: Cracked and debonded condition at load step prior to failure for SpecimenIT12FTCk .......................45

Figure 5.24: Cracked and debonded condition at load step prior to failure for Specimen IT12M...........................45

Figure 5.25: Cracked and debonded condition at load step prior to failure for Specimen IT12MCK .......................46

Figure 5.26: Cracked and debonded condition at load step prior to failure for Specimen ITT12FTCK.....................46

Figure 5.27: Cracked and debonded condition at load step prior to failure for Specimen T18Control......................46

Figure 5.28: Cracked and debonded condition at load step prior to failure for Specimen T18FT ............................46

Figure 5.29: Cracked and debonded condition at load step prior to failure for Specimen T18FTCk ........................47

Figure 5.30: Cracked and debonded condition at load step prior to failure for all Specimen T18FFTCK. ...............47

Figure 5.31: Shear capacities of CFRP specimens compared to identical specimens without CFRP strengthening...48

Figure 5.32: Overall stiffness comparison for specimens IT12FT and T18FT ...................................................49

Figure 5.33: Shear panel 3 stiffness comparison for specimens IT12FT and T18FT...........................................49

Figure 5.34: Shear panel 2 stiffness comparison for specimens IT12FT and T18FT ……...................................50

Figure 5.35: Overall stiffness comparison for specimens IT12FTCK and T18FTCK ….......................................51

Figure 5.36: Shear panel 3 stiffness comparison for specimens IT12FTCK and T18FTCK ……….......................51

Figure 5.37: Shear panel 2 stiffness comparison for specimens IT12FTCK and T18FTCK ……............................52

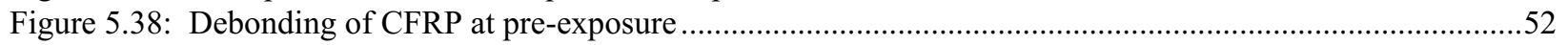

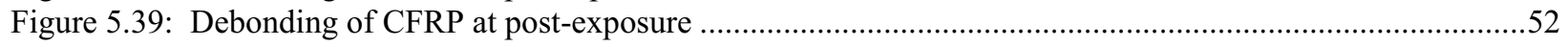

Figure 5.40: Debonding of CFRP at pre-exposure

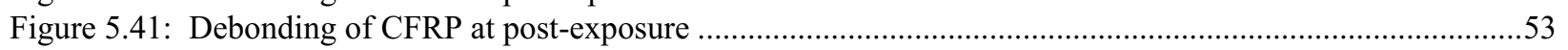

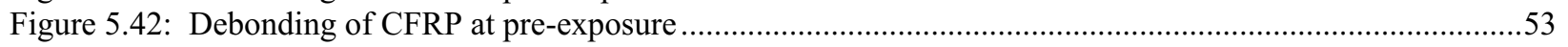

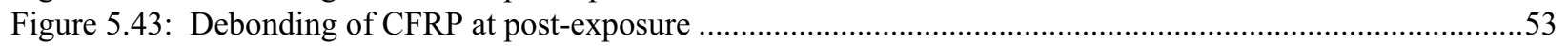

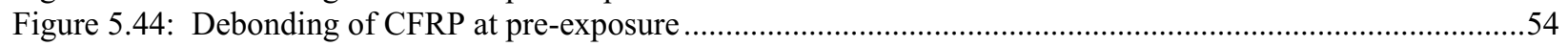

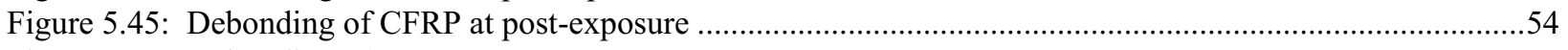

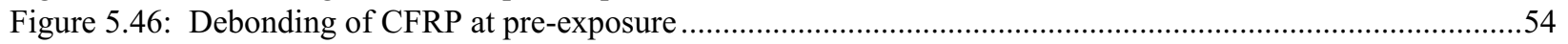

Figure 5.47: Debonding of CFRP at post-exposure ……….............................................................................54

Figure 5.48: Cyclic average vertical strain response for T-Specimens at different instrumented shear panels along

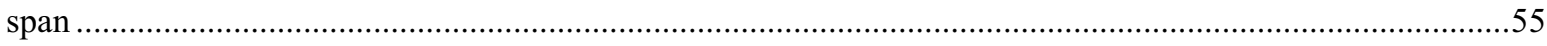

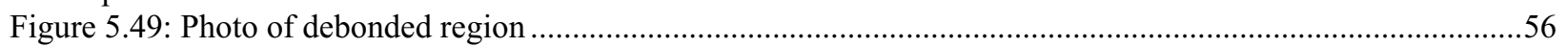

Figure 5.50: Shear vs. CFRP out-of-plane displacement for Specimen T18Control strip 2S ..................................57

Figure 5.51: Assumed deflected shapes and boundary conditions for debonded regions of CFRP...........................58

Figure 5.52: Shear versus strain for Specimen T18Control CFRP strain gage 4S. .................................................59

Figure 5.53: Freeze-thaw cycling and associated CFRP surface strains .............................................................60

Figure 5.54: Change in stiffness for specimen T18FFTCK. ...........................................................................61

Figure 6.1: Base capacities of specimens from ACI 318-08 and Response-2000 ……..........................................66

Figure 6.2: Dimensional variables used in ACI 440 FRP shear contribution calculations.............................................68

Figure 6.3: Base capacities of specimens from Response- 2000 for variable stirrup spacings. ..................................74 


\subsection{INTRODUCTION}

Many existing conventionally reinforced concrete deck-girder (RCDG) bridges, particularly those from the 1950's, were originally designed with relatively light shear reinforcing and poor flexural detailing. These bridges can exhibit diagonal cracking that has been attributed to increased truck loads and volumes as well as temperature and shrinkage effects. Load rating of older RCDG bridges, especially for shear, may limit or preclude permit and legal loads on the bridge. To renew or strengthen existing RCDG bridges, surface-bonded carbon fiber -reinforced polymers (CFRP) have become an attractive option. As an example, the Oregon Department of Transportation (ODOT) has applied surface-bonded CFRP for live-load shear strengthening of many RCDG bridges in their inventory as part of a significant transportation infrastructure reinvestment.

The current practice for some transportation agencies is to consider surface-bonded CFRP as a temporary measure, thereby requiring further retrofits or bridge replacement in the future. This is due to the relatively short performance history of CFRP for bridge applications and uncertainties related to long-term durability. Studies on the performance of surface-bonded CFRP for RC bridge members under long-term environmental exposure are lacking. 


\subsection{BACKGROUND}

Civil engineering structures, and bridge structures in particular, can be subjected to a wide range of environmental exposures including temperature and humidity variations, wetting and drying, water submersion, salt water contact, and freezing and thawing. Long-term durability of the materials used in construction is essential to ensure desired performance over the anticipated life of a structure. The in-situ performance of traditional civil engineering materials is generally well understood and reasonably predicable based on their long history of use. In contrast, new and emerging materials, such as surface-bonded CFRP for civil infrastructure applications, do not have an established history of long-term durability based on actual in-service performance. A recent survey of transportation agencies in 2005 indicated that field applications of CFRP for shear strengthening have been in-service less than 10 years (Higgins et al. 2006). Due to the lack of field performance data, long-term durability of fiber-reinforced polymer (FRP) materials is typically predicted using accelerated laboratory tests.

Surface-bonded CFRP for shear strengthening of RC members is a relatively recent development and long-term durability of this technique has not been well established. Of particular interest for this research was the durability of surface-bonded CFRP for shear strengthening of RC girders under freeze-thaw and water submersion. The technical literature related to performance of CFRP under environmental exposure conditions and current American design provisions were reviewed. Based on this review, limitations in the current body of knowledge were identified.

\subsection{ACI 440.2R-08 DESIGN PROVISIONS}

The emergence of FRP as a strengthening material for RC members has resulted in development of design guides and specifications. The American Concrete Institute (ACI) established guidelines for the design of reinforced concrete structures strengthened with FRP components in ACI-440.2R-08 (2008) that are based on limit-states design principles. ACI-440 generically treats the various types of FRP reinforcing such as aramid fiber, glass fiber, or the fiber in the present study, carbon fiber. The issue of long-term durability for surface-bonded FRP is recognized in the design approach and ACI-440 provides a list of possible environmental exposure conditions that may impact performance, including salt water, high temperatures, high humidity, and freezing and thawing cycles. ACI-440 points out in Section 3.5 that the manufacturer reported tensile properties are based on laboratory studies and do not necessarily reflect actual tensile properties in service after environmental exposure. The approach is to adjust the FRP material's ultimate tensile strength, $f_{f u}{ }^{*}$, and the ultimate rupture strain, $\varepsilon_{f u}{ }^{*}$ with an environmental-reduction factor, $C_{E}$, as:

$$
f_{f u}=C_{E} f_{f u}^{*}(\mathbf{A C I}-440 \text { 8-3) }
$$




$$
\varepsilon_{f u}=C_{E} \varepsilon_{f u}^{*}(\mathbf{A C I}-440 \text { 8-4) }
$$

to produce the design ultimate tensile strength, $f_{f u}$, and design rupture strain, $\varepsilon_{f u}$. The environmental-reduction factors depend on the exposure condition and the type of FRP material as shown in Table 2.1.

Table 2.1: ACI-440 Reduction factors for various FRP systems subjected to environmental exposure conditions (ACI 2008).

\begin{tabular}{|c|c|c|}
\hline Exposure Conditions & Fiber and Resin Type & $\begin{array}{c}\text { Environmental-reduction } \\
\text { factor } C_{E}\end{array}$ \\
\hline \multirow{3}{*}{ Interior Exposure } & Carbon/epoxy & 0.95 \\
\hline & Glass/epoxy & 0.75 \\
\hline & Aramid/epoxy & 0.85 \\
\hline \multirow{3}{*}{$\begin{array}{l}\text { Exterior exposure (bridges, } \\
\text { piers, and unenclosed } \\
\text { parking garages) }\end{array}$} & Carbon/epoxy & 0.85 \\
\hline & Glass/epoxy & 0.65 \\
\hline & Aramid/epoxy & 0.75 \\
\hline \multirow{3}{*}{$\begin{array}{l}\text { Aggressive environment } \\
\text { (chemical plants and waste } \\
\text { water treatment plants) }\end{array}$} & Carbon/epoxy & 0.85 \\
\hline & Glass/epoxy & 0.50 \\
\hline & Aramid/epoxy & 0.70 \\
\hline
\end{tabular}

The above modification to the FRP material design properties is the only means employed in ACI-440 to reflect the effects of environmental exposure on FRP performance. There is no reduction taken directly for bond strength based on environmental exposure. Bond reduction coefficients are based on the wrap configuration and compressive concrete strength and are used to further reduce the design rupture strain to produce an effective strain. The maximum effective strain is limited at $0.4 \%(0.004 \mathrm{in} / \mathrm{in})$. Using this approach in practice, while the manufacturerspecified ultimate rupture strain is reduced to account for environmental exposure, wrap configuration, and compressive concrete strength, the resulting effective strain may still be computed as greater than $0.4 \%$. As a result, the effective strain for design would be taken as $0.4 \%$ and in effect, the environmental exposure may not be adequately captured if it has especially deleterious effects on the bond properties.

ACI-440 Section 8.3.1 also describes the thermal response of FRP and concrete. Due to differences in the thermal expansion coefficients of concrete and the polymers used in FRP, thermally induced strains are produced. It has been determined through research (Motavalli et al. 1993; Soudki and Green 1997; Green et al. 1998) that bond is not affected "for small ranges of temperature change, such as $\pm 50^{\circ} \mathrm{F}\left( \pm 28^{\circ} \mathrm{C}\right)$."

\subsection{TEMPERATURE EFFECTS ON SURFACE BONDED FRP}

Based on review of the literature, temperature changes, either low or high, have not been shown to greatly affect strength. Low temperature $\left(-28^{\circ} \mathrm{C}\right)$ was not found to significantly affect bond between CFRP and concrete when tested on 1/3 scale beams (El-Hacha et al. 2004), although 
other studies found some deleterious effects in the form of matrix hardening and fiber-matrix bond degradation under subzero temperatures (Karbhari 2002).

Chajes et al. (1995) tested $38.1 \mathrm{~mm}$ x $28.6 \mathrm{~mm}$ x $330 \mathrm{~mm}$ (1.5 in. x 1.1 in. x 13 in.) flexurally strengthened prisms in four-point bending. The uncracked specimens were reinforced with aramid, e-glass, and graphite fabric surface-bonded to the concrete and subjected to 50 and 100 wet freeze-thaw cycles. Chajes et al. (1995) found that freeze-thaw exposure decreased the ultimate capacity of the beam and led to deterioration of the bond. Full-scale durability testing was recommended.

Dutta (1995) reported that freeze-thaw exposure on FRP material tensile properties in the normal temperature range $\left(-20^{\circ} \mathrm{C}\right.$ to $\left.30^{\circ} \mathrm{C}\right)\left(-4^{\circ} \mathrm{F}\right.$ to $\left.86^{\circ} \mathrm{F}\right)$ were "insignificant." Bond was not investigated in this study. It was noted that large thermal cycles $\left(-60^{\circ} \mathrm{C}\right.$ to $\left.60^{\circ} \mathrm{C}\right)\left(-76^{\circ} \mathrm{F}\right.$ to $\left.140^{\circ} \mathrm{F}\right)$ may reduce tensile properties due to polymer matrix cracking based on earlier work (Lord and Dutta 1988). Additionally, very low temperatures $\left(-50^{\circ} \mathrm{C}\right)\left(-58^{\circ} \mathrm{F}\right)$ may reduce unidirectional tensile strength (Dutta 1992).

In a study by del Mar Lopez et al. (1999), 48 small-scale beam specimens were tested and it was found that the moment capacity and the maximum deflection decreased as a function of freezethaw cycles. It was also noted that precracked beams exhibited a larger decrease than initially uncracked specimens.

Green et al. (2000) studied pre-cured CFRP plates surface-bonded to concrete. Both $150 \mathrm{~mm} \mathrm{x}$ $150 \mathrm{~mm} \times 400 \mathrm{~mm}$ (6 in. x 6 in. x 16 in.) pull-off specimens and $100 \mathrm{~mm} \times 150 \mathrm{~mm}$ and 1220 $\mathrm{mm}$ (4 in. $\mathrm{x} 6$ in. $\mathrm{x} 48$ in.) flexurally strengthened reinforced concrete beams were tested. Beams were uncracked prior to CFRP application. Specimens were subjected to various degrees of freeze-thaw ranging from 0-300 cycles. Freezing occurred in air, while thawing was performed in water. It was concluded that freeze-thaw cycling did not affect the load carrying capacity of the bond between the plate and concrete. It was noted, though, that the adhesive may be affected resulting in a change of failure mode.

Bisby and Green (2002) investigated $102 \mathrm{~mm}$ x $152 \mathrm{~mm}$ x $1220 \mathrm{~mm}$ (4 in. x 6 in. x 48 in.) uncracked beams flexurally strengthened with surface-bonded CFRP and GFRP pre-cured plates. Beams were subjected to various numbers of freeze-thaw cycles ranging from 0-300. Freezing occurred in air, while thawing occurred in a water bath. It was concluded that freeze-thaw exposure had no affect on the anchorage of the FRP plates to concrete.

Green et al. (2003) investigated $102 \mathrm{~mm}$ x $152 \mathrm{~mm}$ x $1220 \mathrm{~mm}$ (4 in. x 6 in. x 48 in.) uncracked beams flexurally strengthened with surface-bonded CFRP and GFRP sheets. Beams were exposed to varying numbers of freeze-thaw cycles ranging from 0-200. Freezing occurred in air, while thawing occurred in a water bath. It was concluded that freeze-thaw exposure had no adverse affect on the FRP bond.

Grace and Singh (2005) found reductions in strength of 3.3\% and 9.5\% for beam specimens strengthened with CFRP plates subjected to 350 and 700 freeze-thaw cycles, respectively. 
Saenz et al. (2004) found degradation of a range of FRP composite systems after 50 accelerated freeze-thaw cycles, although the thaw cycles were conducted in salt water.

Grace and Singh (2005) studied $152 \mathrm{~mm}$ x $254 \mathrm{~mm}$ x $2743 \mathrm{~mm}$ (6 in. x 12 in. x 108 in.) beams, flexurally strengthened with surface-bonded CFRP pre-cured plates and fabrics. Again, the beams were uncracked prior to CFRP application. Beams were exposed to 350 and 700 freezethaw cycles. Freezing occurred in air, while thawing occurred in water. It was determined that the load carrying capacity of the beams was decreased when exposed to freeze-thaw cycling.

Kong et al. (2005) showed that axial compressive strength of wrapped concrete cylinders was reduced only $3 \%$ as a result of cyclic thermal exposure. The bond of the FRP to the concrete was not affected by the cyclic exposure, but there was a change in the adhesive properties as evidenced by a change in failure modes.

Myers and Ekenel (2005) examined installation temperatures and established recommended limits based on strength and workability to be between $4^{\circ} \mathrm{C}$ and $32^{\circ} \mathrm{C}$ for the two FRP systems studied.

\subsection{MOISTURE EFFECTS ON SURFACE BONDED FRP}

Exposure to moisture alone has not been as well-researched because it is commonly coupled with other environmental effects, such as temperature or various solutions. Grace and Singh (2005) found that $33 \%$ of can be lost if the specimen is exposed to long-term relative humidity of $100 \%$. Karbhari et al. (2003) performed a gap analysis, which confirmed this finding, showing that exposure to moisture can have deleterious effects on the fiber-matrix bond due to wicking along the interface.

Sen et al. (2001) investigated the effects of moisture exposure combined with thermal changes for CFRP bonded to concrete slabs over a period of 17 months. Tensile and shear bond tests were performed after exposure and results indicated that wetting and drying produced lower strengths and addition of temperature cycling did not prove detrimental.

Wu et al. (2004) studied the effect of water on the cure and mechanical properties of epoxy adhesives. They found that a small amount of water $(+2 \%)$ improved the cure time and the modulus and strength properties but excess water $(>+4 \%)$ had a negative impact on these same properties.

\subsection{SHEAR FATIGUE OF CFRP STRENGTHENED MEMBERS}

A previous laboratory investigation (Higgins et al. 2006) involving fatigue response of externally bonded FRP laminates studied full-scale girders, replicated to the existing conditions of typical 1950`s vintage RCDG bridges. Loading conditions for the tests were established from measurements of in-situ CFRP strain data under ambient traffic conditions over a period of 30 
days. Service-level fatigue loading, accelerated to simulate extended service life, was found to not significantly change the ultimate capacity of the specimens. However, cyclic loading test showed that the interface debonding propagates progressively with increase of the fatigue cycles. Interface debonding areas may accelerate in the presence of combined fatigue and freeze-thaw exposures.

\subsection{SYNERGISTIC EFFECTS}

Karbhari et al. (2003) conducted a durability gap analysis and one of the main conclusions was the need for examination of combined effects. In-situ FRP installations do not have just one of these environmental conditions in isolation, so further studies under more realistic combined conditions was recommended.

Some durability studies have already examined the effects from combinations of environmental conditions. Malvar et al. (2003) found that the combination of high humidity and high temperature had a large impact on the bond strength as measured by pull-off tests. Maximum relative humidity during adhesive application was recommended to be $85 \%$, which was later confirmed by research done by Myers and Ekenel (2005).

Mukhopadhyaya et al. (1998) investigated GFRP plates surface-bonded to $100 \mathrm{~mm}$ x $100 \mathrm{~mm}$ x $300 \mathrm{~mm}$ (4 in. $\mathrm{x} 4$ in. $\mathrm{x} 12 \mathrm{in}$.) uncracked concrete prisms and subjected to 450 dry freeze-thaw cycles. Another set of specimens was exposed to wet-dry cycling and freeze-thaw cycling simultaneously. These specimens saw one week of immersion in water then one week of freezethaw cycling. This resulted in a total of 36 weeks of water immersion and 252 freeze-thaw cycles. Push-off tests were done to evaluate the shear stress at the bond interface. It was noted that plate slip was higher in specimens exposed to freeze-thaw than control specimens. Additionally, it was observed that bond degradation first occurred at the plate edge.

\subsection{SUMMARY}

The additional strength provided by CFRP materials depends principally on the bond between the member substrate and the CFRP, which allows stress transfer from the concrete component to CFRP laminate. For most common shear strengthening applications, the member strength is governed by debonding of the CFRP strips and thus the material strength cannot be fully utilized. The causes and mechanisms of bond failure are complex, and past research has shown conflicting results related to the effects of different environmental exposures. Very limited previous work had been conducted related to CFRP for shear strengthening, and a need existed to quantify the effects of environmental exposure on structural performance of CFRP shearstrengthened members and identify possible negative consequences of combined high-cycle fatigue and environmental exposure. 
The objectives of this research were as follows:

- Develop realistic full-size specimens, apply CFRP reinforcement, and subject specimens to accelerated environmental exposures. Consider the following exposures: freeze-thaw, freeze-thaw combined with high-cycle fatigue, and water immersion.

- Experimentally determine the effects of the environmental exposures on the structural performance of the CFRP shear-strengthened members by comparing with similar unexposed specimens.

- Analytically predict the shear strength of the CFRP strengthened specimens and quantitatively estimate the effects of the environmental exposures.

- Report experimental and analytical findings and make recommendations for CFRP strengthening applications with long-term environmental exposures. 


\subsection{RESEARCH SIGNIFICANCE}

Long-term durability of surface-bonded CFRP for strengthening reinforced concrete bridge members has remained uncertain due to the limited field experience with these materials. The possible long-term durability issues were the structural performance of CFRP strengthened members under moisture and freeze-thaw as well as combined with high-cycle fatigue loading. Past experimental research on environmental durability has been limited to reduced-scale specimens and has focused primarily on flexural reinforcing and bond strength. The influence of both environmental conditioning and structural performance of CFRP materials on small scale samples was not well understood and extrapolation to full-scale performance was uncertain. No information was available regarding shear strengthening applications and the effect of environmental exposure in shear dominant regions. Previous research investigated environmental exposure for applications without previous cracking of the base concrete. There was concern that previous cracking may have an impact on the durability due to water moving through the material at those locations. Previous research has avoided these issues by testing structural performance of full-scale RC bridge girder specimens strengthened for shear after extended environmental exposures. A test protocol was developed for environmental exposure cycling and the experimental results provided new information on long-term durability of CFRP under these conditions. 


\subsection{EXPERIMENTAL PROGRAM}

To investigate the effects of environmental durability and combined action of cyclic loading and environment exposure on the structural performance of reinforced concrete bridge girders strengthened for shear with surface-bonded CFRP, an experimental program was undertaken. The general testing procedure consisted of the following steps:

1. Imposition of initial diagonal and flexural cracking in the RC specimens (defined here as precracking).

2. Epoxy injection of diagonal cracks.

3. Preparation of concrete surfaces.

4. Installation of CFRP materials.

5. Reloading of CFRP strengthened beam to reproduce diagonal cracking (defined here as recracking, not performed for all specimens).

6. Development and application of an environmental exposure protocol (combined with high-cycle fatigue load cycles for specimen T18FFTCK).

7. Structural testing to failure.

In addition to full-scale girder tests, a series of scaled specimens were also tested in order to investigate the scaling effects in CFRP applications to reinforced concrete beams. Results from this additional study are given in Appendix B.

\subsection{T SPECIMENS}

Full-scale reinforced concrete girder specimens, representative of 1950's vintage proportions and detailing for conventionally reinforced concrete deck girders found in highway bridges (Higgins et al. 2004), were used in this test program. The specimens consisted of T and inverted-T (IT) beams and were designed to fail in shear with typically encountered flexural steel proportions to provide realistic shear-moment interaction. The $\mathrm{T}$ configuration represents shear in the presence of positive moment, as near abutment locations, and the IT configuration represents shear in the presence of negative moment, as near continuous support locations. The specimens had an overall height of $1219 \mathrm{~mm}$ (48 in.), a web thickness of $356 \mathrm{~mm}$ (14 in.), a flange thickness of $152 \mathrm{~mm}$ (6 in.), and a flange width of $914 \mathrm{~mm}$ (36 in.) and are illustrated in Figures 4.1 and 4.2. The flexural steel for both T and IT-Specimens consisted of well anchored \#36 (\#11) bars that enable development of the bar yield stress at diagonal crack locations within the span. 


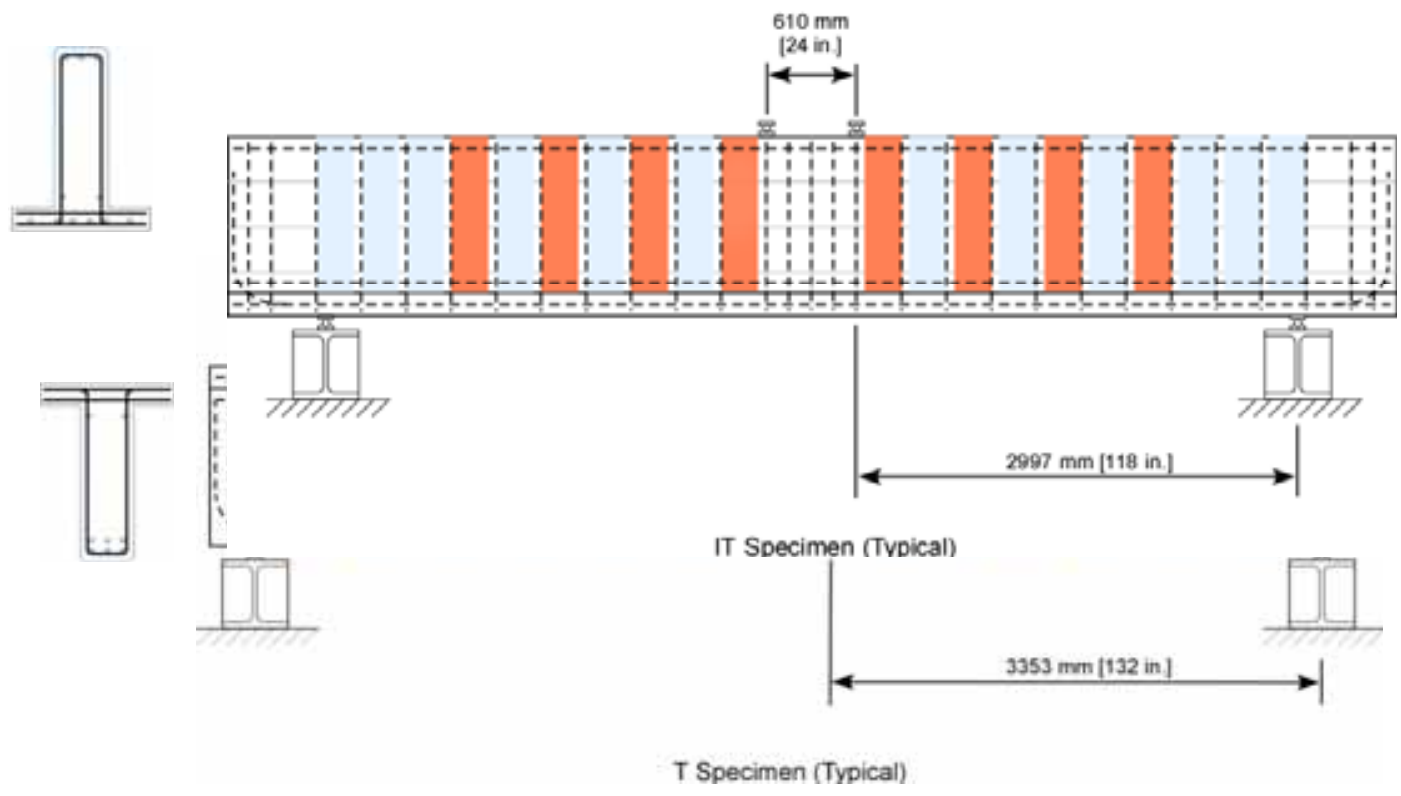

Figure 4.1: Typical inverted-T and T specimen elevation views.

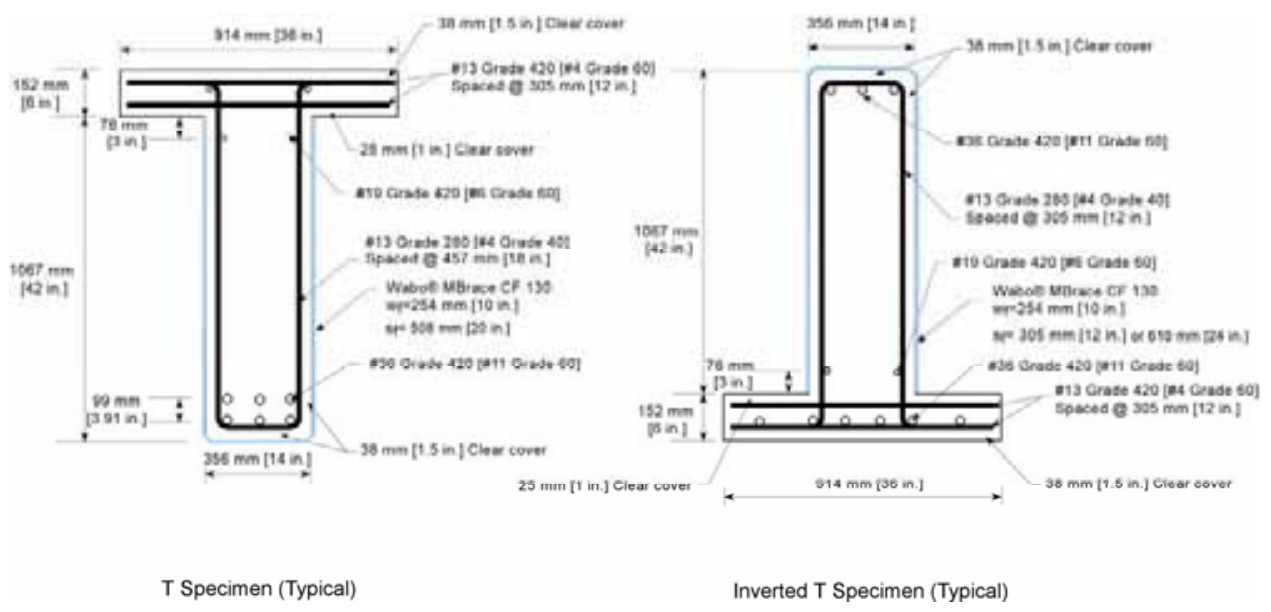

Figure 4.2: Typical $\mathrm{T}$ and inverted-T specimen section views

The experimental program consisted of 10 specimens, identified in Table 4.1. The first indicator in the specimen naming convention identifies the failure testing configuration (T or IT). The second indicator designates the internal stirrup spacing given in inches (12 or 18). To characterize the performance of the CFRP strengthened specimens independent of the environmental exposure, two control specimens were used (identified with "Control" in the specimen naming convention): one for the IT configuration and one for the T configuration. Five of the specimens were reloaded after CFRP strengthening to reproduce diagonal cracking, where recracked specimens were identified with $\mathrm{CK}$ in the naming convention. Environmental effects 
were imposed in two ways: freeze-thaw exposure (FT) or moisture exposure (M). One specimen was also subjected to high-cycle fatigue loading $(\mathrm{F})$ in addition to freeze-thaw exposure. It should be noted that specimen ITT12FTCK was subjected to freeze-thaw cycles in T orientation, but failure testing was performed in IT orientation. Applied precracking and recracking shear loads, number of applied freeze-thaw cycles, and the duration of moisture exposure are summarized in Table 4.1. The specimens' ages at key points in the test program are shown in Table 4.2.

Table 4.1: Experimental program

\begin{tabular}{|c|c|c|c|c|c|}
\hline Specimen & Type & $\begin{array}{c}\text { Precrack Shear Load Step } \\
(k N) \text { (kip) } \\
\end{array}$ & $\begin{array}{c}\text { Recrack Shear } \\
(\text { kN) (kip) }\end{array}$ & $\begin{array}{c}\text { Freeze-Thaw } \\
\text { (cycles) }\end{array}$ & $\begin{array}{l}\text { Moisture Exposure } \\
\text { (Time in Months) }\end{array}$ \\
\hline IT12Control & IT & $\begin{array}{c}667 \\
(150) \\
\end{array}$ & N/A & N/A & N/A \\
\hline IT12FT & IT & $\begin{array}{c}667 \\
(150) \\
\end{array}$ & N/A & $550 *$ & N/A \\
\hline IT12FTCK & IT & $\begin{array}{c}667 \\
(150) \\
\end{array}$ & $\begin{array}{l}1001 \\
(225) \\
\end{array}$ & $550 *$ & N/A \\
\hline IT12M & IT & $\begin{array}{c}667 \\
(150) \\
\end{array}$ & $\mathrm{N} / \mathrm{A}$ & N/A & 6 \\
\hline IT12MCK & IT & $\begin{array}{c}667 \\
(150) \\
\end{array}$ & $\begin{array}{c}890 \\
(200) \\
\end{array}$ & N/A & 6 \\
\hline ITT12FTCK & IT & $\begin{array}{c}667 \\
(150) \\
\end{array}$ & $\begin{array}{c}100 \\
(225)\end{array}$ & 300 & N/A \\
\hline T18Control & $\mathrm{T}$ & $\begin{array}{c}556 \\
(125) \\
\end{array}$ & $\mathrm{N} / \mathrm{A}$ & N/A & N/A \\
\hline $\mathrm{T} 18 \mathrm{FT}$ & $\mathrm{T}$ & $\begin{array}{c}556 \\
(125) \\
\end{array}$ & $\mathrm{N} / \mathrm{A}$ & 300 & N/A \\
\hline T18FTCK & $\mathrm{T}$ & $\begin{array}{c}556 \\
(125) \\
\end{array}$ & $\begin{array}{c}725 \\
(163) \\
\end{array}$ & 300 & N/A \\
\hline T18FFTCK & $\mathrm{T}$ & $\begin{array}{c}556 \\
(125) \\
\end{array}$ & $\begin{array}{c}729 \\
(163) \\
\end{array}$ & 300 & $\mathrm{~N} / \mathrm{A}$ \\
\hline
\end{tabular}

*: Final 250 cycles were dry freeze-thaw

Table 4.2: Specimen cast dates and testing ages

\begin{tabular}{c|c|c|c|c|c}
\hline Specimen & Cast Date & $\begin{array}{c}\text { Age at Precrack } \\
\text { (Days) }\end{array}$ & $\begin{array}{c}\text { Age at Recrack } \\
\text { (Days) }\end{array}$ & $\begin{array}{c}\text { Age at F-T Start } \\
\text { (Days) }\end{array}$ & $\begin{array}{c}\text { Age at Failure } \\
\text { (Days) }\end{array}$ \\
\hline IT12Control & $3 / 4 / 08$ & 43 & N/A & N/A & 71 \\
\hline IT12FT & $9 / 7 / 07$ & 32 & 70 & 125 & 209 \\
\hline IT12FTCK & $9 / 7 / 07$ & 42 & N/A & N/A & 216 \\
\hline IT12M & $09 / 07 / 07$ & 104 & 149 & N/A & 389 \\
\hline IT12MCK & $09 / 07 / 07$ & 110 & 72 & 78 & 385 \\
\hline ITT12FTCK & $04 / 30 / 08$ & 58 & N/A & 54 & 191 \\
\hline T18Control & $3 / 4 / 08$ & 48 & N/A & 42 & 69 \\
\hline T18FT & $2 / 14 / 08$ & 22 & 71 & 54 & 105 \\
\hline T18FTCK & $2 / 14 / 08$ & 27 & 57 & 78 & 109 \\
\hline T18FFTCK & $04 / 30 / 08$ & & & & 197 \\
\hline
\end{tabular}




\subsection{MATERIALS}

Concrete was provided by a local ready-mix supplier for all specimens. The concrete mix design was based on 1950's AASHTO "Class A" concrete used in previous research at OSU (Higgins et al. 2004). The aggregate composition for the mix was reported by the supplier as: $97 \%$ passing the $19 \mathrm{~mm}$ sieve ( $3 / 4 \mathrm{in}$.), $82 \%$ passing $16 \mathrm{~mm}$ (5/8 in.), $57 \%$ passing $12.5 \mathrm{~mm}(1 / 2 \mathrm{in}),. 33 \%$ passing $9.5 \mathrm{~mm}$ (3/8 in.), $21 \%$ passing $8 \mathrm{~mm}$ (5/16 in.), $9.3 \%$ passing $6.3 \mathrm{~mm}(1 / 4 \mathrm{in}$.), $3.0 \%$ passing $4.75 \mathrm{~mm}(\# 4), 0.6 \%$ passing $2.36 \mathrm{~mm}(\# 8)$ and $0.3 \%$ passing the $0.075 \mathrm{~mm}(\# 200)$ sieve. The sand composition of the mix was also reported as: $99.7 \%$ passing the $6.3 \mathrm{~mm}$ sieve (1/4 in.), 96.8\% passing $2.36 \mathrm{~mm}$ (\#8), 59.4\% passing $1.18 \mathrm{~mm}(\# 16), 44.9 \%$ passing $0.600 \mathrm{~mm}$ (\#30), 17.9\% passing $0.300 \mathrm{~mm}(\# 50), 3.7 \%$ passing $0.150 \mathrm{~mm}$ (\#100) and 1.7\% passing the $0.075 \mathrm{~mm}$ (\#200) sieve. The coarse aggregate was from Willamette River bed deposits consisting of smooth rounded basaltic rock. Specified compressive strength was $21 \mathrm{MPa}$ (3000 psi), which is comparable to the specified design strength in the original 1950's bridges. Actual concrete compressive strengths were determined from $152 \times 305 \mathrm{~mm}(6$ in. $\times 12$ in.) cylinders tested for 28-day and day-of-test strengths in accordance with ASTM C39M/C 39M-05 and ASTM C61705. Concrete cylinder strengths for each specimen are shown in Table 4.3.

Table 4.3: Concrete cylinder strengths

\begin{tabular}{|c|c|c|c|c|c|c|c|}
\hline \multirow[b]{2}{*}{ Specimen } & \multirow{2}{*}{$\begin{array}{c}\text { 28-day } \\
f_{c}^{\prime} c \\
(\mathrm{MPa}) \\
\text { (psi) }\end{array}$} & \multicolumn{2}{|c|}{ Precrack } & \multicolumn{2}{|c|}{ Recrack } & \multicolumn{2}{|c|}{ Failure } \\
\hline & & $\begin{array}{c}f_{c}^{\prime} \\
(\mathbf{M P a}) \\
(\mathbf{p s i})\end{array}$ & $\begin{array}{c}f_{t} \\
(\mathbf{M P a}) \\
(\mathbf{p s i})\end{array}$ & $\begin{array}{c}f_{c}^{\prime} \\
(\mathbf{M P a}) \\
(\mathbf{p s i})\end{array}$ & $\begin{array}{c}f_{t} \\
(\mathbf{M P a}) \\
(\mathbf{p s i})\end{array}$ & $\begin{array}{c}f_{c}^{\prime} \\
(\mathbf{M P a}) \\
(\mathbf{p s i})\end{array}$ & $\begin{array}{c}f_{t} \\
\text { (MPa) } \\
(\mathbf{p s i})\end{array}$ \\
\hline IT12Control & $\begin{array}{c}27.6 \\
(4008)\end{array}$ & $\begin{array}{c}31.0 \\
(4498)\end{array}$ & $\begin{array}{c}2.74 \\
(398)\end{array}$ & N/A & $\mathrm{N} / \mathrm{A}$ & $\begin{array}{c}31.8 \\
(4606)\end{array}$ & $\begin{array}{c}2.93 \\
(425)\end{array}$ \\
\hline IT12FT & $\begin{array}{c}32.1 \\
(4656)\end{array}$ & $\begin{array}{c}34.3 \\
(4969)\end{array}$ & $\begin{array}{l}2.16 \\
(313)\end{array}$ & N/A & N/A & $\begin{array}{c}32.8 \\
(4756)\end{array}$ & $\begin{array}{c}2.33 \\
(339)\end{array}$ \\
\hline IT12FTCK & $\begin{array}{c}26.9 \\
(3902)\end{array}$ & $\begin{array}{c}29.1 \\
(4222)\end{array}$ & $\begin{array}{c}2.22 \\
(322)\end{array}$ & $\begin{array}{c}28.30 \\
(4105)\end{array}$ & $\begin{array}{l}2.15 \\
(312)\end{array}$ & $\begin{array}{c}28.5 \\
(4137)\end{array}$ & $\begin{array}{c}2.40 \\
(349)\end{array}$ \\
\hline IT12M & $\begin{array}{c}30.03 \\
(4356) \\
\end{array}$ & $\begin{array}{c}32.92 \\
(4776) \\
\end{array}$ & $\begin{array}{c}3.42 \\
(497) \\
\end{array}$ & $\mathrm{N} / \mathrm{A}$ & N/A & $\begin{array}{c}33.18 \\
(4813) \\
\end{array}$ & $\begin{array}{c}3.6 \\
(523) \\
\end{array}$ \\
\hline IT12MCK & $\begin{array}{c}28.35 \\
(4112) \\
\end{array}$ & $\begin{array}{c}29.21 \\
(4237) \\
\end{array}$ & $\begin{array}{r}3.54 \\
(513) \\
\end{array}$ & $\begin{array}{r}29.75 \\
(4314) \\
\end{array}$ & N/A & $\begin{array}{c}30.4 \\
(4409) \\
\end{array}$ & $\begin{array}{c}3.84 \\
(557) \\
\end{array}$ \\
\hline ITT12FTCK & $\begin{array}{c}25.26 \\
(3664) \\
\end{array}$ & $\begin{array}{c}24.7 \\
(3583)\end{array}$ & $\begin{array}{c}2.9 \\
(422) \\
\end{array}$ & $\begin{array}{c}24.3 \\
(3526) \\
\end{array}$ & N/A & $\begin{array}{c}22.74 \\
(3298) \\
\end{array}$ & $\begin{array}{c}2.4 \\
(353) \\
\end{array}$ \\
\hline T18Control & $\begin{array}{c}26.9 \\
(3900) \\
\end{array}$ & $\begin{array}{c}30.1 \\
(4372)\end{array}$ & $\begin{array}{c}2.95 \\
(427) \\
\end{array}$ & N/A & N/A & $\begin{array}{c}29.8 \\
(4329)\end{array}$ & $\begin{array}{l}2.93 \\
(425) \\
\end{array}$ \\
\hline $\mathrm{T} 18 \mathrm{FT}$ & $\begin{array}{c}30.6 \\
(4435)\end{array}$ & $\begin{array}{c}30.8 \\
(4461)\end{array}$ & $\begin{array}{c}2.23 \\
(325) \\
\end{array}$ & N/A & N/A & $\begin{array}{c}33.7 \\
(4886)\end{array}$ & $\begin{array}{c}2.71 \\
(393) \\
\end{array}$ \\
\hline T18FTCK & $\begin{array}{c}29.3 \\
(4249) \\
\end{array}$ & $\begin{array}{r}29.9 \\
(4339) \\
\end{array}$ & $\begin{array}{c}2.10 \\
(304) \\
\end{array}$ & $\begin{array}{c}30.7 \\
(4454) \\
\end{array}$ & $\begin{array}{l}2.76 \\
(401) \\
\end{array}$ & $\begin{array}{c}30.9 \\
(4487) \\
\end{array}$ & $\begin{array}{c}2.54 \\
(368)\end{array}$ \\
\hline T18FFTCK & $\begin{array}{c}31 \\
(4496)\end{array}$ & $\begin{array}{c}28.94 \\
(4197)\end{array}$ & $\begin{array}{c}3.98 \\
(577)\end{array}$ & $\begin{array}{c}29.45 \\
(4272)\end{array}$ & $\mathrm{N} / \mathrm{A}$ & $\begin{array}{c}28.34 \\
(4112)\end{array}$ & $\begin{array}{c}2.8 \\
(404)\end{array}$ \\
\hline $\begin{array}{c}\text { Bond } \\
\text { Specimens }\end{array}$ & $\begin{array}{c}26.9 \\
(3900)\end{array}$ & $\begin{array}{c}30.1 \\
(4372)\end{array}$ & $\begin{array}{l}2.95 \\
(427)\end{array}$ & N/A & N/A & $\begin{array}{c}29.8 \\
(4329)\end{array}$ & $\begin{array}{l}2.93 \\
(425)\end{array}$ \\
\hline
\end{tabular}

Longitudinal steel consisted of \#36 ASTM A615 Grade 420 (\#11 Grade 60) and \#19 ASTM A615 Grade 420 (\#6 Grade 60) bars while transverse steel was \#13 ASTM A615 Grade 280 (\#4 Grade 40) open stirrups. Actual steel reinforcing properties were determined from tensile tests 
per ASTM A370 and ASTM E8. Tensile specimens were tested with a $489 \mathrm{kN}$ (110 kip) universal testing machine with constant head speeds of $0.0169 \mathrm{~mm} / \mathrm{sec}(0.000667 \mathrm{in} . / \mathrm{sec})$ for \#13 (\#4) and \#36 (\#11) bars. Strain was measured using a class B1 extensometer with $50 \mathrm{~mm}$ (2 in.) gage length. Measured mean steel properties are given in Table 4.4.

Table 4.4: Mean reinforcing steel properties

\begin{tabular}{|c|c|c|c|c|c|c|c|c|}
\hline \multirow{2}{*}{ Specimens } & \multicolumn{2}{|c|}{ Concrete } & \multicolumn{2}{|c|}{$\begin{array}{l}\text { \#36 Gr. 420 } \\
\text { (\# } 11 \text { Gr. 60) }\end{array}$} & \multicolumn{2}{|c|}{$\begin{array}{l}\text { \#13 Gr. } 280 \\
\text { (\# } 4 \text { Gr. 40) }\end{array}$} & \multicolumn{2}{|c|}{$\begin{array}{l}\text { \#19 Gr. } 420 \\
\text { (\# } 6 \text { Gr. 60) }\end{array}$} \\
\hline & $\begin{array}{c}f_{c}^{\prime} \\
(\mathbf{M P a}) \\
(\mathbf{p s i})\end{array}$ & $\begin{array}{c}f_{t} \\
\text { (MPa) } \\
\text { (psi) }\end{array}$ & $\begin{array}{c}f_{y} \\
(\mathbf{M P a}) \\
(\mathbf{k s i})\end{array}$ & $\begin{array}{c}f_{\text {ult }} \\
(\mathrm{MPa}) \\
(\mathbf{k s i})\end{array}$ & $\begin{array}{c}f_{y} \\
\text { (MPa) } \\
\text { (ksi) }\end{array}$ & $\begin{array}{c}f_{\text {ult }} \\
(\mathbf{M P a}) \\
(\mathbf{k s i})\end{array}$ & $\begin{array}{c}f_{y} \\
(\mathbf{M P a}) \\
(\mathbf{k s i})\end{array}$ & $\begin{array}{c}f_{u l t} \\
\text { (MPa) } \\
(\mathbf{k s i}) \\
\end{array}$ \\
\hline IT12Control & $\begin{array}{c}31.8 \\
(4606)\end{array}$ & $\begin{array}{l}2.93 \\
(425)\end{array}$ & \multirow{5}{*}{$\begin{array}{c}466 \\
(67.6)\end{array}$} & \multirow{5}{*}{$\begin{array}{c}784 \\
(113.7)\end{array}$} & \multirow{5}{*}{$\begin{array}{c}350 \\
(50.7)\end{array}$} & \multirow{5}{*}{$\begin{array}{c}544 \\
(78.9)\end{array}$} & \multirow{5}{*}{$\begin{array}{c}402 \\
(58.3)\end{array}$} & \multirow{5}{*}{$\begin{array}{c}680 \\
(98.6)\end{array}$} \\
\hline IT12FT & $\begin{array}{c}32.8 \\
(4756)\end{array}$ & $\begin{array}{l}2.33 \\
(339)\end{array}$ & & & & & & \\
\hline IT12FTCK & $\begin{array}{c}28.5 \\
(4137)\end{array}$ & $\begin{array}{l}2.40 \\
(349)\end{array}$ & & & & & & \\
\hline IT12M & $\begin{array}{l}33.18 \\
(4813)\end{array}$ & $\begin{array}{c}3.6 \\
(523)\end{array}$ & & & & & & \\
\hline IT12MCK & $\begin{array}{c}30.4 \\
(4409)\end{array}$ & $\begin{array}{c}3.84 \\
(557)\end{array}$ & & & & & & \\
\hline $\begin{array}{c}\text { ITT12FTC } \\
\mathrm{K}\end{array}$ & $\begin{array}{c}22.74 \\
(3298)\end{array}$ & $\begin{array}{c}2.4 \\
(353) \\
\end{array}$ & $\begin{array}{c}492 \\
(71.3)\end{array}$ & $\begin{array}{c}827 \\
(119.9)\end{array}$ & $\begin{array}{c}350 \\
(50.7)\end{array}$ & $\begin{array}{c}544 \\
(78.9)\end{array}$ & $\begin{array}{c}402 \\
(58.3) \\
\end{array}$ & $\begin{array}{c}680 \\
(98.6) \\
\end{array}$ \\
\hline T18Control & $\begin{array}{c}29.8 \\
(4329)\end{array}$ & $\begin{array}{l}2.93 \\
(425)\end{array}$ & \multirow{3}{*}{$\begin{array}{c}466 \\
(67.6)\end{array}$} & \multirow{3}{*}{$\begin{array}{c}784 \\
(113.7)\end{array}$} & \multirow{3}{*}{$\begin{array}{c}350 \\
(50.7)\end{array}$} & \multirow{3}{*}{$\begin{array}{c}544 \\
(78.9)\end{array}$} & \multirow{3}{*}{$\begin{array}{c}402 \\
(58.3)\end{array}$} & \multirow{3}{*}{$\begin{array}{c}680 \\
(98.6)\end{array}$} \\
\hline T18FT & $\begin{array}{c}33.7 \\
(4886)\end{array}$ & $\begin{array}{c}2.71 \\
(393)\end{array}$ & & & & & & \\
\hline T18FTCK & $\begin{array}{c}30.9 \\
(4487)\end{array}$ & $\begin{array}{c}2.54 \\
(368)\end{array}$ & & & & & & \\
\hline T18FFTCK & $\begin{array}{l}28.34 \\
(4112)\end{array}$ & $\begin{array}{c}2.8 \\
(404)\end{array}$ & $\begin{array}{c}492 \\
(71.3)\end{array}$ & $\begin{array}{c}827 \\
(119.9)\end{array}$ & $\begin{array}{c}350 \\
(50.7)\end{array}$ & $\begin{array}{c}544 \\
(78.9)\end{array}$ & $\begin{array}{c}402 \\
(58.3)\end{array}$ & $\begin{array}{c}680 \\
(98.6)\end{array}$ \\
\hline
\end{tabular}

For CFRP material properties, $610 \mathrm{~mm}$ x $610 \mathrm{~mm}(24$ in. $\mathrm{x} 24$ in.) sheets of CFRP were prepared as part of the specimen installation process. One coat of saturant was rolled onto a Teflon board, carbon fiber fabric was placed and saturated with the base saturant, and a final coat of saturant was added before placing another Teflon board on top.

These sample sheets were cured under the same temperature conditions as the specimens. After curing, $25 \mathrm{~mm} \times 305 \mathrm{~mm}$ ( 1 in. $\times 12$ in.) coupons were cut from the sheet using a wet tile saw. Care was taken to ensure cuts were oriented along the fiber direction. The coupons were prepared and tested in accordance with ASTM D 3039. Perforated fiberglass programming board tabs, $25 \mathrm{~mm} \times 57 \mathrm{~mm}$ ( 1 in. $\times 2.25 \mathrm{in}$.), were cut and attached to the ends of the CFRP coupons with cyanoacrolyte adhesive to prevent crushing of the CFRP in the grips of the tensile testing machine. Coupons were tested using a $89 \mathrm{kN}$ (20 kip) universal testing machine with a constant head speed of $1.25 \mathrm{~mm} / \mathrm{min}(0.05 \mathrm{in} . / \mathrm{min})$ and strains were measured using a Class B 
extensometer with a $25 \mathrm{~mm}$ ( 1 in.) gage length. Test values and manufacturers specified design values (Watson Bowman Acme 2003) are shown in Table 4.5.

Table 4.5: Specified and actual CFRP $0^{\circ}$ tensile properties

\begin{tabular}{c|c|c|c}
\hline Property & Wabo® Design & Test Mean & Test St. Dev. \\
\hline $\begin{array}{c}\text { Coupon Thickness, } \\
t_{f}(\mathrm{~mm})(\mathrm{in} .)\end{array}$ & $\begin{array}{c}0.6-1.0 \\
(0.02-0.04)\end{array}$ & $\begin{array}{c}1.16 \\
(0.0458)\end{array}$ & $\begin{array}{c}0.314 \\
(0.0124)\end{array}$ \\
\hline $\begin{array}{c}\text { Tensile Strength, } \\
f_{f u}(\mathrm{MPa})(\mathrm{ksi})\end{array}$ & $\begin{array}{c}625-1042^{\mathbf{a}} \\
(89-179)\end{array}$ & $\begin{array}{c}725 \\
(105)\end{array}$ & $\begin{array}{c}218 \\
(31.6)\end{array}$ \\
\hline Unit Stress, & $\begin{array}{c}0.625 \\
f_{f u} t_{f}(\mathrm{kN} / \mathrm{mm} / \mathrm{ply})(\mathrm{kip} / \mathrm{in} . / \mathrm{ply})\end{array}$ & $\begin{array}{c}0.777 \\
(4.44)\end{array}$ & $\begin{array}{c}0.0422 \\
(0.241)\end{array}$ \\
\hline $\begin{array}{c}\text { Elastic Modulus, } \\
E_{f}(\mathrm{GPa})(\mathrm{ksi})\end{array}$ & $\begin{array}{c}37.4-62.4^{\mathbf{a}} \\
(5300-10700)\end{array}$ & $\begin{array}{c}36.6 \\
(5300)\end{array}$ & $\begin{array}{c}9.34 \\
(1350)\end{array}$ \\
\hline Rupture Strain, \\
$\varepsilon_{f u}(\%)$
\end{tabular}

Direct pull-off tension tests of the CFRP were also completed for each specimen in accordance with ASTM D 4541. After failure testing of specimens, four undisturbed regions of CFRP were prepared and cleaned before applying a $51 \mathrm{~mm} \times 51 \mathrm{~mm}$ (2 in. $\mathrm{x} 2$ in.) steel square dolly with adhesive. The surface was first roughened with the sand paper so that the square dolly would bond well to the CFRP. The adhesive was allowed to cure before using an abrasive cutting wheel to cut the CFRP around the edges of the dolly so as to make the surface contact area 4 sq. in. A $1.6 \mathrm{kN}(3600 \mathrm{lb})$ capacity portable testing device with digital manometer was used to pull and record the maximum load. The maximum load was divided by the dolly surface area to determine the pull-off strength of the CFRP. Failure occurred for all tests in the concrete substrate. The mean and standard deviation of the tension pull-off strengths for each specimen and for different CFRP systems are shown in Table 4.6 and Table 4.7. 
Table 4.6: CFRP pull-off tensile strengths

\begin{tabular}{|c|c|c|}
\hline Specimen & $\begin{array}{l}\text { Mean } f_{\text {pull-off }} \\
\text { (MPa) (psi) }\end{array}$ & $\begin{array}{l}\text { St. Dev. } f_{\text {pull-off }} \\
\text { (MPa) (psi) }\end{array}$ \\
\hline IT12Control & $\begin{array}{c}2.45 \\
(355) \\
\end{array}$ & $\begin{array}{c}0.53 \\
(76.5) \\
\end{array}$ \\
\hline IT12FT & $\begin{array}{l}2.73 \\
(396) \\
\end{array}$ & $\begin{array}{c}0.52 \\
(76.0) \\
\end{array}$ \\
\hline IT12FTCK & $\begin{array}{l}2.67 \\
(387) \\
\end{array}$ & $\begin{array}{c}0.14 \\
(19.8) \\
\end{array}$ \\
\hline IT12M & $\begin{array}{l}3.06 \\
(445) \\
\end{array}$ & $\begin{array}{c}0.94 \\
(136) \\
\end{array}$ \\
\hline IT12MCK & $\begin{array}{l}2.60 \\
(377) \\
\end{array}$ & $\begin{array}{c}1.06 \\
(155) \\
\end{array}$ \\
\hline ITT12FTCK & $\begin{array}{r}2.84 \\
(413) \\
\end{array}$ & $\begin{array}{c}0.84 \\
(123) \\
\end{array}$ \\
\hline T18Control & $\begin{array}{l}2.70 \\
(391) \\
\end{array}$ & $\begin{array}{c}0.80 \\
(116) \\
\end{array}$ \\
\hline T18FT & $\begin{array}{l}2.14 \\
(311) \\
\end{array}$ & $\begin{array}{c}0.63 \\
(91.1) \\
\end{array}$ \\
\hline T18FTCK & $\begin{array}{l}2.32 \\
(337)\end{array}$ & $\begin{array}{c}0.20 \\
(28.7)\end{array}$ \\
\hline T18FFTCK & $\begin{array}{r}2.40 \\
(349) \\
\end{array}$ & $\begin{array}{l}1.51 \\
(219) \\
\end{array}$ \\
\hline
\end{tabular}

Table 4.7: Pull-off tensile strengths for Different CFRP systems

\begin{tabular}{|c|c|c|c|c|}
\hline \multirow[b]{2}{*}{$\begin{array}{c}\text { CFRP } \\
\text { System }\end{array}$} & \multicolumn{2}{|c|}{ Control } & \multicolumn{2}{|c|}{ Freeze-Thaw } \\
\hline & $\begin{array}{l}\text { Mean } f_{\text {pull-off }} \\
\text { (MPa) (psi) }\end{array}$ & $\begin{array}{l}\text { St. Dev. } f_{\text {pull-off }} \\
\text { (MPa) (psi) }\end{array}$ & $\begin{array}{l}\text { Mean } f_{\text {pull-off }} \\
\text { (MPa) (psi) }\end{array}$ & $\begin{array}{l}\text { St. Dev. } f_{\text {pull-off }} \\
\text { (MPa) (psi) }\end{array}$ \\
\hline Edge & $\begin{array}{c}2.63 \\
(383) \\
\end{array}$ & $\begin{array}{l}0.26 \\
(38) \\
\end{array}$ & $\begin{array}{c}2.48 \\
(360) \\
\end{array}$ & $\begin{array}{c}0.7 \\
(100) \\
\end{array}$ \\
\hline Fyfe & $\begin{array}{c}2.5 \\
(361) \\
\end{array}$ & $\begin{array}{l}0.75 \\
(109) \\
\end{array}$ & $\begin{array}{c}2.53 \\
(367) \\
\end{array}$ & $\begin{array}{l}0.21 \\
(31) \\
\end{array}$ \\
\hline Sika & $\begin{array}{c}2.04 \\
(293)\end{array}$ & $\begin{array}{r}0.35 \\
(51)\end{array}$ & $\begin{array}{c}2.3 \\
(334)\end{array}$ & $\begin{array}{l}0.25 \\
(36)\end{array}$ \\
\hline
\end{tabular}

Pull off tests were also done on the exposed concrete surface. The mean and standard deviation of the tension pull-off strengths for concrete are shown in Table 4.8.

Table 4.8: Concrete pull-off tensile strengths

\begin{tabular}{c|c|c}
\hline Specimen & $\begin{array}{c}\text { Mean } \boldsymbol{f}_{\text {pull-off }} \\
(\mathbf{M P a})(\mathbf{p s i})\end{array}$ & $\begin{array}{c}\text { St. Dev. } \boldsymbol{f}_{\text {pull-off }} \\
\mathbf{( M P a )}(\mathbf{p s i})\end{array}$ \\
\hline Control & 2.15 & 0.25 \\
& $(312)$ & $(37.5)$ \\
\hline Moisture Specimens & 2.84 & 0.33 \\
& $(413)$ & $(49.0)$ \\
\hline Freeze-Thaw & 2.71 & 0.56 \\
Specimens & $(393)$ & $(81.8)$ \\
\hline
\end{tabular}




\subsection{STRUCTURAL TESTING}

\subsubsection{Static Loading Setup}

Specimens were subjected to the precrack, recrack, and failure tests on the strong floor at the Structural Engineering Research Laboratory at Oregon State University. The specimens were tested in a simply supported configuration under four-point loading. The typical loading setup is shown in Figure 4.3.

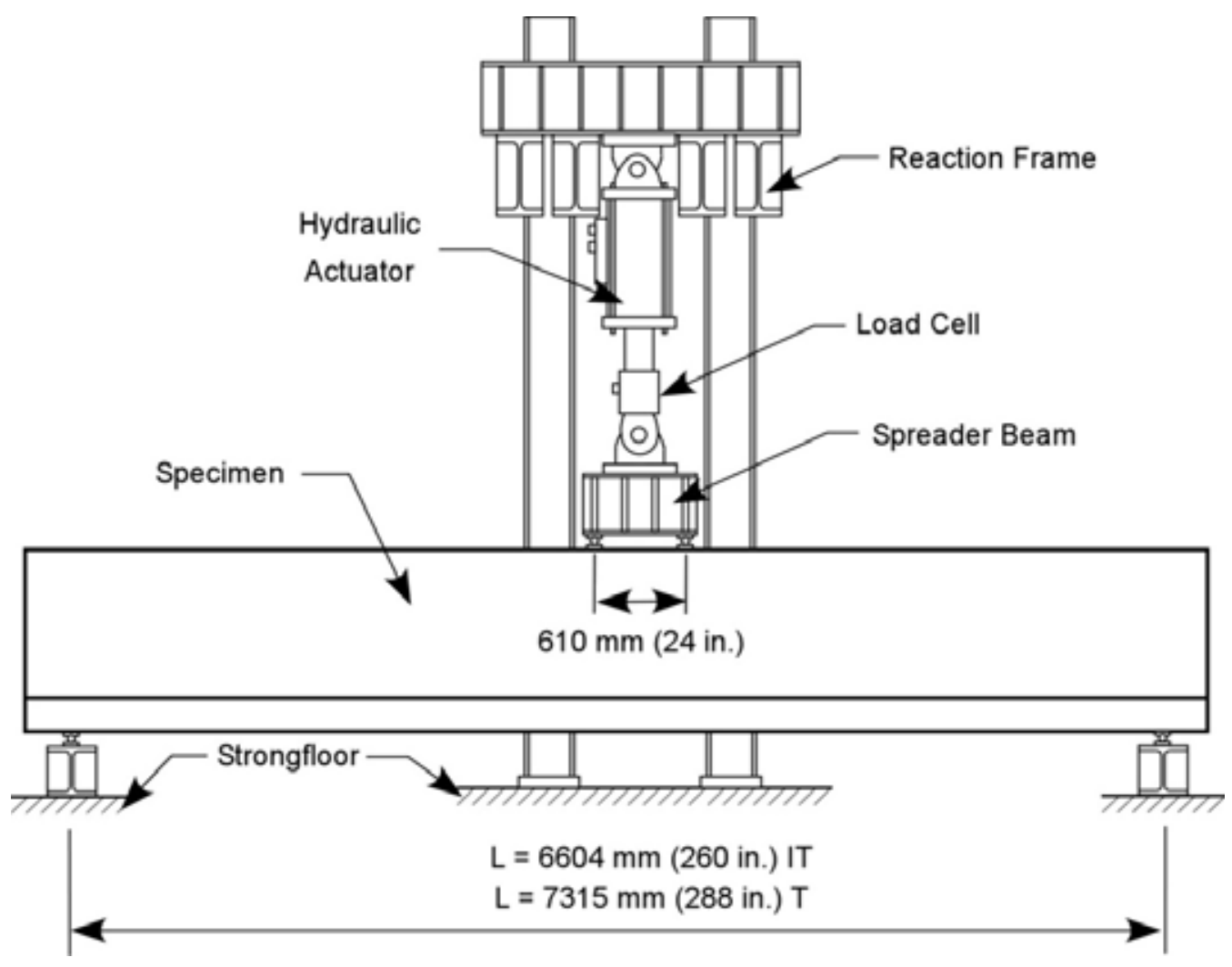

Figure 4.3: Typical static load setup

IT-Specimens were loaded on a $6604 \mathrm{~mm}$ (260 in.) overall span while T-Specimens were loaded on a $7315 \mathrm{~mm}$ (288 in.) overall span. The specimens were supported on $102 \mathrm{~mm}$ (4 in.) wide bearing plates resting on $51 \mathrm{~mm}$ ( 2 in.) diameter rollers. Load was applied at midspan to $51 \mathrm{~mm}$ ( 2 in.) rollers resting on $102 \mathrm{~mm}$ (4 in.) wide bearing plates through a spreader beam with a 610 mm (24 in.) span. Loads were measured with a $2224 \mathrm{kN}$ (500 kip) capacity load cell and applied using a hydraulic actuator at a rate of $9 \mathrm{kN} / \mathrm{sec}$. (2 kip/sec.). All tests included several load cycles; with the applied load increasing $222 \mathrm{kN}$ (50 kip) for each cycle. For each cycle, once the target load amplitude was achieved, it was immediately decreased by $10 \%$ to permit identification of visible cracks and debonding, and then the specimen was unloaded to continue on to the next loading sequence. Debonding of the CFRP was identified by tapping on the surface and listening for a distinct hollow sound. Additionally, a FLIR infrared camera was used 
to identify debonding. A halogen light was passed across regions of suspected debonding and a thermographic image was taken. Debonded regions did not dissipate the heat quickly and appeared warmer on the thermographic image. A correlation of a debonded region identified by the tapping method with the thermographic image is shown in Figure 4.4.

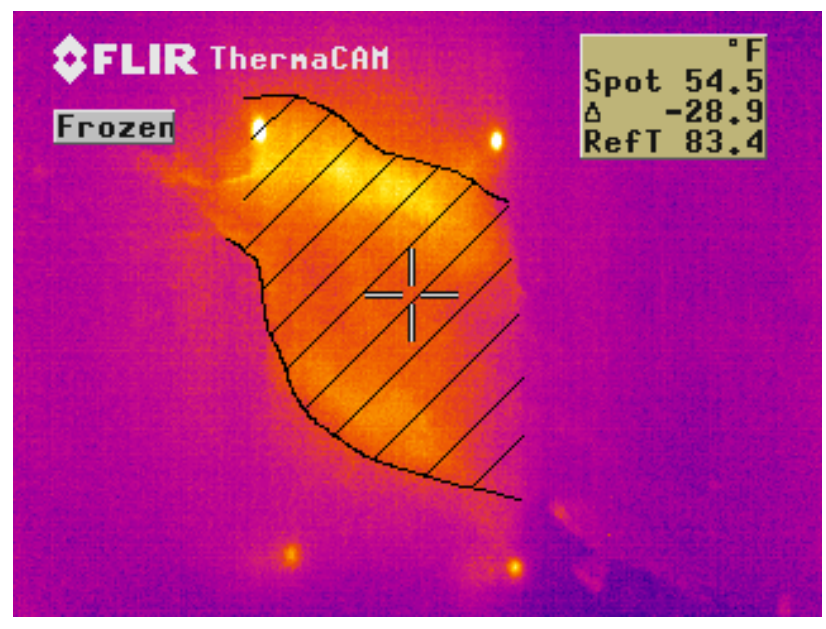

Figure 4.4: Thermographic image of debonding

\subsubsection{Fatigue Loading Setup}

Fatigue loading was conducted for specimen T18FFTCK using a sinusoidal loading function with unique load ranges to obtain target damage for one million applied load cycles. A $1334 \mathrm{kN}$ (300 kip) capacity load cell was used for feedback of the load control protocol and load was applied with a $978 \mathrm{kN}(220 \mathrm{kip})$ capacity actuator. Specimen T18FFTCK was fatigued at a load range of $267 \mathrm{kN}$ (60 kips) with a mean of $445 \mathrm{kN}$ (100 kips) at a frequency of $1.00 \mathrm{~Hz}$. Each day 25,000 cycles were completed and the hydraulic system was turned off at the end of each day. The applied load coincided with simultaneous freeze-thaw cycles. Load was applied at midspan on a steel plate size $256 \mathrm{~mm}$ (14 in.) x $256 \mathrm{~mm}$ (14 in.). Before starting the actual load cycles, a baseline test was conducted because the shear span of the beam in the environmental chamber was slightly larger due to the single point load. After every 100,000 cycles a baseline test was conducted to check the stiffness and overall deflection. After the baseline test, both the specimens in the freezer were inspected for cracks and CFRP debonding. A schematic presentation of the loading setup in the freezer is shown in Figure 4.5 and Figure 4.6. 


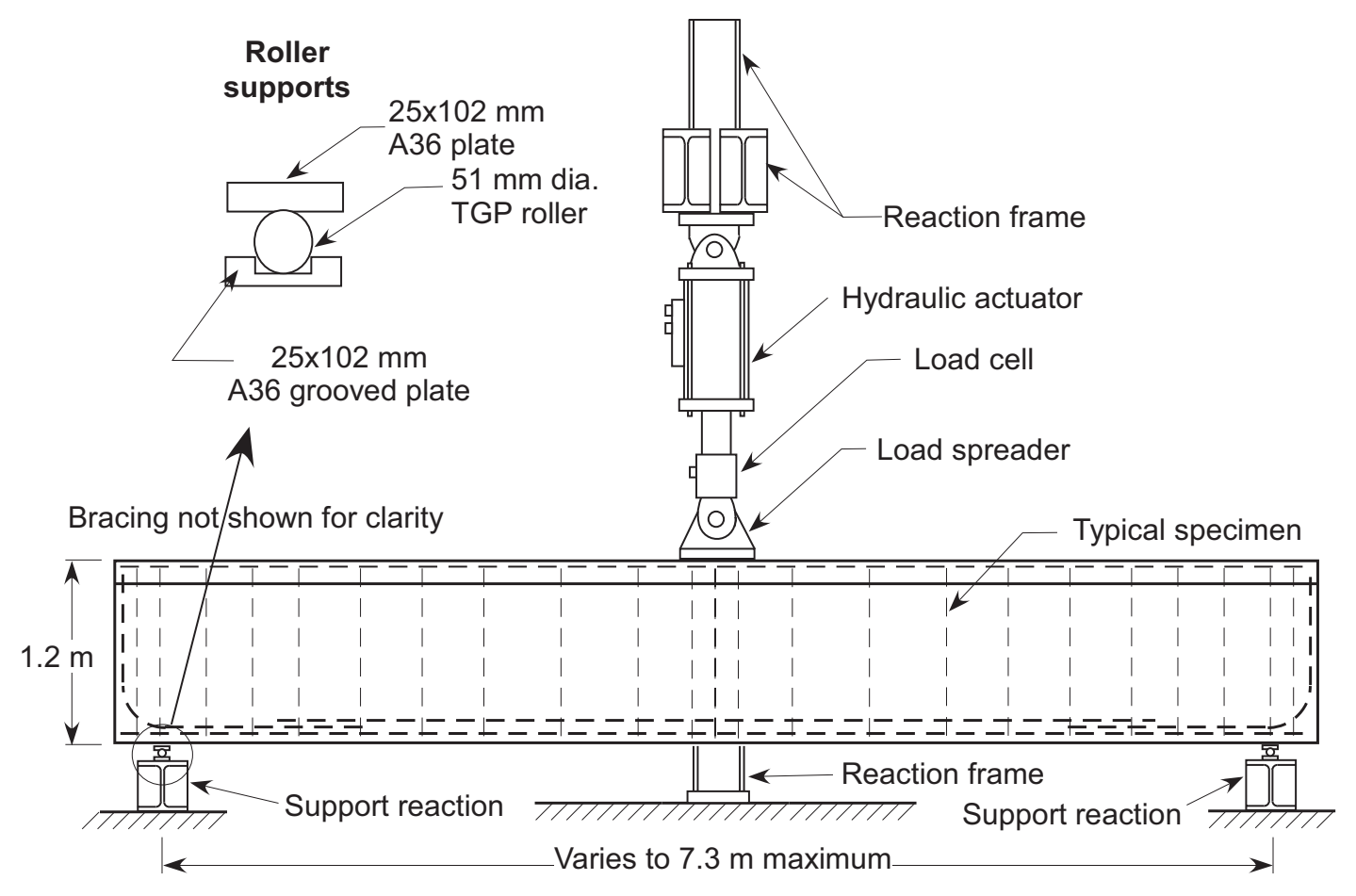

Figure 4.5: Fatigue + Freeze-Thaw Loading Setup (Side View)

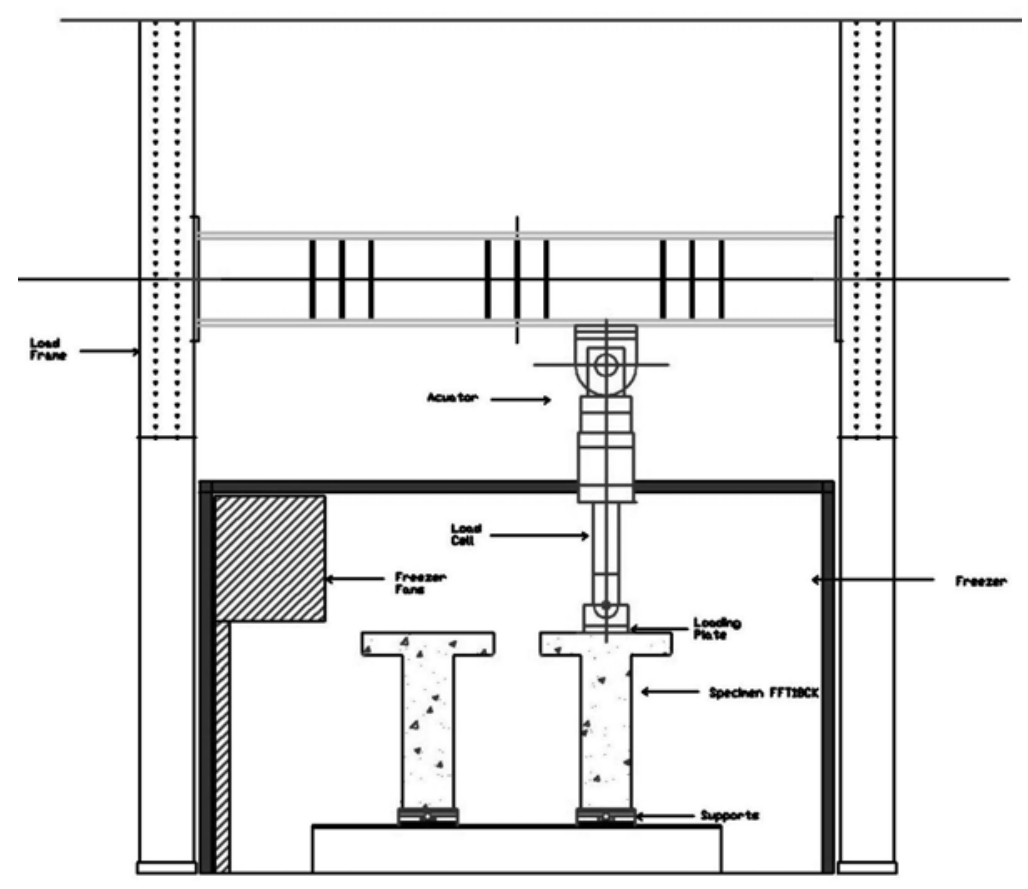

Figure 4.6: Fatigue + Freeze-Thaw Loading Setup (South View) 


\subsection{INSTRUMENTATION}

Instruments were applied to the specimens to measure overall and local deformations, CFRP and reinforcing steel strains, support motions, and applied force. Typical instrumentation layout used for all specimens is illustrated in Figure 4.7. Transverse steel strains were measured locally at midheight of the specimen, while longitudinal rebar strains were measured at midspan. Steel strains were measured using short gage length CEA-06-125UN-120 strain gages to minimize the locally debonded region around the sensors. Local CFRP strains were measured at expected diagonal crack locations using either N2A-06-20CBW-120 or EA-06-20CBW-120. These gages had a $51 \mathrm{~mm}$ ( $2 \mathrm{in}$.) length, allowing for the strains to be averaged over multiple CFRP weaves. Diagonal deformations were measured with $51 \mathrm{~mm}(2 \mathrm{in}$.) string potentiometers, to permit average strains to be calculated over three regions on each shear span. Midspan displacements were measured using $127 \mathrm{~mm}$ (5 in.) string potentiometers, while support settlements were measured using $13 \mathrm{~mm}(0.5 \mathrm{in}$.) range displacement sensors. Support deformations were subtracted from midspan displacements so rigid body displacements were removed from the reported overall midspan displacement of the specimens.

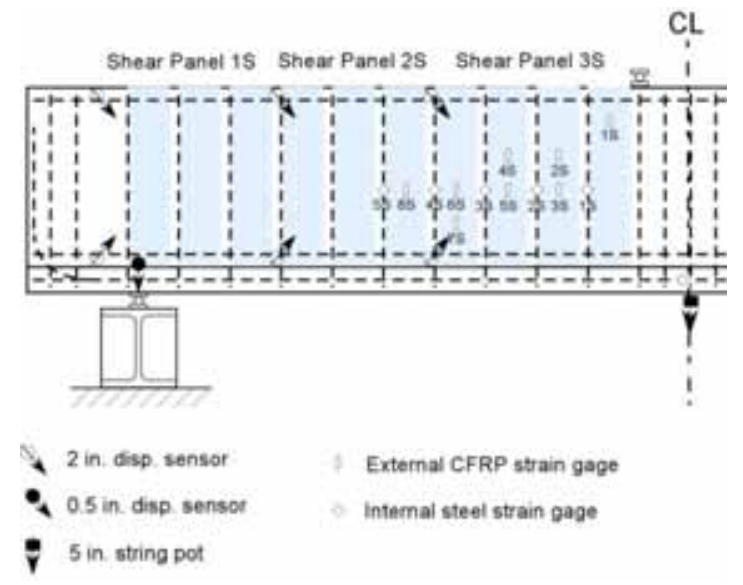

Figure 4.7: Typical instrumentation layout for all specimens

\subsection{PRECRACKING}

All specimens first produced diagonal cracking at applied shears of approximately $137 \mathrm{kN}$ ( 31 kips). Initial cracking for the specimens (called precracking in this study) was done by subjecting the initial RC beam to a maximum shear of $667 \mathrm{kN}$ (150 kips) for the IT and $556 \mathrm{kN}$ (125 kip) for the T-Specimens. These forces correspond to about $90 \%$ and $83 \%$ of the ultimate capacity as predicted by Response-2000 (Bentz 2001) for the IT and T-Specimens, respectively. The maximum diagonal crack widths under load at these stages were $1.52 \mathrm{~mm}(0.06 \mathrm{in}$.) for the ITSpecimens and $1.78 \mathrm{~mm}(0.07 \mathrm{in}$.) for the T-Specimens. After initial cracking, a baseline test 
was performed to evaluate the stiffness, deformations, and stresses of the cracked beams. The precracked condition for all specimens is shown in Figures 4.8-4.17.

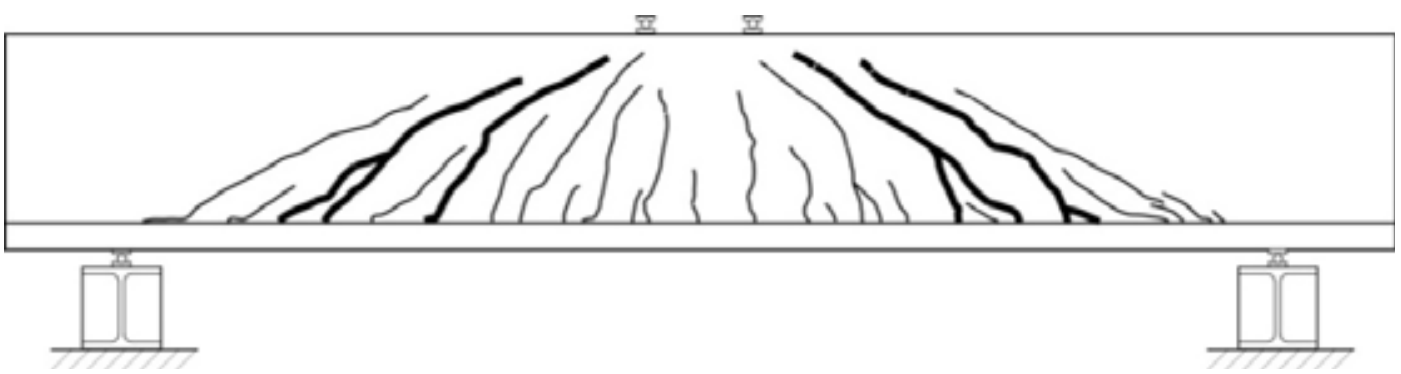

Figure 4.8: Precracked condition Specimen IT12Control

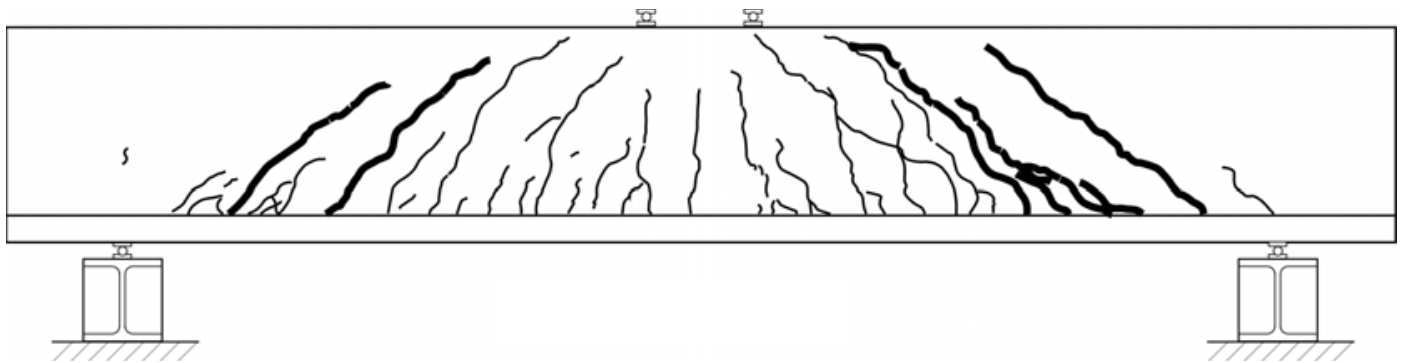

Figure 4.9: Precracked condition Specimen IT12FT

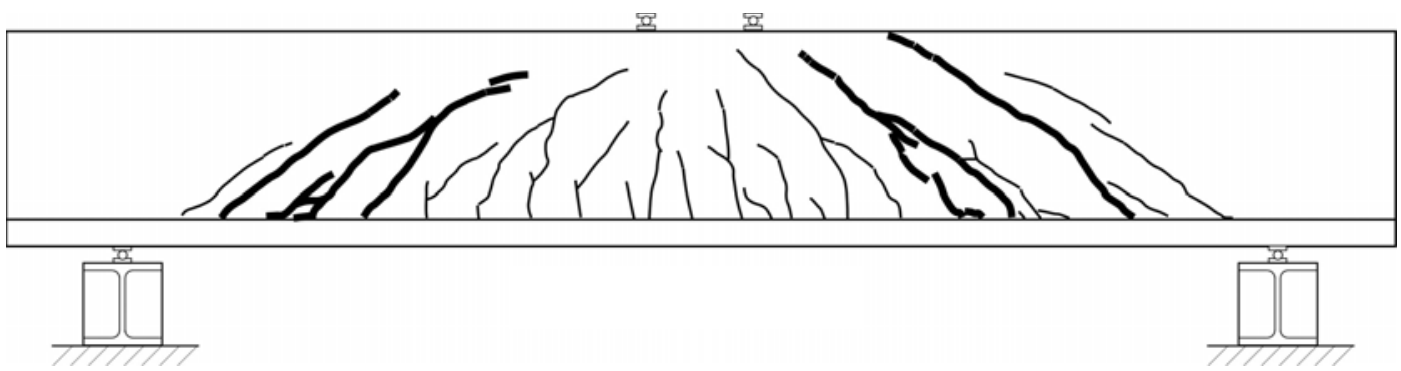

Figure 4.10: Precracked condition Specimen IT12FTCk 


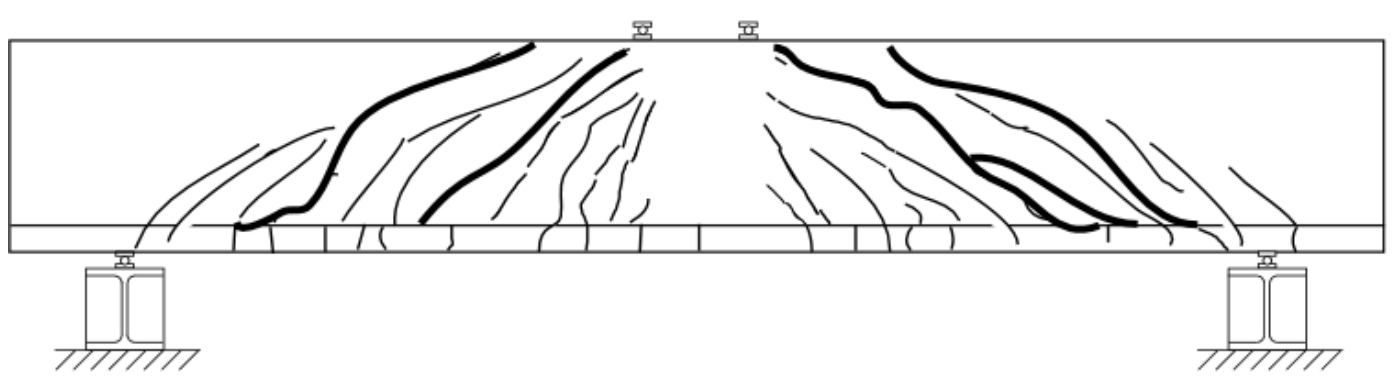

Figure 4.11: Precracked condition Specimen IT12M

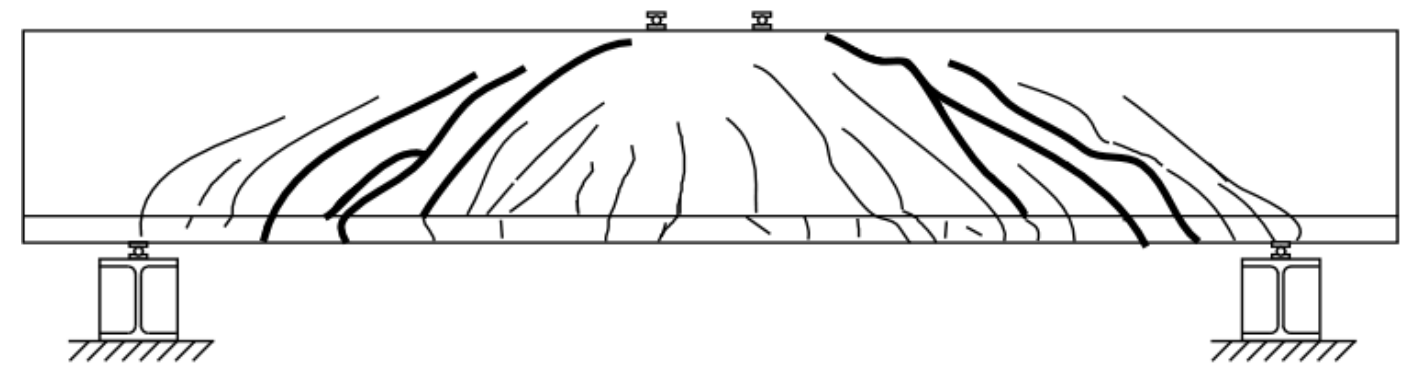

Figure 4.12: Precracked condition Specimen IT12MCK

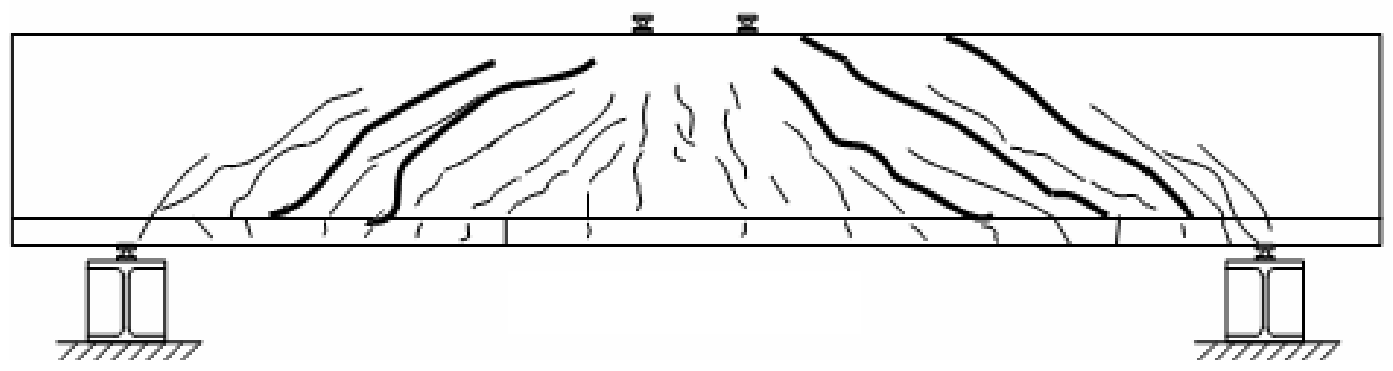

Figure 4.13: Precracked condition Specimen ITT12FTCK

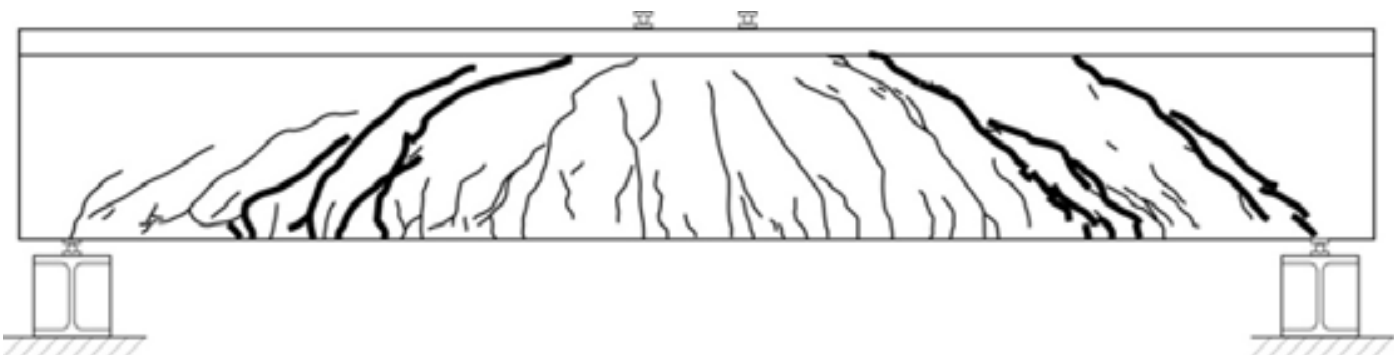

Figure 4.14: Precracked condition Specimen T18 Control 


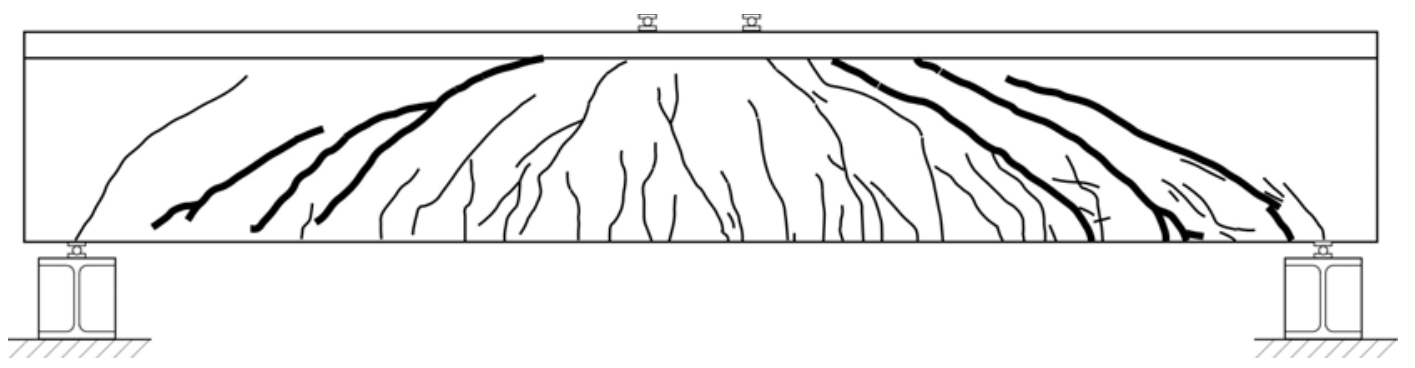

Figure 4.15: Precracked condition Specimen T18FT

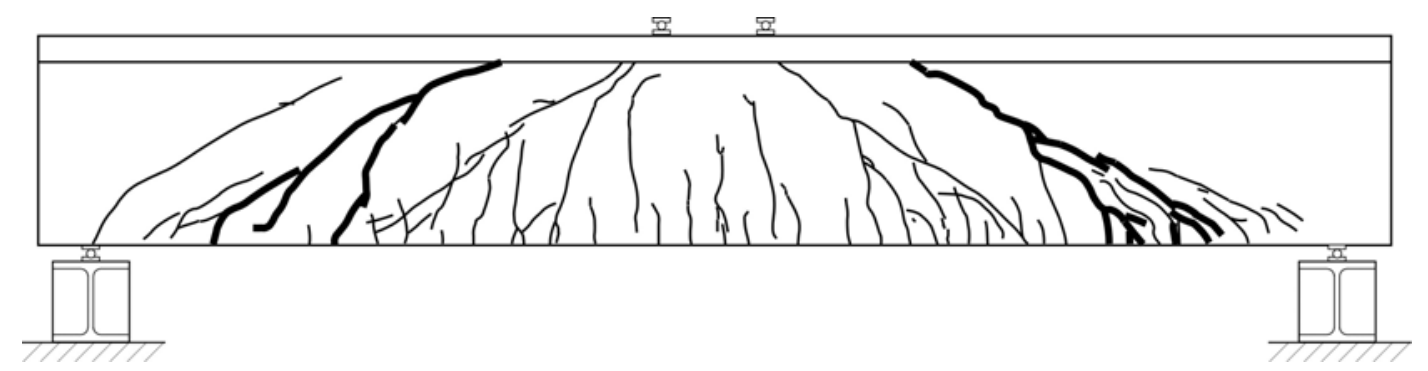

Figure 4.16: Precracked condition Specimen T18FTCk

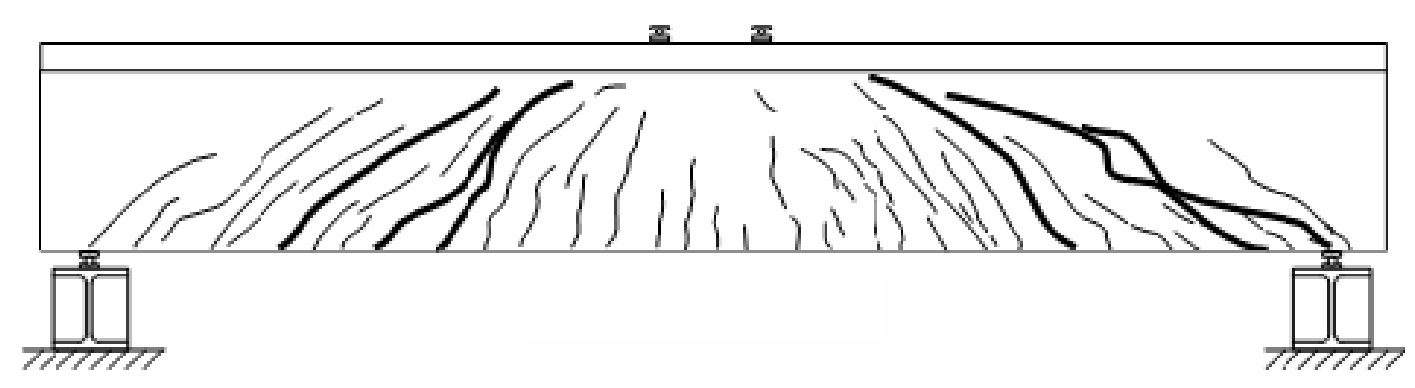

Figure 4.17: Precracked condition Specimen FFT18CK

\subsection{CFRP INSTALLATION}

After precracking, the load was removed from the specimens, select cracks were epoxy injected, and the unidirectional CFRP U-wraps were applied using a wet lay-up procedure. Application was performed according to the manufacturer's specifications (Watson Bowman Acme 2002) and is described below. 


\subsubsection{Epoxy Injection}

Cracks wider than $0.25 \mathrm{~mm}$ (0.010 in.) were epoxy injected using Chemrex SCB Concresive 1360. The concrete surface around the diagonal cracks was cleaned and the cracks were sealed and injection ports were placed at the crack surface. Concresive SPL paste was used to seal the cracks at the concrete surface. On one side of the web, injection ports were installed at a spacing of approximately $356 \mathrm{~mm}$ (14 in.), while only three injection ports were placed on the opposite side of the web. One port was placed at the bottom of the web, one at mid-height, and one near the top. The surface sealant was allowed to cure for 24 hours before injection. An epoxy injection machine with mixing nozzle was used, allowing for the proper proportioning and mixing of the two-part epoxy. The machine also provided pressure readings during injection. The injection nozzle was placed at the bottom-most port and the injection pressure kept below $0.69 \mathrm{MPa}$ (100 psi) until epoxy was visible in the port above. The lower port was capped and the injection nozzle moved to the next port. Window ports on the opposite side of the web were monitored to ensure epoxy was flowing through the thickness of the web. Injection continued from the bottom to the top of the specimen until the top-most port was reached. Epoxy was injected at this port until a pressure of $0.69 \mathrm{MPa}(100 \mathrm{psi})$ could be maintained. The epoxy was allowed to cure for at least 7 days at temperature above $4^{\circ} \mathrm{C}\left(40^{\circ} \mathrm{F}\right)$ before the next application step. Injected cracks are shown in bold in Figures 4.8-4.17.

\subsubsection{CFRP Application MBrace system}

After epoxy injection, the surface was prepared for CFRP application. First, the surface crack sealing paste was removed by heating and scraping it off. Next, the surface was ground using a diamond dressed masonry disc, removing the concrete paste surface to expose aggregate and small voids. Additionally, all sharp corners were rounded using the masonry disc. Finally, the surface was vacuumed to remove dust that had accumulated during grinding. Once the surface preparation was completed, the CFRP system was installed. First, the two-part MBrace Primer was mixed with a mechanical mixer for 3 minutes and applied to the concrete surface using nap rollers with a coverage rate of approximately 3.8-4.9 m2/L (150-200 ft2/gal). The primer was allowed to cure for several hours before the two-part MBrace putty was applied. Part A of the putty was premixed for 3 minutes, as was Part B. Part A was then added to Part B and mixed for 3 minutes. This was then applied using trowels to fill small voids and smooth small imperfections in the concrete surface. Finally, the two-part MBrace saturant was mixed. Part A was premixed for 3 minutes, Part B was added and then the combined elements were mixed for an additional 3 minutes. This was then rolled onto the surface with a thickness of approximately $0.46-0.51 \mathrm{~mm}(18-20 \mathrm{mil})$ corresponding to a coverage rate of approximately $1.3 \mathrm{~m} 2 / \mathrm{L}(35-55$ $\mathrm{ft} 2$ /gal). Strips of dry MBrace CF130 carbon fiber fabric were then applied while the saturant was still wet. A plastic putty knife, running in the direction of the fibers, was used to press the fabric into the saturant, impregnating the fabric and removing air bubbles. A final coat of MBrace saturant was rolled over the fabric with the same thickness and coverage rate as the first coat. As learned from previous repairs, for Freeze-Thaw specimens, care was taken that CFRP strips ending at the edges of the beams were fully saturated with the resin and more resin was intentionally used to seal the nearby area to protect it against moisture. The specimen was then cured for at least 7 days in a heated enclosure to ensure the ambient temperature remained above $4^{\circ} \mathrm{C}\left(40^{\circ} \mathrm{F}\right)$. Average 7 day curing temperatures for each application are shown in Table 4.9. 
After the saturant set up, it was scuffed with sandpaper and vacuumed to permit application of the topcoat. The MBrace Topcoat ATX was mixed for 3 minutes with a mechanical mixer then rolled on with a coverage rate of approximately 1.94-2.43 m2/L (80 to $100 \mathrm{ft} 2 / \mathrm{gal}$ ) using a nap roller.

Table 4.9: Average 7 day curing temperatures

\begin{tabular}{c|c}
\hline Specimen & $\begin{array}{c}\text { Average Curing } \\
\text { Temperature } \\
\left({ }^{\circ} \mathbf{C}\right)(\mathbf{~} \mathbf{F})\end{array}$ \\
\hline IT12Control & $17(62)$ \\
\hline IT12FT & $14(57)$ \\
\hline IT12FTCK & $14(57)$ \\
\hline IT12M & $8(48)$ \\
\hline IT12MCK & $8(48)$ \\
\hline ITT12FTCK & $22(73)$ \\
\hline T18Control & $17(62)$ \\
\hline T18FT & $15(59)$ \\
\hline T18FTCK & $15(59)$ \\
\hline T18FFTCK & $22(73)$ \\
\hline
\end{tabular}

\subsection{RECRACKING}

After epoxy injection and application of CFRP, five of the specimens (denoted with CK) were then recracked by applying $1001 \mathrm{kN}$ (225 kips) and $725 \mathrm{kN}$ (163 kips) of shear to the IT and T beams, respectively. Similar to the initial precracking phase, a second baseline test was performed to evaluate the stiffness, deformations, and stresses of the recracked CFRP strengthened beams. Recracked conditions of example specimens are shown in Figure 4.18. 

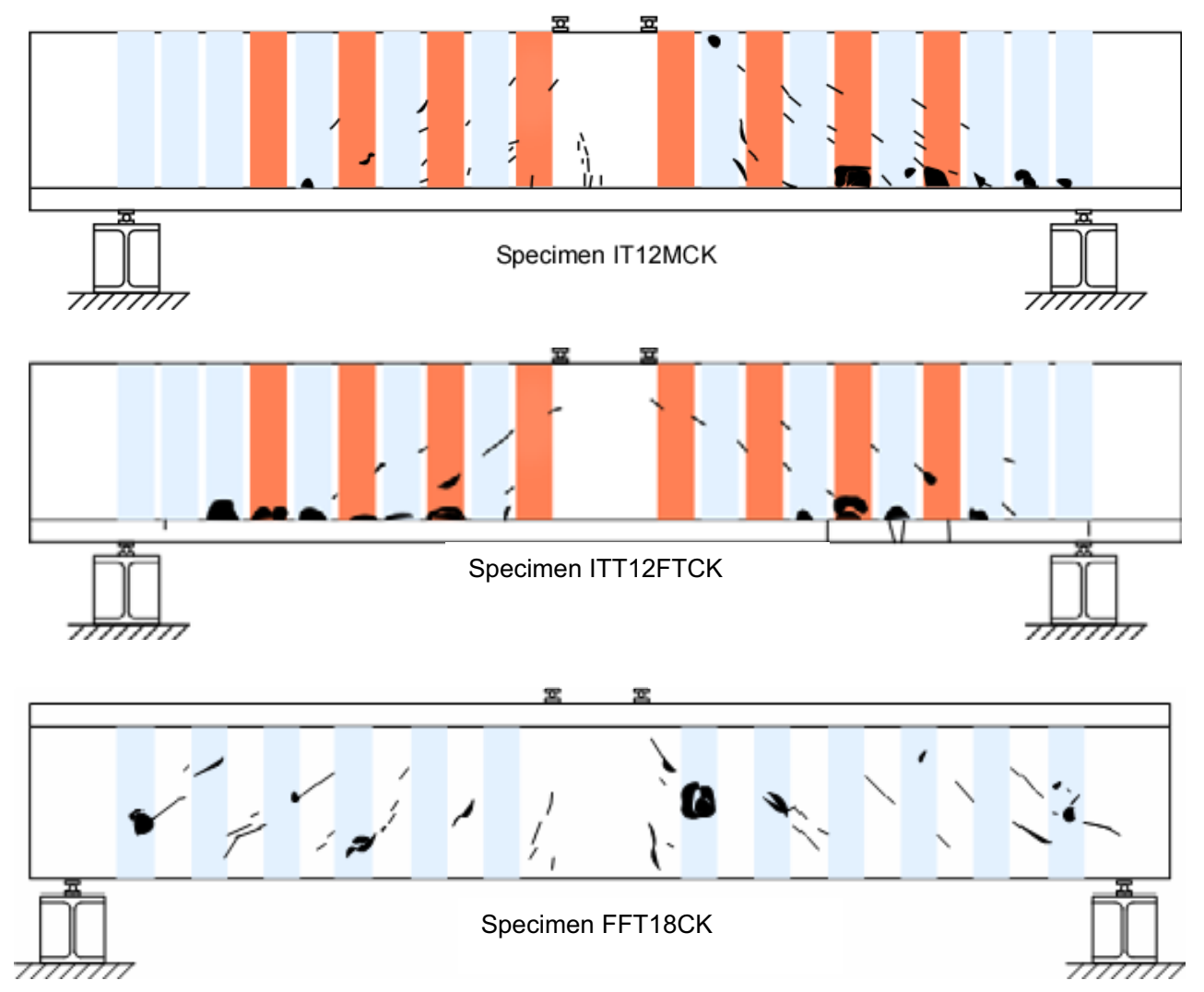

Figure 4.18: Recracked condition of example specimens

\subsection{ENVIRONMENTAL EXPOSURE}

\subsubsection{Moisture Specimens}

Two full scale specimens, IT12M and IT12MCK, were kept submerged under water for six months in a bath tub. A tub with length $8180 \mathrm{~mm}$ (322 in.), width $2413 \mathrm{~mm}$ (95 in.) and height $1372 \mathrm{~mm}$ (54 in.) was constructed using plywood and dimensional lumber. A pond liner was placed inside the tank to hold the water. Threaded rods were used at the top and bottom along the long walls of the tub to resist the hydrostatic pressure in the tub and $12.7 \mathrm{~mm}(0.5 \mathrm{in}$.) bolts were used to connect the corners of the wall. During the exposure, the water level in the tank was maintained above the level of the specimens. To monitor the water temperature, two thermocouples were installed to measure water and air temperatures around and in the tank. The average measured temperatures during the exposure were $17^{\circ} \mathrm{C}\left(62^{\circ} \mathrm{F}\right)$ and $15^{\circ} \mathrm{C}\left(59^{\circ} \mathrm{F}\right)$ for air and water, respectively. A schematic representation of the tank is shown in Figure 4.19 below with a photo of the specimens inside the tank. Example air and moisture temperatures around the bathtub are shown in Figure 4.20. 

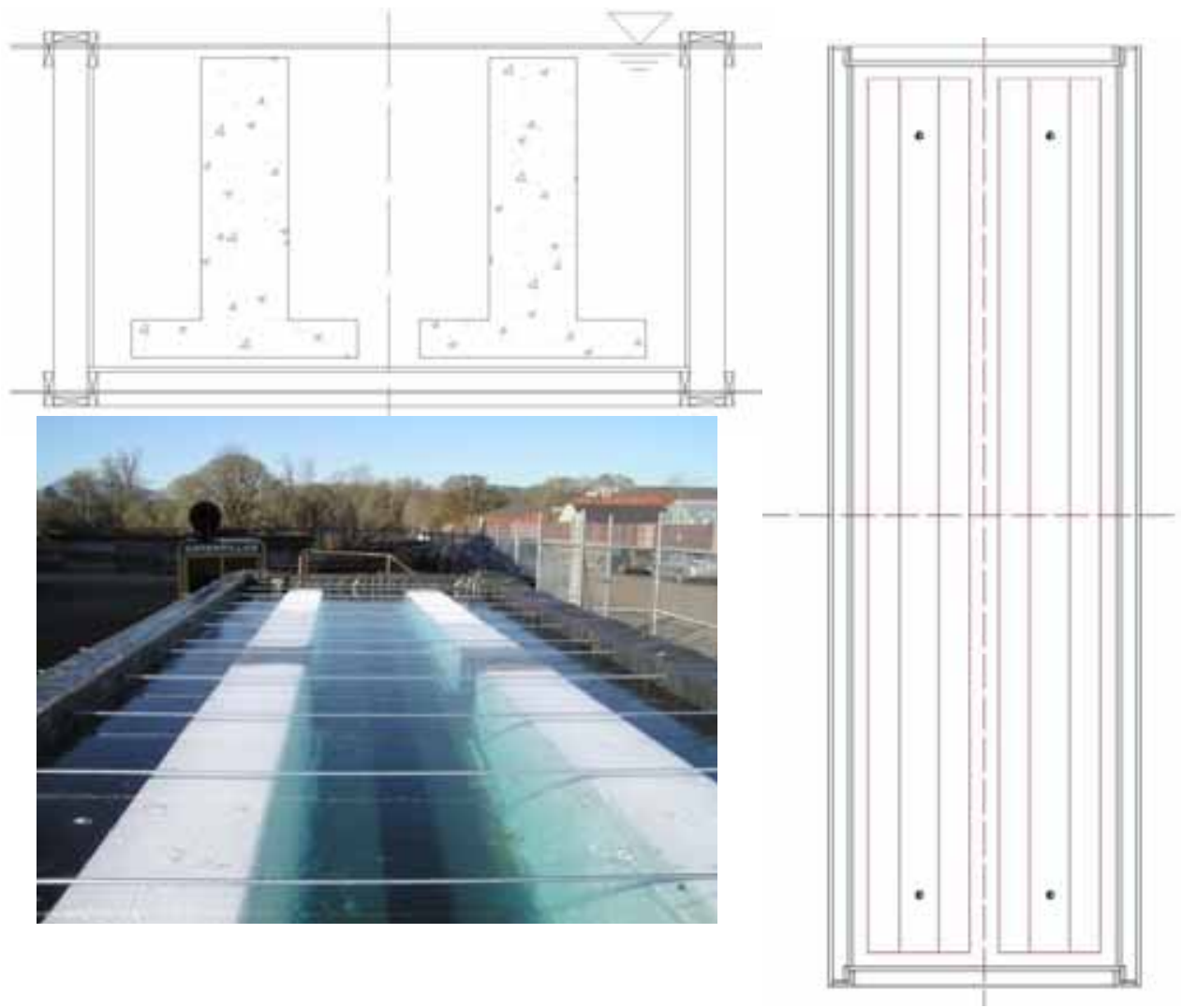

Figure 4.19: Section, Elevation and photo of bathtub

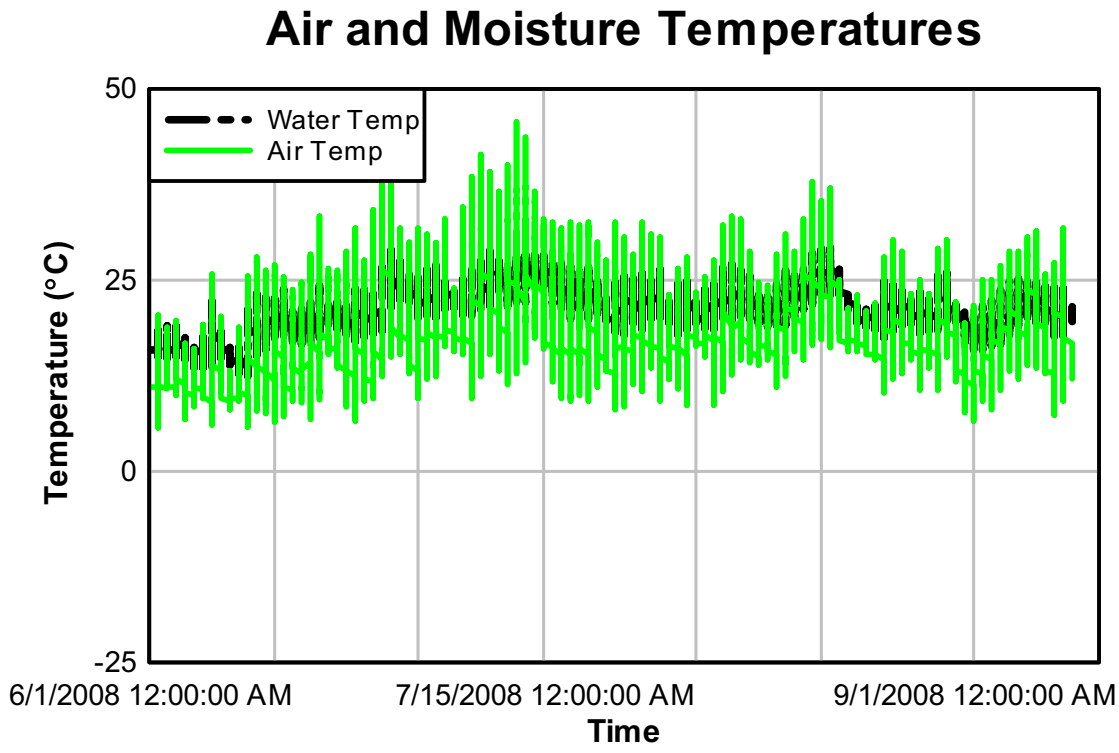

Figure 4.20: Typical temperature cycles for exposure conditions of moisture specimens 


\subsubsection{Freeze-Thaw specimens}

The freeze-thaw specimens were subjected to rapid freeze-thaw cycling. Freezing and thawing of the specimens was achieved by cycling the ambient air temperature with a one-hour soak at $16^{\circ} \mathrm{C}\left(3^{\circ} \mathrm{F}\right)$, a 30 minute ramp to $16^{\circ} \mathrm{C}\left(61^{\circ} \mathrm{F}\right)$, a one hour soak at $16^{\circ} \mathrm{C}\left(61^{\circ} \mathrm{F}\right)$, and a 30 minute ramp back to $-16^{\circ} \mathrm{C}\left(3^{\circ} \mathrm{F}\right)$. This ensured that the outer $13 \mathrm{~mm}(0.5 \mathrm{in}$.) of the specimen was thoroughly frozen and thawed during each cycle. This area was of interest and targeted for freeze-thaw because CFRP that is used in bond-critical applications, such as U-wrapped shear applications, must rely on stress transfer through the epoxy into the underlying concrete at the surface skin of the beam. Each exposure specimen was subjected to 300 freeze-thaw cycles. Temperatures in the environmental enclosure were measured using Type $\mathrm{T}$ thermocouples. Ambient air temperatures were measured at both ends of the specimen. The specimen surface temperature and internal temperature $51 \mathrm{~mm}(2 \mathrm{in}$.) from the surface were measured at midspan. Typical temperature cycling during the freeze-thaw conditioning at all four temperature measurement locations for a specimen is shown in Figure 4.21.

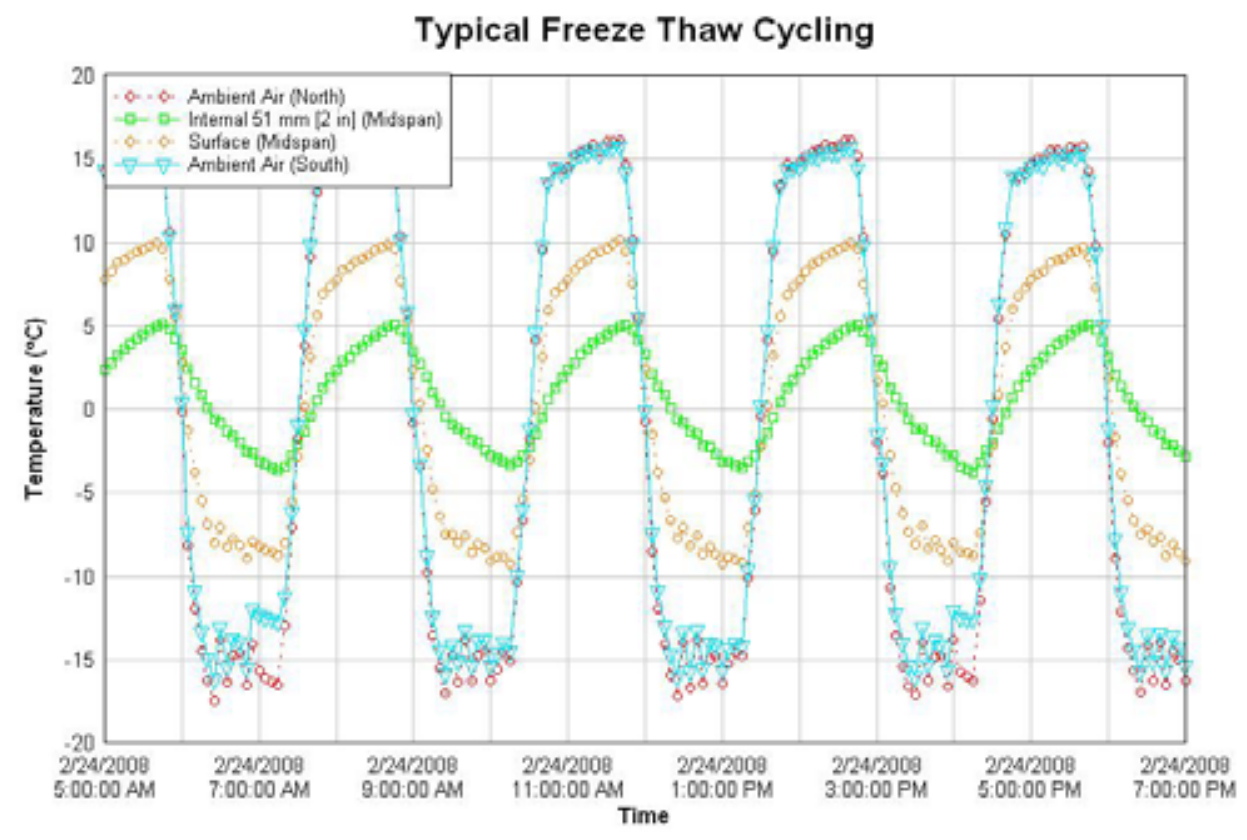

Figure 4.21: Typical temperature measurements during freeze-thaw cycling

The number of freeze-thaw cycles chosen for the test protocol was based on review of existing ASTM standards and by calculating expected freeze-thaw cycles for various regions in Oregon. Oregon contains a wide range of climatic conditions that in many ways reflect those across the US broadly and thus produce a wide-range of disparate number of freeze-thaw cycles. Extreme temperatures in the eastern half of the state may produce many cycles per year, while the fairly stable temperatures of near coastal Oregon may produce far fewer. Review of ASTM C 666 indicates that 300 cycles are used to characterize the freeze-thaw durability of concrete under fully wet freezing and thawing conditions. This condition of freezing and thawing is not 
practical for bridge girders as these are not fully submerged, although they may have surface moisture from rain events or roadway splash when freezing occurs. The concept of a finite number of cycles was then considered within the framework to make this exposure variable but representative of local climatic conditions. To determine the exposure period, given a finite number of freeze-thaw cycles (selected as 300), heat transfer analysis was used. Also based on review of ASTM C 666, it was clear that moisture must be available to expand upon freezing to produce accelerated concrete deterioration. As it is not representative of in-situ conditions or practical to submerge and freeze a large full-size RC girder, it was decided that the girder should be surface saturated every eight cycles (once a day) by spraying it with water during the thaw cycle. This routine made water available that could penetrate cracks or debonded regions and subsequently expand upon freezing and thereby possibly accelerate deterioration.

The heat transfer analysis was conducted using a general one-dimensional heat transfer finite difference solution method (Incropera and DeWitt 2002). A typical girder stem width of 356 $\mathrm{mm}$ (14 in.) was discretized into 100 elements. Symmetry was assumed for the core of the girder. Two forms of heat transfer were considered: conduction and convection. Solar absorption and grey-body irradiation were not considered as the girder stems are generally shaded by the deck and do not heat significantly from solar exposure, and little radiation of the stem heat will take place into space. The initial girder temperature distribution was taken as 12 ${ }^{\circ} \mathrm{C}\left(54{ }^{\circ} \mathrm{F}\right)$, although this assumption does not affect the outcome, as the system achieves equilibrium reasonably quickly regardless of the initial temperature. The material properties chosen for the system are shown in Table 4.10 and are typical values for concrete (Holman 1997).

Table 4.10: Material Properties for Heat Transfer Calculations

\begin{tabular}{c|c|c}
\hline $\begin{array}{c}\text { Thermal Conductivity, } \boldsymbol{k} \\
\left(\mathbf{W} / \mathbf{m} \cdot{ }^{\circ} \mathbf{C}\right)\left(\mathrm{Btu} / \mathbf{h r} \cdot{ }^{\mathrm{f}} \cdot{ }^{\circ} \mathbf{F}\right)\end{array}$ & $\begin{array}{c}\text { Specific Heat, } \boldsymbol{c} \\
\left(\mathrm{J} / \mathbf{k g} \cdot{ }^{\circ} \mathbf{C}\right)\left(\mathbf{B t u} / \mathbf{l b}{ }^{\circ} \mathbf{F}\right)\end{array}$ & $\begin{array}{c}\text { Density, } \boldsymbol{\rho} \\
\left(\mathrm{kg} / \mathbf{m}^{3}\right)\left(\mathbf{~ l b} / \mathbf{f t}{ }^{3}\right)\end{array}$ \\
\hline $1.5(0.87)$ & $880(0.21)$ & $2243(140)$ \\
\hline
\end{tabular}

The convection coefficient was taken to be related to the wind speed at the site (Bentz 2000). Wind speed data were reported coincident with the temperature data. The convection coefficients, $h\left(\mathrm{~W} / \mathrm{m}^{2} \cdot{ }^{\circ} \mathrm{C}\right)\left(\mathrm{Btu} / \mathrm{hr} \cdot \mathrm{ft}^{2} \cdot{ }^{\circ} \mathrm{F}\right)$, were computed as shown in Equation 4.1 and 4.2 (Schlangen 2000).

$$
\begin{aligned}
& h=5.6+4.0 V_{\text {wind }} \text { for } V_{\text {wind }} \leq 5 \mathrm{~m} / \mathrm{s} \\
& h=7.2\left(V_{\text {wind }}\right)^{0.78} \text { for } V_{\text {wind }}>5 \mathrm{~m} / \mathrm{s}
\end{aligned}
$$

Heat convection plays an important role in determining how quickly the surface cools or heats. The general conditions on a real bridge provide higher exposure for the exterior girders which tend to shield the interior girders. Thus, the computed temperature responses from the heat transfer analysis would tend to be more applicable to the exterior girders.

Climate data were examined from four locations across Oregon that represent high-desert central region (Tumalo Ridge), Willamette Valley (Stayton), coast region (Tillamook), and eastern region (Sage-Hen). Details regarding these sites can be found on the Western Regional Climate 
Center's website (http://www.wrcc.dri.edu/). All sites are part of the Remote Automated Weather Station (RAWS) network. Weather data for each of these sites are reported every hour. Linear interpolation was used to generate data each minute. During each minute, it was assumed that the conditions remained stable and the heat-transfer analysis was conducted at a 1.0 second time step to assure convergence. The number of freeze-thaw cycles was determined as the number of positive slope crossings of the computed temperature-time response at the surface of the girder. Typical surface and air temperature response for the Stayton site are shown in Figure 4.22 for an entire year. For each of the sites selected, Table 4.11 shows the average number of freeze-thaw cycles per year and number of years corresponding to a cumulative total of 300 freeze-thaw cycles. In general, for the girder size typical of RCDG bridges and the weather sites considered, the 300 freeze-thaw cycle count corresponded to variable service exposure life. The Tumalo Ridge and Sage Hen sites showed only approximately seven year service exposure, but it was assumed that, due to the high desert climate, many of those cycles occured with little moisture present. The Stayton and Tillamook sites showed fewer cycles and many years of service exposure, however these likely corresponded with moist conditions.

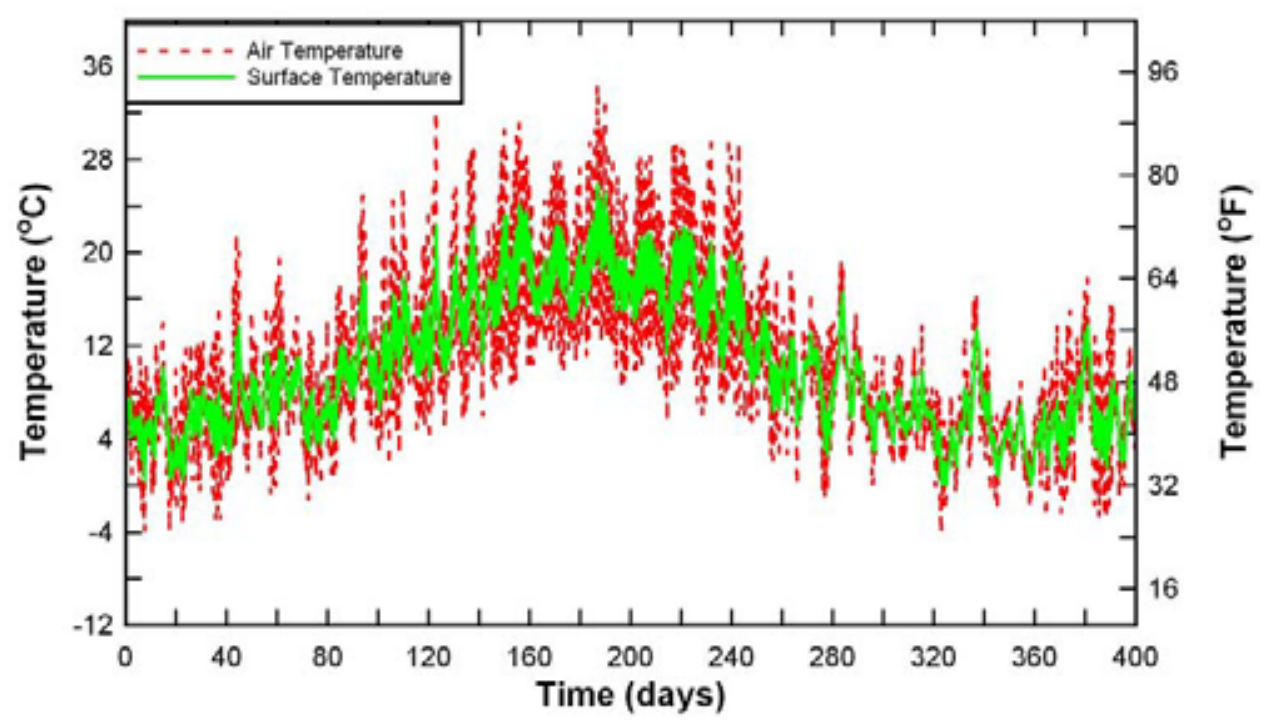

Figure 4.22: Typical surface and air temperature response for Stayton site 
Table 4.11: Freeze-thaw cycles in Oregon

\begin{tabular}{c|c|c|c|c}
\hline Location & $\begin{array}{c}\text { Freeze-Thaw } \\
\text { Cycles }\end{array}$ & $\begin{array}{c}\text { Period of } \\
\text { Temperature Record } \\
\text { (Years) }\end{array}$ & $\begin{array}{c}\text { Freeze-Thaw } \\
\text { Frequency } \\
\text { (Cycles/Year) }\end{array}$ & $\begin{array}{c}\text { 300 Cycle } \\
\text { Duration } \\
\text { (Years) }\end{array}$ \\
\hline $\begin{array}{c}\text { Tillamook } \\
\text { (Coast) }\end{array}$ & 8 & 11 & 0.73 & 412 \\
\hline $\begin{array}{c}\text { Stayton } \\
\text { (Valley) }\end{array}$ & 45 & 12 & 3.75 & 80 \\
\hline $\begin{array}{c}\text { Tumalo Ridge } \\
\text { (Central) }\end{array}$ & 243 & 6 & 40.5 & 7.4 \\
\hline $\begin{array}{c}\text { Sage Hen } \\
\text { (Eastern) }\end{array}$ & 868 & 22 & 39.5 & 7.6 \\
\hline
\end{tabular}

The same heat transfer analysis was conducted with the environmental enclosure temperature history shown in Figure 4.21 for the specimens. The predicted temperature at the surface and 51 $\mathrm{mm}$ ( 2 in.) in from the surface are shown in Figure 4.23 and correlated well with the measured response.

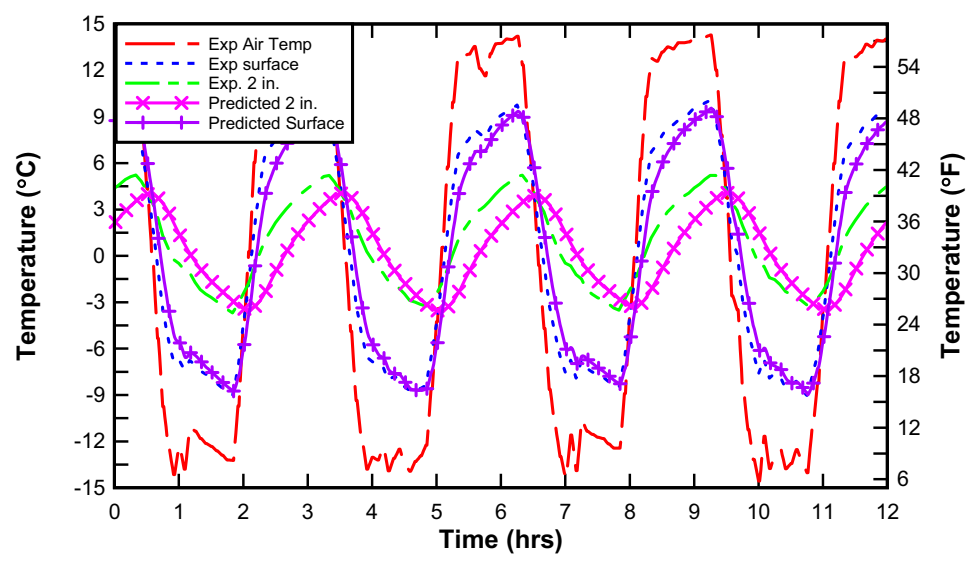

Figure 4.23: Predicted and measured temperatures during experimental freeze-thaw exposure 


\subsection{EXPERIMENTAL RESULTS}

After installation of the CFRP and the environmental exposure, the specimens were moved to the strong floor and tested to failure. The experimental findings for each specimen and comparisons between measured responses are reported in this section. The salient structural response quantities for all specimens are contained in Table 5.1.

Table 5.1: Structural response quantities at failure

\begin{tabular}{|c|c|c|c|}
\hline Specimen & $\begin{array}{c}\text { Applied Shear, } \\
V_{a p p} \\
(\mathrm{kN})(\mathrm{kip}) \\
\end{array}$ & $\begin{array}{c}\text { Shear Load from Self } \\
\text { Weight, } V_{D L} \\
\text { (kN) (kip) } \\
\end{array}$ & $\begin{array}{c}\text { Midspan Displacement, } \\
\Delta_{C L} \\
(\mathrm{~mm})(\mathrm{in}) \\
\end{array}$ \\
\hline IT12Control & $1179(265)$ & $22(5)$ & $30(1.19)$ \\
\hline IT12FT & $1157(260)$ & $22(5)$ & $28(1.11)$ \\
\hline IT12FTCK & $1157(260)$ & $22(5)$ & $32(1.27)$ \\
\hline IT12M & $1134(255)$ & $22(5)$ & $34(1.34)$ \\
\hline IT12MCK & $1074(241)$ & $22(5)$ & $26(1.04)$ \\
\hline $\begin{array}{c}\text { ITT12FTC } \\
\mathrm{K}\end{array}$ & $1136(255)$ & $22(5)$ & $25(1.01)$ \\
\hline T18Control & $988(222)$ & $22(5)$ & $30(1.18)$ \\
\hline $\mathrm{T} 18 \mathrm{FT}$ & $845(190)$ & $13(3)$ & $22(0.87)$ \\
\hline T18FTCK & $832(187)$ & $36(8)$ & $25(0.97)$ \\
\hline T18FFTCK & $1005(226)$ & $36(8)$ & $28(1.11)$ \\
\hline
\end{tabular}

\subsection{GLOBAL STRUCTURAL BEHAVIOR}

\subsubsection{Specimen IT12Control}

Specimen IT12Control was initially tested using the increasing amplitude cyclical loading protocol. After achieving the maximum load in each cycle, visual inspection was performed to track cracks at the concrete surface and debonding of the CFRP. Debonding of the CFRP was identified by tapping the CFRP surface and listening for a distinct hollow sound. The specimen was loaded to $2224 \mathrm{kN}$ (500 kips), which corresponded to the nominal capacity of the hydraulic actuator, but the specimen did not fail. To produce a shear dominated failure, every other CFRP strip was removed and the load reapplied with the hydraulic system pressure increased to permit failure of the specimen. The applied shear at failure was $1179 \mathrm{kN}$ (265 kips) with a midspan displacement of $27 \mathrm{~mm}$ (1.06 in.). The applied shear-midspan displacement response of the specimen is shown in Figure 5.1. The failure crack angle was approximately $30^{\circ}$ from horizontal and crossed the three CFRP U-wraps closest to midspan as shown in Figure 5.11. The concrete cracking and CFRP debonding at the load step prior to failure are shown in Figure 5.21. 


\subsubsection{Specimen IT12FT}

Specimen IT12FT was tested in a similar manner to IT12Control up to a load of $2224 \mathrm{kN}$ (500 kips). At this load, the specimen appeared to be near-failure with a midspan displacement of $21.3 \mathrm{~mm}$ (0.84 in.). The $2224 \mathrm{kN}$ (500 kip) load was repeated and produced a midspan displacement of $22.0 \mathrm{~mm}(0.87 \mathrm{in}$.) on the second cycle, without failure. When failure was not achieved, every other CFRP strip was removed and the specimen was again loaded cyclically and failed at an applied shear of $1157 \mathrm{kN}$ (260 kips). Load deformation response is shown in Figure 5.2. The failure crack was similar to Specimen IT12Control, as the angle was approximately $30^{\circ}$ degrees from horizontal and crossed the three CFRP U-wraps nearest midspan, shown in Figure 5.12. The concrete cracking and CFRP debonding at the load step prior to failure are shown in Figure 5.22.

\subsubsection{Specimen IT12FTCK}

Specimen IT12FTCK was also tested using increasing amplitude cyclical loading to $2224 \mathrm{kN}$ (500 kips). When failure did not occur, alternating CFRP strips were removed, one at a time, with loading to $2313 \mathrm{kN}$ (520 kips) between removals. Failure occurred after the removal of the fourth strip at an applied shear of $1157 \mathrm{kN}$ (260 kips). Load deformation response is shown in Figure 5.3. The failure crack, shown in Figure 5.13, was similar to the other IT-Specimens, crossing the three CFRP U-wraps nearest load application with an angle of approximately $30^{\circ}$ from horizontal. The concrete cracking and CFRP debonding at the load step prior to failure are shown in Figure 5.23.

\subsubsection{Specimen IT12M}

Specimen IT12M was tested in a similar manner to IT12Control up to a load of $2224 \mathrm{kN}$ (500 kips) and produced a midspan displacement of $23 \mathrm{~mm}$ (0.9 in.). After the initial load step, the capacity of the actuator was increased and the $2393 \mathrm{kN}$ (538 kip) load step was repeated resulting in a midspan displacement of $27 \mathrm{~mm}$ (1.06 in.) on the second cycle, without failure. The specimen was again loaded with a maximum load of $2464 \mathrm{kN}$ (554 kip) and the load deflection curve turned flat with midspan deflection $31 \mathrm{~mm}(1.24 \mathrm{in})$, flexural failure was imminent. As shear failure was not achieved, the first two alternate strips were removed and the $2224 \mathrm{kN}$ (500 kips) load was applied producing 32mm (1.27 in). The final failure diagonal crack passed through two CFRP sheets but the fourth strip was able to maintain the beam strength, even as the crack crossed near the edge of the strip. Before going on to the next load step, the fourth CFRP strip was removed and the beam failed at a shear of $1134 \mathrm{kN}$ (255 kips) with midspan displacement $34 \mathrm{~mm}$ (1.34 in). Load deformation response is shown in Figure 5.4. The failure crack was similar to Specimen IT12Control, as the angle was approximately $30^{\circ}$ degrees from horizontal and crossed the three CFRP U-wraps nearest midspan, as shown in Figure 5.14. The concrete cracking and CFRP debonding at the load step prior to failure are shown in Figure 5.24 . 


\subsubsection{Specimen IT12MCK}

Specimen IT12MCK was also tested using increasing amplitude cyclical loading to $2224 \mathrm{kN}$ (500 kips). It was loaded to $2375 \mathrm{kN}$ (534 kips) after increasing the actuator capacity. After removing alternate CFRP strips, failure occurred at $2144 \mathrm{kN}$ (482 kips) load with midspan displacement $26 \mathrm{~mm}$ (1.04 in). Load deformation response is shown in Figure 5.5. The failure crack was similar to the other IT-Specimens, crossing the three CFRP U-wraps nearest load application with an angle of approximately $30^{\circ}$ from horizontal, as shown in Figure 15 . The concrete cracking and CFRP debonding at the load step prior to failure are shown in Figure 5.25.

\subsubsection{Specimen ITT12FTCK}

Specimen ITT12FTCK was tested in a similar way for the first load cycle step to $2224 \mathrm{kN}$ (500 kips). As per the previous tests, for shear dominant failure, alternate strips were removed and again the load step of $2224 \mathrm{kN}$ (500 kips) was repeated. It was then loaded with increased actuator capacity to $2268 \mathrm{kN}$ (510 kips), failing with an ultimate midspan displacement of 26 $\mathrm{mm}$ (1.01 in). Load deformation response is shown in Figure 5.6. The failure crack, shown in Figure 5.16, was similar to the other IT-Specimens, crossing the three CFRP U-wraps nearest load application with an angle of approximately $30^{\circ}$ from horizontal. The concrete cracking and CFRP debonding at the load step prior to failure are shown in Figure 5.26.

\subsubsection{Specimen T18Control}

Specimen T18Control was loaded in the same manner as the IT-Specimens to a load of $1975 \mathrm{kN}$ (444 kips). Failure occurred at an applied shear of $988 \mathrm{kN}$ (222 kip) with a midspan displacement of $30.0 \mathrm{~mm}$ (1.18 in.). Load deformation response is shown in Figure 5.7. The failure crack angle was approximately $30^{\circ}$ degrees from horizontal, crossing the $2 \mathrm{nd}$, 3rd and 4th CFRP U-wraps away from midspan, as shown in Figure 5.17 The concrete cracking and CFRP debonding at the load step prior to failure are shown in Figure 5.27.

\subsubsection{Specimen T18FT}

Specimen T18FT was loaded cyclically to $1690 \mathrm{kN}$ (380 kip). Failure occurred at an applied shear of $845 \mathrm{kN}$ (190 kip) with a midspan displacement of $22.4 \mathrm{~mm}(0.88 \mathrm{in}$.). Load deformation response is shown in Figure 5.8. Figure 5.18 shows the failure crack was approximately $45^{\circ}$, crossing the $2^{\text {nd }}$ and $3^{\text {rd }}$ CFRP U-wraps away from load application. Moisture was apparent at the CFRP-concrete bond interface near the failure crack. The concrete cracking and CFRP debonding at the load step prior to failure are shown in Figure 5.28.

\subsubsection{Specimen T18FTCK}

Specimen T18FTCK was loaded cyclically to $1753 \mathrm{kN}$ (394 kips). Failure occurred at an applied shear of $832 \mathrm{kN}$ (187 kip) with a midspan displacement of $24.6 \mathrm{~mm}$ (0.97 in.). Load deformation response is shown in Figure 5.9. The failure crack angle was approximately $30^{\circ}$ from horizontal, crossing the $3^{\text {rd }}, 4^{\text {th }}$, and $5^{\text {th }}$ CFRP U-wraps away from midspan, as shown in Figure 5.19. As in Specimen T18FT, moisture was present at the CFRP-concrete bond interface 
near the failure crack. The concrete cracking and CFRP debonding at the load step prior to failure are shown in Figure 5.29.

\subsubsection{Specimen T18FFTCK}

Specimen T18FFTCK was loaded cyclically to $2019 \mathrm{kN}$ (454 kips). Failure occurred at an applied shear of $1010 \mathrm{kN}$ (227 kip) with a midspan displacement of $28 \mathrm{~mm}$ (1.11 in.). Load deformation response is shown in Figure 5.10. The failure crack angle was approximately $30^{\circ}$ from horizontal, crossing the $3^{\text {rd }}, 4^{\text {th }}$, and $5^{\text {th }}$ CFRP U-wraps away from midspan, as shown in Figure 5.20. This specimen seemed to contain less moisture as compared to the freeze-thaw Tspecimens tested previously. The concrete cracking and CFRP debonding at the load step prior to failure are shown in Figure 5.30.

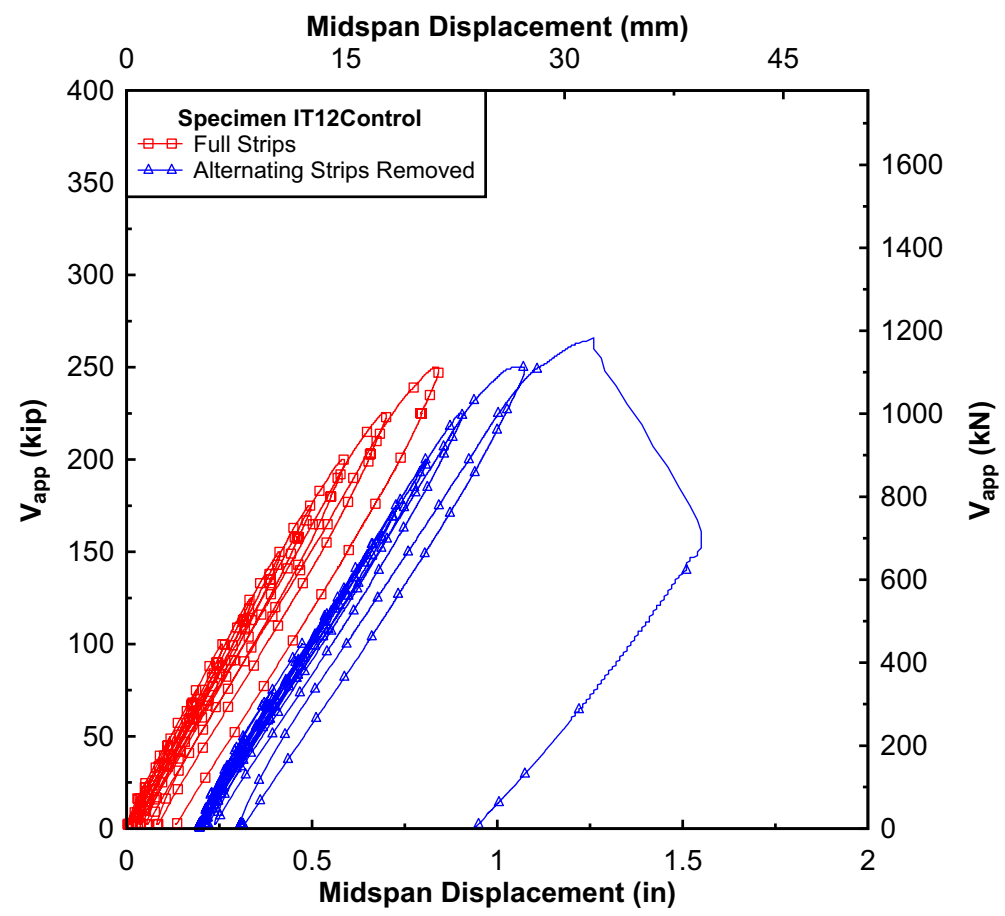

Figure 5.1: Specimen IT12Control Midspan shear - deflection curves at failure 


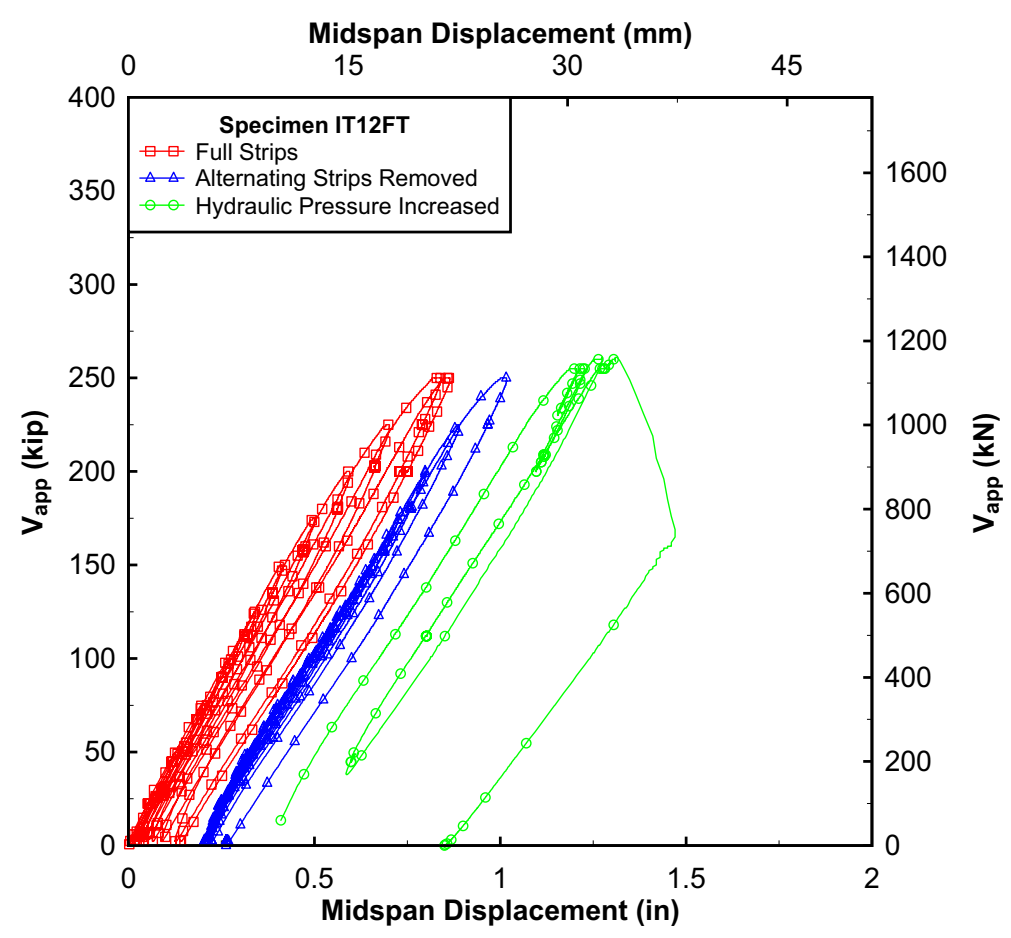

Figure 5.2: Specimen IT12FT Midspan shear - deflection curves at failure

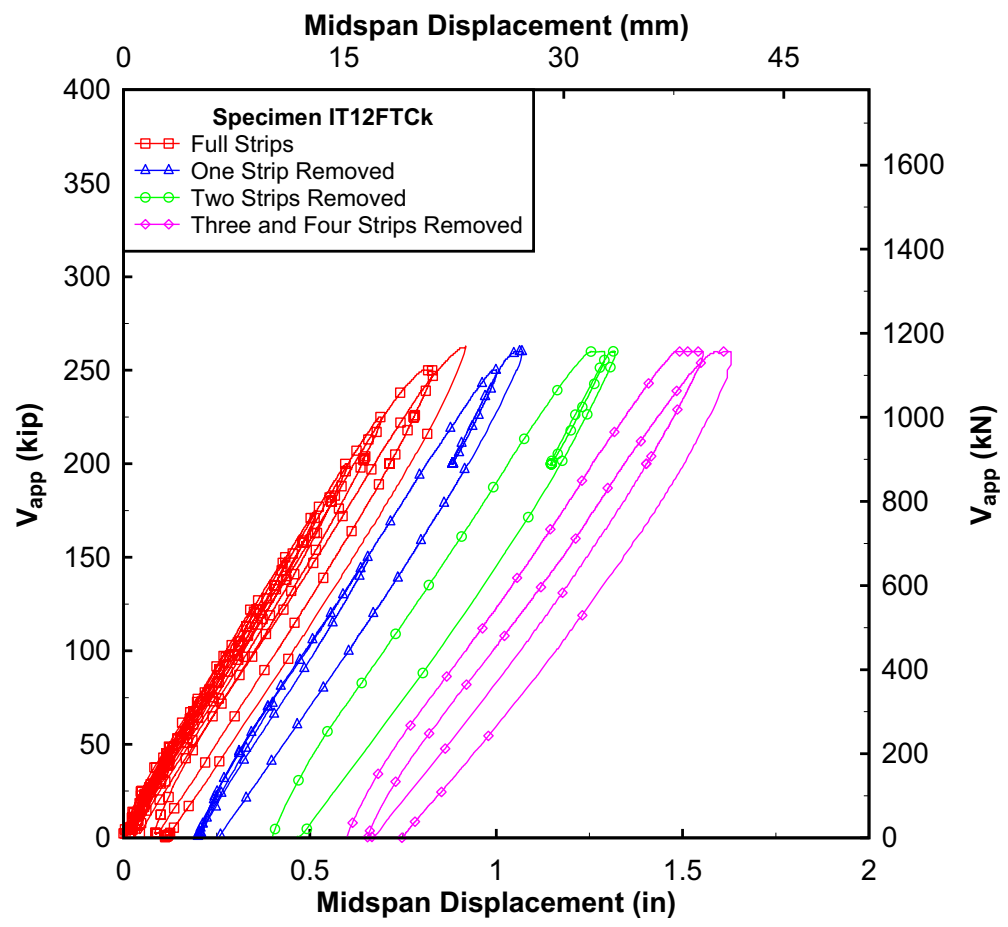

Figure 5.3: Specimen IT12FTCk Midspan shear - deflection curves at failure 


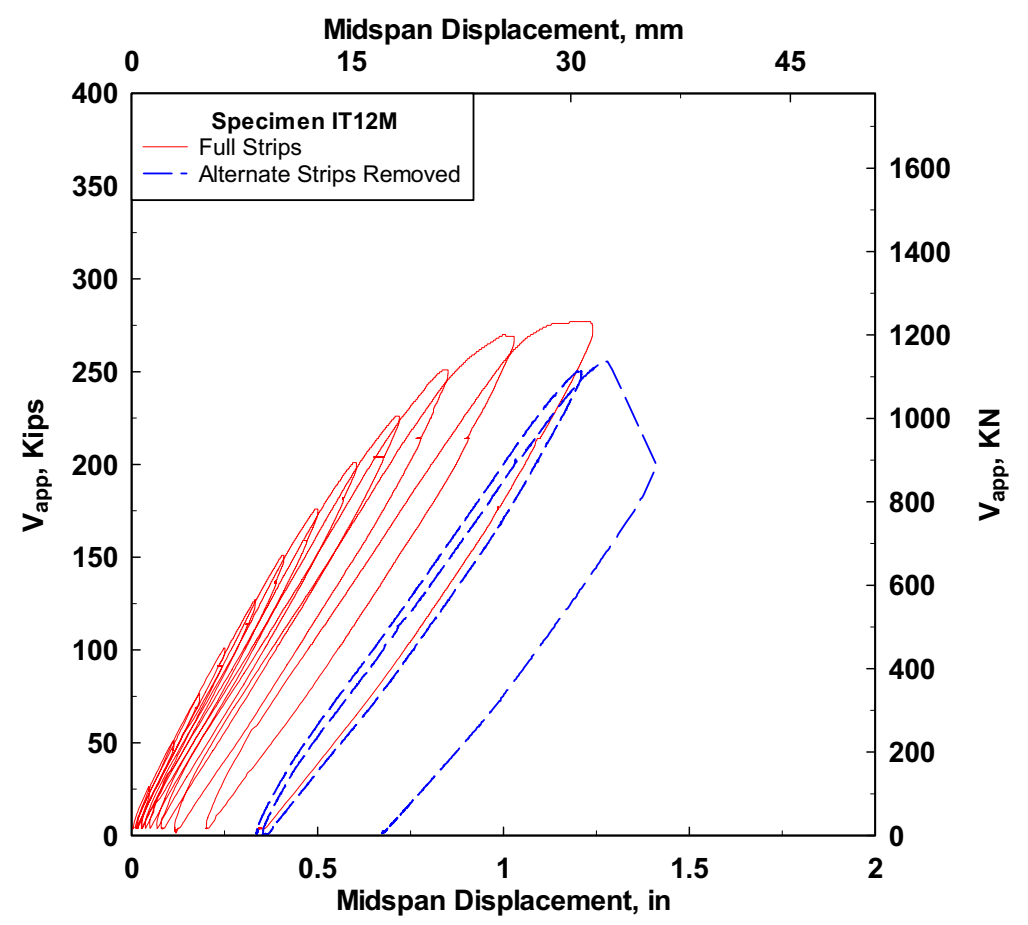

Figure 5.4: Specimen IT12M Midspan shear - deflection curves at failure

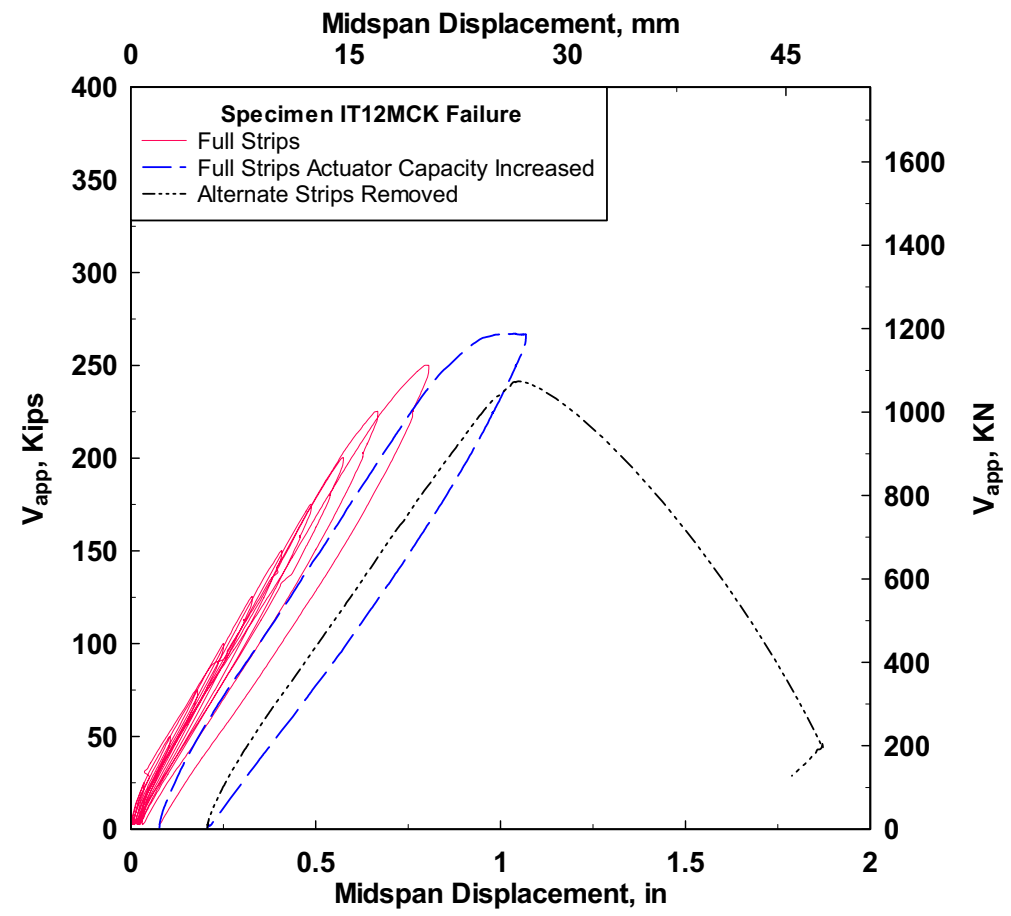

Figure 5.5: Specimen IT12MCK Midspan shear - deflection curves at failure 


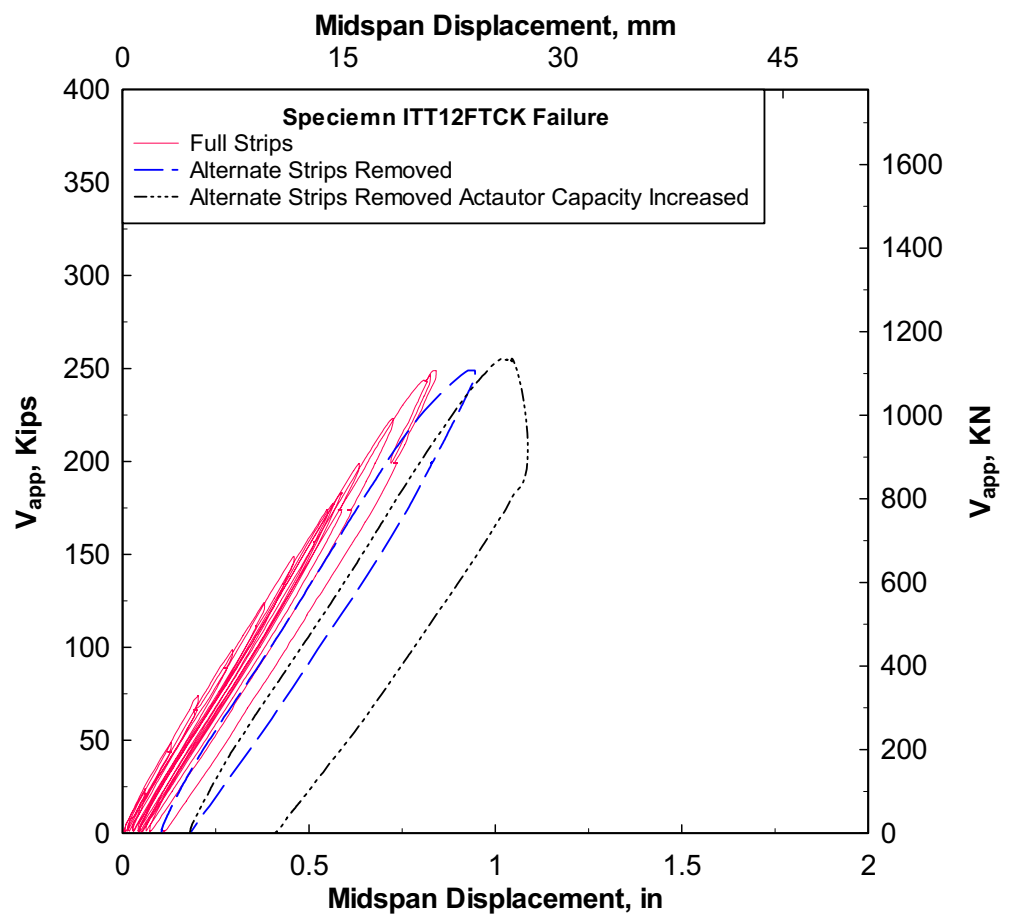

Figure 5.6: Specimen ITT12FTCK Midspan shear - deflection curves at failure

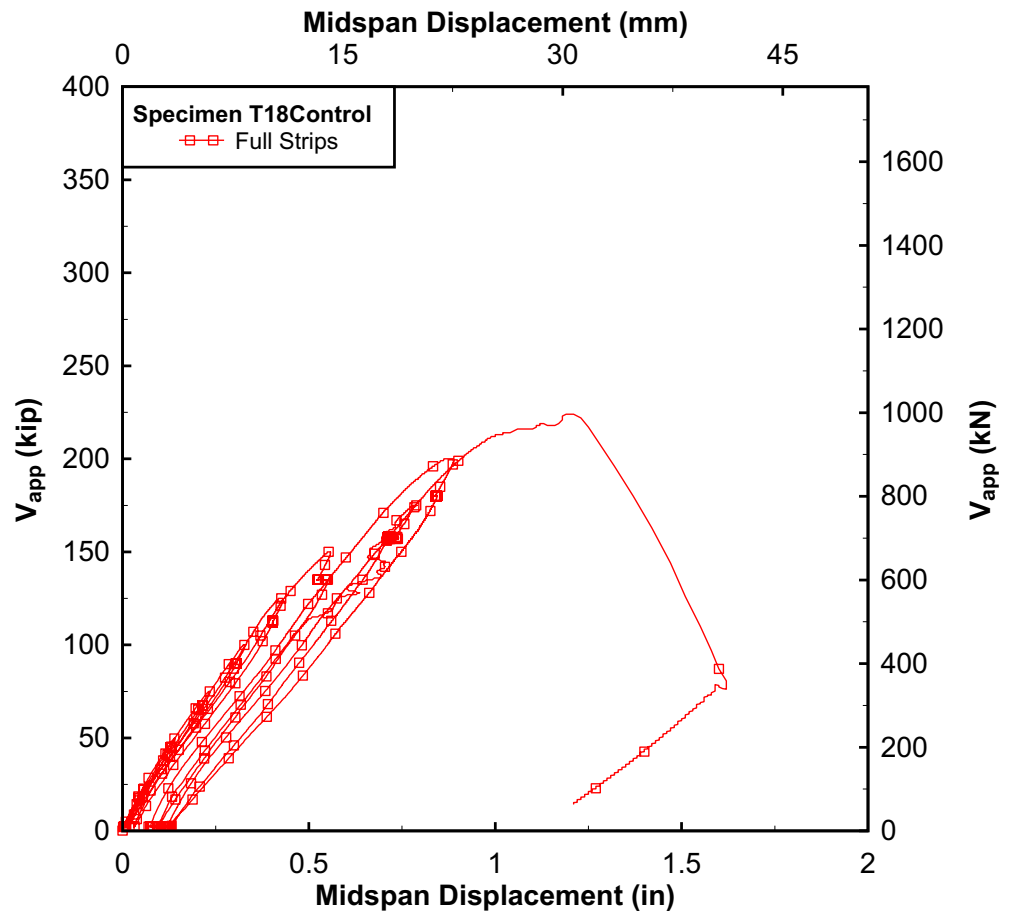

Figure 5.7: Specimen T18Control Midspan shear - deflection curves at failure 


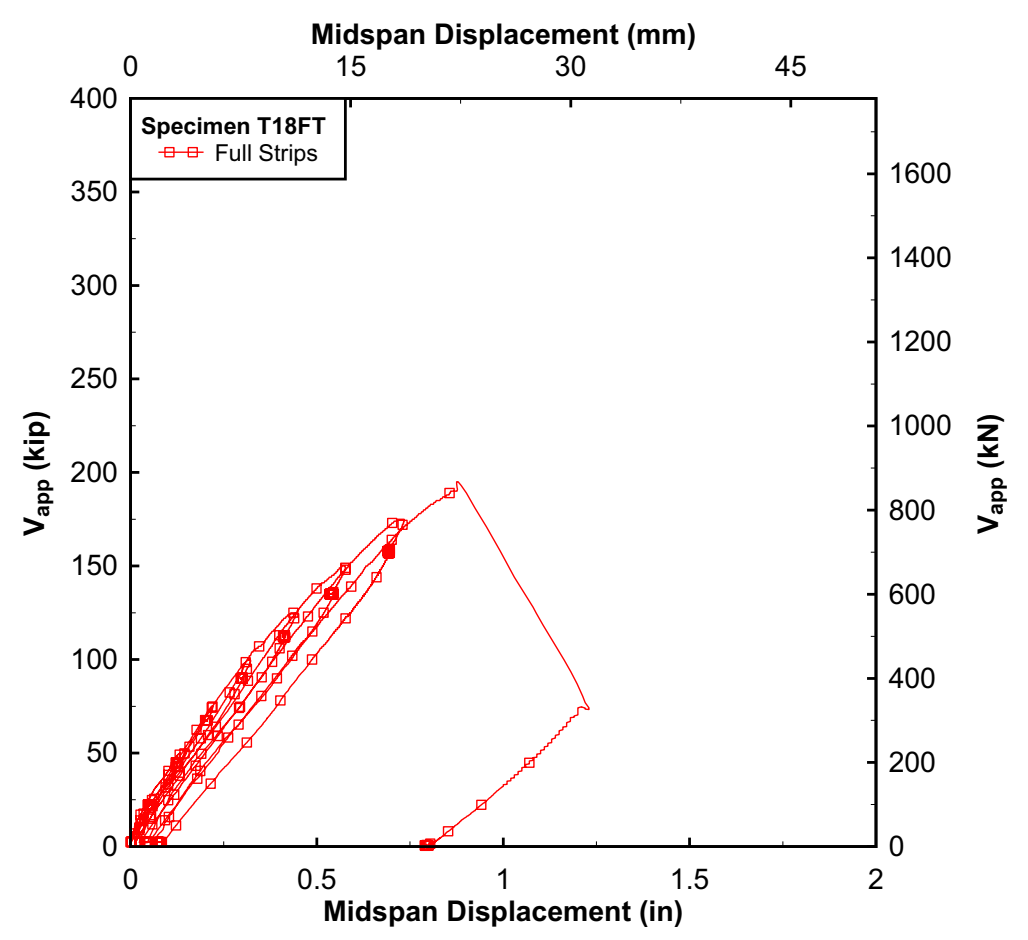

Figure 5.8: Specimen T18FT Midspan shear - deflection curves at failure

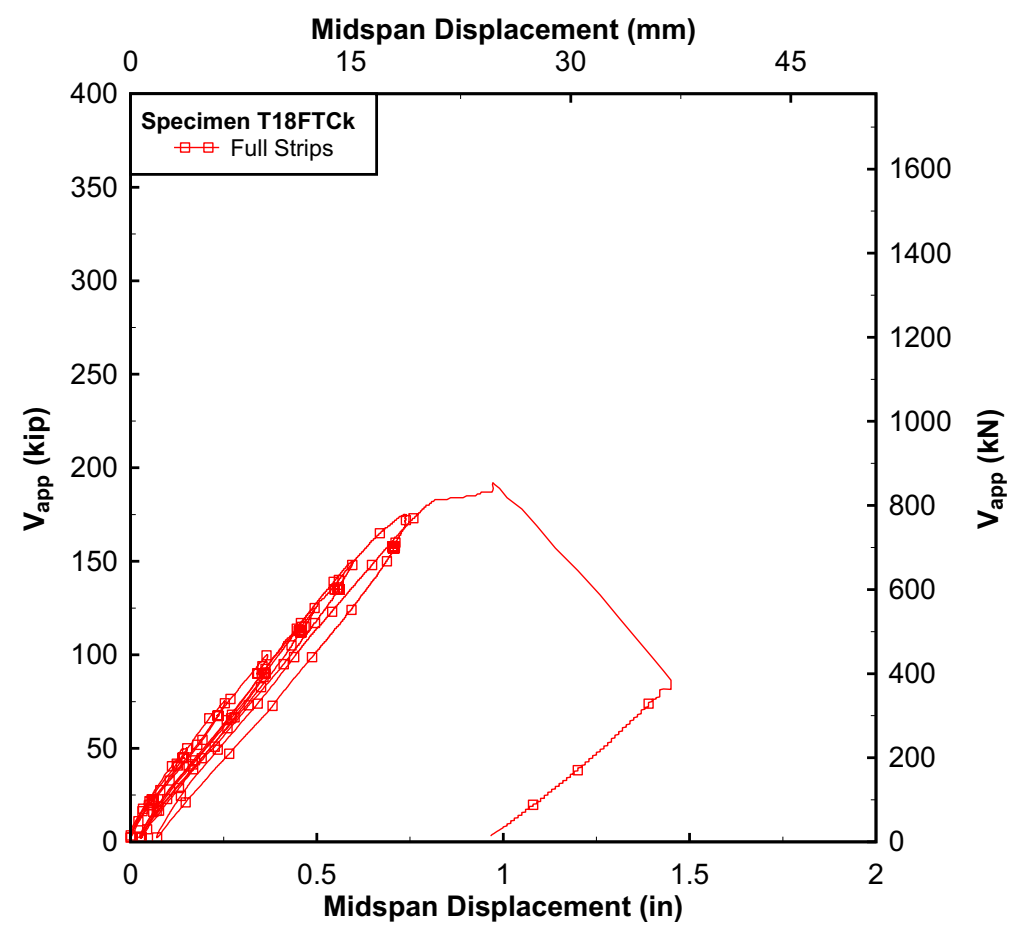

Figure 5.9: Specimen T18FTCk Midspan shear-deflection curves at failure 


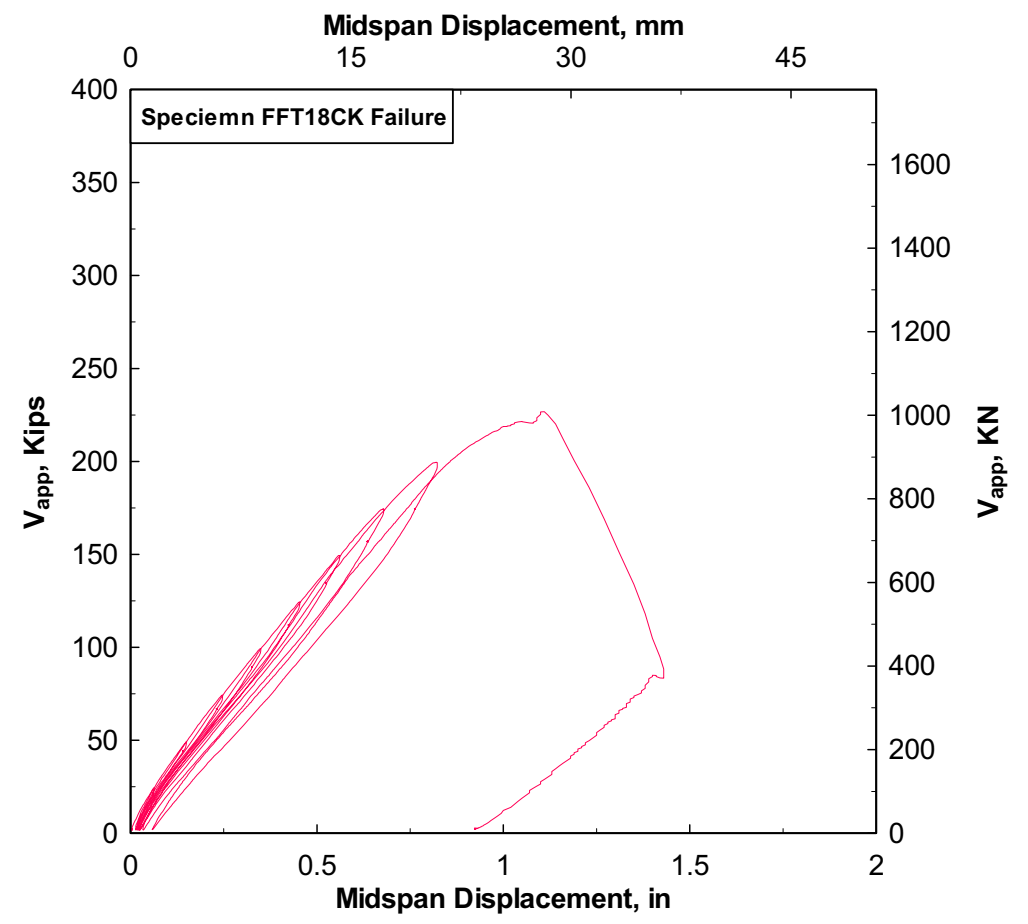

Figure 5.10: Specimen FFT18CK Midspan shear - deflection curves at failure

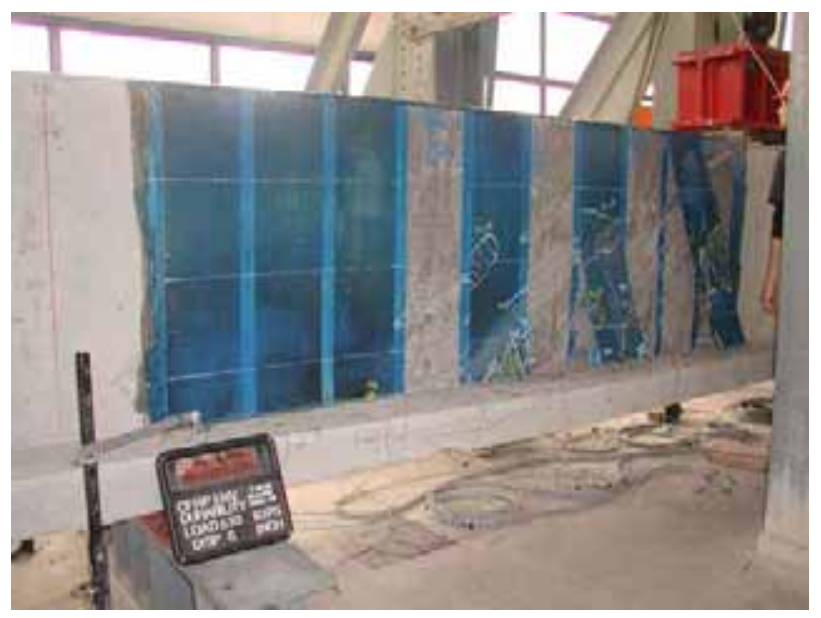

Figure 5.11: Failure photograph of Specimen IT12Control 


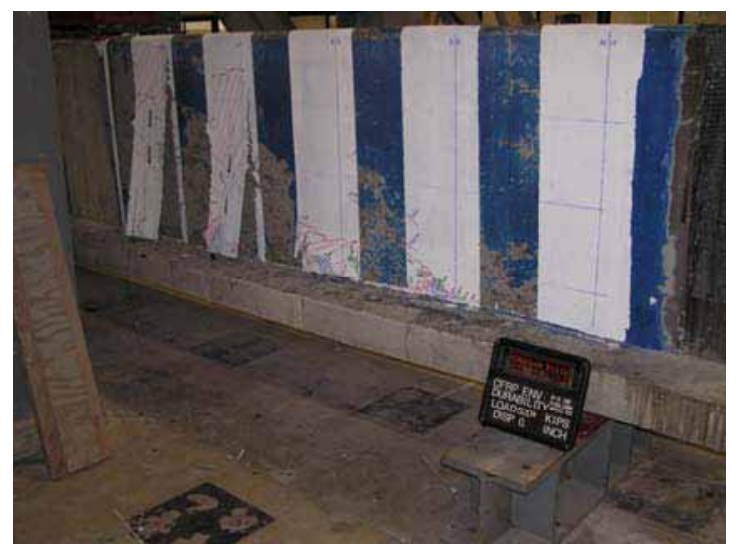

Figure 5.12: Failure photograph of Specimen IT12FT

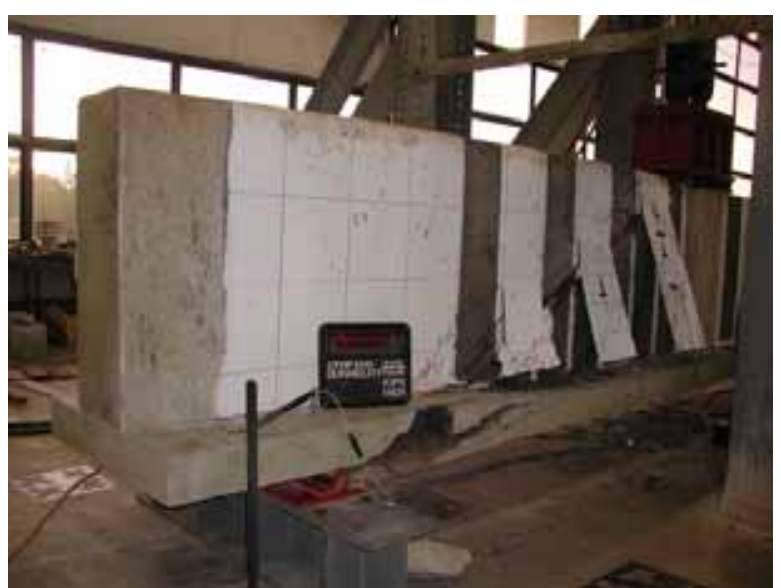

Figure 5.13: Failure photograph of Specimen IT12FTCK

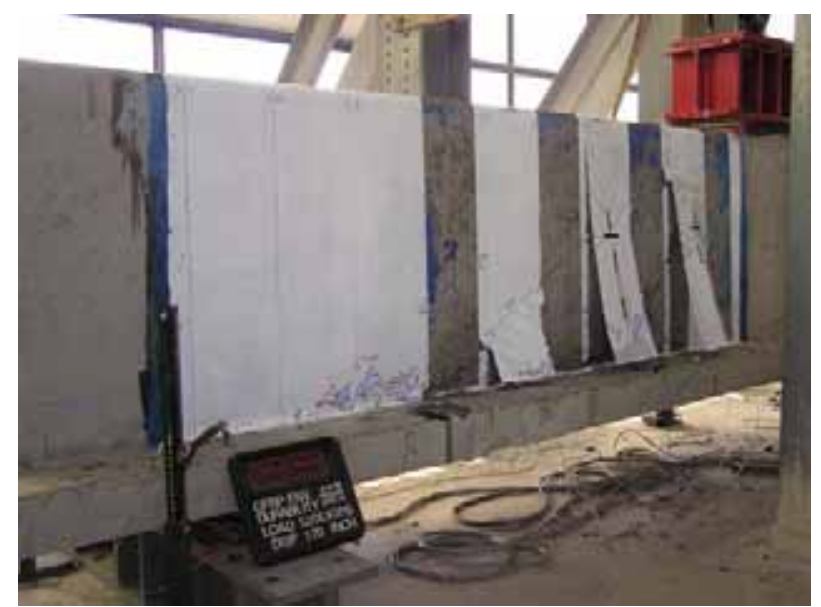

Figure 5.14: Failure photograph of Specimen IT12M 


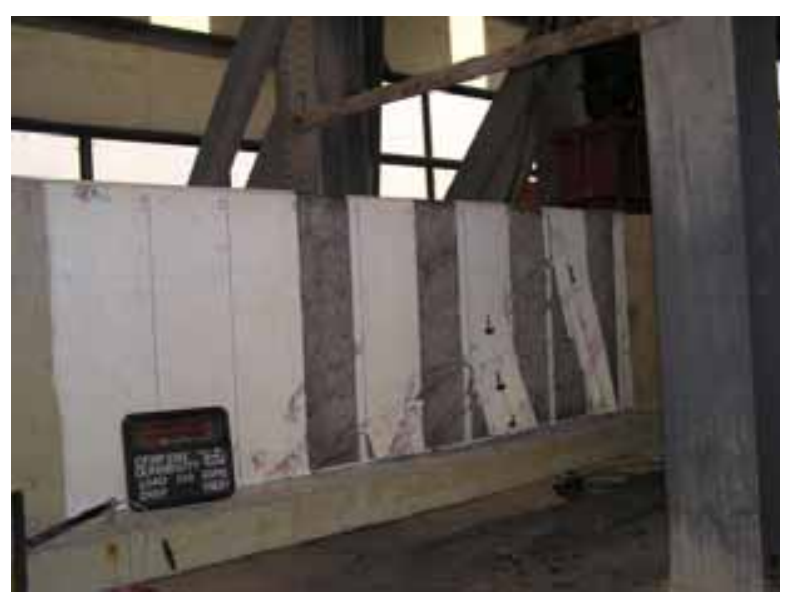

Figure 5.15: Failure photograph of Specimen IT12MCK

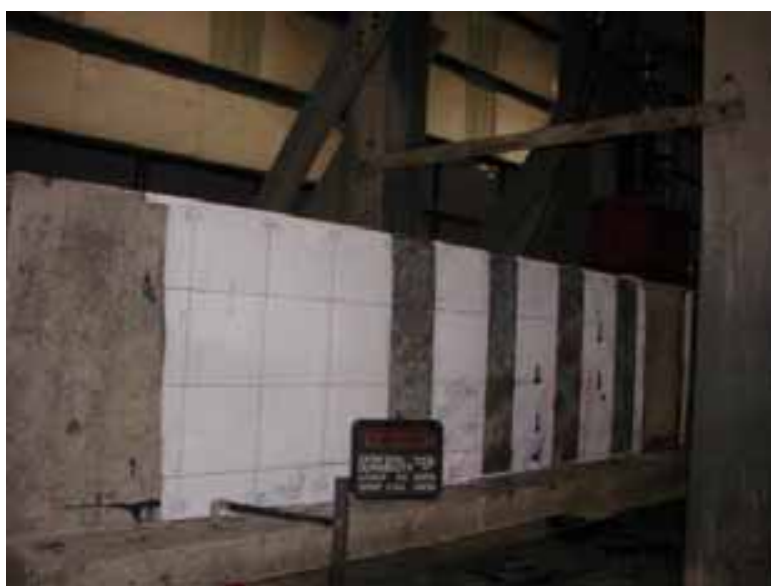

Figure 5.16: Failure photograph of Specimen IT12FTCK

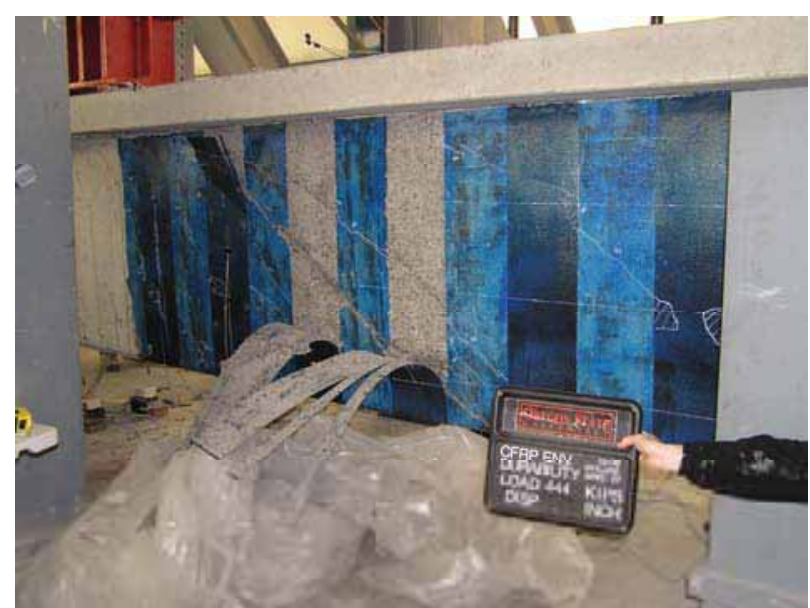

Figure 5.17: Failure photograph of Specimen T18Control 


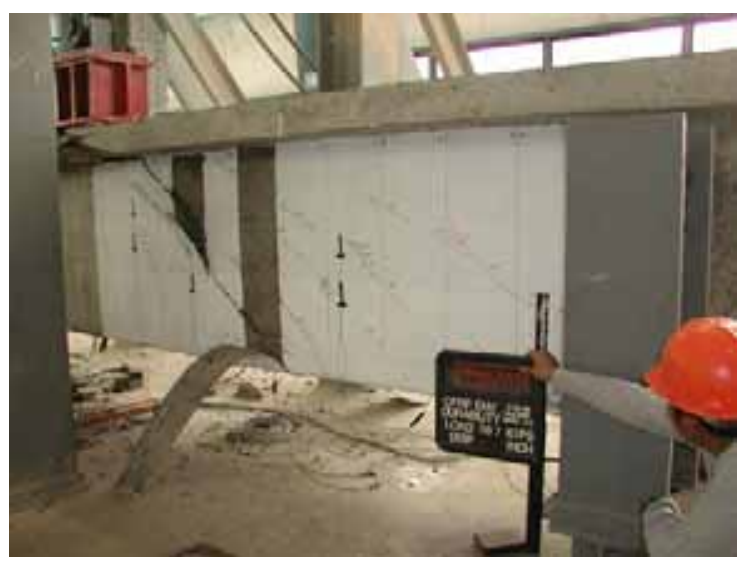

Figure 5.18: Failure photograph of Specimen T18FT

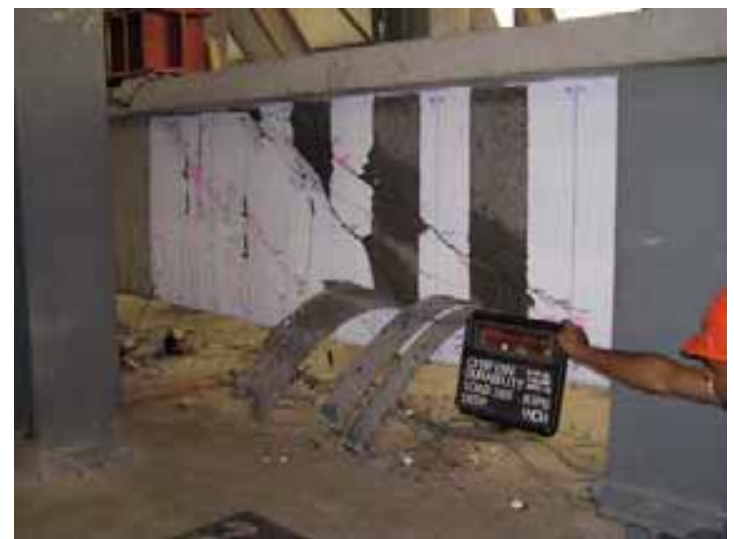

Figure 5.19: Failure photograph of Specimen IT12FTCK

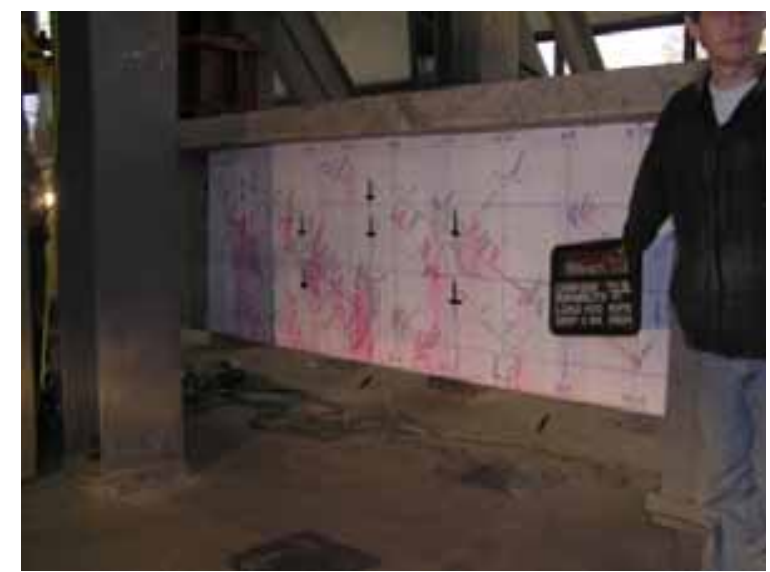

Figure 5.20: Failure photograph of SpecimenT18FFTCK 


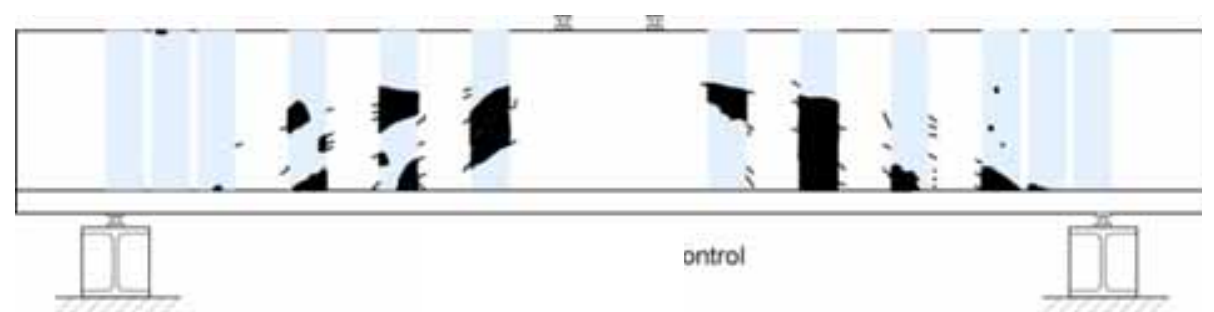

Figure 5.21: Cracked and debonded condition at load step prior to failure for Specimen IT 12 Control

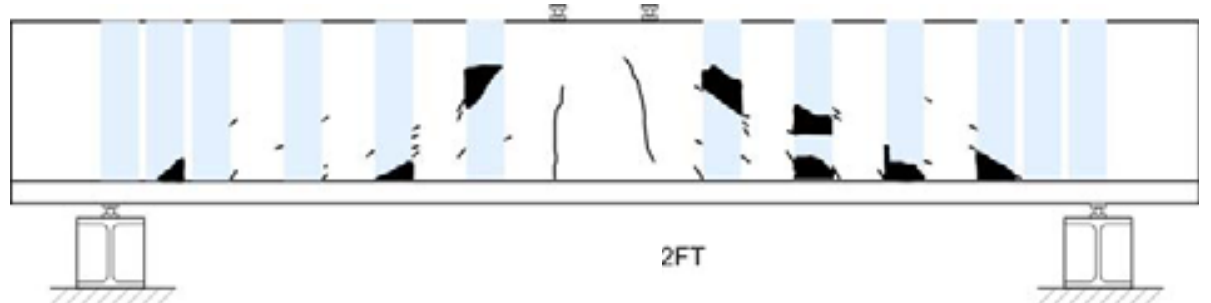

Figure 5.22: Cracked and debonded condition at load step prior to failure for Specimen IT12FT

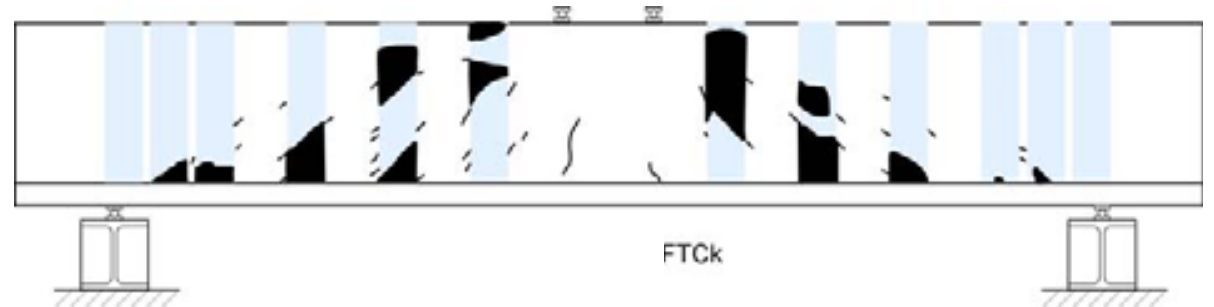

Figure 5.23: Cracked and debonded condition at load step prior to failure for SpecimenIT12FTCk

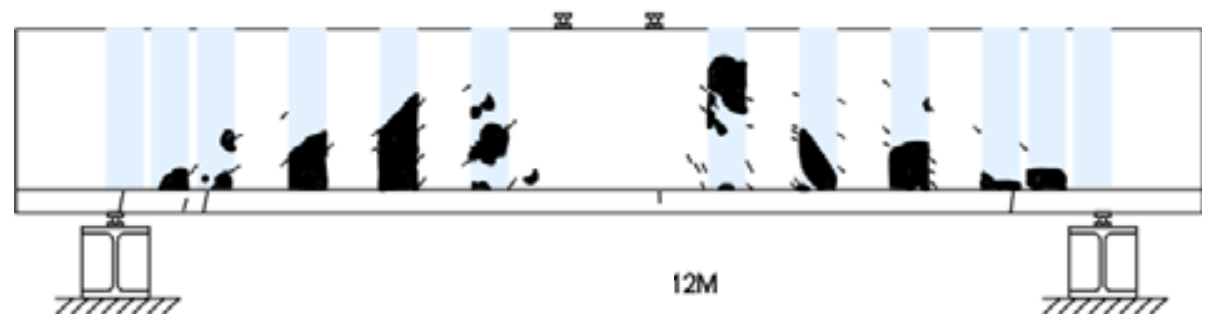

Figure 5.24: Cracked and debonded condition at load step prior to failure for Specimen IT12M 


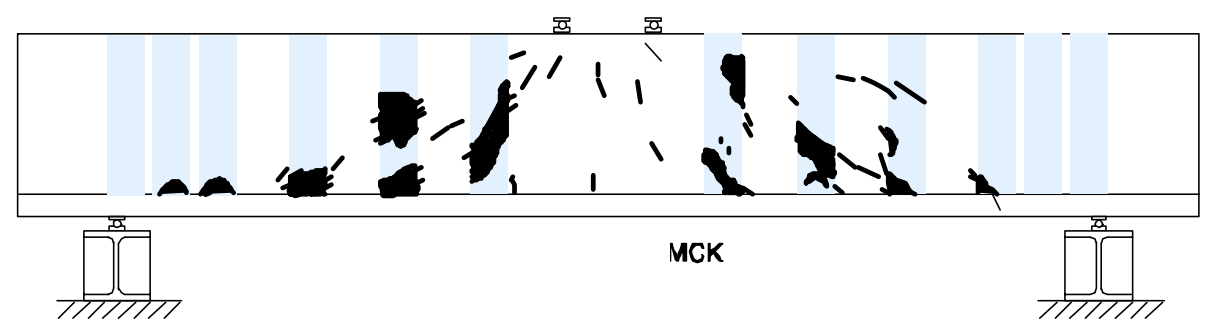

Figure 5.25: Cracked and debonded condition at load step prior to failure for Specimen IT12MCK

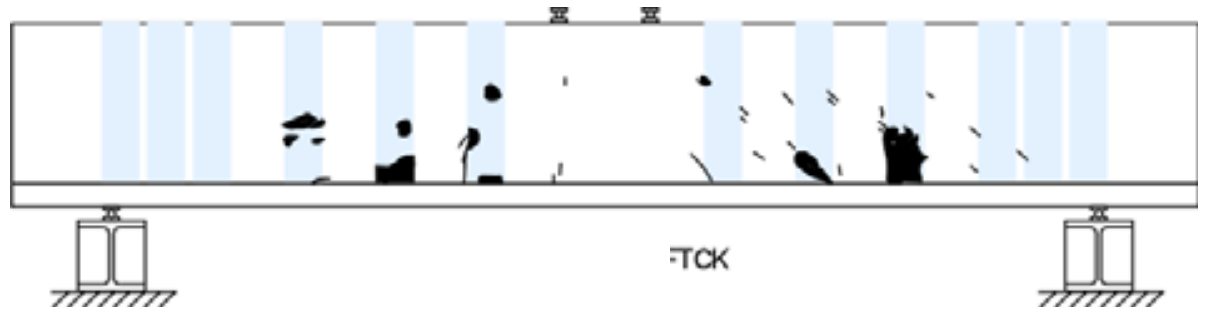

Figure 5.26: Cracked and debonded condition at load step prior to failure for Specimen ITT12FTCK

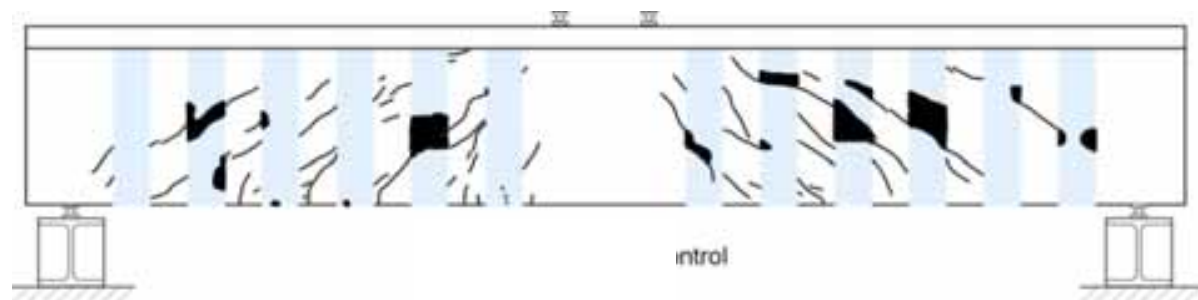

Figure 5.27: Cracked and debonded condition at load step prior to failure for Specimen T18Control

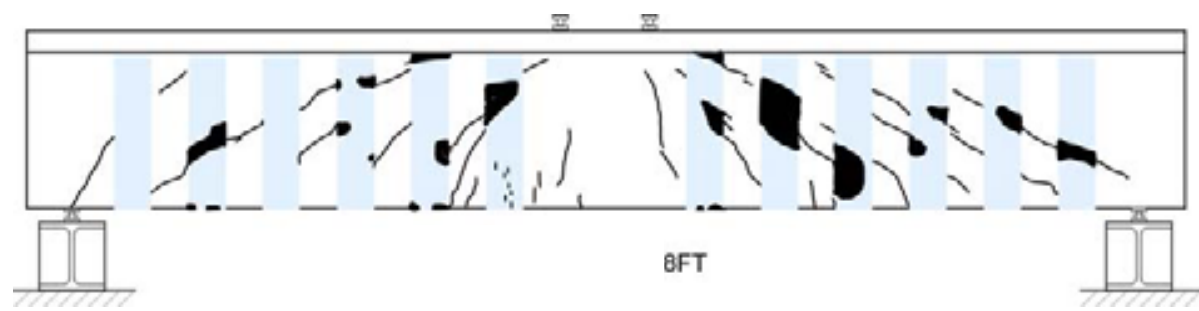

Figure 5.28: Cracked and debonded condition at load step prior to failure for Specimen T18FT 


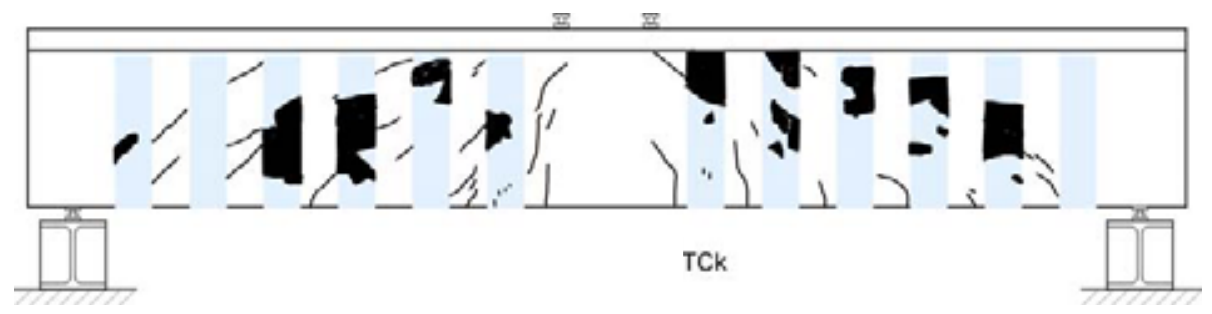

Figure 5.29: Cracked and debonded condition at load step prior to failure for Specimen T18FTCk

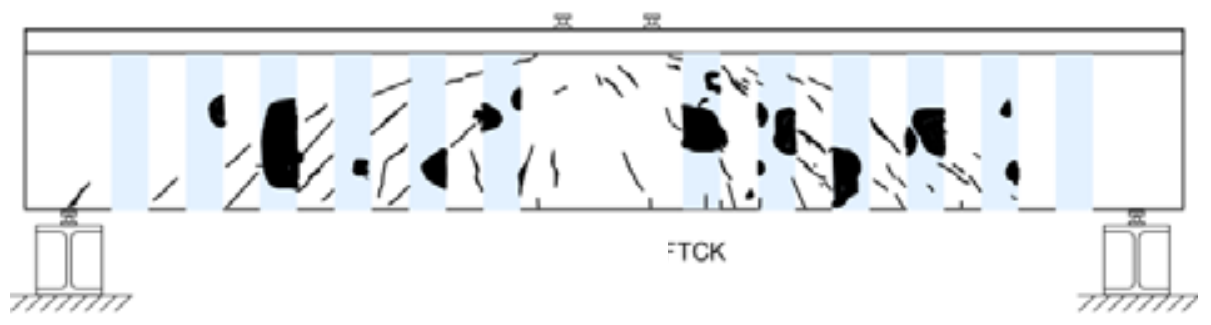

Figure 5.30: Cracked and debonded condition at load step prior to failure for all Specimen T18FFTCK.

\subsection{COMPARISON OF PRE-STRENGTHENING - POST- STRENGTHENING RESPONSES}

The changes in structural response of the specimens provided by the CFRP strengthening and the role of environmental durability is of particular interest to this study. A key issue was the additional shear strength provided by the CFRP. Because the CFRP strengthened specimens contained different concrete material properties, it became necessary to estimate the base capacity of the specimens without the addition of CFRP. Previous research on unstrengthened $\mathrm{RC}$ girders of the same proportions and similar materials were conducted at Oregon State University (Higgins et al. 2004). The reported shear capacities of identical IT and T configurations with similar shear and flexural steel reinforcing ratios to those tested here were, $921 \mathrm{kN}$ (207 kips) and 756 (170 kips) respectively. Shear capacities of all CFRP specimens, and the identical specimens without CFRP strengthening is shown in Figure 5.31. A detailed analysis methodology to determine the CFRP contribution to the shear strength is presented in Chapter 6 . 


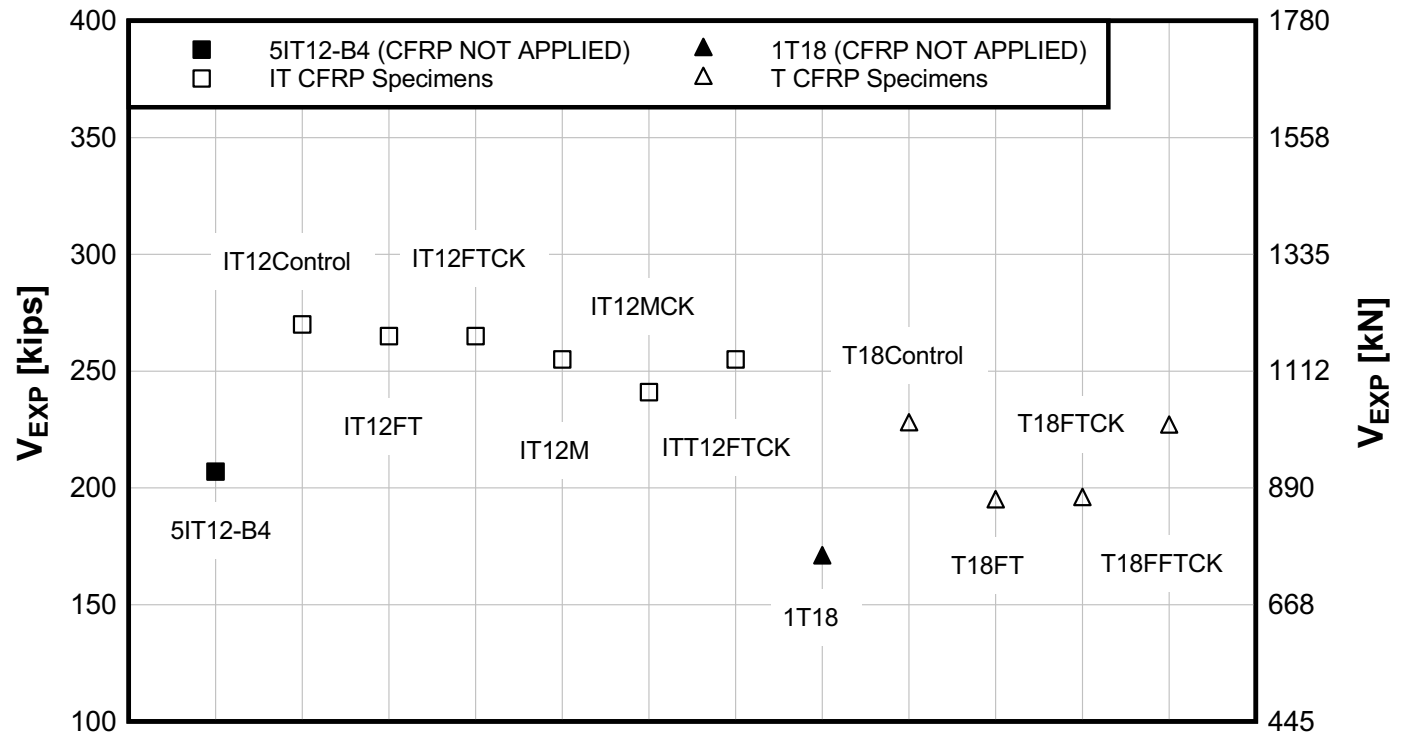

Figure 5.31: Shear capacities of CFRP specimens compared to identical specimens without CFRP strengthening

The effect of adding CFRP on stiffness was also of interest. Comparisons of responses without environmental exposure can be made considering both the overall member stiffness as indicated by the midspan displacement and individual shear panel stiffness measured within the six different diagonally instrumented shear panels. Changes were observed by comparing the precrack baseline response (pre-strengthening) to the recrack response (post-strengthening) for the CK specimens, and comparing the precrack baseline response (pre-strengthening) to the failure response (post-strengthening) for the control specimens. Stiffness changes were not apparent in the specimens when considering midspan displacements. This was reasonable, as midspan displacements are dominated by flexural deformations and increasing shear reinforcement has little effect on flexural deformations. Changes in stiffness considering the midspan displacement in specimens IT12FT and T18FT are shown in Figure 5.32, as an example. A full set of data is given in Appendix A. 

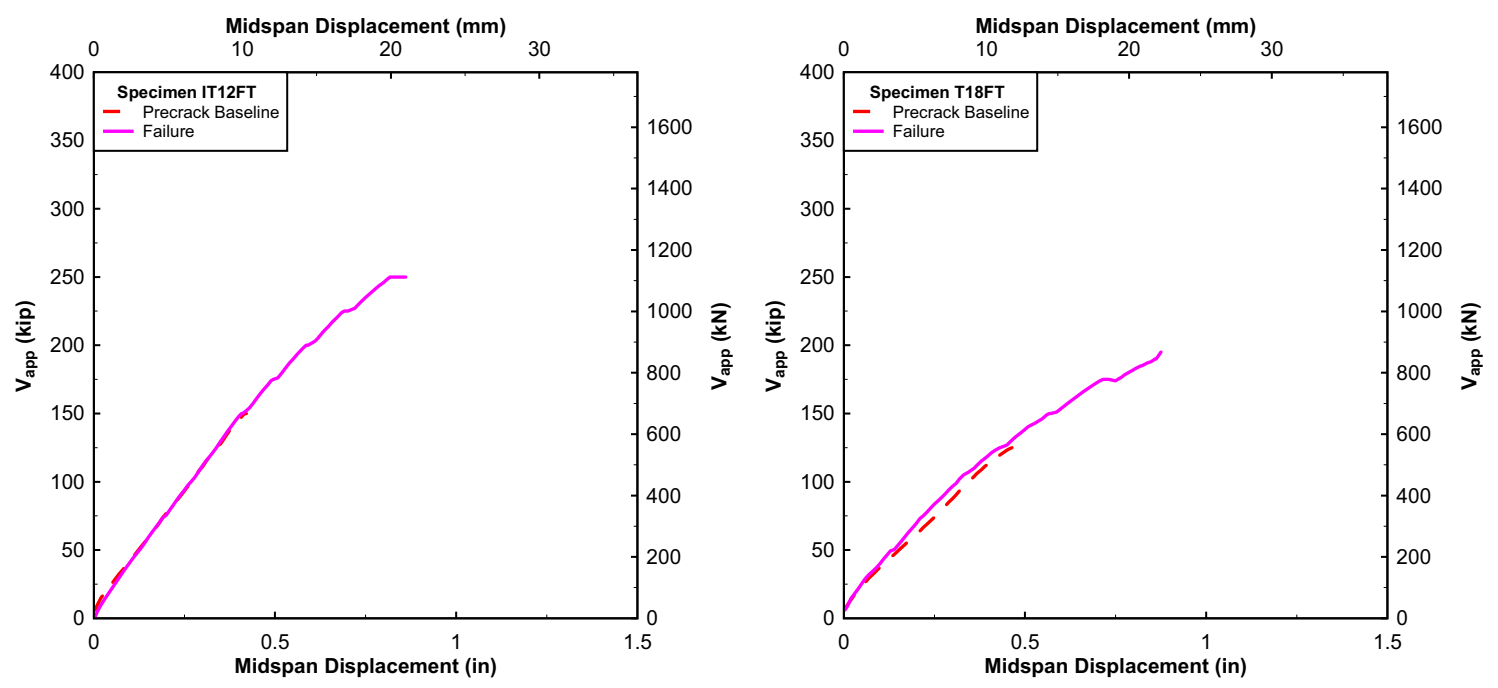

Figure 5.32: Overall stiffness comparison for specimens IT12FT and T18FT

A second measurement of change in stiffness can be taken as the relationship between the applied shear load and the average vertical strain in shear panels. When shear panel 3 was taken into consideration, a slight change in stiffness due to CFRP application was seen across all specimens. Shear panel 3 is located nearest midspan where diagonal cracking is not apparent until higher loads. As the panel is typically already stiff at lower load, an increase in stiffness is more difficult to detect. Changes in stiffness considering the average vertical strain in shear panel 3 in specimens IT12FT and T18FT are shown in Figure 5.33, as an example.
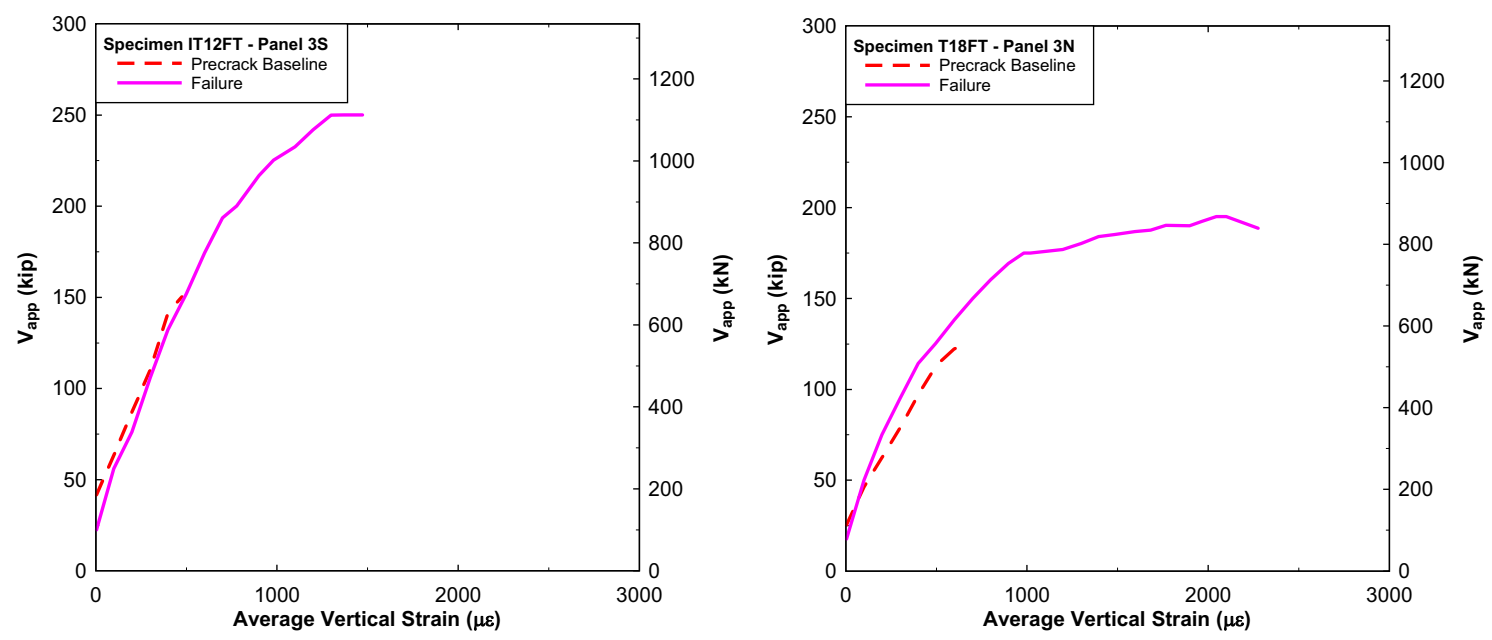

Figure 5.33: Shear panel 3 stiffness comparison for specimens IT12FT and T18FT 
In contrast to shear panel 3, the change in stiffness due to CFRP application was very apparent in shear panel 2. This panel is located in the middle of the shear span and typically exhibits significant diagonal cracking through the height of the web. The increased shear reinforcement provided by the CFRP constrained the crack deformations well. It is also likely that the smearing effect of the CFRP strips provide better crack control than discrete internal steel stirrups. Changes in stiffness considering the average vertical strain in shear panel 2 in. specimens IT12FT and T18FT are shown in Figure 5.34, as an example.
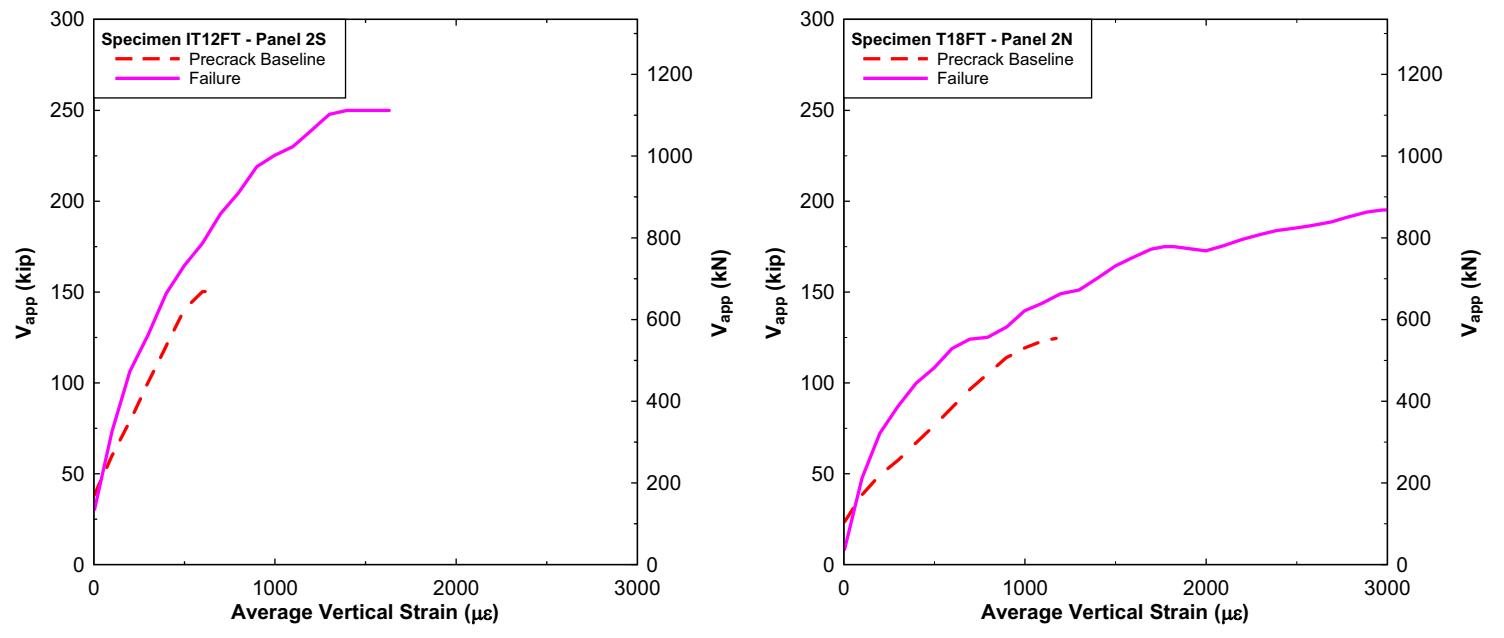

Figure 5.34: Shear panel 2 stiffness comparison for specimens IT12FT and T18FT

\subsection{COMPARISON OF PRE-EXPOSURE AND POST-EXPOSURE RESPONSES}

In order to identify environmental effects on the specimens, changes in stiffness were considered. Both overall specimen stiffness (applied shear vs. midspan displacement) and individual panel stiffnesses (applied shear vs. average vertical strain) were investigated. Specimens IT12FTCK, IT12MCK, ITT12FTCK, and T18FTCK were recracked after strengthening. After recracking, these specimens were cyclically reloaded to produce a baseline for post-exposure comparison. Any change in stiffness post-exposure can be attributed to the effects of the environmental exposure. Changes were observed by comparing the recrack baseline response (pre-exposure) to the failure response (post-exposure). The overall specimen stiffnesses for specimens IT12FTCK and T18FTCK are shown in Figure 5.35, as an example. 

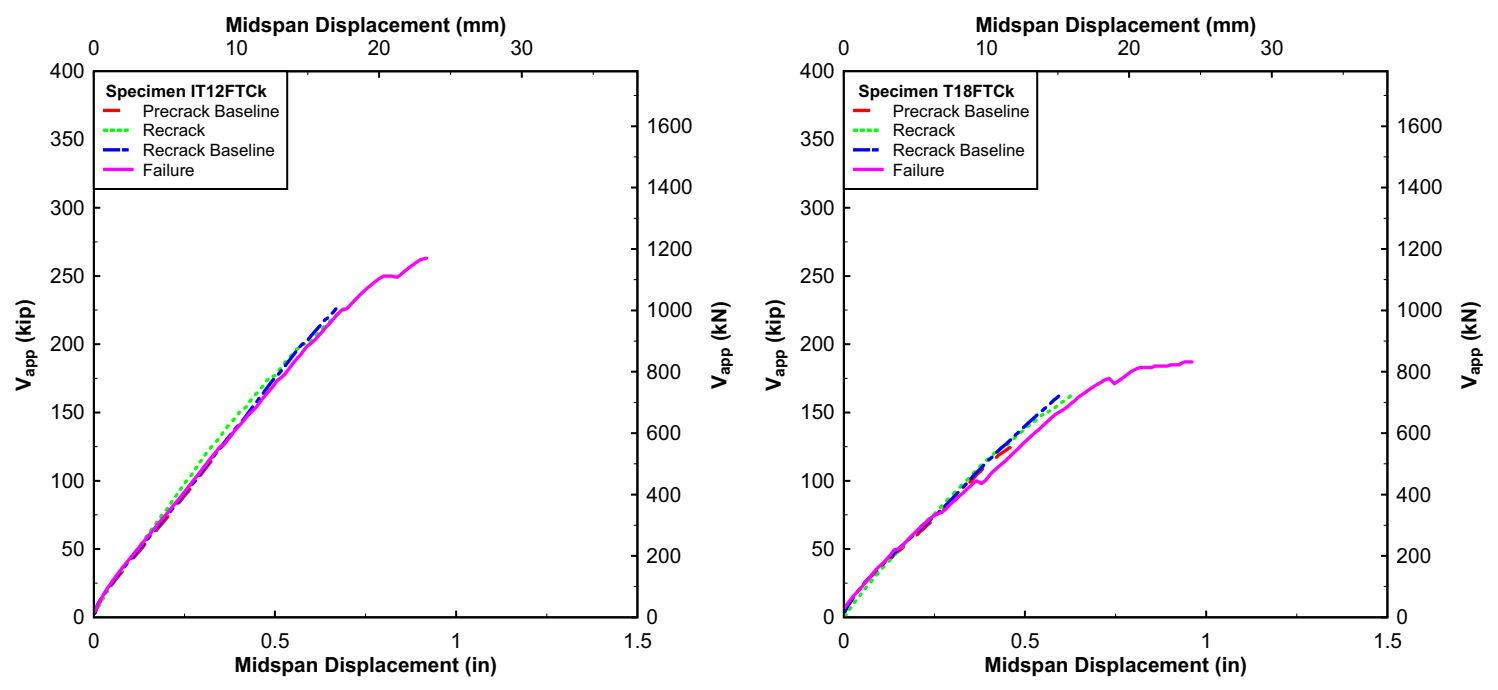

Figure 5.35: Overall stiffness comparison for specimens IT12FTCK and T18FTCK

A change in stiffness due to freeze-thaw exposure was not apparent in either specimen when the midspan displacements were examined. Again this was reasonable as additional shear reinforcing did not appear to increase the overall stiffness and thus any degradation of the shear reinforcing due to environmental exposure would not significantly impact the overall stiffness.

Shear panel 3 stiffnesses in terms of the relationship between the applied shear load and the average vertical strain for specimens IT12FTCK and T18FTCK, are shown in Figure 5.36, as an example. While no change in stiffness is apparent in the IT specimen, a slight decrease in stiffness can be detected in the T specimen.
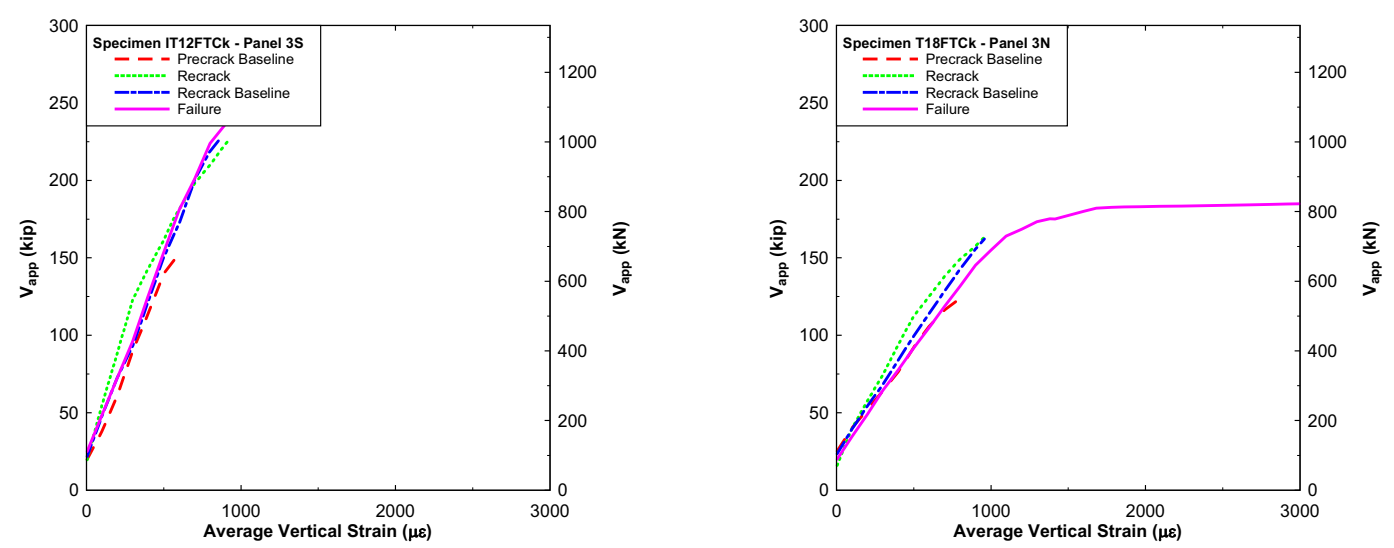

Figure 5.36: Shear panel 3 stiffness comparison for specimens IT12FTCK and T18FTCK 
Shear panel 2 stiffnesses for specimens IT12FTCK and T18FTCk are given in Figure 5.37, as an example. Again, no change in stiffness is apparent in the IT specimen, but a decrease in stiffness can be seen in the T specimen. This change in stiffness is caused by the increase in debonded CFRP strip areas, which in turn, is a result of freeze-thaw exposure as shown in Figure 5.38Figure 5.47. As debonded lengths increase, crack control is reduced and the panel stiffness decreases.
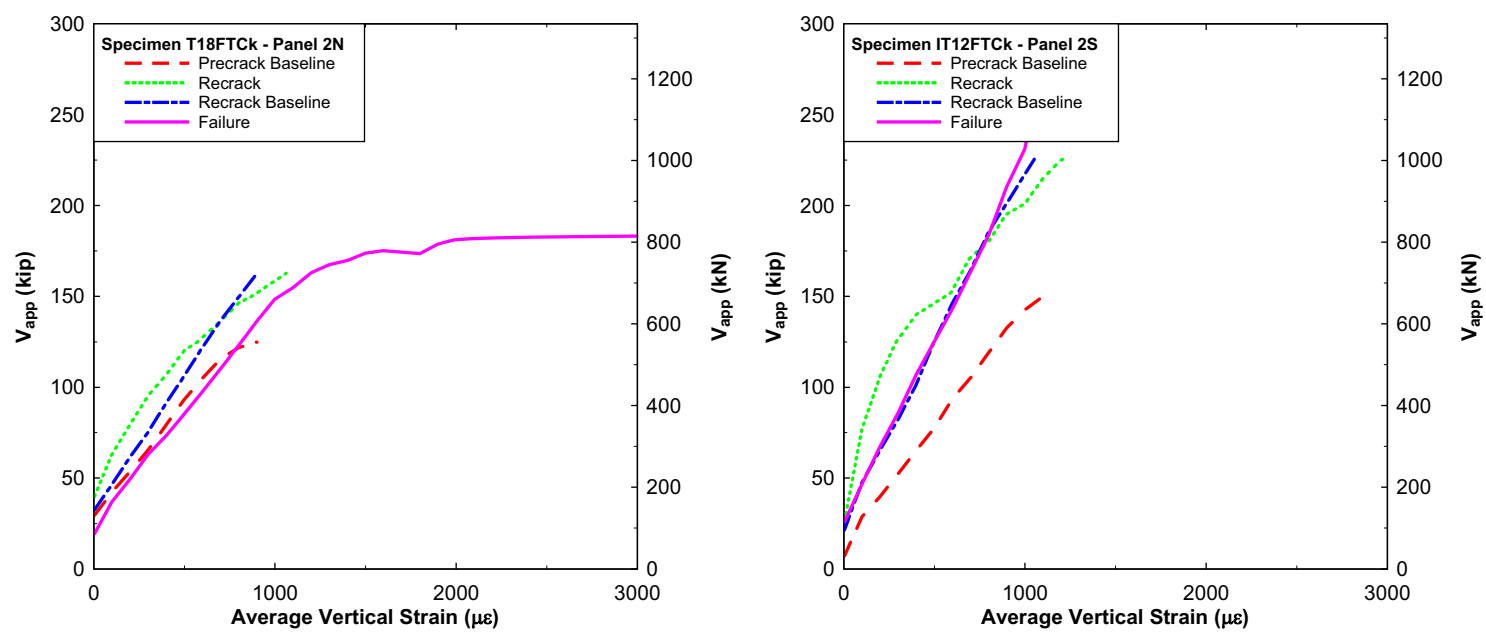

Figure 5.37: Shear panel 2 stiffness comparison for specimens IT12FTCK and T18FTCK

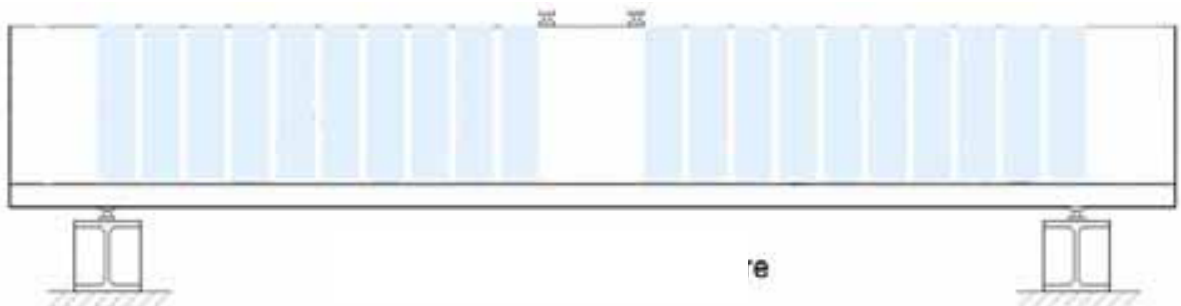

Figure 5.38: Debonding of CFRP at pre-exposure

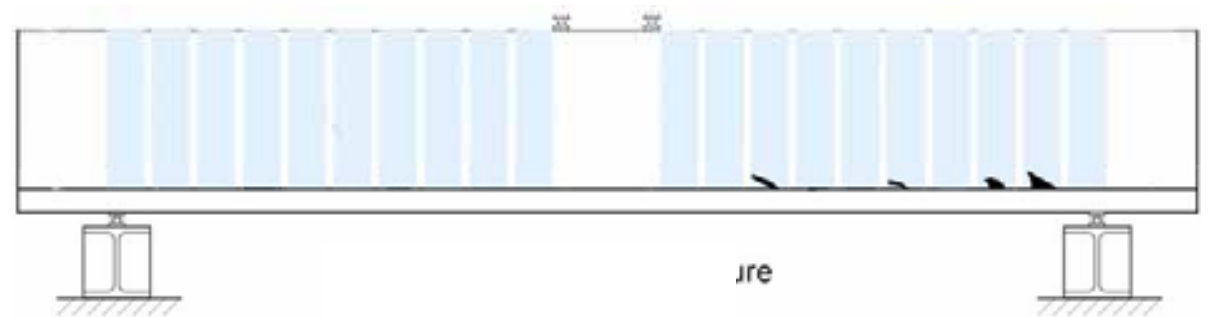

Figure 5.39: Debonding of CFRP at post-exposure 


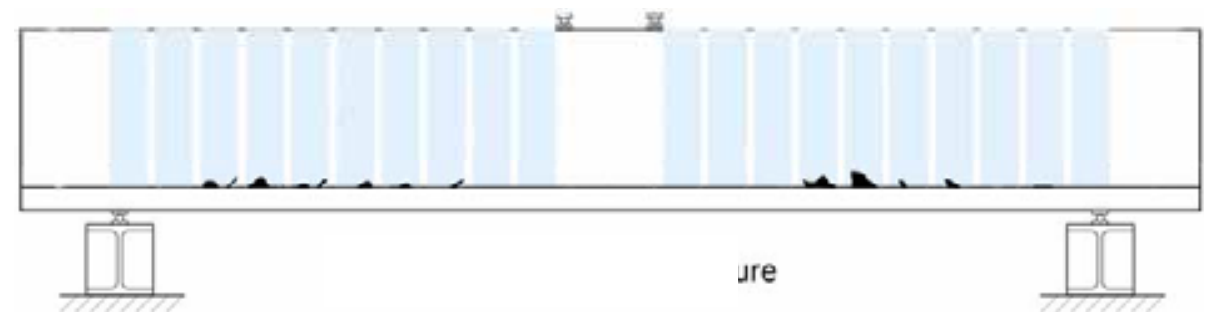

Figure 5.40: Debonding of CFRP at pre-exposure

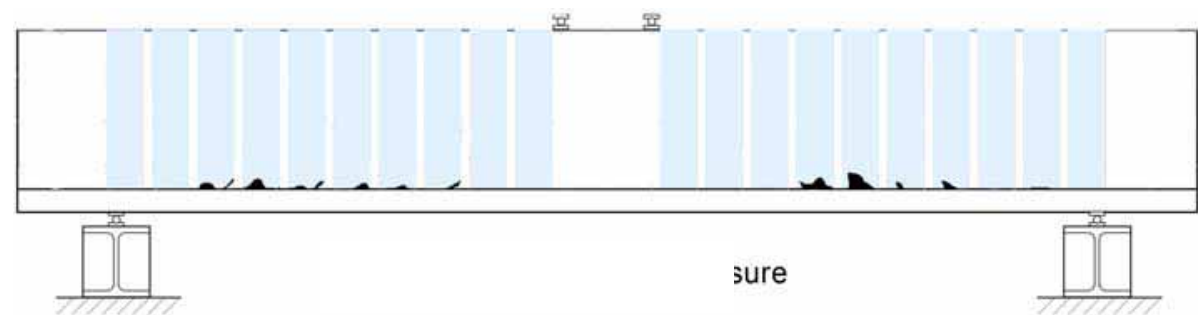

Figure 5.41: Debonding of CFRP at post-exposure

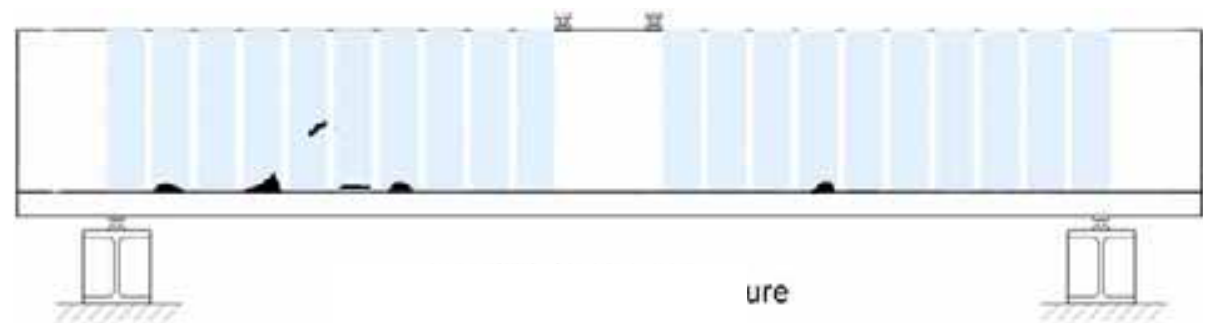

Figure 5.42: Debonding of CHKY at pre-exposure

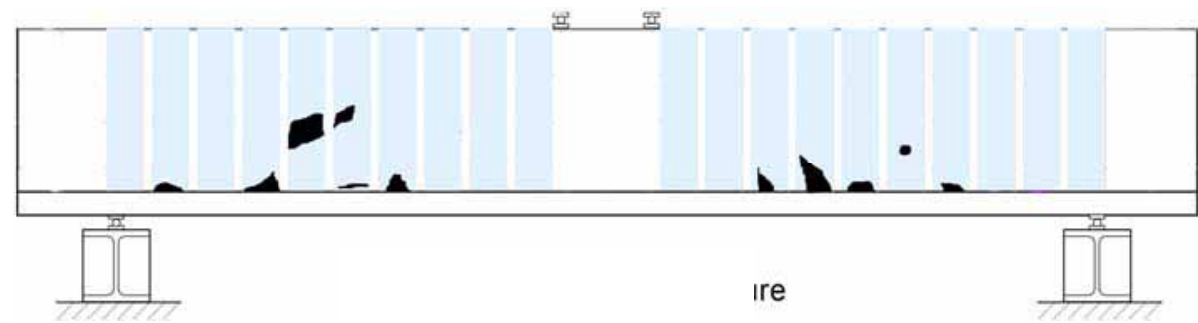

Figure 5.43: Debonding of CFRP at post-exposure 


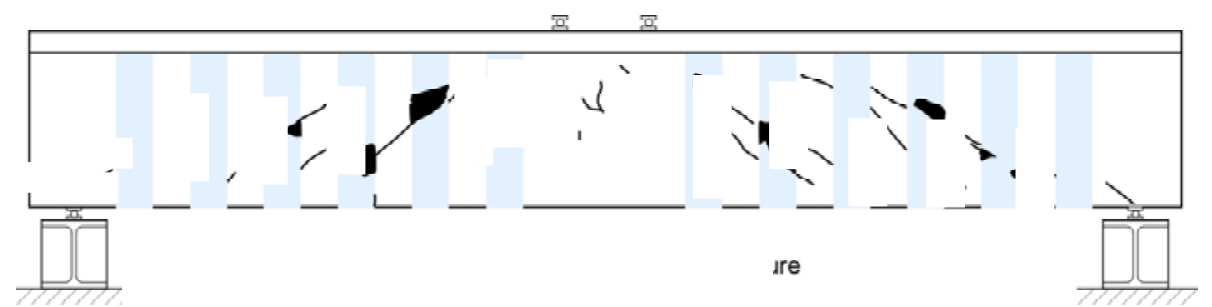

Figure 5.44: Debonding of CFRP at pre-exposure

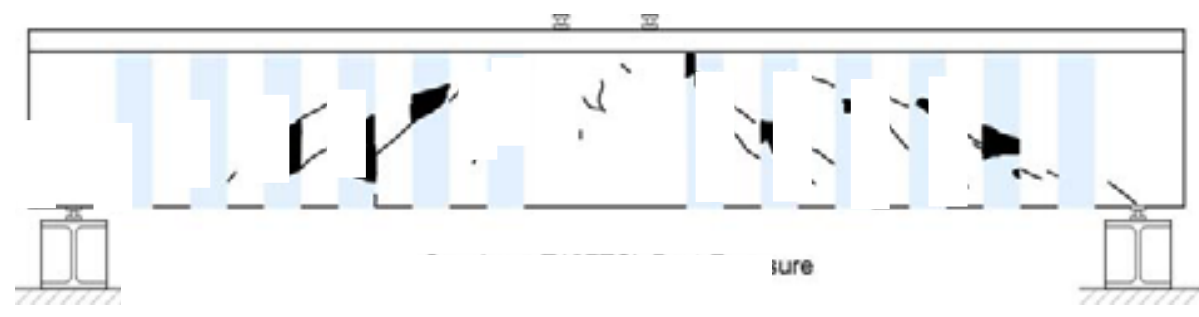

Figure 5.45: Debonding of CFRP at post-exposure

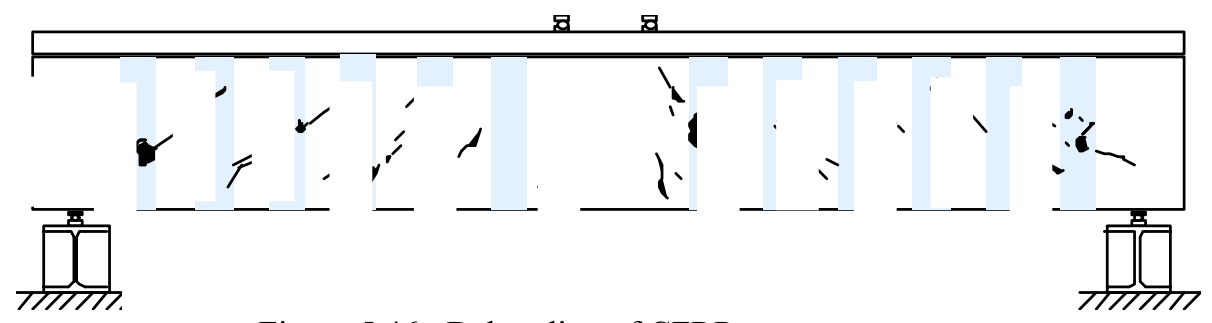

Figure 5.46: Debonding of CFRP at pre-exposure

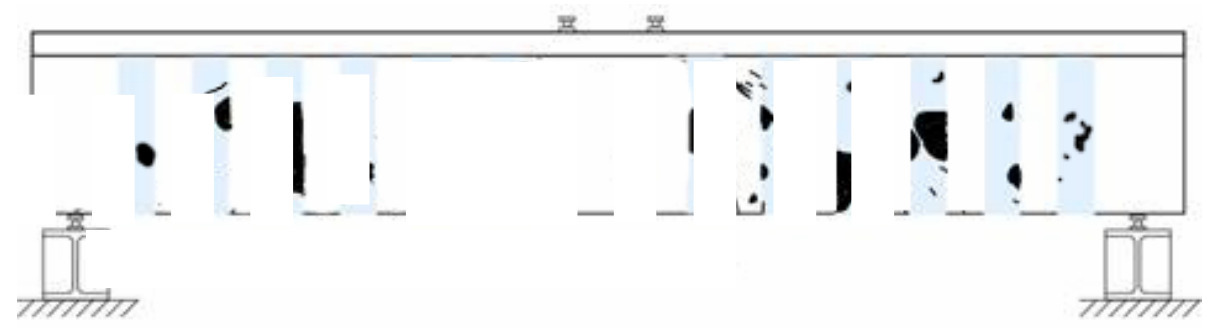

Figure 5.47: Debonding of CFRP at post-exposure

It was also useful to compare the cyclic response of average vertical strains in each specimen. Strain offsets following a cycle typically indicate debonding and increased diagonal crack widths. When comparing average vertical strain data in the T-Specimens, a difference in strain offset following the $778 \mathrm{kN}$ (175 kip) applied shear cycle can be seen across the specimens for shear panels 3N and 2N, as shown in Figure 5.48a and 5.48b, respectively. In Panel 3N, 
Specimen T18FT exhibited a plastic strain offset of $275 \mu \varepsilon$ after the $778 \mathrm{kN}$ (175 kip) applied shear cycle. Summing the plastic strain offset from the pre-exposure and post-exposure tests on Specimen T18FTCk yields a total plastic strain offset of $327 \mu \varepsilon$ after the $778 \mathrm{kN}$ (175 kip) applied shear cycles. Finally, Specimen T18Control exhibited a plastic strain offset of $182 \mu \varepsilon$ after the $778 \mathrm{kN}$ (175 kip) applied shear cycle. In Panel 2N, Specimen T18FT exhibited a plastic strain offset of $557 \mu \varepsilon$ after the $1557 \mathrm{kN}$ (350 kip) cycle. Summing the plastic strain offset from the pre-exposure and post-exposure tests on Specimen T18FTCk yields a total plastic strain offset of $644 \mu \varepsilon$ after the $1557 \mathrm{kN}$ (350 kip) cycles. Finally, Specimen T18Control exhibited a plastic strain offset of $290 \mu \varepsilon$ after the $1557 \mathrm{kN}$ (350 kip) cycle.

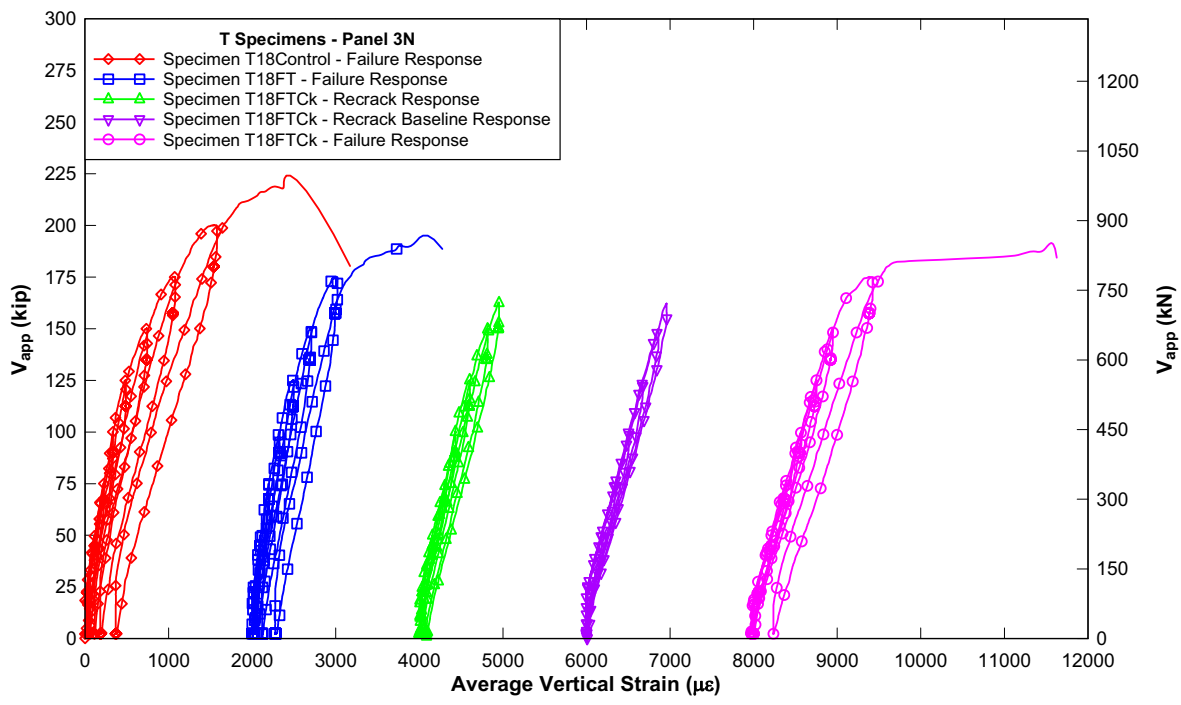

(a)

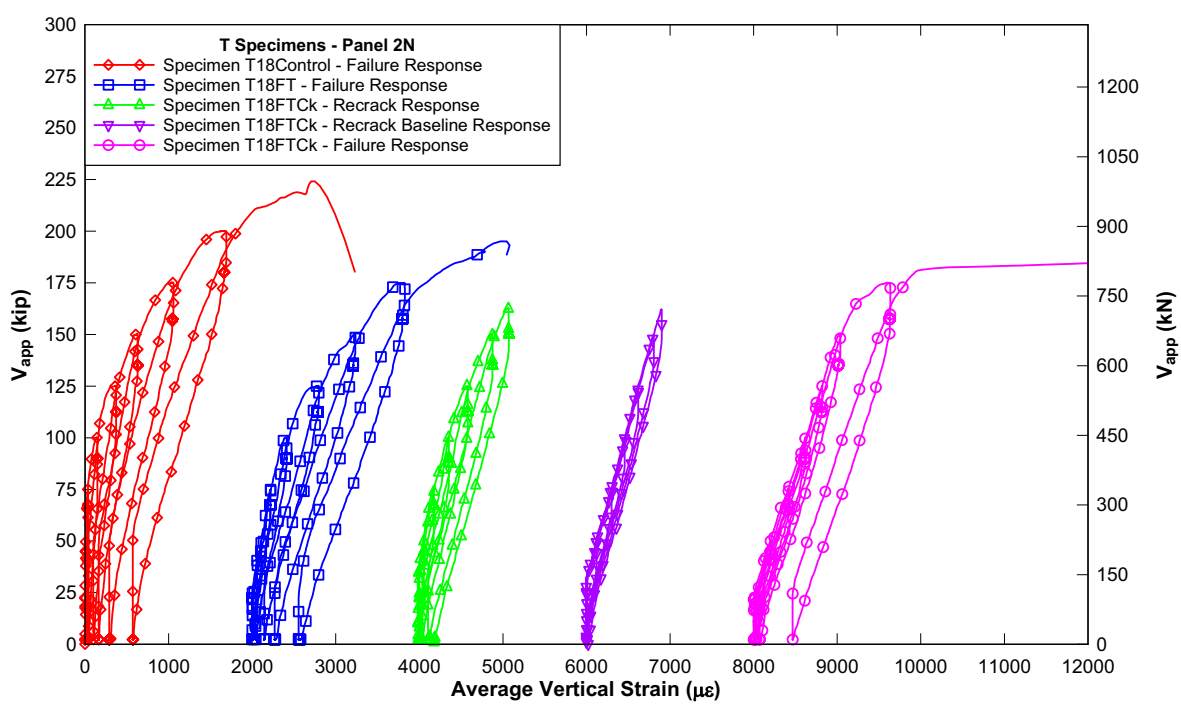

(b)

Figure 5.48: Cyclic average vertical strain response for T-Specimens at different instrumented shear panels along span 
It can be stated that freeze-thaw exposure caused larger offsets in strains after unloading from the same load amplitude. This was due to larger debonded regions in the strips, which allowed larger crack widths.

\subsection{INTERNAL STRAIN GAGE DATA}

Data were collected from internal stirrup strain gages. While local strain data can be useful, it did not provide insight into freeze-thaw effects. Strain gage results depend heavily on their location relative to the diagonal cracks. Due to varying crack patterns, local strain data were difficult to compare across specimens. Additionally, these internal strain gages were often damaged during casting, precracking or recracking. Due to the CFRP application and chipping into the concrete, repairing the strain gages was not possible.

\subsection{CFRP FLEXURAL STRAIN FROM DEBONDING}

The introduction of flexural strains in the CFRP strips due to debonding makes comparison of CFRP strain measurements difficult. The dilation of the cracked concrete behind the CFRP surface forces the debonded region outward resulting in out-of-plane deformations. Since CFRP strain gages were applied on the outer surface of the strips, due to the strip bending, flexural tension strains are introduced and this contaminates the intended uniaxial strain measurements. This behavior was measured during testing as shown in Figure 5.49 and Figure 5.50.

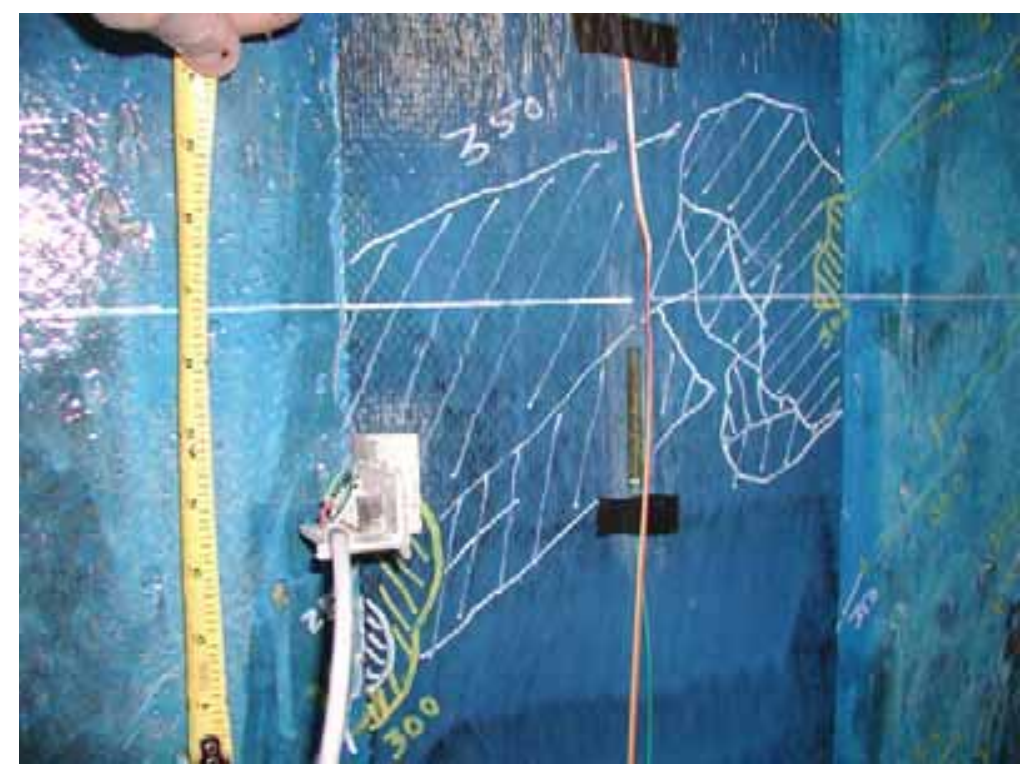

Figure 5.49: Photo of debonded region 


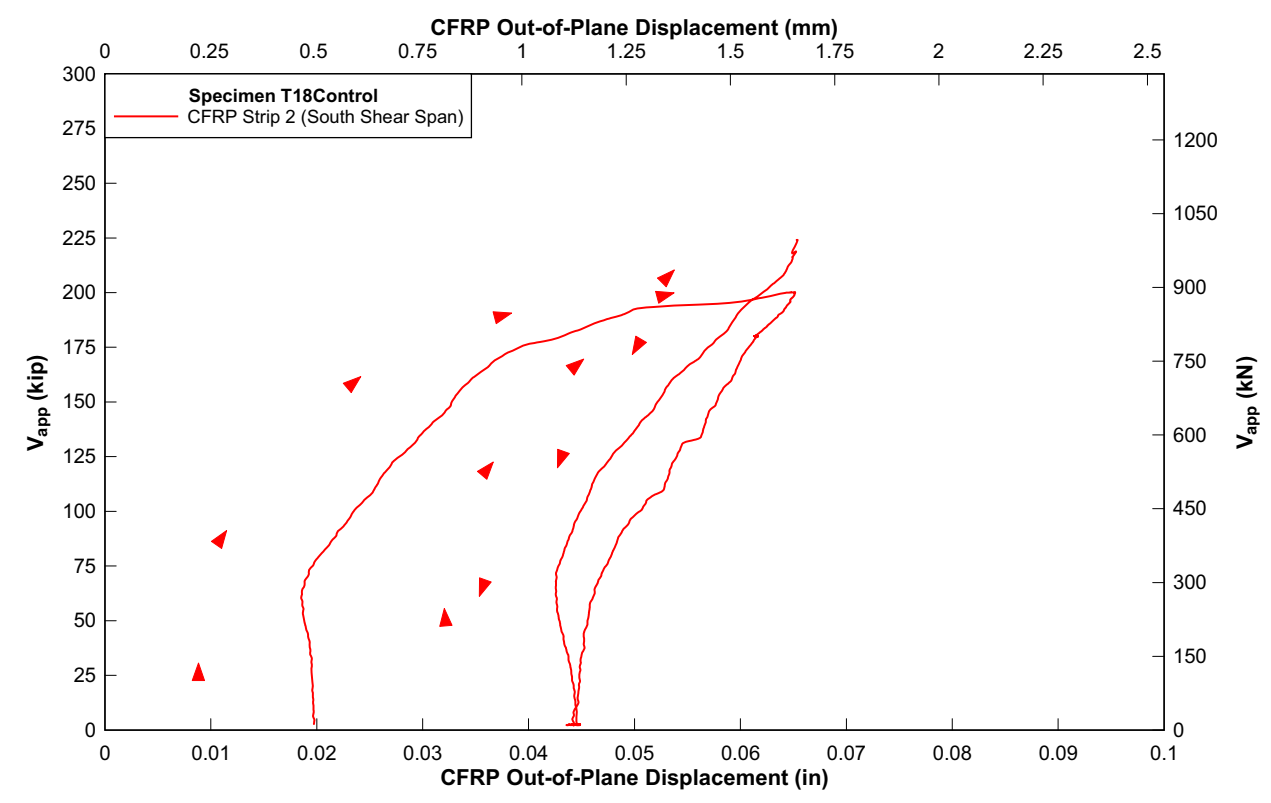

Figure 5.50: Shear vs. CFRP out-of-plane displacement for Specimen T18Control strip 2S

Data for Figure 5.50 were collected during the 890 and $987 \mathrm{kN}$ (200 and $222 \mathrm{kip}$ ) applied shear steps on CFRP strip 2 in the south shear span of specimen T18Control. A $13 \mathrm{~mm}$ (0.5 in.) range displacement sensor was mounted to the CFRP strip and displacement was measured relative to the adjacent concrete surface. An initial out-of-plane displacement of approximately $0.5 \mathrm{~mm}$ (0.02 in.) was measured. An initial debonded length of approximately $127 \mathrm{~mm}$ (5 in.) was measured prior to the $890 \mathrm{kN}$ (200 kip) applied shear step and a debonded length of approximately $254 \mathrm{~mm}$ (10 in.) was measured prior to the $987 \mathrm{kN}$ (222 kip) applied shear step.

The flexural strains could be modeled using the idealized deflected shapes shown in Figure 5.51. 


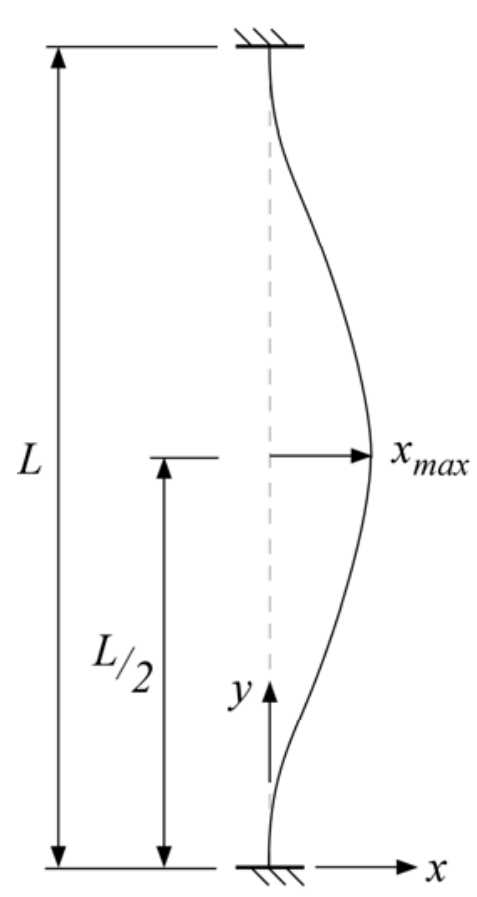

(a)

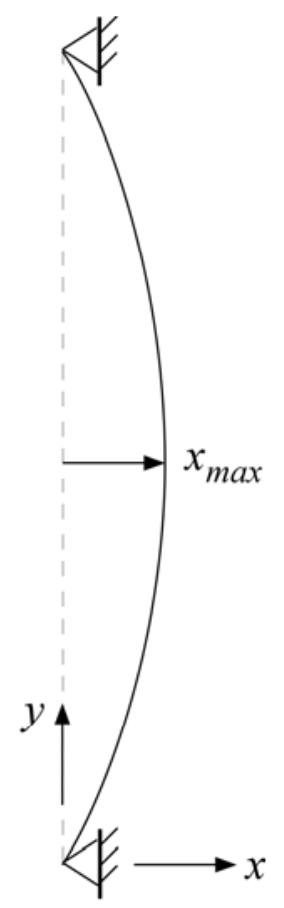

(b)

Figure 5.51: Assumed deflected shapes and boundary conditions for debonded regions of CFRP.

Flexural strain for the fixed-fixed condition shown in Figure 5.51a can be determined by Equation 5.1:

$$
\varepsilon_{f d}=\frac{16 x_{\max } t_{f}}{L^{2}}
$$

where $t_{f}$ is the thickness of the CFRP, $x_{\max }$ is the maximum out-of-plane deformation, and $L$ is the unbonded length.

Using Equation 5.1, $t_{f}=1.16 \mathrm{~mm}(0.0458 \mathrm{in}$.), and the measured values given above for CFRP strip 2 flexural strains can be estimated prior to the 890 and $987 \mathrm{kN}$ (200 and $222 \mathrm{kip}$ ) applied shear steps. Calculated flexural strains were $586 \mu \varepsilon$ and $330 \mu \varepsilon$, respectively at these applied shear levels. As seen in Figure 5.49, the CFRP strain gage 4S is not located at the center of the debonded region prior to the $890 \mathrm{kN}$ (200 kip) applied shear step so direct comparison of strains is difficult. As debonding progresses, the strain gage becomes closer to the center of the debonded region. As seen in Figure 5.52 the strain offset prior to the $987 \mathrm{kN}$ (222 kip) load step is $1347 \mu \varepsilon$. The calculated bending strain of $330 \mu \varepsilon$ is nearly $25 \%$ of the strain measured by the surface strain gage. This significantly skews the intended uniaxial strain measurement.

While the introduction of flexural strains can help identify debonding, it hampers the use of CFRP measured surface strains as a measure of the uniaxial strain, as they can be very different based on the size of the debonded region and out-of-plane displacement. 


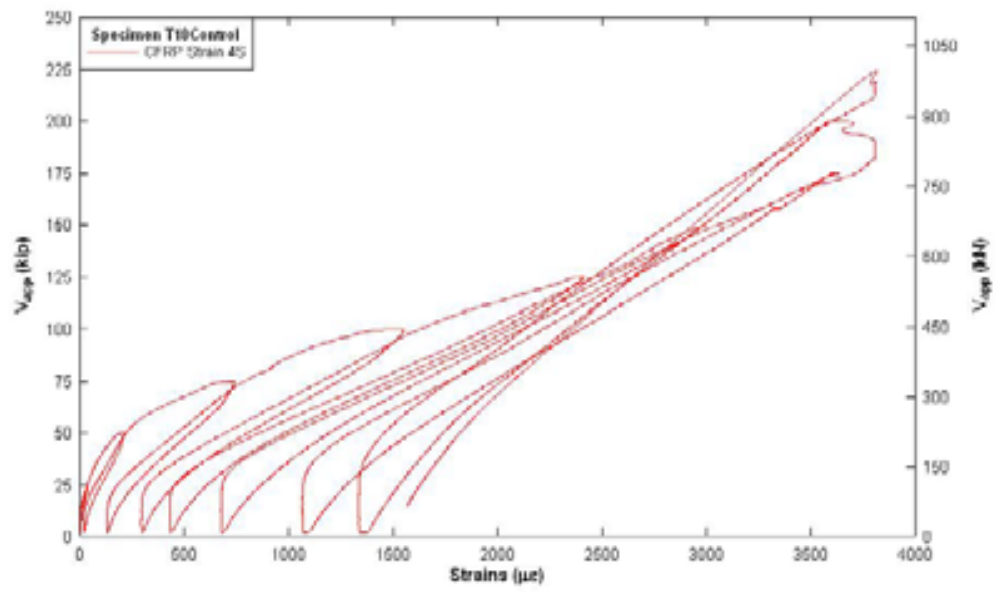

Figure 5.52: Shear versus strain for Specimen T18Control CFRP strain gage 4S.

\subsection{SPECIMEN ORIENTATION}

As shown in Figure 5.31 freeze-thaw exposure did not appear to adversely affect the additional shear response or strength gained for CFRP strengthening of the IT-Specimens where no significant moisture was apparent in the interface between the concrete and CFRP, while it significantly affected the capacity of the T-Specimens where such moisture was apparent in the bonding interface. Moisture appears to play a significant role in the effect of freeze-thaw exposure. The difference in moisture seen in the specimens may be attributed to the orientation of the specimens during CFRP application and freeze-thaw exposure, whereby water may have got into the interface from the free edge and was trapped behind the CFRP composite layer and thus repeated expansion and contraction could have led to bond deterioration. The terminating edges of the CFRP strips were of particular interest.

During CFRP application on the IT-Specimens, the fibers were impregnated by running the putty knife downward toward the free edge of the strip near the flange. This allowed excess saturant to puddle at the free edge of the CFRP strips at the flange interface. During CFRP application on the T-Specimens, the fibers were impregnated by running the putty knife upward toward the free edge of the strip near the flange. Gravity did not allow saturant to puddle along the free edge in this case. This added epoxy matrix at the strip edge and deck-step interface appears to have limited the ability of moisture to enter the CFRP-concrete interface and at the strip termination. During freeze-thaw exposure the specimens were oriented in the same manner as during testing, except specimen ITT12FTCK, where the specimen orientation was T during freeze-thaw exposure, and IT during testing. For specimens with $\mathrm{T}$ orientation during freezethaw cycles, this meant there was exposed concrete on the top of the beam, where moisture could enter the specimen, but a moisture barrier at the bottom of the specimen. If moisture was continually working downward through the girder, this allowed for ingress but no egress. The opposite was true for the IT-Specimens. The CFRP formed a moisture barrier at the top of the 
specimen while concrete was exposed at the bottom. In order for moisture to enter the web, it would have to wick upward or through available cracks.

\subsection{THERMALLY INDUCED STRAINS}

Concrete and CFRP have very different coefficients of thermal expansion (CTE) causing thermally induced strains at the bond interface during freeze-thaw. Normal-weight concrete has a CTE ranging from 9-12.6 $\times 10^{-6} /{ }^{\circ} \mathrm{C}\left(5-7 \times 10^{-6} /{ }^{\circ} \mathrm{F}\right)($ MacGregor and Wight 2005), while Wabo ${ }^{\circledR}$ reports a CTE of $-0.38 \times 10^{-6} /{ }^{\circ} \mathrm{C}\left(-0.21 \times 10^{-6} /{ }^{\circ} \mathrm{F}\right)$ for the CFRP. Not only are the CTEs orders of magnitude different, they have opposite signs indicating one expands while the other contracts and vice versa, which results in thermally induced stresses. As seen in Figure 5.53 the surface of the specimens experienced a temperature range of $20^{\circ} \mathrm{C}\left(36^{\circ} \mathrm{F}\right)$ during freeze-thaw exposure. This corresponds to thermally induced concrete strains between $180-252 \mu \varepsilon$ for the given range of concrete CTE, and a CFRP strain of -7.6 $\mu \varepsilon$. However, the measured CFRP surface strain range was approximately $200 \mu \varepsilon$ during freeze-thaw exposure, as shown in Figure 5.53 which was within the boundaries of the calculated thermally induced concrete strain values. Thus, it can be stated that CFRP strains are mainly controlled by the expansion/shrinkage of the concrete surface, due to the stiffness difference between the concrete block and CFRP sheets.

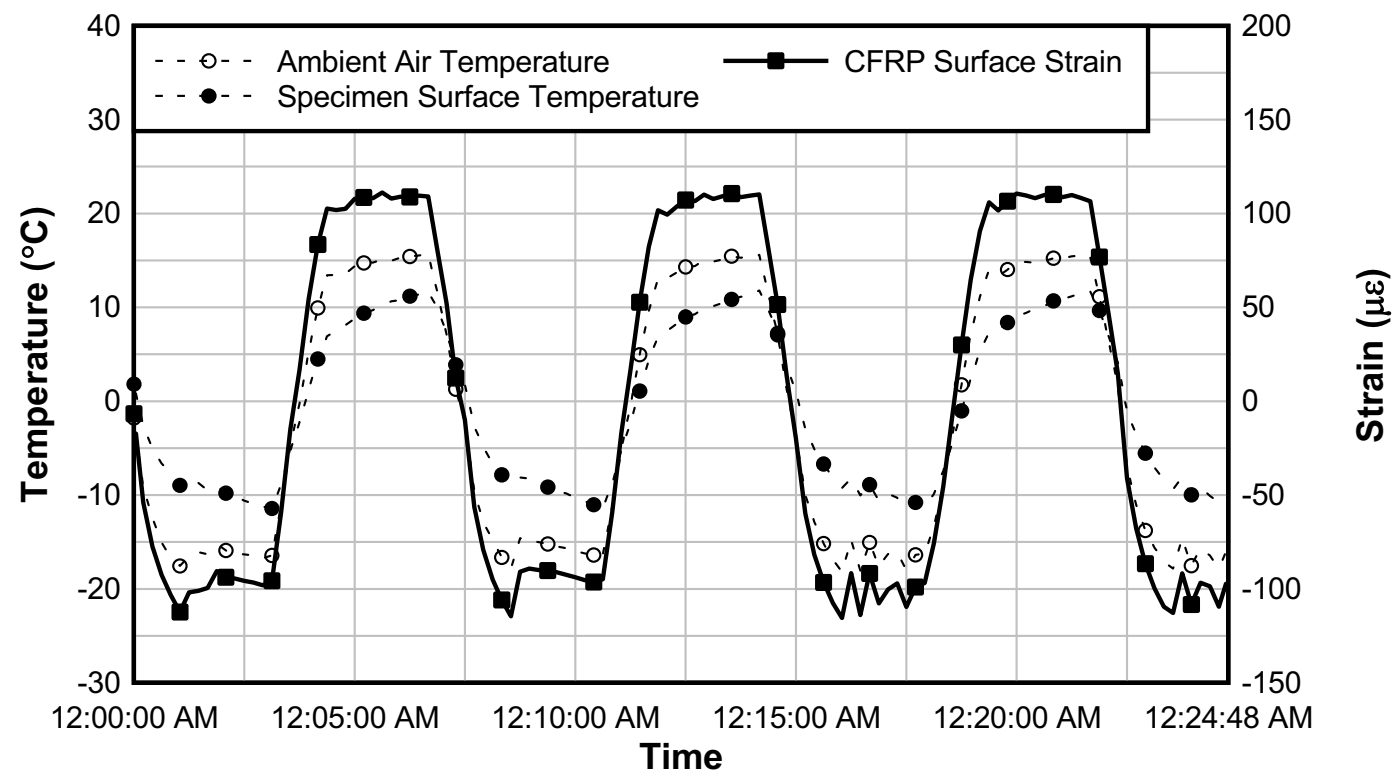

Figure 5.53: Freeze-thaw cycling and associated CFRP surface strains

Thermally induced strains of this magnitude up to 550 cycles do not appear to have a detrimental effect, as no loss in shear capacity was seen for the IT-Specimens. In the field, bridge members may undergo even larger surface temperature fluctuations daily. No conclusions can be drawn from this data about the long-term effect of larger thermally induced strains in the field. In order to investigate the change in stiffness for the fatigue/freeze-thaw specimen T18FFTCK, a series of baseline tests were performed. For the baseline tests, displacement sensors which were kept 
unattached during fatigue cycling to prevent fatigue effects on the sensors were re-attached, and the specimen was loaded to produce a shear of $712 \mathrm{kN}$ (160 kips) and unloaded back to $0 \mathrm{kN}(0$ kips), for three times. An equivalent secant stiffness (the difference in applied shear load divided by the difference in midspan displacement) was calculated for the load range between $89-178$ $\mathrm{kN}(20-40 \mathrm{kips})$ (initial stage), and also for the load range between $579-712 \mathrm{kN}(130-160$ kips) (final stage), as shown in Figure 5.54 For both stages, a reduction in stiffness around 10\% was observed at the end of the fatigue cycling compared to the pre-fatigue stiffness of the specimen. The displacement sensors did not seem to be effected by different test-day temperatures.
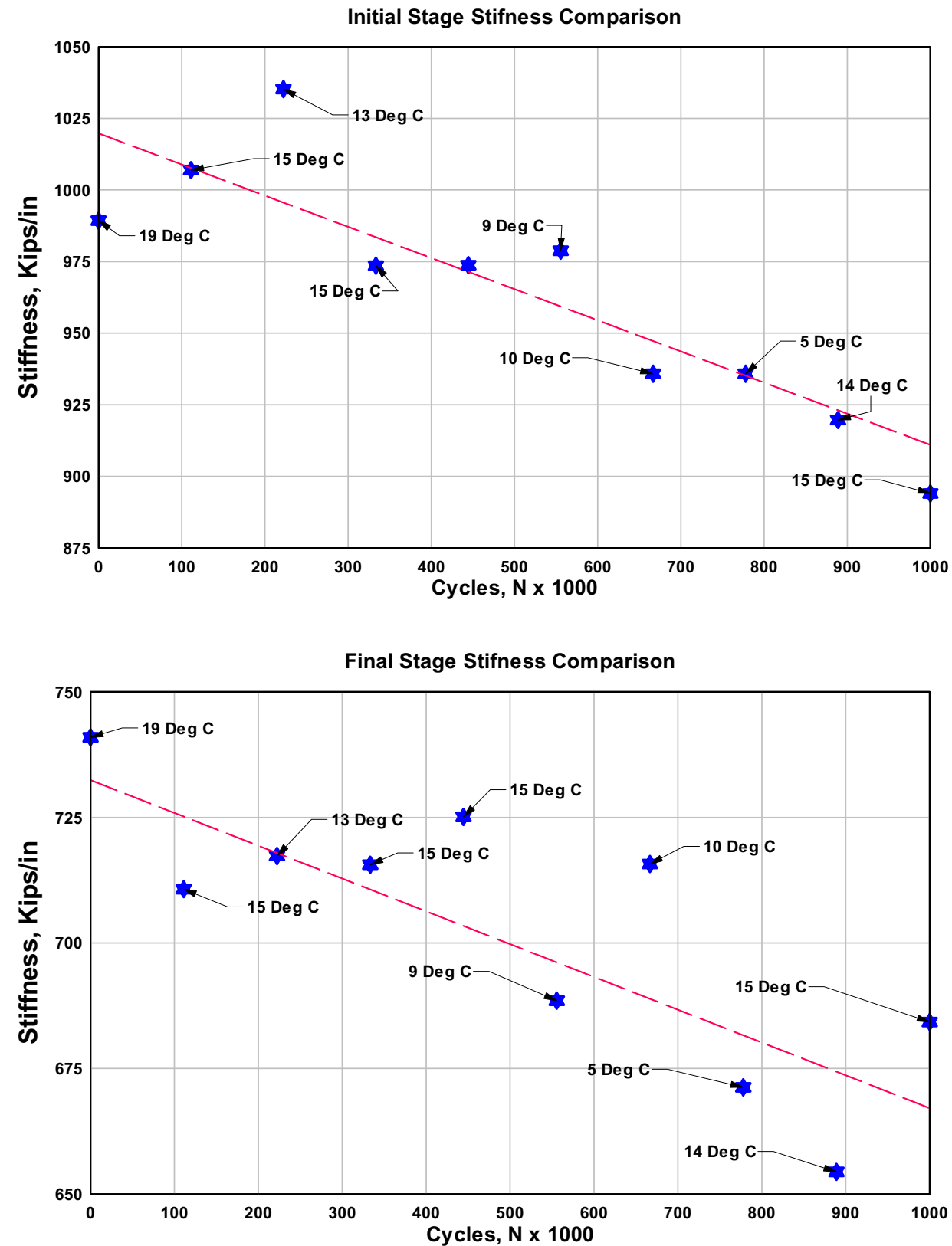

Figure 5.54: Change in stiffness for specimen T18FFTCK. 


\subsection{COMPARATIVE ANALYSIS}

The changes in structural response of the specimens provided by the CFRP strengthening and the role of freeze-thaw and moisture exposure on long-term durability were of particular interest to this study. A key issue was the shear strength provided by the CFRP after exposure. It was necessary to estimate the base capacity of the specimens without the addition of CFRP first, in order to determine the contribution provided by CFRP. Once the additional shear strength provided by the CFRP was estimated, it was possible to make further comparisons between experimental CFRP contributions and the design strengths calculated from ACI 440.2R (2008).

\subsection{BASE CAPACITY PREDICTION}

The calculations for predicting the base capacities of the CFRP specimens were performed in two ways: the traditional ACI 318-08 shear strength provisions, and the sectional implementation of the Modified Compression Field Theory (MCFT). Unstrengthened control specimens (5IT12-B4 and 1T18), which were tested in a previous test series (Higgins et al. 2004), were also included in this study to make comparisons and determine the most suitable methodology to predict the base capacities of the specimens. The strengthened specimen shear capacity was found by taking the applied shear from the actuator, $V_{a p p}(\mathrm{kN})$ (kip), and adding the specimen self-weight, $V_{D L}(\mathrm{kN})$ (kip) acting at the failure diagonal crack to determine the experimental shear strength, $V_{E X P}(\mathrm{kN})$ (kip).

\subsubsection{ACI 318-08 Shear Design Method}

ACI 318-08 design method for shear is based on a parallel truss model with $45^{\circ}$ constant inclination diagonals supplemented by an empirical concrete contribution, where nominal shear strength of a conventionally reinforced concrete beam is calculated as shown in Equation 6.1.

$$
V_{n}=V_{c}+V_{s}
$$

where $V_{s}(N)(l b s)$ and $V_{c}(N)(l b s)$ are shear resistances of transverse steel and concrete respectively.

ACI 318-08 uses a concrete shear resistance, $V_{c}$, which is taken to be equal to the shear strength of a beam without transverse reinforcement. This concrete contribution is computed as shown in Equations 6.2a and 6.2b.

$$
\begin{gathered}
V_{c}=2 \sqrt{f_{c}{ }^{\prime}} b_{w} d \quad \mathbf{U S} \\
V_{c}=0.17 \sqrt{f_{c}{ }^{\prime}} b_{w} d \quad \mathbf{S I}
\end{gathered}
$$


where $f_{c}{ }^{\prime}$ is the concrete compression strength (MPa) (psi), $b_{w}$ is the beam width (mm) (in.), and $d$ is the effective depth (mm) (in.).

ACI 318-08 assumes all stirrups yield at failure within the horizontal projection of the $45^{\circ}$ inclined crack, which is taken to be equal to the effective depth, $d(\mathrm{~mm})$ (in.). The shear resistance provided by the transverse steel is determined as shown in Equation 6.3.

$$
V_{s}=\frac{A_{v} f_{y t} d}{s}
$$

where $A_{v}\left(\mathrm{~mm}^{2}\right)\left(\mathrm{in}^{2}\right)$ is the area of the transverse steel, $\mathrm{f}_{\mathrm{yt}}$ is the yield strength of the transverse steel (MPa) (psi), and s (mm) (in.) is the spacing of the transverse steel. Actual day-of-test compressive concrete strengths and the actual steel properties were used in this analysis.

\subsubsection{MCFT Sectional Analysis Approach}

Response-2000 was used to predict the base capacities of the specimens. This program was developed at the University of Toronto (Bentz 2001) and uses a nonlinear sectional analysis based on MCFT to predict shear-moment capacity of RC elements. Instead of simple superposition of concrete and reinforcement contributions to achieve the shear strength of a section, as given in ACI 318-08 provisions, the interaction between moment and shear is taken into account when predicting the load capacity of the section with the sectional implementation of MCFT. Application of this program to a suite of 44 similar full-scale RC specimens tested at Oregon State University predicted the unrepaired member capacity to within $2 \%$ with a coefficient of variation of 7\% (Higgins et al. 2004). Actual day-of-test compressive concrete strengths along with actual flexural and transverse steel properties determined from materials testing and reported in Tables 4.3 and 4.4 were used in the analysis. The shear strength was predicted at the location $d_{v}$ away from the edge of the loading plate (near midspan) and resulted in a M/V ratio of $1923 \mathrm{~mm}(6.31 \mathrm{ft}$.) and $2298 \mathrm{~mm}(7.54 \mathrm{ft}$.) for the IT and T-Specimens, respectively. The expected mean shear capacities $\left(V_{R 2 K}\right.$ mean $)$ were calculated by reducing the Response- 2000 output by $2 \%$ to account for the statistical bias of the analysis method. In addition, one-sided confidence limits of 5\% $\left(V_{R 2 K} 5 \%\right)$ and $95 \%\left(V_{R 2 K} 95 \%\right)$ for shear strength were determined using the coefficient of variation of $7 \%$ for the analysis method. $V_{R 2 K} 5 \%$ and $V_{R 2 K} 95 \%$ correspond to calculated shear strengths which are larger than the actual shear strength with probabilities of $5 \%$ and $95 \%$, respectively.

\subsubsection{Results from Base Capacity Calculations}

The analysis results from ACI 318-08 and sectional MCFT (Response-2000) are summarized in Table 6.1, and shown in Figure 6.1. For both T and IT configurations, ACI 318-08 conservatively underestimates the shear capacities of the unstrengthened specimens as compared to Response-2000. Response-2000 is seen to do a good job predicting the base capacities of reference specimens tested previously (5IT12-B4 and 1T18) as compared to the ACI 318 method. Considering the statistical results from past research over a wide range of salient material and geometric properties for similar girders (Higgins et al. 2004), it was expected that 
the Response-2000 results would provide better estimates of the CFRP shear contribution in the subsequent analysis steps.

Table 6.1: Structural response quantities.

\begin{tabular}{|c|c|c|c|c|c|}
\hline Specimen & $\begin{array}{c}V_{E X P} \\
(\mathrm{kN})(\mathrm{kip}) \\
\end{array}$ & $\begin{array}{c}V_{A C I} 318 \\
(\mathrm{kN}) \text { (kip) } \\
\end{array}$ & $\begin{array}{c}V_{R 2 K ~ 5 \%}(\mathrm{kN}) \\
(\mathrm{kip})\end{array}$ & 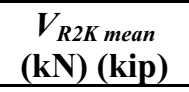 & $\begin{array}{c}V_{R 2 K} 95 \%(\mathrm{kN}) \\
(\mathrm{kip}) \\
\end{array}$ \\
\hline 5IT12-B4* & $921(207)$ & $704(158.1)$ & 835 (187.7) & $943(212.0)$ & $1052(236.5)$ \\
\hline IT12Control & $1202(270)$ & 724 (162.6) & $857(192.5)$ & $968(217.6)$ & $1080(242.6)$ \\
\hline IT12FT & $1179(265)$ & $730(164.0)$ & $856(192.4)$ & $968(217.5)$ & $1079(242.5)$ \\
\hline IT12FTCK & $1179(265)$ & $704(158.1)$ & $830(186.4)$ & $938(210.7)$ & $1046(235.0)$ \\
\hline IT12M & $1157(260)$ & 733 (164.6) & $857(192.5)$ & $968(217.6)$ & $1080(242.6)$ \\
\hline IT12MCK & $1095(246)$ & $716(160.8)$ & $850(191.1)$ & $961(216.0)$ & $1072(240.9)$ \\
\hline ITT12FTCK & $1157(260)$ & $665(149.4)$ & $769(172.8)$ & 869 (195.3) & $969(217.8)$ \\
\hline $1 \mathrm{~T} 18^{*}$ & $708(159)$ & $603(135.5)$ & $689(154.9)$ & $779(175.0)$ & 869 (195.2) \\
\hline T18Control & $1010(227)$ & $579(130.2)$ & $664(149.3)$ & $751(168.8)$ & $838(188.2)$ \\
\hline T18FT & $863(194)$ & $602(135.2)$ & $689(154.9)$ & $779(175.0)$ & 869 (195.2) \\
\hline T18FTCK & $868(195)$ & $586(131.6)$ & 667 (149.9) & 754 (169.4) & $841(189.0)$ \\
\hline T18FFTCK & $1041(234)$ & $570(128.1)$ & $662(148.8)$ & $749(168.2)$ & 834 (187.5) \\
\hline
\end{tabular}

* Specimen from previously conducted research, CFRP strengthening not applied.

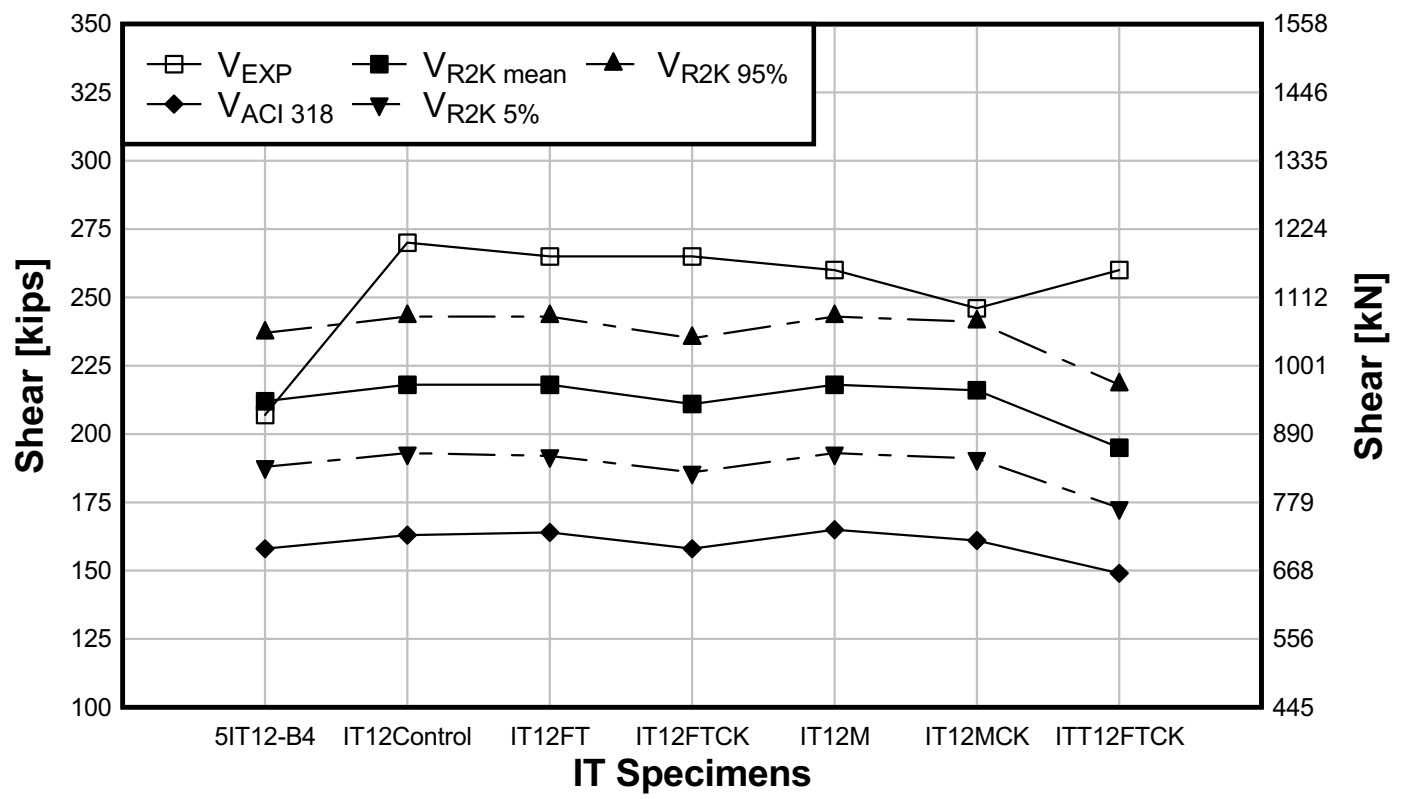




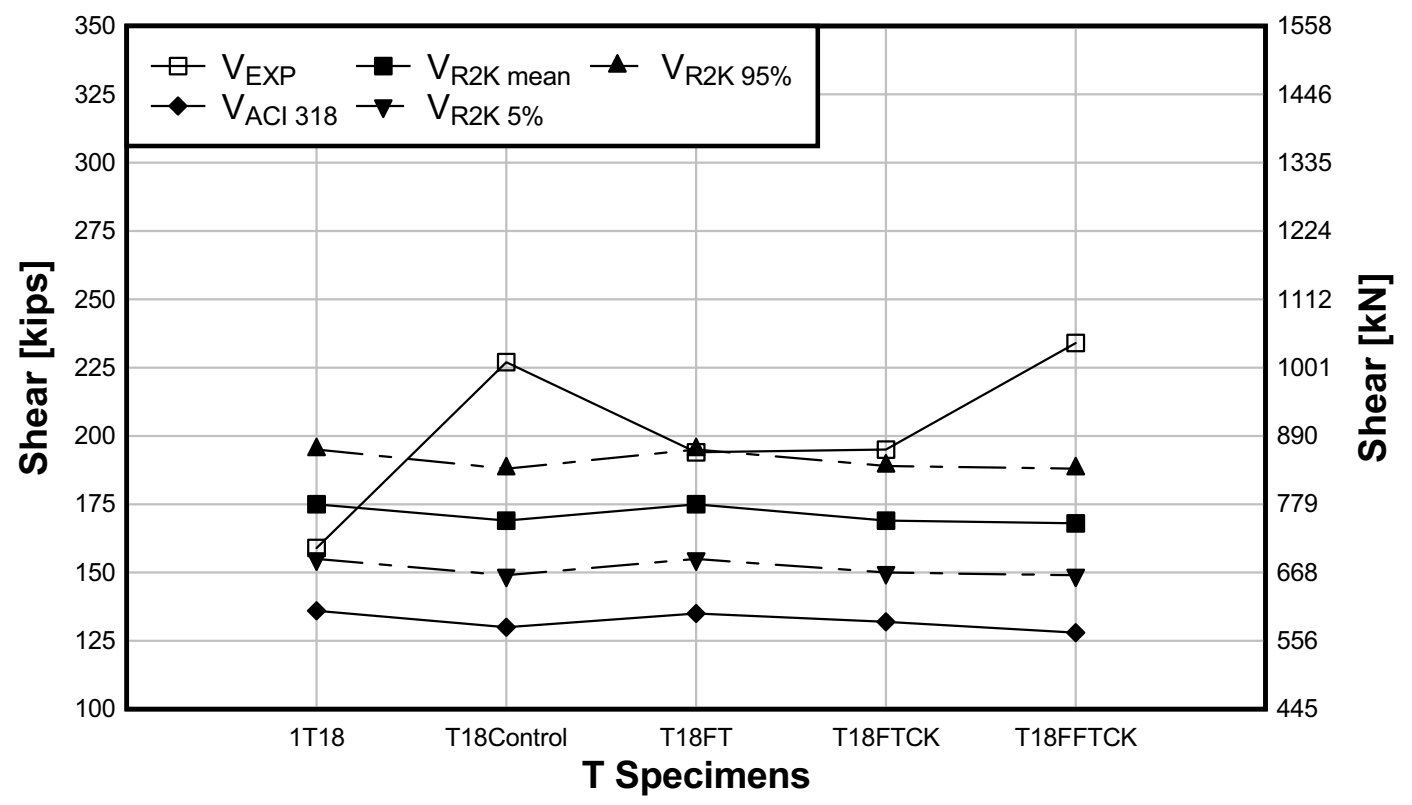

Figure 6.1: Base capacities of specimens from ACI 318-08 and Response-2000

\subsection{CFRP SHEAR STRENGTH CONTRIBUTION}

The shear strength contribution from CFRP was estimated in two ways. The first method takes the difference between the experimental shear strength and the ACI 318 base shear strength (Equations (6.1), (6.2), and (6.3)) as the CFRP shear contribution. The second method takes the difference between the experimental shear strength and the mean base capacity predicted using Response-2000. The experimentally estimated CFRP shear contributions are compared with the expected shear design strength for the CFRP from ACI 440. These approaches assume that the ultimate shear strength can be determined from superposition of contributions from concrete, web reinforcement, and CFRP, ignoring the full shear moment interaction that occurs (using Response-2000 for the base strength calculation only incorporates shear-moment interaction of the section without CFRP). CFRP demands including detailed shear-moment interactions are treated in Section 6.3.

\subsubsection{CFRP Shear Strength Contribution from ACI 440.2R}

ACI 440.2R-08 requires that the FRP material properties reported by manufacturers be reduced to account for long-term exposure to environmental conditions. Design ultimate tensile strength and rupture strain are determined as shown in Equations 6.4 and 6.5.

$$
\begin{aligned}
& f_{f u}=C_{E} f_{f u}^{*} \\
& \varepsilon_{f u}=C_{E} \varepsilon_{f u}^{*}
\end{aligned}
$$


where $f_{f u}^{*}$ and $\varepsilon_{f u}^{*}$ are the ultimate tensile strength, and ultimate rupture strain of FRP material as reported by the manufacturer. The environmental reduction factor, $\mathrm{C}_{\mathrm{E}}$, for exterior exposure in bridges, is given as 0.85 for carbon fiber type.

ACI 440.2R-08 indicates that the modulus of elasticity for FRP material is typically unaffected by environmental conditions. Considering FRP materials are linear elastic until failure, the modulus is calculated using Equation 6.6, shown below.

$$
E_{f}=f_{f u} / \varepsilon_{f u}
$$

As seen in Equation 6.6, the environmental reduction factor does not have an effect on the value of the design modulus of elasticity of the FRP material, and the initial value reported by the manufacturer can be directly used in subsequent calculations.

The ACI 440.2R-08 design method for shear is based on the work by Khalifa et al.(1998), where the shear strength provided by the FRP reinforcement is determined by calculating the force resulting from the tensile stress in the FRP across an assumed crack pattern, depending on the orientation of the fibers. The contribution of FRP reinforcement to shear resistance is given in Equations 6.7 and 6.8 .

$$
V_{f}=\frac{A_{f v} f_{f e}(\sin \alpha+\cos \alpha) d_{f v}}{s_{f}}
$$

where

$$
A_{f v}=2 n t_{f} w_{f}
$$

where $n$ is the number of plies of FRP reinforcement, $t_{f}$ is the nominal thickness of one ply of FRP reinforcement, $w_{f}$ is the width of FRP reinforcing plies, $\alpha$ is the orientation angle, $s_{f}$ is the strip spacing, $d_{f v}$ is the effective depth of FRP reinforcement, and $f_{f e}$ is the effective stress in the FRP, calculated as shown in Equation 6.9.

$$
f_{f e}=\varepsilon_{f e} E_{f}
$$

The dimensional variables used in Equations 6.7 and 6.8 are illustrated in Figure 6.2. The effective depth of FRP reinforcement in T oriented beams is defined as the distance between the top fiber of the FRP reinforcement and the centroid of the tension reinforcement. However, ACI440.2R-08 does not provide a clear definition of the effective depth when IT oriented beams (negative moment region) are considered, which should be addressed in the future editions of the guide. 

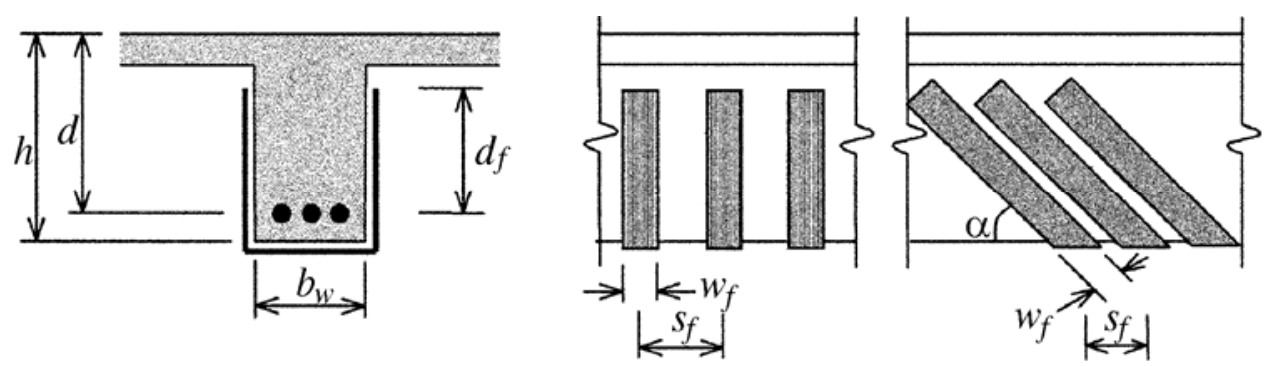

Figure 6.2: Dimensional variables used in ACI 440 FRP shear contribution calculations

ACI 440.2R-08 limits the effective strain, $\varepsilon_{f e}$ to a maximum value of $0.004 \mathrm{in} / \mathrm{in} .(\mathrm{mm} / \mathrm{mm})$ Furthermore, for U-wrap schemes, the effective strain, $\varepsilon_{f e}$, is calculated using a bond-reduction coefficient, $\kappa_{v}$, by reducing the design rupture strain at least by $25 \%$, as shown in Equations 6.10, 6.11a, and $6.11 \mathrm{~b}$.

$$
\begin{gathered}
\varepsilon_{f e}=\kappa_{v} \varepsilon_{f u} \leq 0.004 \\
\kappa_{v}=\frac{k_{1} k_{2} L_{e}}{468 \varepsilon_{f u}} \leq 0.75 \mathbf{U S} \\
\kappa_{v}=\frac{k_{1} k_{2} L_{e}}{11,900 \varepsilon_{f u}} \leq 0.75 \mathbf{S I}
\end{gathered}
$$

The bond-reduction coefficient, $\kappa_{v}$, is a function of the concrete strength, the type of the wrapping scheme used, and the number, length, thickness, and the stiffness of the FRP plies, where the affecting parameters in U-wrap configurations are given in Equations 6.12a - 6.14.

$$
\begin{aligned}
L_{e} & =\frac{2500}{\left(n t_{f} E_{f}\right)^{0.58}} \mathbf{U S} \\
L_{e} & =\frac{23,300}{\left(n t_{f} E_{f}\right)^{0.58}} \mathbf{S I} \\
k_{1} & =\left(\frac{f_{c}^{\prime}}{4000}\right)^{2 / 3} \mathbf{U S} \\
k_{1} & =\left(\frac{f_{c}^{\prime}}{27}\right)^{2 / 3} \mathbf{S I}
\end{aligned}
$$




$$
k_{2}=\frac{d_{f v}-L_{e}}{d_{f v}} \quad \text { (for U-wraps) }
$$

ACI 440.2R-08 recognizes that the outlined methodology has not been confirmed for "shear strengthening in areas subjected to combined high flexural and shear stresses, or in regions where the web is primarily in compression (negative moment regions)". However, ACI 440.2R08 suggests that the bond-reduction coefficient, $\kappa_{\mathrm{v}}$, is "sufficiently conservative" for such cases.

Using ACI-440 for shear design, there are three possible outcomes for the effective stress in the FRP and Equation 6.9 can be re-written as Equation 6.15a and 6.15b.

$$
\begin{gathered}
f_{f e}=\min \left\{\begin{array}{c}
\frac{k_{1} k_{2} L_{e}}{468} \\
0.75 C_{E} \varepsilon_{f u}^{*} \\
0.004
\end{array}\right\} \times E_{f} \mathbf{U S} \\
f_{f e}=\min \left\{\begin{array}{c}
\frac{k_{1} k_{2} L_{e}}{11,900} \\
0.75 C_{E} \varepsilon_{f u}^{*} \\
0.004
\end{array}\right\} \times E_{f} \mathbf{I S}
\end{gathered}
$$

As seen in Equations 6.15a and 6.15b, environmental exposure effects are only accounted for in one of the three possible outcomes, which may result in neglecting environmental exposure effects in practice. The environmental reduction factor was not used in the following analyses for predicting the ACI 440 design strength of the CFRP, since the only term including the environmental reduction factor did not control the effective strain.

The FRP shear contribution, $V_{f}(\mathrm{~N})(\mathrm{lb})$, is reduced using an additional factor, $\psi_{f}$, to account for the wrapping scheme and is taken as 0.85 for U-wrapping. The design shear strength is taken by superimposing the concrete, steel, and FRP contributions and applying the shear strength reduction factor of 0.85 as shown in Equation 6.16.

$$
\phi V_{n}=\phi\left(V_{c}+V_{s}+\psi_{f} V_{f}\right)
$$

In the present study, the shear strength reduction factor was not used and just the nominal shear strengths were used. ACI-440.2R limits on the total amount of shear reinforcing (steel and FRP), to prevent web crushing, as shown in Equations 6.17 and 6.18. 


$$
\begin{gathered}
V_{s}+V_{f} \leq 0.66 \sqrt{f_{c}{ }^{\prime}} b_{w} d \mathbf{U S} \\
V_{s}+V_{f} \leq 8 \sqrt{f_{c}{ }^{\prime}} b_{w} d \mathbf{S I}
\end{gathered}
$$

\subsubsection{CFRP Shear Strength Contribution Estimates}

The experimentally predicted CFRP contributions from the specimens were compared with the ACI 440.2R design contributions as shown in Table 6.2. As seen in this table, the experimentally predicted CFRP shear contributions were larger than the ACI-440 design contributions for mosT-Specimens on average by margins of 3.4, 1.7, and 1.1 for the ACI-318, Response-2000 mean, and Response- 2000 at the $95 \%$ confidence interval base strengths, respectively. The approach of combining ACI 318 base strength with ACI-440 CFRP strength tends to show that the CFRP contribution is more substantial than using the Response- 2000 predicted base strengths. This is, however, primarily due to the conservative prediction of the base strength rather than the conservative prediction of the CFRP contribution, based on findings in Section 6.1.3.

When results were compared across all the control and environmental exposure specimens, the analysis results indicated that the CFRP contributions for T-Specimens (T18FT, T18FTCK) subjected to freeze-thaw exposure were significantly less than the other specimens in the group. Interestingly, the same trend was not seen for the T-specimen exposed to combined fatigue and freeze-thaw (T18FFTCK) or the IT-Specimens subjected to freeze-thaw exposure. This was due to improved installation of the CFRP in specimen T18FFTCK, where additional saturant was applied and extended past the terminations onto the deck soffit to better protect against moisture infiltration, as compared to the first group of T-specimen freeze-thaw specimens. As a result, these CFRP strengthened girders were less susceptible to freeze-thaw bond deterioration when the strip termination was well protected against moisture infiltration.

Freeze-thaw was not seen to reduce the CFRP shear contribution for IT-Specimens (IT12FT, IT12FTCK), compared to T-Specimens. For the IT-Specimens, the environmental exposure position (upside down) did not easily allow water to infiltrate into the stem. Also, for the ITSpecimens, due to the installation procedure when working the epoxy matrix into the fibers, additional epoxy flowed and was worked downward toward the free strip edges and onto the deck soffit. This offered additional protection as a barrier to restrict moisture ingress that could damage the bond between the CFRP strips and the concrete surface due to the volumetric change between water and ice during freeze-thaw cycles. The shear contribution for the affected freezethaw T-specimens was observed to be 3 times lower than the average of the other $\mathrm{T}$-specimens using ACI 318 base strengths (when T18FT and T18FTCK are removed from the statistics), even though the observed strength was less than the ACI 440 specified contribution. When considering the more likely base specimen shear capacity using Response-2000, it can be seen that ACI 440 does not provide conservative design strengths for the CFRP. As a result of this finding, designers are cautioned against mixing different analysis and design methods. Design for CFRP should only be done by combining the ACI 318 base strength with ACI 440 procedures. Significant code calibration would be required to use MCFT with ACI 440. 
Considering the moisture exposed IT-Specimens (IT12M, IT12MCK) using the ACI 318 method for base strength prediction, these were also observed to exhibit strength reductions of greater than 2.5 standard deviations below the mean of the other IT-Specimens. This reduction was more apparent in the cracked specimen (IT12MCK), which allowed additional moisture to move into the stem and was more than 3 standard deviations below the mean of the other IT-Specimens. Similar disparities were observed using Response-2000 predicted base strengths.

Table 6.2: CFRP Shear Strength Contributions

\begin{tabular}{|c|c|c|c|c|c|c|c|}
\hline Specimen & $\begin{array}{c}\text { Nominal } \\
\text { Design } \\
\text { CFRP Shear } \\
\text { Contribution } \\
\text { ACI-440 } \\
V_{f} \\
\text { (kN) (kip) } \\
\end{array}$ & $\begin{array}{c}\text { Estimated } \\
\text { CFRP Shear } \\
\text { Contribution } \\
V_{\text {Exp }}-V_{A C I 318} \\
\text { ACI } 318 \\
\text { Base } \\
\text { (kN) (kip) } \\
\end{array}$ & $\begin{array}{c}\text { Estimated } \\
\text { CFRP Shear } \\
\text { Contribution } \\
V_{\text {Exp }}-V_{\text {R2KMean }} \\
\text { Response2K } \\
\text { Mean Base } \\
\text { (kN) (kip) } \\
\end{array}$ & $\begin{array}{c}\text { Estimated } \\
\text { CFRP Shear } \\
\text { Contribution } \\
V_{\text {Exp- }}-V_{R 2 K 95 \%} \\
\text { Response2K } \\
95 \% \text { Base } \\
\text { (kN) (kip) } \\
\end{array}$ & $\begin{array}{c}V_{E x p} \\
V_{A C I 31} \\
\quad 8 \\
/ V_{f}\end{array}$ & $\begin{array}{c}V_{\text {Exp }} \\
V_{R 2 K} \\
/ V_{f} \\
\text { Mean }\end{array}$ & $\begin{array}{l}V_{E x p}- \\
V_{R 2 K} \\
/ V_{f} \\
95 \%\end{array}$ \\
\hline IT12Control & $121(27.1)$ & $478(107.4)$ & $235(52.7)$ & $146(32.7)$ & 3.96 & 1.94 & 1.21 \\
\hline IT12FT & $121(27.1)$ & 449 (101.0) & $212(47.7)$ & $123(27.6)$ & 3.73 & 1.76 & 1.02 \\
\hline IT12FTCK & $117(26.2)$ & $475(106.9)$ & $242(54.4)$ & $156(35.0)$ & 4.08 & 2.08 & 1.34 \\
\hline IT12M & $121(27.1)$ & 424 (95.4) & $189(42.5)$ & $99(22.3)$ & 3.52 & 1.57 & 0.82 \\
\hline IT12MCK & $121(27.1)$ & $379(85.2)$ & $134(30.0)$ & $45(10.2)$ & 3.14 & 1.11 & 0.38 \\
\hline ITT12FTCK & $100(22.5)$ & $492(110.6)$ & $288(64.8)$ & $208(46.7)$ & 4.92 & 2.88 & 2.08 \\
\hline T18Control & $129(29.0)$ & $431(96.8)$ & $259(58.2)$ & $190(42.6)$ & 3.34 & 2.01 & 1.47 \\
\hline T18FT & $130(29.3)$ & $262(58.8)$ & $84(18.8)$ & $12(2.7)$ & 2.01 & 0.64 & 0.09 \\
\hline T18FTCK & $130(29.3)$ & $282(63.4)$ & $118(26.5)$ & $49(10.9)$ & 2.16 & 0.90 & 0.37 \\
\hline T18FFTCK & $125(28.0)$ & $471(105.9)$ & $293(65.8)$ & $223(50.1)$ & 3.78 & 2.35 & 1.79 \\
\hline Average & & & & & 3.46 & 1.72 & 1.06 \\
\hline
\end{tabular}

\subsection{CFRP SHEAR STRENGTH DEMANDS ESTIMATED WITH SHEAR- MOMENT INTERACTION}

To include shear moment interaction effects, additional analyses were made to estimate the actual demands on the CFRP based on the given specimen cross-section and M/V ratio for a range of different transverse reinforcing amounts. This methodology was used to estimate the likely CFRP effective stress and bond stress. Here, shear strength is expressed as average shear stress at ultimate as shown in Equation 6.19.

$$
v_{\text {average }}=\frac{V}{b d_{v}}
$$

where $V$ is the shear strength (N) (lbs), $b$ is beam width (mm) (in.), and $d_{v}(\mathrm{~mm})$ (in.) is the distance between tension and compression resultants in a section. These values are shown relative to an equivalent stirrup pressure, given in Equation 6.20. 


$$
v_{\text {stirrup }}=\frac{A_{v} f_{y v}}{b s}
$$

where, $A_{v}\left(\mathrm{~mm}^{2}\right)\left(\mathrm{in}^{2}\right)$ is the area of the web reinforcement, $f_{y v}(\mathrm{MPa})(\mathrm{psi})$ is the yield strength of the web reinforcement, and $s(\mathrm{~mm})$ (in.) is the spacing of the web reinforcement.

Base shear capacities of each specimen including 5\% and 95\% one-sided confidence limits were determined with Response-2000 for variable stirrup spacings ranging between $51 \mathrm{~mm}(2 \mathrm{in}$.) and $1626 \mathrm{~mm}$ (64 in.), to aid in later stages of analysis. The results are expressed in terms of average shear stress and equivalent stirrup pressure, and shown in Figure 6.3 for each specimen. Top (blue), middle and bottom (blue) average shear stress vs. equivalent stirrup pressure curves correspond to $95 \%$ one-sided confidence limit, mean, and $5 \%$ one-sided confidence limit, respectively. Equivalent stirrup pressures corresponding to the key stirrup spacings such as (6 in.), (12 in.), and (18 in.), as well as to ACI 318-08 minimum and maximum stirrup spacings calculated from Equations 6.21 and 6.22 are identified in the plots.

$$
\begin{gathered}
v_{\text {stirrup }(A C I 318 M I N)}=\max \left\{\begin{array}{c}
50 \\
0.75 \sqrt{f_{c}^{\prime}}
\end{array}\right\} \quad(\mathrm{psi}) \\
v_{\text {stirrup }(A C I 318 M A X)}=8 \sqrt{f_{c}^{\prime}} \quad(\mathrm{psi})
\end{gathered}
$$

In addition, the ACI-318 approach is shown as a straight line in these figures, whereby the addition of stirrups linearly increases the shear strength of the section.

As clearly seen in Figure 6.3, the section shear strength does not increase linearly as additional transverse reinforcing is added. Above a certain threshold (roughly twice the minimum amount of stirrups for the given specimens), it requires a significant increase in transverse reinforcing to produce a small increment in shear capacity. Thus the demands in the CFRP can go up substantially; even as the overall member strength increases only marginally. This is due to softening of the section due to yielding of the flexural steel. These observations are confirmed based on the large calibration data of 44 full-size girders tested in an Oregon DOT study (Higgins et al. 2004). 

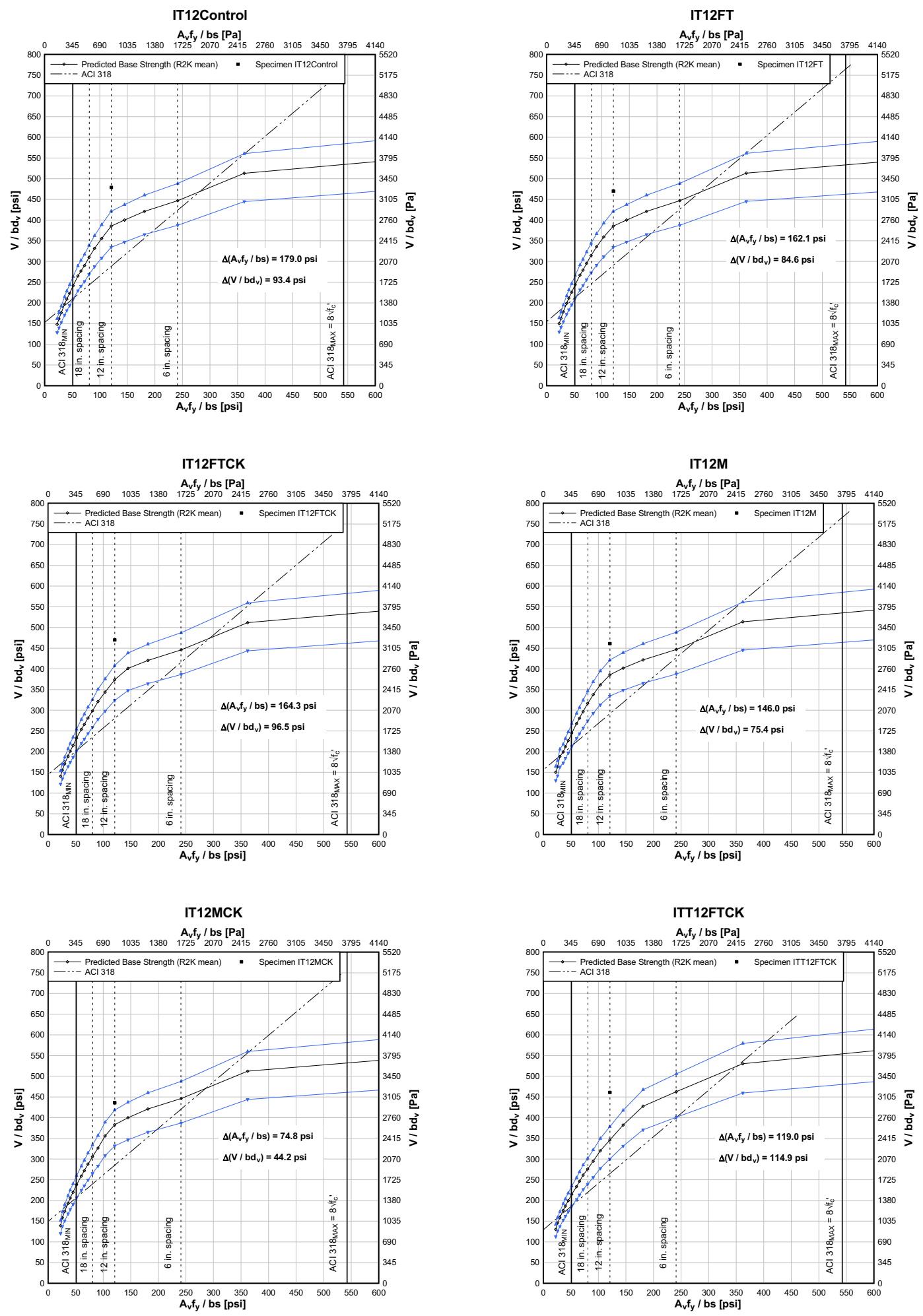

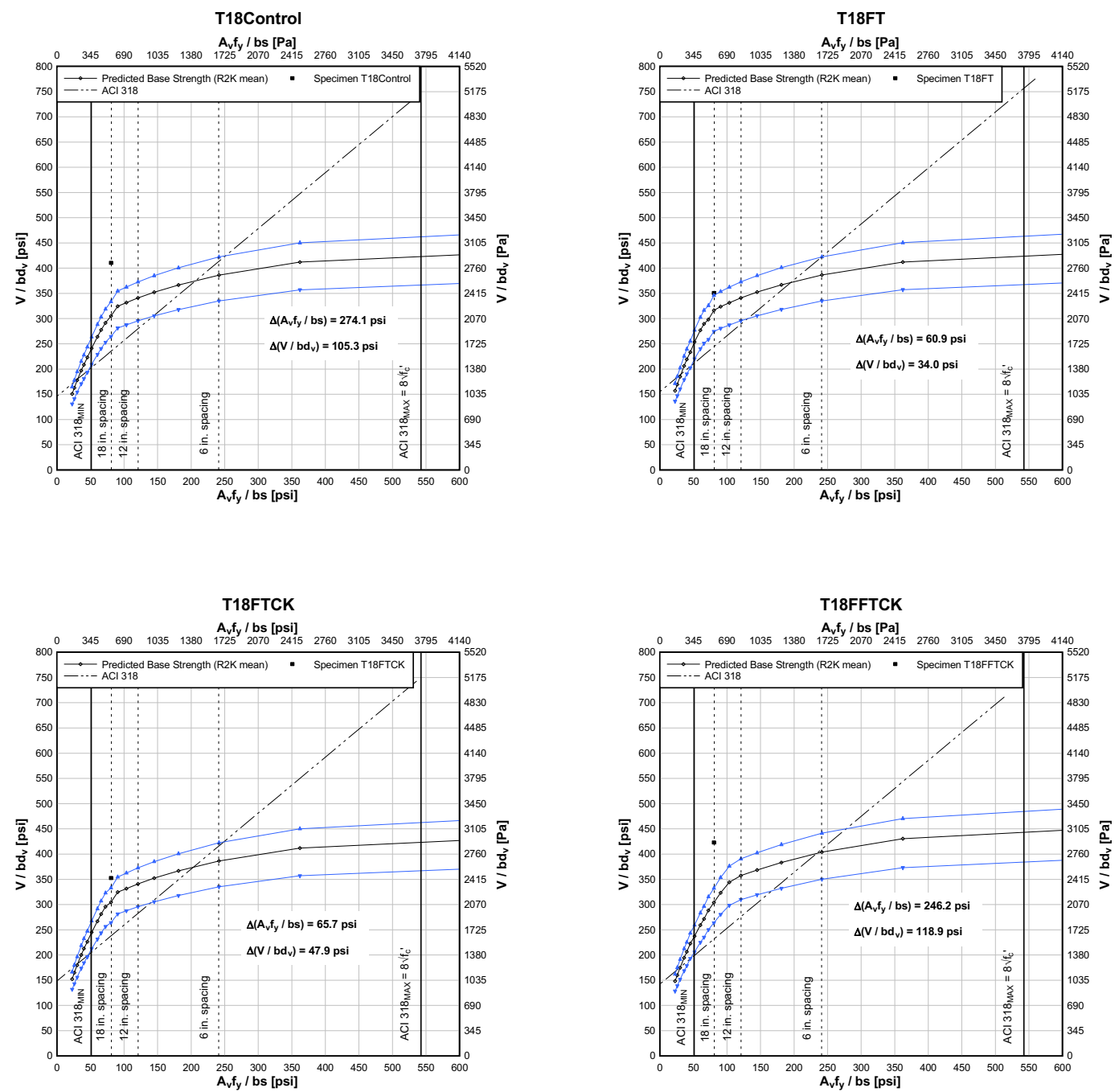

Figure 6.3: Base capacities of specimens from Response-2000 for variable stirrup spacings.

\subsubsection{CFRP Effective Stress}

The design effective stress for CFRP using ACI-440 $\left(f_{f e}\right)$ can be expressed as shown in Equation 6.23 .

$$
f_{f e}=\frac{V_{f} s_{f}}{A_{f v} d_{f}}
$$

where $\mathrm{V}_{\mathrm{f}}$ is calculated and the variables are as shown in Section 6.2.1. The experimentally estimated effective stress in the CFRP can also be estimated using the ACI 318 predicted base strength as shown in Equation 6.24. 


$$
f_{C F R P_{A C I}}=\frac{\left(V_{E X P}-V_{A C I 318}\right) s_{f}}{A_{f v} d_{f}}
$$

Similarly, the experimentally estimated effective stress in the CFRP can be determined from the mean Response-2000 predicted base strength as shown in Equation 6.25.

$$
f_{C F R P_{R 2 \text { Kman }}}=\frac{\left(V_{E X P}-V_{R 2 K \text { mean }}\right) s_{f}}{A_{f v} d_{f}}
$$

These approaches again assume superposition of the concrete, steel stirrup, and CFRP stirrup contributions, although the use of Response- 2000 for the base capacity includes a small portion of the moment-shear interaction from the base specimen. However, as shown in Figure 6.3, the demands on the transverse reinforcing go up nonlinearly once the flexural steel begins to yield and thus while the overall section capacity doesn't increase significantly, the CFRP effective stresses and resulting bond stresses could be larger than the overall strength response would suggest. To capture this effect, the experimentally predicted effective stress in the CFRP using Response-2000 results for the given cross-section and $\mathrm{M} / \mathrm{V}$ ratio $\left(f_{\text {CFRP-MVInt }}\right)$ can be determined from the shear strength - transverse reinforcing quantity interaction (seen in Figure 6.3) as shown in Equation 6.26.

$$
f_{C F R P-M V}=\left[\Delta\left(\frac{A_{v} f_{y v}}{b s}\right)\right] \frac{b s_{f}}{A_{f v}}
$$

where $\left[\Delta\left(\frac{A_{v} f_{y v}}{b s}\right)\right]$ is the horizontal distance between the experimentally measured average shear stress at ultimate plotted at the base member stirrup quantity and the intersection of the experimentally measured average shear stress value on the shear stress-transverse reinforcing quantity curve (see Figure 6.3). In calculating $f_{C F R P-M V}$, CFRP strips were treated as extra steel web reinforcement, which are required to achieve the experimentally observed shear capacity. Similar to previous comparisons, the calculations were performed for both mean and $95 \%$ confidence intervals. Results are summarized in Table 6.3a and comparisons with respect to ACI-440 design values are shown in Table 6.3b. 
Table 6.3a: CFRP effective stress

\begin{tabular}{|c|c|c|c|c|c|c|}
\hline Specimen & $\begin{array}{c}f_{f e} \text { ACI-440 } \\
\text { Design } \\
\text { MPa (ksi) } \\
\end{array}$ & $\begin{array}{c}f_{C F R P-A C I} \\
\text { MPa (ksi) }\end{array}$ & $\begin{array}{c}f_{C F R P-R 2 K} \\
m e a n \\
\operatorname{MPa}(\mathrm{ksi})\end{array}$ & $\begin{array}{c}f_{C F R P-R 2 K} \\
95 \% \\
\operatorname{MPa~(ksi)~}\end{array}$ & $\begin{array}{c}f_{C F R P-M V} \\
m e a n \\
\text { MPa (ksi) }\end{array}$ & $\begin{array}{c}f_{C F R P-M V} \\
95 \% \\
\operatorname{MPa}(\mathrm{ksi})\end{array}$ \\
\hline IT12Control & $\begin{array}{c}822 \\
(119.1)\end{array}$ & $\begin{array}{c}3256 \\
(472.1)\end{array}$ & $\begin{array}{c}1588 \\
(230.3)\end{array}$ & $\begin{array}{c}831 \\
(120.4)\end{array}$ & $\begin{array}{c}3190 \\
(462.6)\end{array}$ & $\begin{array}{c}1783 \\
(258.5)\end{array}$ \\
\hline IT12FT & $\begin{array}{c}822 \\
(119.1)\end{array}$ & $\begin{array}{c}3062 \\
(444.0)\end{array}$ & $\begin{array}{c}1440 \\
(208.8)\end{array}$ & $\begin{array}{c}682 \\
(98.9)\end{array}$ & $\begin{array}{c}2889 \\
(418.9)\end{array}$ & $\begin{array}{c}1426 \\
(206.8)\end{array}$ \\
\hline IT12FTCK & $\begin{array}{c}794 \\
(115.2)\end{array}$ & $\begin{array}{c}3241 \\
(469.9)\end{array}$ & $\begin{array}{c}1646 \\
(238.7)\end{array}$ & $\begin{array}{c}909 \\
(131.9)\end{array}$ & $\begin{array}{c}2928 \\
(424.6)\end{array}$ & $\begin{array}{c}873 \\
(126.6)\end{array}$ \\
\hline IT12M & $\begin{array}{c}822 \\
(119.1)\end{array}$ & $\begin{array}{c}2892 \\
(419.3)\end{array}$ & $\begin{array}{c}1285 \\
(186.4)\end{array}$ & $\begin{array}{c}527 \\
(76.5)\end{array}$ & $\begin{array}{c}2308 \\
(334.7)\end{array}$ & $\begin{array}{c}802 \\
(116.3)\end{array}$ \\
\hline IT12MCK & $\begin{array}{c}822 \\
(119.1)\end{array}$ & $\begin{array}{c}2583 \\
(374.5)\end{array}$ & $\begin{array}{c}909 \\
(131.9)\end{array}$ & $\begin{array}{c}155 \\
(22.4)\end{array}$ & $\begin{array}{c}1333 \\
(193.3)\end{array}$ & $\begin{array}{c}196 \\
(28.4)\end{array}$ \\
\hline ITT12FTCK & $\begin{array}{c}682 \\
(98.9)\end{array}$ & $\begin{array}{c}3353 \\
(486.2)\end{array}$ & $\begin{array}{c}1961 \\
(284.4)\end{array}$ & $\begin{array}{c}1279 \\
(185.5)\end{array}$ & $\begin{array}{c}1827 \\
(264.9)\end{array}$ & $\begin{array}{c}873 \\
(126.6)\end{array}$ \\
\hline T18Control & $\begin{array}{c}813 \\
(117.9)\end{array}$ & $\begin{array}{c}2714 \\
(393.6)\end{array}$ & $\begin{array}{c}1632 \\
(236.6)\end{array}$ & $\begin{array}{c}1088 \\
(157.7)\end{array}$ & $\begin{array}{c}4071 \\
(590.3)\end{array}$ & $\begin{array}{c}1916 \\
(277.8)\end{array}$ \\
\hline T18FT & $\begin{array}{c}822 \\
(119.1)\end{array}$ & $\begin{array}{c}1649 \\
(239.1)\end{array}$ & $\begin{array}{c}533 \\
(77.2)\end{array}$ & $\begin{array}{c}0 \\
(0.0)\end{array}$ & $\begin{array}{c}905 \\
(131.2)\end{array}$ & $\begin{array}{c}90 \\
(13.0)\end{array}$ \\
\hline T18FTCK & $\begin{array}{c}822 \\
(119.1)\end{array}$ & $\begin{array}{c}1778 \\
(257.8)\end{array}$ & $\begin{array}{c}718 \\
(104.1)\end{array}$ & $\begin{array}{c}168 \\
(24.4)\end{array}$ & $\begin{array}{c}976 \\
(141.5)\end{array}$ & $\begin{array}{c}137 \\
(19.8)\end{array}$ \\
\hline T18FFTCK & $\begin{array}{c}785 \\
(113.8)\end{array}$ & $\begin{array}{c}2969 \\
(430.6)\end{array}$ & $\begin{array}{c}1845 \\
(267.5)\end{array}$ & $\begin{array}{c}1304 \\
(189.1)\end{array}$ & $\begin{array}{c}2739 \\
(397.2)\end{array}$ & $\begin{array}{c}1174 \\
(170.2)\end{array}$ \\
\hline Average & $\begin{array}{c}800 \\
(116.1)\end{array}$ & $\begin{array}{c}2750 \\
(398.7)\end{array}$ & $\begin{array}{c}1356 \\
(196.6)\end{array}$ & $\begin{array}{c}694 \\
(100.7)\end{array}$ & $\begin{array}{c}2317 \\
(335.9)\end{array}$ & $\begin{array}{c}927 \\
(134.4)\end{array}$ \\
\hline $\operatorname{COV}(\%)$ & 5.4 & 21.7 & 35.8 & 68.1 & 44.9 & 71.0 \\
\hline
\end{tabular}


Table 6.3b: CFRP effective stress

\begin{tabular}{c|c|c|c|c|c}
\hline Specimen & $\begin{array}{c}f_{\text {CFRP-ACI }} / \\
f_{\text {fe ACI-440 Design }}\end{array}$ & $\begin{array}{c}f_{\text {CFRP-R2K mean }} / \\
f_{\text {fe ACI-440 Design }}\end{array}$ & $\begin{array}{c}f_{\text {CFRP-R2K 95\% }} / \\
f_{\text {fe ACI-440 Design }}\end{array}$ & $\begin{array}{c}f_{\text {CFRP-MV mean }} / \\
f_{\text {fe ACI-440 Design }}\end{array}$ & $\begin{array}{c}f_{C F R P-M V 95 \%} / \\
f_{\text {fe ACI-440 Design }}\end{array}$ \\
\hline IT12Control & 3.96 & 1.93 & 1.01 & 3.88 & 2.17 \\
\hline IT12FT & 3.73 & 1.75 & $\mathbf{0 . 8 3}$ & 3.52 & 1.74 \\
\hline IT12FTCK & 4.08 & 2.07 & 1.15 & 3.69 & 1.10 \\
\hline IT12M & 3.52 & 1.56 & $\mathbf{0 . 6 4}$ & 2.81 & $\mathbf{0 . 9 8}$ \\
\hline IT12MCK & 3.14 & 1.11 & $\mathbf{0 . 1 9}$ & 1.62 & $\mathbf{0 . 2 4}$ \\
\hline ITT12FTCK & 4.92 & 2.88 & 1.88 & 2.68 & 1.28 \\
\hline T18Control & 3.34 & 2.01 & 1.34 & 5.01 & 2.36 \\
\hline T18FT & 2.01 & $\mathbf{0 . 6 5}$ & $\mathbf{0 . 0 0}$ & 1.10 & $\mathbf{0 . 1 1}$ \\
\hline T18FTCK & 2.16 & $\mathbf{0 . 8 7}$ & $\mathbf{0 . 2 0}$ & 1.19 & $\mathbf{0 . 1 7}$ \\
\hline T18FFTCK & 3.78 & 2.35 & 1.66 & 3.49 & 1.49 \\
\hline Average & 3.5 & 1.7 & 0.9 & 2.9 & 1.2 \\
\hline COV (\%) & 25.2 & 40.0 & 71.7 & 44.0 & 69.6 \\
\hline
\end{tabular}

The ACI 440.2R design values for effective CFRP stress were on average 3.5 times less than that observed when using the ACI 318 base strength for all specimens. When using the Response2000 predicted base strength, the design effective CFRP stresses were on average lower by about a factor of 2 and of particular interest, for specimens T18FT and T18FTCK the estimated stresses were below the design values. When considering the $95 \%$ confidence interval, mosTSpecimens were at or above the design values; however, again the same freeze-thaw Tspecimens and the IT moisture specimens indicated reduced CFRP stress magnitudes. When considering the moment-shear interaction demands required of the transverse reinforcing to produce the specimen strength, the effective stresses were higher than the design values by around 3.5. However, here again some freeze-thaw T-specimens (T18FT and T18FTCK) and IT12MCK show reduced effective CFRP stress as compared with the other specimens in the sample. The shear-moment interaction suggests that demands on the CFRP can be much higher for sections that fail in shear after the flexural steel begins to yield, even when the observed section strength is not markedly higher.

\subsubsection{CFRP Average Bond Stress}

Bond stresses were estimated for the different effective CFRP stress values determined in the previous section. It was assumed that bond stress increased linearly to the CFRP effective stress over the active bond length, $L_{e}(\mathrm{~mm})$ (in.), so that the average bond stress, $\tau$ (Mpa) (ksi), was calculated as shown in Equation 6.27.

$$
\tau=\frac{f_{C F R P} t_{f}}{L_{e}}
$$


where $f_{C F R P}$ is the effective CFRP stress computed by the different methods described in Section 6.3.1, $\mathrm{t}_{\mathrm{f}}$ is the thickness of the CFRP material, and $\mathrm{L}_{\mathrm{e}}$ is the active bond length computed per ACI-440 recommendations described in Section 6.2.1. Assuming no change in active bond length for the different exposure conditions, the average bond stress determined by ACI-440 and the experimental bond stress were calculated and are shown in Table 6.4.

Table 6.4: CFRP bond stresses

\begin{tabular}{|c|c|c|c|c|c|c|}
\hline Specimen & $\begin{array}{c}\tau_{f e ~ A C I-440} \\
\text { Design } \\
\text { MPa (psi) }\end{array}$ & $\begin{array}{c}\tau_{C F R P-A C I} \\
\operatorname{MPa}(p s i)\end{array}$ & $\begin{array}{c}\tau_{C F R P-R 2 K} \\
\text { mean } \\
\operatorname{MPa}(p s i)\end{array}$ & $\begin{array}{c}\tau_{C F R P-R 2 K} \\
95 \% \\
\text { MPa (psi) }\end{array}$ & $\begin{array}{c}\tau_{C F R P-M V} \\
\text { mean } \\
\text { MPa (psi) }\end{array}$ & $\begin{array}{c}\tau_{C F R P-M V} \\
95 \% \\
\operatorname{MPa}(\mathrm{psi})\end{array}$ \\
\hline IT12Control & $\begin{array}{c}5.7 \\
(396) \\
\end{array}$ & $\begin{array}{c}22.5 \\
(1571) \\
\end{array}$ & $\begin{array}{c}11.0 \\
(766) \\
\end{array}$ & $\begin{array}{c}5.7 \\
(401) \\
\end{array}$ & $\begin{array}{c}22.0 \\
(1539) \\
\end{array}$ & $\begin{array}{c}12.3 \\
(860) \\
\end{array}$ \\
\hline IT12FT & $\begin{array}{c}5.7 \\
(396)\end{array}$ & $\begin{array}{c}21.1 \\
(1477)\end{array}$ & $\begin{array}{c}9.9 \\
(695)\end{array}$ & $\begin{array}{c}4.7 \\
(329)\end{array}$ & $\begin{array}{c}19.9 \\
(1394)\end{array}$ & $\begin{array}{c}9.8 \\
(688)\end{array}$ \\
\hline IT12FTCK & $\begin{array}{c}5.5 \\
(383) \\
\end{array}$ & $\begin{array}{c}22.4 \\
(1563) \\
\end{array}$ & $\begin{array}{c}11.4 \\
(794) \\
\end{array}$ & $\begin{array}{c}6.3 \\
(439) \\
\end{array}$ & $\begin{array}{c}20.2 \\
(1413) \\
\end{array}$ & $\begin{array}{c}6.0 \\
(421) \\
\end{array}$ \\
\hline IT12M & $\begin{array}{c}5.7 \\
(396)\end{array}$ & $\begin{array}{c}19.9 \\
(1395)\end{array}$ & $\begin{array}{c}8.9 \\
(620)\end{array}$ & $\begin{array}{c}3.6 \\
(254)\end{array}$ & $\begin{array}{c}15.9 \\
(1113)\end{array}$ & $\begin{array}{c}5.5 \\
(387)\end{array}$ \\
\hline IT12MCK & $\begin{array}{c}5.7 \\
(396)\end{array}$ & $\begin{array}{c}17.8 \\
(1246)\end{array}$ & $\begin{array}{c}6.3 \\
(439)\end{array}$ & $\begin{array}{c}1.1 \\
(75)\end{array}$ & $\begin{array}{c}9.2 \\
(643)\end{array}$ & $\begin{array}{c}1.4 \\
(94)\end{array}$ \\
\hline ITT12FTCK & $\begin{array}{c}4.7 \\
(329) \\
\end{array}$ & $\begin{array}{c}23.1 \\
(1617) \\
\end{array}$ & $\begin{array}{c}13.5 \\
(946) \\
\end{array}$ & $\begin{array}{c}8.8 \\
(617) \\
\end{array}$ & $\begin{array}{c}12.6 \\
(881) \\
\end{array}$ & $\begin{array}{c}6.0 \\
(421) \\
\end{array}$ \\
\hline T18Control & $\begin{array}{c}5.6 \\
(392) \\
\end{array}$ & $\begin{array}{c}18.7 \\
(1309) \\
\end{array}$ & $\begin{array}{c}11.3 \\
(787) \\
\end{array}$ & $\begin{array}{c}7.5 \\
(525) \\
\end{array}$ & $\begin{array}{c}28.1 \\
(1964) \\
\end{array}$ & $\begin{array}{r}13.2 \\
(924) \\
\end{array}$ \\
\hline T18FT & $\begin{array}{c}5.7 \\
(396)\end{array}$ & $\begin{array}{c}11.4 \\
(795)\end{array}$ & $\begin{array}{c}3.7 \\
(257)\end{array}$ & $\begin{array}{l}0.0 \\
(0)\end{array}$ & $\begin{array}{c}6.2 \\
(436)\end{array}$ & $\begin{array}{l}0.62 \\
(43)\end{array}$ \\
\hline T18FTCK & $\begin{array}{c}5.7 \\
(396) \\
\end{array}$ & $\begin{array}{c}12.3 \\
(858) \\
\end{array}$ & $\begin{array}{c}5.0 \\
(346) \\
\end{array}$ & $\begin{array}{c}1.2 \\
(81) \\
\end{array}$ & $\begin{array}{c}6.7 \\
(471) \\
\end{array}$ & $\begin{array}{l}0.94 \\
(66) \\
\end{array}$ \\
\hline T18FFTCK & $\begin{array}{c}5.4 \\
(379) \\
\end{array}$ & $\begin{array}{c}20.5 \\
(1432) \\
\end{array}$ & $\begin{array}{c}12.7 \\
(890) \\
\end{array}$ & $\begin{array}{c}9.0 \\
(629) \\
\end{array}$ & $\begin{array}{c}18.9 \\
(1321) \\
\end{array}$ & $\begin{array}{c}8.1 \\
(566) \\
\end{array}$ \\
\hline Average & $\begin{array}{c}5.5 \\
(386) \\
\end{array}$ & $\begin{array}{c}19.0 \\
(1326) \\
\end{array}$ & $\begin{array}{c}9.4 \\
(654) \\
\end{array}$ & $\begin{array}{c}4.8 \\
(335) \\
\end{array}$ & $\begin{array}{c}16.0 \\
(1118) \\
\end{array}$ & $\begin{array}{c}6.4 \\
(447) \\
\end{array}$ \\
\hline COV $(\%)$ & 5.4 & 21.7 & 35.8 & 68.1 & 44.9 & 71.0 \\
\hline
\end{tabular}

As expected, bond stress comparisons were similar to those from effective stress comparisons and the ratios of experimentally predicted to design values were the same as those in Table $6.3 \mathrm{~b}$. The results indicated the specimens T18FT and T18FTCK have significantly reduced estimated bond strengths compared to the control T-specimen and others in the sample. In addition, Specimen IT12MCK shows bond strength substantially below others in the group when using the more advanced analysis techniques. Statistically, these three specimens were more than two standard deviations below the average of the data when they are not included in the statistics. While the ACI-440 specification design values for bond stress were in general conservative for most samples (although not necessarily for specimens T18FT and T18FTCK when Response2000 base strengths were used), it did not provide uniform levels of safety as reflected in the observed differences between some exposed and unexposed specimens. Clearly there is a need for some additional conservatism for long-term applications of surface bonded CFRP strips for shear strengthening in climates that experience many freeze-thaw cycles with moisture present or long term moisture exposures if the concrete recracks after application of the CFRP. Using the 
mean moment-shear interaction results, to bring the bond stresses for the $\mathrm{T}$ freeze-thaw specimens into line with the sample average (after removing T18FT, T18FTCK, and IT12MCK) would require a bond stress modification factor of 0.33 and for long-term moisture exposure after cracking, a bond stress modification factor of 0.47. If the ACI 318 results are used, to bring the bond stresses for the $\mathrm{T}$ freeze-thaw specimens into line with the sample average (after removing T18FT, T18FTCK, and IT12MCK) would require a bond stress modification factor of 0.56 and for long-term moisture exposure after cracking, a bond stress modification factor of 0.85 would be required. These average bond stress values were calculated assuming no change in the CFRP active bond length. The active bond length could change based on environmental exposure, but no data from the current tests are available to assess this effect.

While the current design provisions provided conservative strength results for all the specimens, to better predict the CFRP bond strength demands that can occur due to shear-moment interaction, a further check of the design should be made beyond those required by ACI-440. The ACI-440 design procedure should proceed normally to proportion and select the CFRP for the desired shear capacity of the section. Base strengths should be estimated with ACI 318 . The CFRP shear contribution should be computed and the total shear stress $\left(V_{c}+V_{s}+V_{f}\right) / b d_{v}$ should be calculated. The CFRP bond demands for this expected capacity should be determined from the shear-moment interaction of the section (produce charts like those shown in Figure 6.3 for the given section and load effects). The horizontal difference between the stirrup quantity of the base specimen and the point where the shear stress $\left(\left(V_{c}+V_{s}+V_{f}\right) / b d_{v}\right)$ intersects the interaction curve should be used to estimate the CFRP effective stress and subsequently transformed into the bond strength demand as shown in Equation 6.27. These should be compared with design capacity values to ensure sufficient strength. The code specified environmental factors do not appear to be sufficient to provide uniform levels of safety and based on this research some additional conservatism is warranted. To include the effects of the environmental exposures seen for specimens in this study, the environmental exposure factor should be applied at the final step to limit the effective CFRP stress/strain, even if the specified maximum strain is achievable with the proposed design (established currently as strain of 0.004). This would limit CFRP strains to a maximum of $0.85^{*} 0.004=0.0034$ for exposed conditions. For locations with very large numbers of wet freeze-thaw cycles and extended exposure to continuous moisture, the environmental reduction factors should be reduced even further. These may require designers to provide additional plies of CFRP on top of each other to limit bond stresses, which may not contribute to additional member shear strength. Additionally or alternatively, to minimize the environmental effects, installation techniques should apply additional epoxy materials and coatings to protect the strip edges from moisture ingress, including application beyond the CFRP strip edge to the deck soffit for a distance of at least 2 in. In addition, where existing deck or stem cracking allows water to get into the girder stems, this source of free moisture should be mitigated as part of the overall rehabilitation strategy. Post-installation inspections should identify subsequent concrete stem cracking and routine maintenance should include sealing any observed cracks to prevent moisture ingress. 


\subsection{CONCLUSIONS}

Based upon the results of experimental testing and analysis, the following conclusions are presented:

- CFRP application increased the shear capacity of all specimens based on comparison with Response-2000 predictions of the unstrengthened base specimens and previous testing of similar unstrengthened specimens.

- Overall member stiffness (applied shear versus midspan displacement) was not affected by the application of CFRP shear reinforcing however, local shear panel stiffnesses (applied shear versus average vertical strain), increased due to the application of CFRP shear reinforcing. This increased stiffness indicated reduced diagonal crack widths, which were observed during testing.

- CFRP-strengthened T-Specimens subjected to freeze-thaw exposure demonstrated a change in shear panel stiffness (applied shear versus average vertical strain) from preexposure response to post-exposure response. This decrease in stiffness was attributed to increases in debonded areas of the CFRP strips incurred during freeze-thaw exposure. CFRP strengthened T-Specimens subjected to the combined action of freeze-thaw and fatigue had more pronounced effect of debonding.

- CFRP-strengthened T-Specimens subjected to freeze-thaw exposure exhibited less shear capacity than the unexposed CFRP strengthened T specimen. But if the CFRP was well protected against moisture infiltration at the strip termination, the beam was less susceptible to freeze-thaw strength deterioration.

- Freeze-thaw exposure had little effect on CFRP-strengthened IT-Specimens because moisture was not able to infiltrate the free ends of the strips due to the downward orientation of the strip terminations (even with larger numbers of exposure cycles). Installers should apply extra saturant past the edge of the CFRP material and insure a good seal to minimize moisture infiltration along the edge while in service.

- The combined actions of fatigue and freeze-thaw did not exhibit strength reductions when the CFRP edges were well protected with saturant. The stress levels induced by fatigue loading were sufficient to increase the debonded CFRP strip regions, showing a gradual loss of stiffness. However, the CFRP stresses were not sufficient to disturb the CFRP bonding along the top near the terminations and thus did not reduce overall member strength.

- Long term moisture exposure also reduced the CFRP shear contribution in ITSpecimens, with more significant effects from the specimen that was recracked after 
installation of the CFRP. The effects were less than those observed for the T-Specimens subjected to freezing and thawing.

- Even though epoxy injection does not increase the capacity of the beam, it plays an important role of keeping moisture from freely moving through the cracks in the beam. After failure, moisture was clearly seen to have been arrested at the injected cracks for the moisture specimens.

- Use of ACI 318 with ACI 440 provided conservative predicted shear strengths after environmental exposure but not uniform levels of safety across the exposure conditions. The observed conservatism of the ACI approach may be misleading as it is due in large extent to the conservatism in the prediction of the unstrengthened base specimen. Use of Response-2000 predicted average base capacities with ACI 440 CFRP shear contributions led to unconservative shear strength predictions for the T-Specimens subjected to freeze-thaw and show that likely shear contribution from the CFRP is less than predicted by ACI 440 .

- The code-specified environmental factors do not appear to be sufficient to provide uniform levels of safety, and based on this research some additional conservatism is warranted. To include the effects of the environmental exposures seen for specimens in this study, the environmental exposure factor should be applied at the final step to limit the effective CFRP stress/strain, even if the specified maximum strain is achievable with the proposed design. For locations with very large numbers of wet freeze-thaw cycles and extended exposure to continuous moisture, the environmental reduction factors should be reduced even further.

- While the current ACI design provisions provided conservative total shear strength results for all the specimens, to better predict the CFRP bond strength demands that can occur due to shear-moment interaction, a further check of the design should be made beyond those required by ACI 440. This may require designers to provide additional plies of CFRP to limit bond stresses, which may not contribute to additional member shear strength. 


\subsection{RECOMMENDATIONS}

\subsection{CFRP SHEAR STRENGTHENING}

The conclusions presented in Section 7.0 lead to the following recommendations regarding design, installation, and monitoring for environmental durability of CFRP shear strengthened RC bridge girders:

\subsubsection{Design}

Equations used in ACI 440 CFRP shear contribution calculations are calibrated to base strengths calculated from ACI 318. Thus, designs for shear strengthening should use ACI 440 calculated CFRP shear contribution which should only be superimposed with unstrengthened base capacities calculated with ACI 318. Superimposition of ACI 440 CFRP contribution with refined unstrengthened base capacity predictions (such as AASHTO-MCFT or Response-2000) may lead to unconservative strength predictions.

ACI 440 did not reflect the experimentally observed strength reductions for environmentally exposed specimens, even as it conservatively predicted strengths for all specimens. To provide uniform levels of reliability for the exposures considered with those of control specimens, CFRP bond strength should be reduced using a factor of 0.25 for members exposed to freeze-thaw conditions with moisture when no special detailing is used to protect strip terminations and reduced using a factor of 0.50 for members exposed to continuously moist environments (defined here as 6 months).

CFRP bond strength demands should be checked using Response-2000 as in Figure 6.3 with Equations 6.26 and 6.27 for each critical cross-section to better assess realistic bond stress demands for the given increment in shear strength desired from the CFRP. These demands should be compared with design strengths in ACI 440 (modified with the above reduction factors) to determine if the bond strength is adequate.

\subsubsection{Installation}

Long term durability of RC girders strengthened with CFRP strips for shear relies on prevention of moisture from infiltrating the bonded region between CFRP and concrete. Additional care should be used during CFRP installation to ensure the terminating strip edges are very well saturated with the epoxy matrix and the saturant should be rolled past the strip edges onto the concrete deck soffit for a distance of about 2 in. 
Where moisture is able to work into the girder stems from deck cracks that link to web diagonal crack networks, some means must be employed to mitigate this condition and prevent moisture from getting behind the CFRP.

Epoxy injection should be applied to all injectable cracks prior to CFRP application to restrict moisture movement through the girders.

\subsubsection{Inspection and Monitoring}

CFRP strengthened bridges in regions of high freeze-thaw and/or long term moisture exposures should be routinely monitored for degradation in bond properties of the CFRP as this may indicate decreased capacity. It may be beneficial to install pull-off patch tests to enable assessment of bond strengths over time.

Exterior girders would tend to be more susceptible to moisture exposure and where concrete cracking or CFRP debonding are identified during routine inspections of in-service CFRP applications, these should be remediated to prevent moisture infiltration.

\subsection{FUTURE TESTING}

Additional testing and examination of the durability of RCDG bridge member strengthened for shear with surface-bonded CFRP under environmental exposure are warranted based on the limited number of specimens available in the present study. The following recommendations are made for future testing:

- Specimens with even lower transverse steel shear contributions should be investigated to enable shear failure with increased CFRP shear contribution. Specimens should still conform to minimum transverse steel requirements.

- Specimens should be precracked prior to application of CFRP, as this is representative of field applications.

- Specimens should be reloaded after strengthening, to produce recracking prior to environmental exposure.

- Specimens should be strengthened and be subjected to freeze-thaw exposure in the orientation that reflects field conditions.

- Additional data are needed for combined environmental exposure and fatigue loading. 


\subsection{REFERENCES}

American Concrete Institute. 440.2R-08: Design and construction of externally bonded FRP systems. ACI Manual of Concrete Practice. Farmington Hills, Michigan.2008,

American Concrete Institute. 318-08: Building code requirements for structural concrete and commentary. ACI Manual of Concrete Practice. Farmington Hills, Michigan.2008.

ASTM A 370-97a, American Society of Testing and Materials. Standard Test Methods and Definitions for Mechanical Testing of Steel Products. ASTM, West Conshohocken, PA, 1997.

ASTM C 666-97, American Society of Testing and Materials. Standard Test Method for Resistance of Concrete to Rapid Freezing and Thawing. ASTM, West Conshohocken, PA, 1997.

ASTM D 3039/D 3039M-00, American Society of Testing and Materials. Standard Test Method for Tensile Properties of Polymer Matrix Composite Materials. ASTM, West Conshohocken, PA, 2001.

ASTM D 4541-02, American Society of Testing and Materials. Standard Test Method for PullOff Strength of Coatings Using Portable Adhesion Testers. ASTM, West Conshohocken, PA, 2002.

ASTM E 8-00, American Society of Testing and Materials. Standard Test Methods for Tension Testing of Metallic Materials. ASTM, West Conshohocken, PA, 2000.

Bentz, D. P. A computer model to predict the surface temperature and time-of-wetness of concrete pavements and bridge decks, NISTIR 6551. U.S. Department of Commerce. 2000.

Bentz, E.C., 2001, "Membrane-2000, Response-2000, Triax-2000, Shell-2000 User Manual," University of Toronto, <http://www.ecf.utoronto.ca/ bentz/manual.shtml $>$.

Bisby, L. A., and M.F. Green. Resistance to freezing and thawing of fiber-reinforced polymerconcrete bond. ACFI Structural Journal, Vol 99, No. 2, 2002, pp. 215-223.

Chajes, M. J., T.A. Thomson, and C.A. Farschman. Durability of concrete beams externally reinforced with composite fabrics. Construction and Building Materials, Vol 9, No. 3, 1995, pp. 141-148.

del Mar Lopez, M., A.E. Naaman, and R.D. Till. Bending Behavior of Reinforced Concrete Beams Strengthened with Carbon Polymer Laminates and Subjected to Freeze-Thaw Cycles. ACI SP-188: $4^{\text {th }}$ International Symposium on Fiber-Reinforced Polymer Reinforcement for Concrete Structures, 1999, pp. 559-576. 
Dutta, P. K. Tensile strength of unidirectional fiber composites at low temperatures. $6^{\text {th }}$ JapanU.S. Conference on Composite Materials, Proceedings, Orlando, 1992, pp. 782-792.

Dutta, P. K. Durability issues of FRP composites in offshore structures. $5^{\text {th }}$ International Offshore and Polar Engineering Conference, Proceeedings, Vol. 4, 1995, Hague, Netherlands, pp. 271-277.

El-Hacha, R., M. F.Green., and R. G.Wight. Flexural behavior of concrete beams strengthened with prestressed carbon fiber reinforced polymer sheets subjected to sustained loading and low temperature," Canadian Journal of Civil Engineering, Vol. 31, 2004, pp. 239-252.

Grace, N. F., and S. B. Singh. Durability evaluation of carbon fiber-reinforced polymer strengthened concrete beams: experimental study and design. ACI Structural Journal, Vol. 102, No. 1, 2005, pp. 40-53.

Green, M. F., L. A. Bisby, Y. Beaudoin, and P. Labossiere. Effect of freeze-thaw action on the bond of FRP sheets to concrete. Proceedings of the First International Conference on Durability of Composites for Construction, Sherbrooke, Quebec, 1998, pp. 179-190.

Green, M. F., L. A. Bisby, Y. Beaudoin, and P. Labossiere. Effect of freeze-thaw cycles on the bond durability between FRP plate reinforcement and concrete. Canadian Journal of Civil Engineering, Vol. 27, 2000, pp. 949-959.

Green, M. F., A. J. S. Dent, and L. A.Bisby. Effect of freeze-thaw cycling on the behaviour of reinforced concrete beams strengthened in flexure with fibre reinforced polymer sheets. Canadian Journal of Civil Engineering, Vol. 30, 2003, pp. 1081-1088.

Higgins, C., T.H. Miller, D.V. Rosowsky, S.C.Yim, T.Potisuk, T.K. Daniels, B.S. Nicholas, M.J. Robelo, A-Y Lee, and R.W. Forrest. Assessment Methodology for Diagonally Cracked Reinforced Concrete Deck Girders. Publication FHWA-OR-RD-05-04. FHWA, U.S. Department of Transportation, 2004.

Higgins, C., G.Williams, , and L. Elkins. Capabilities of Diagonally-Cracked Girders Repaired with CFRP. Publication FHWA-OR-RD-06-16. FHWA, U.S. Department of Transportation. 2006.

Incropera, F., and P. DeWitt. Introduction to Heat Transfer. John Wiley \& Sons Inc., New York, 2002 ,

Holman, J.P. Heat Transfer. McGraw-Hill Inc., New York,1997.

Karbhari V. M. Response of Reinforced Polymer Confined Concrete Exposed to Freeze and Freeze-Thaw Regimes. ACI Journal of Composites for Construction, Vol. 6, No. 1, 2002, pp. 3540. 
Karbhari V. M., J.W. Chin, D. Hunston, B. Benmokrane, T. Juska, R., Morgan, J.J. Lesko, U. Sorathia, D. Reynaud. Durability Gap Analysis for Fiber-Reinforced Polymer Composites in Civil Infrastructure. ASCE Journal of Composites for Construction, Vol. 7, No. 3, 2003, pp. 238247.

Kong, A., A. Fam, M.F. Green. Freeze-Thaw Behavior of FRP-Confined Concrete under Sustained Load. ACI SP-230: $7^{\text {th }}$ International Symposium on Fiber-Reinforced Polymer Reinforcement for Concrete Structures, 2005, pp. 705-722.

Lord, H. W., and P. K. Dutta. On the design of polymeric composite structures for cold regions applications. Journal of Reinforced Plastics and Composites, Vol. 7, 1988, pp. 435-458.

MacGregor, J. G. and J. K. Wight. Reinforced Concrete Mechanics and Design. Pearson Prentice Hall, New Jersey, 2005.

Malvar, L. J., N. R. Joshi, J. A. Beran, and T. Novinson. Environmental Effects on the ShortTerm Bond of Carbon Fiber-Reinforced Polymer (CFRP) Composites. ACI Journal of Composites for Construction, Vol. 7, No. 1, 2003, pp. 58-63.

Motavalli, M., G. P. Terrasi, and U. Meier. On the behavior of hybrid aluminum/CFRP box beams at low temperatures. Swiss Federal Laboratories for Materials Testing and Research (EMPA), Switzerland 1993.

Mukhopadhyaya, P., R. N. Swamy, and C. J. Lynsdale. Influence of aggressive exposure conditions on the behaviour of adhesive bonded concrete-GFRP joints. Construction and Building Materials, Vol. 12, 1998, pp. 427-446.

Myers, J. J., and M. Ekenel. Effect of Environmental Conditions on Bond Strength between CFRP Laminate and Concrete Substrate. ACI SP-230: $7^{\text {th }}$ International Symposium on FiberReinforced Polymer Reinforcement for Concrete Structures, 2005, pp. 1571-1592.

Saenz N., C.P. Pantelides, and L.D. Reveley. Long Term Durability of Strengthened Concrete with Externally Applied FRP Composites. Proceedings of the SAMPE Conference, Long Beach, CA, 2004.

Schlangen, E. Online help/manual module HEAT of FEMMASSE. The Netherlands, 2000.

Sen, R., L. Liby, and G. Mullins. Strengthening Steel Bridge Sections Using CFRP Laminates. Composites: Part B, Vol. 32, 2001, pp. 309-322.

Soudki, K. A., and M. F. Green. Freeze-thaw response of CFRP wrapped concrete. Concrete International, Vol. 19, No. 8, 1997, pp. 64-67.

Watson Bowman Acme Corporation. Specification: Wabo ${ }^{\circledR}$ MBrace Composite Strengthening System with Carbon Fiber Reinforcement. Amherst, NY, March 2002.

Watson Bowman Acme Corporation. Wabo ${ }^{\circledR}$ MBrace CF130. Amherst, NY, February 2003. 
Wu, L., S. V. Hoa, and M. Ton-That. Effects of Water on the Curing and Properties of Epoxy Adhesive Used for Bonding FRP Composite Sheet to Concrete. Journal of Applied Polymer Science, Vol. 92, No. 4, 2004, pp. 2261-2268. 
APPENDIX A:

RESULTS OF BEAM TESTS 



\section{Specimen IT12Control}
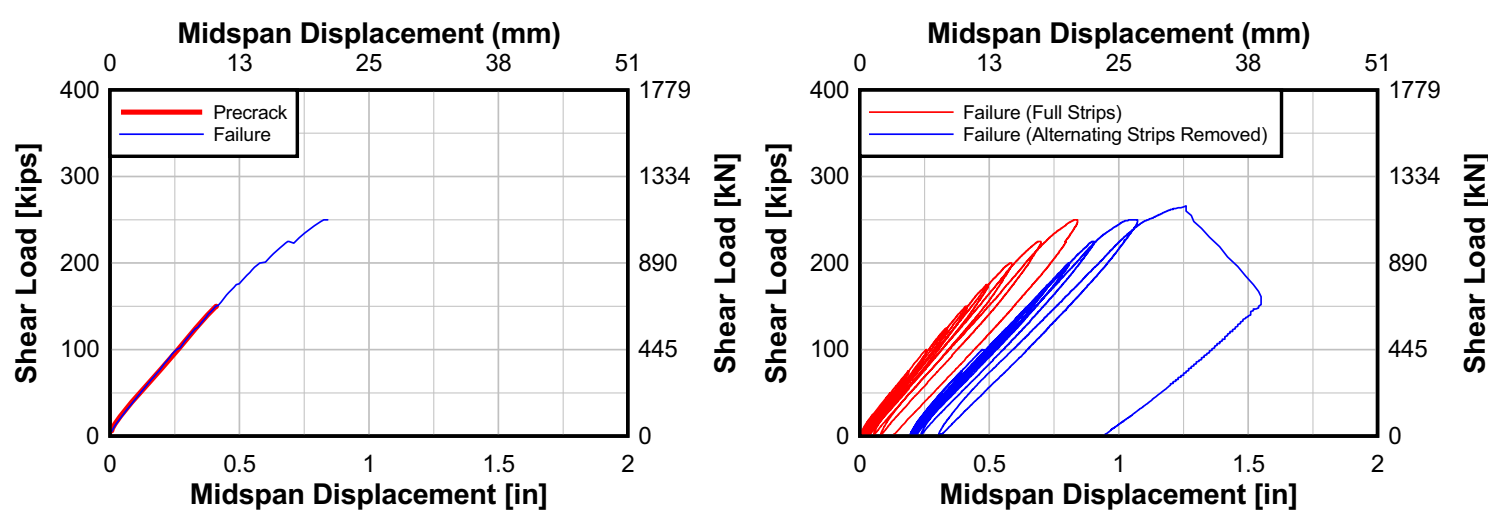

Panel 2S
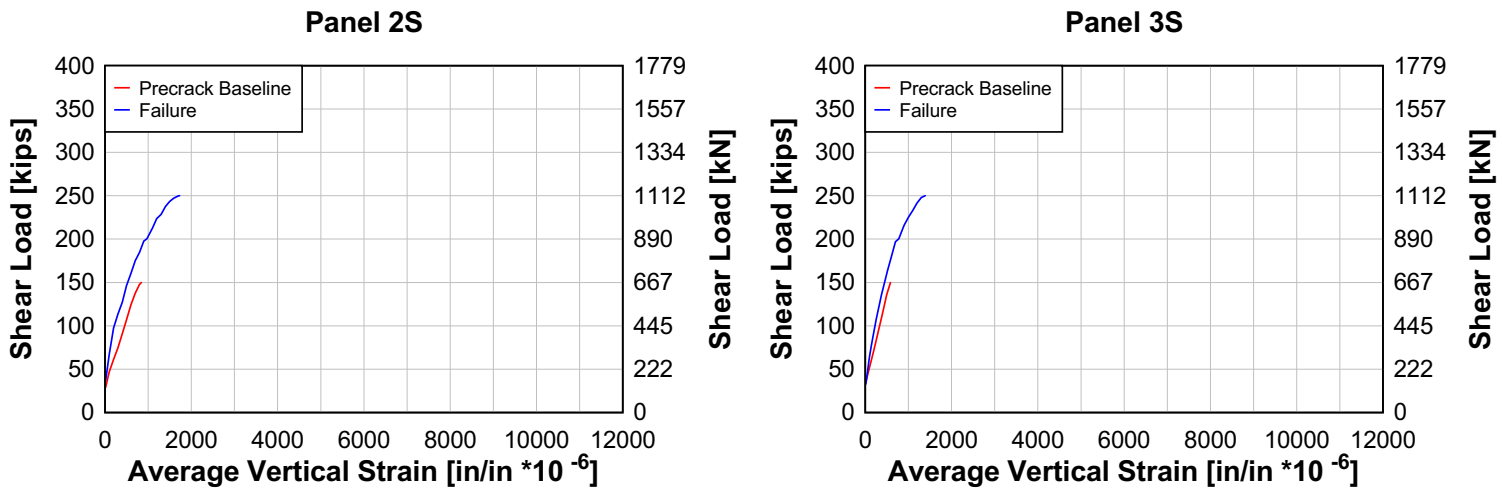

\section{Specimen IT12FT}
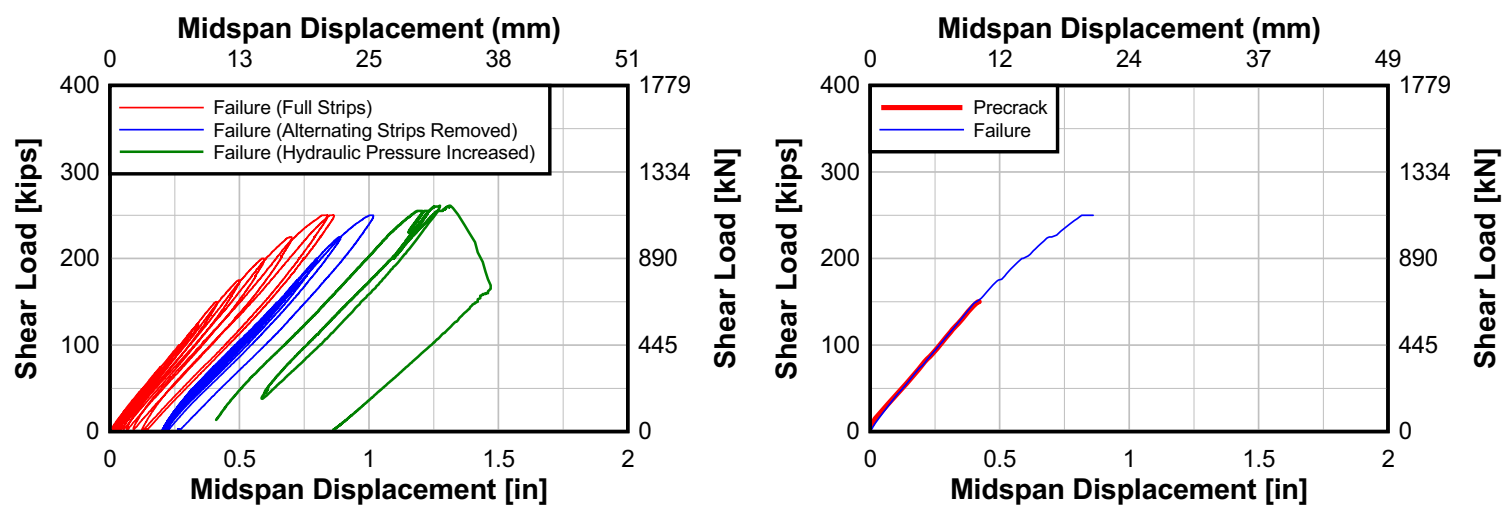
Panel 2S

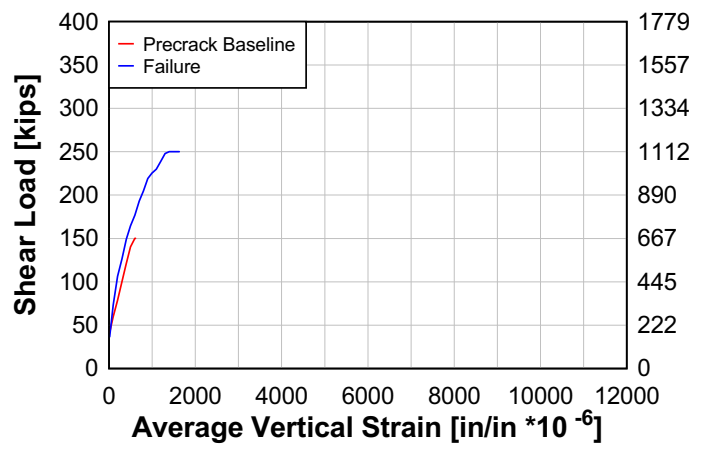

\section{Specimen IT12FTCK}

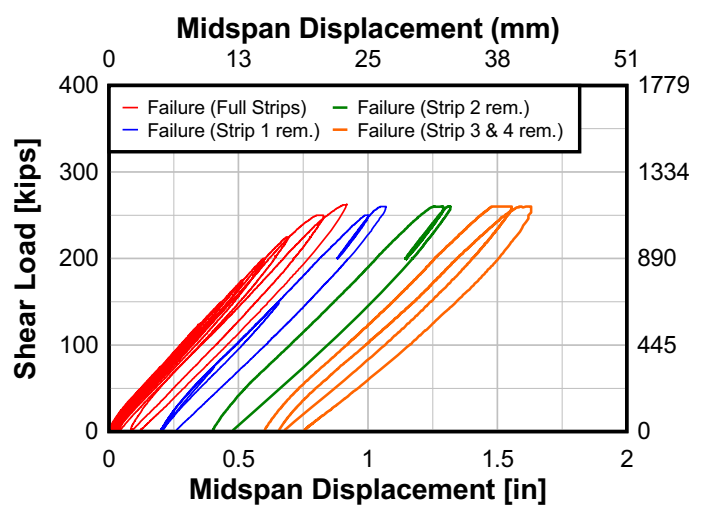

Panel 2S

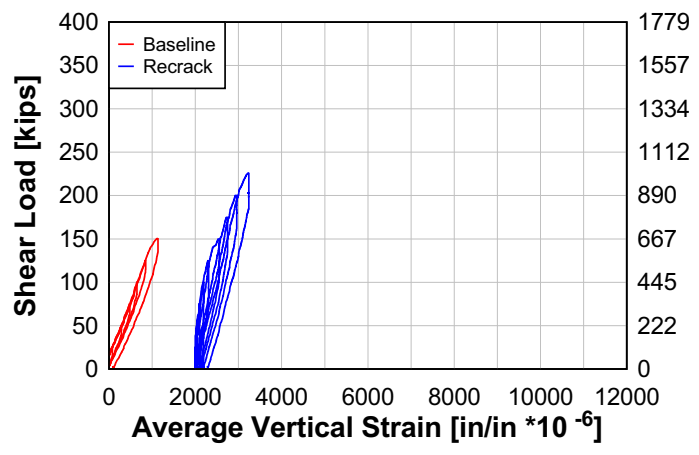

Panel 2S

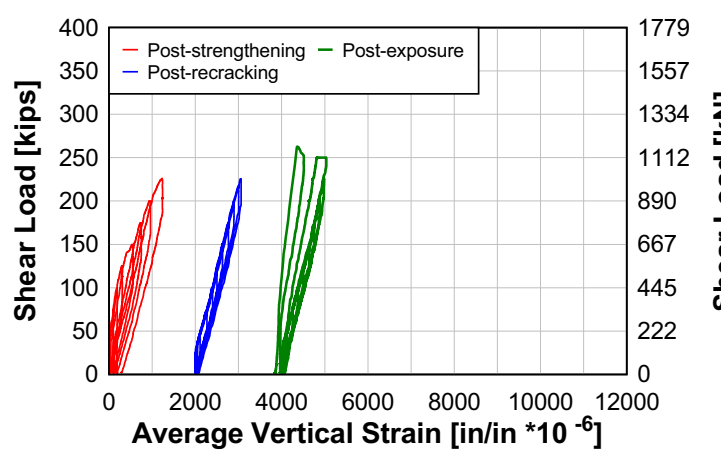

Panel 3S
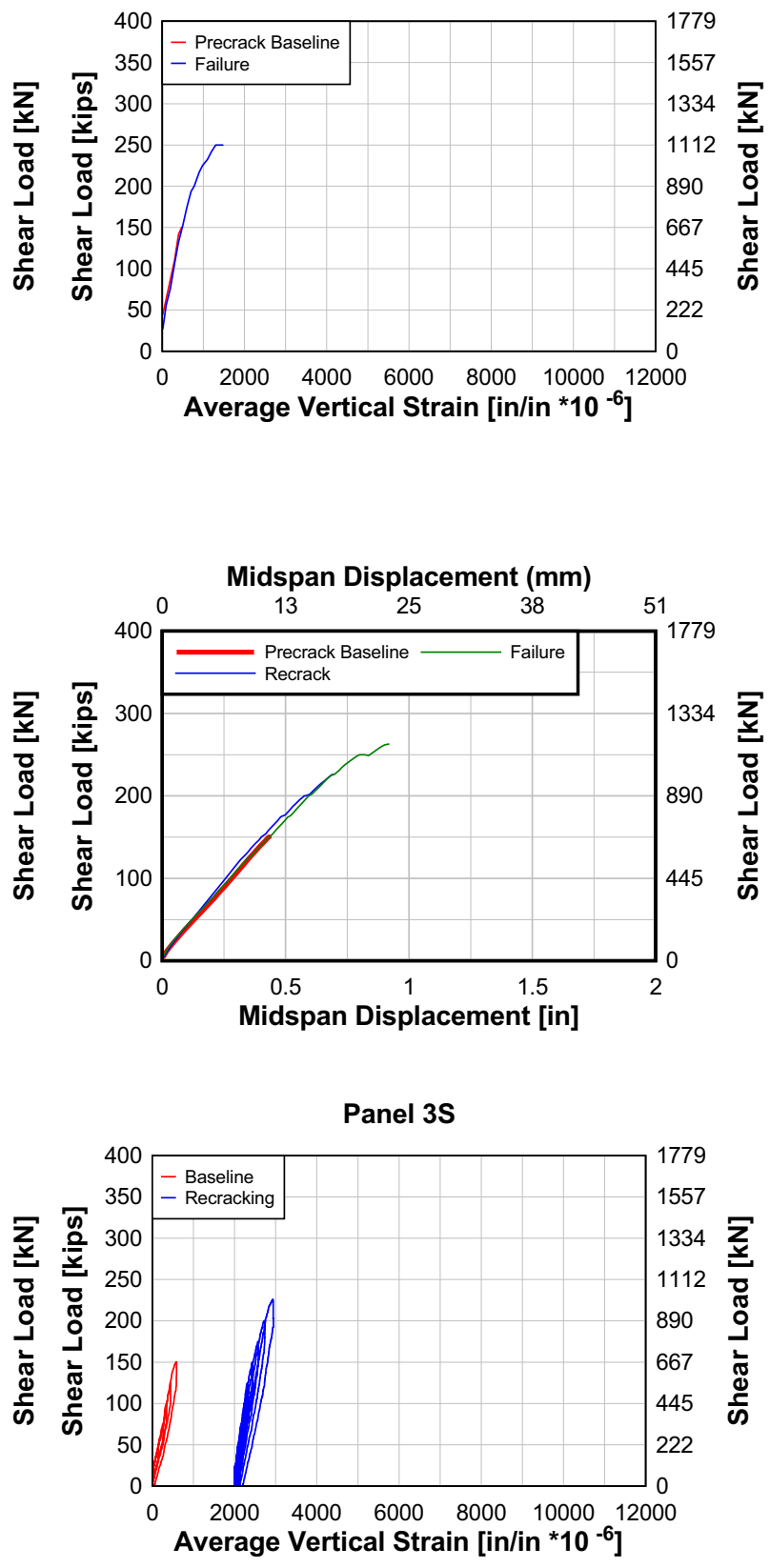

Panel 3S

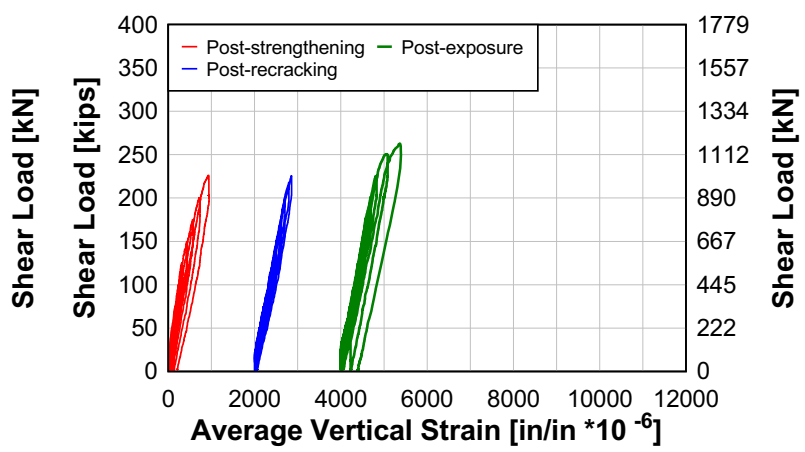




\section{Specimen IT12M}
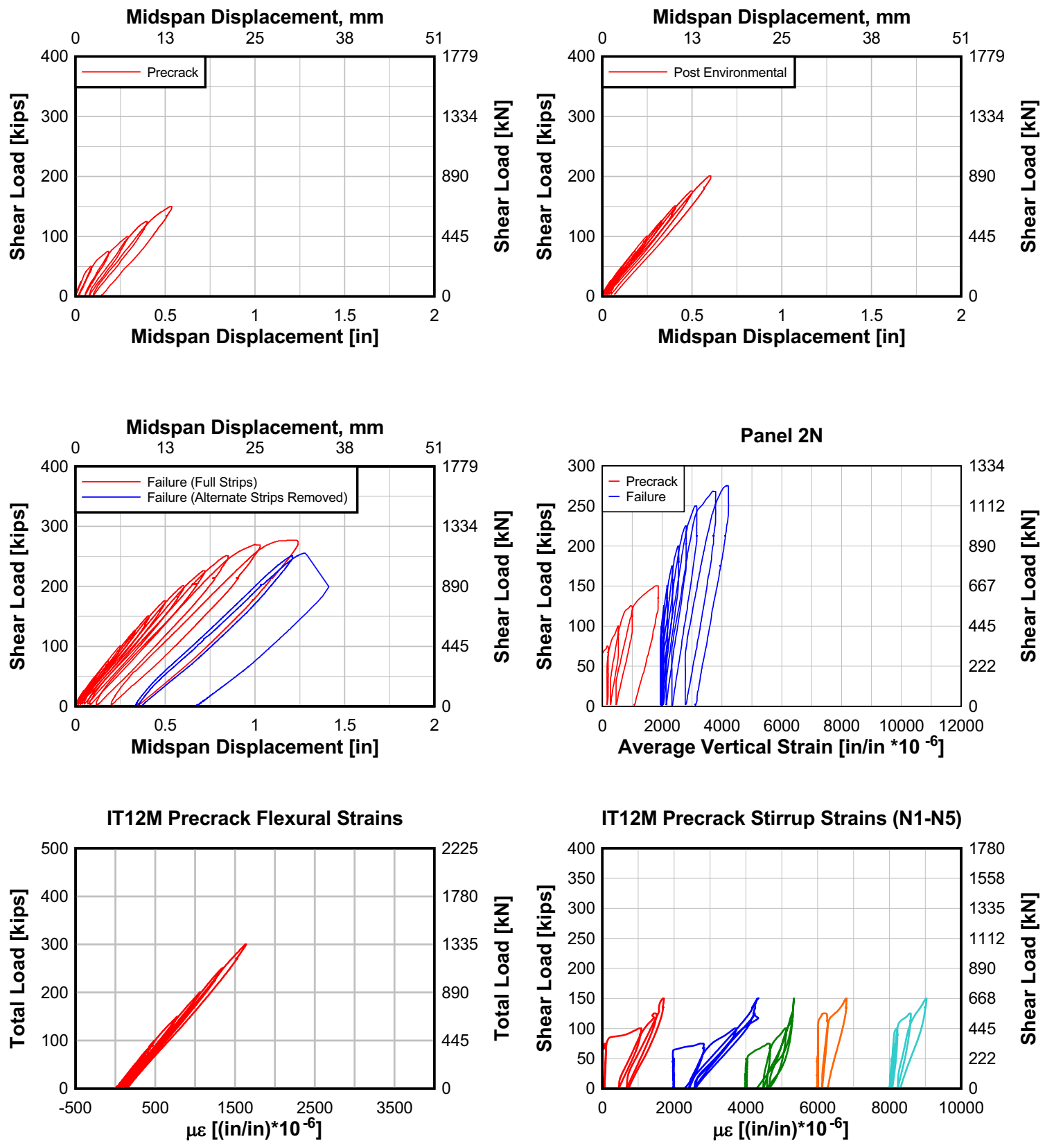
IT12M Precrack Stirrup Strains (S1, S2)

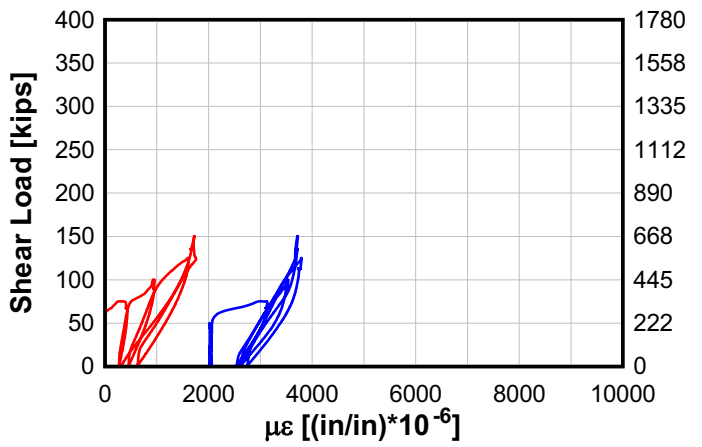

IT12M Failure Stirrup Strains (N1, N2, N3)

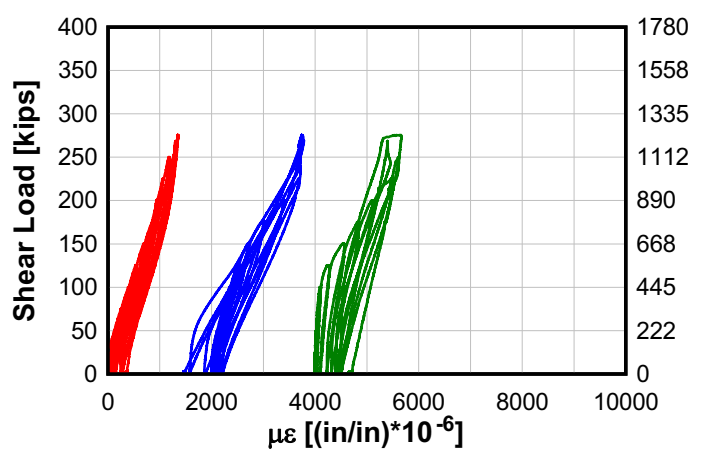

IT12M Failure South CFRP Strains

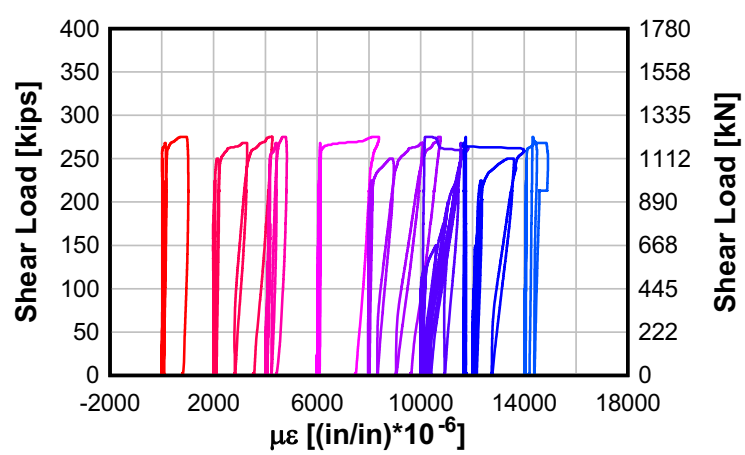

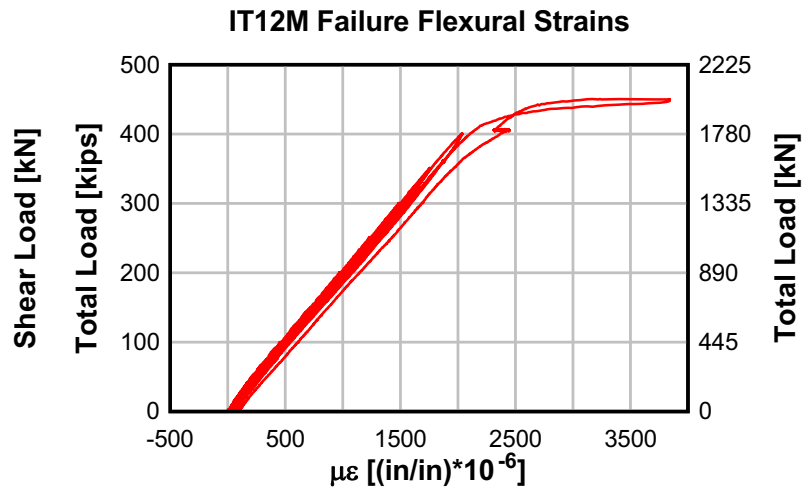

IT12M Failure North CFRP Strains

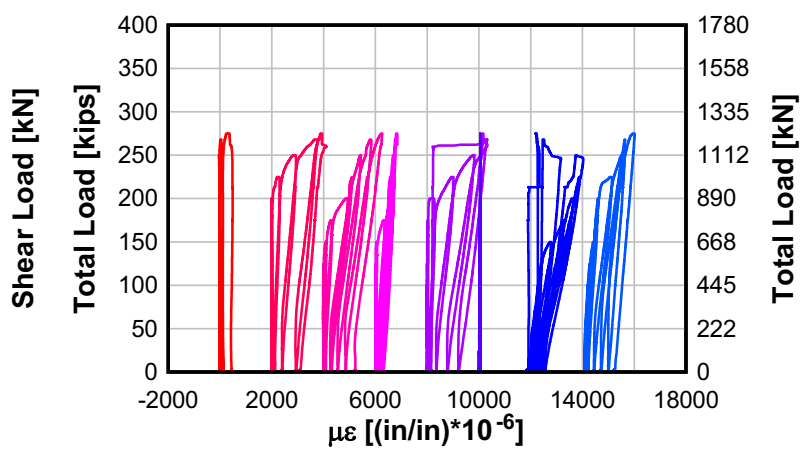

Specimen IT12MCK
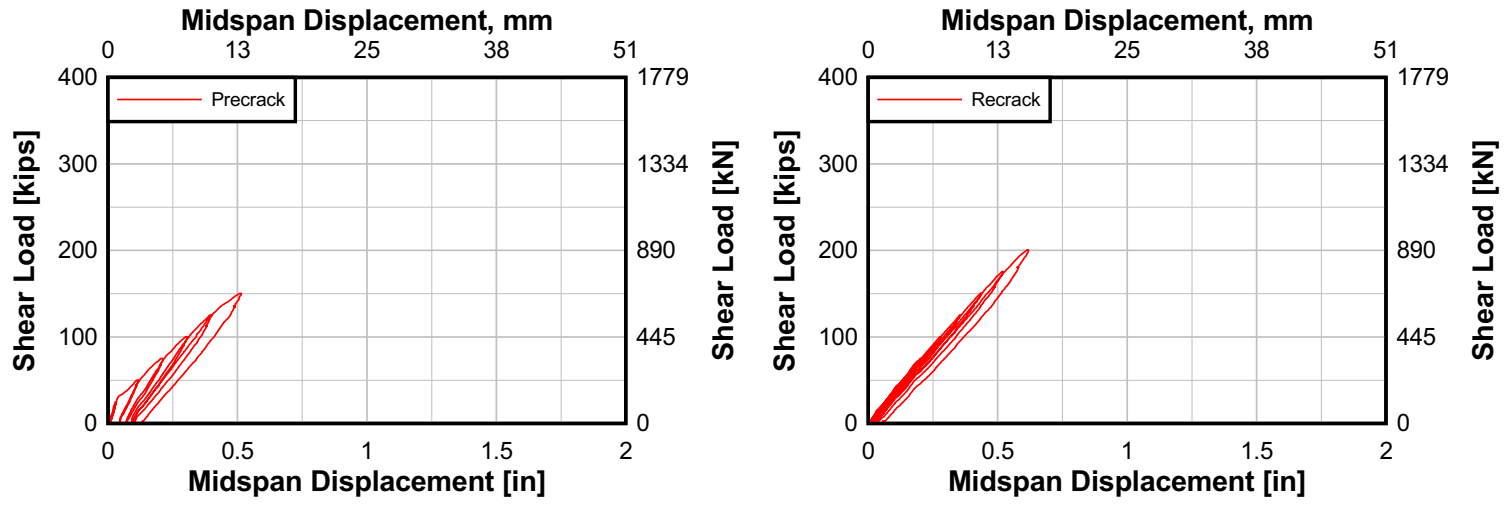


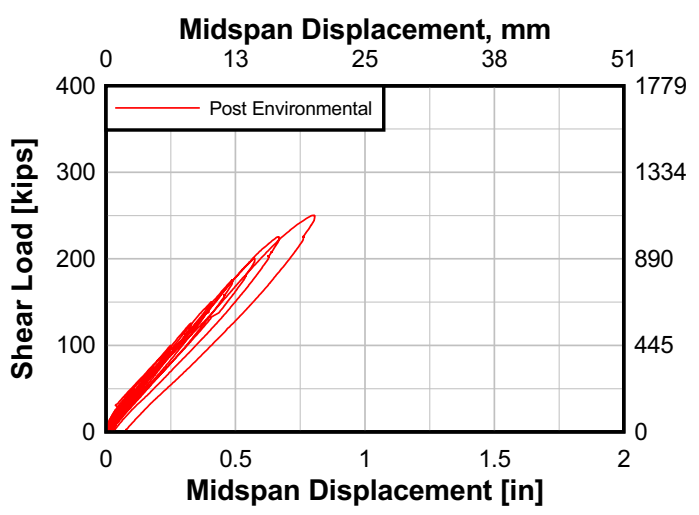

Panel 2N

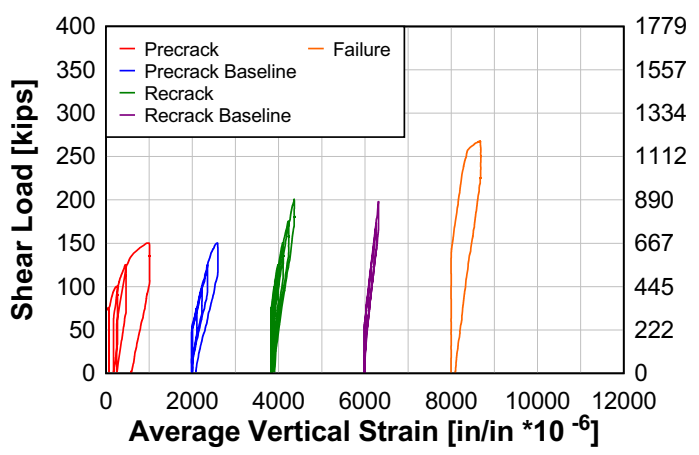

Panel 3N

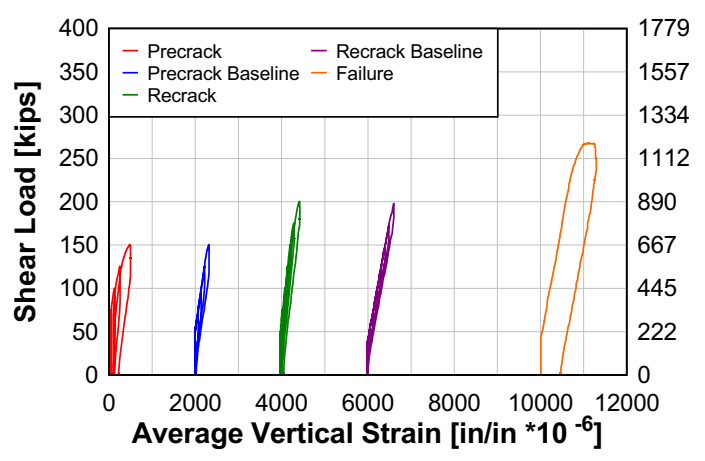

IT12MCK Precrack Flexural Strains

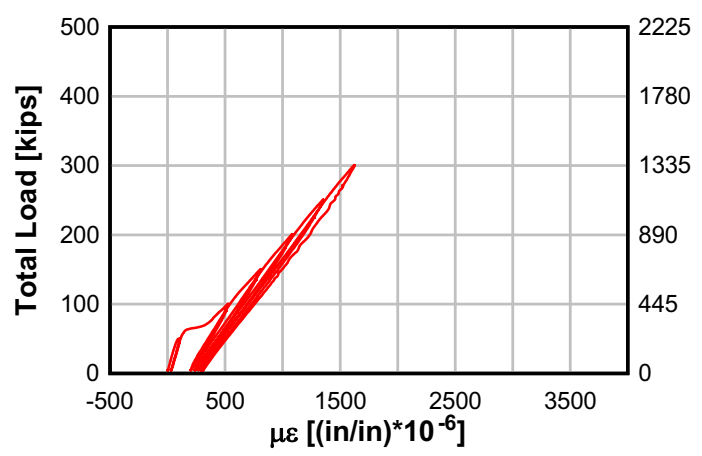

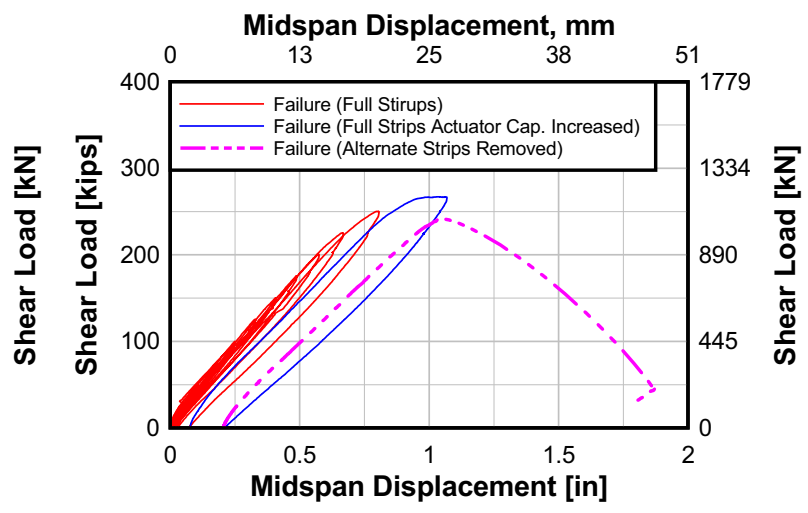

Panel 2S

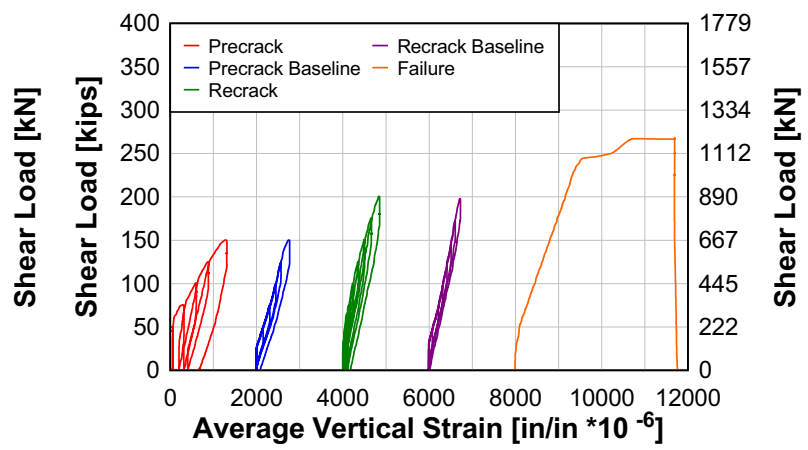

Panel 3S

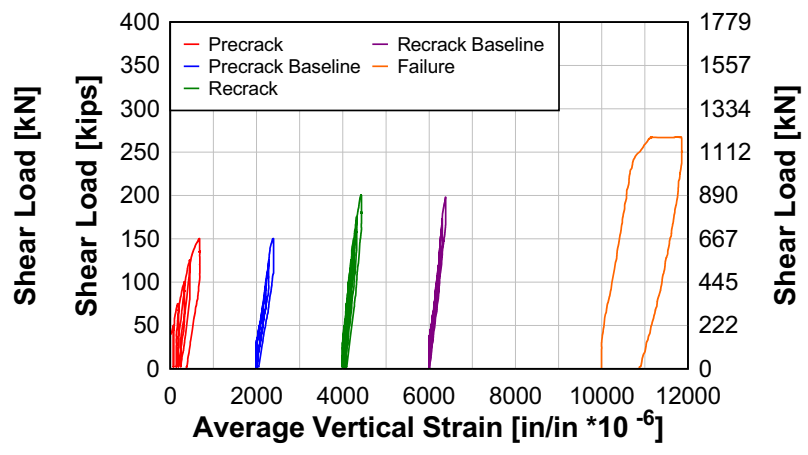

IT12MCK Precrack Stirrup Strains (N1-N5)

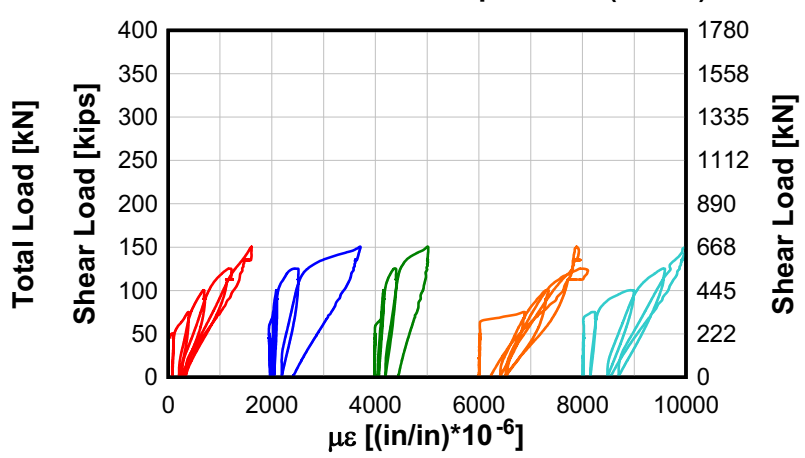


IT12MCK Precrack Stirrup Strains (S1, S2, S3, S4)

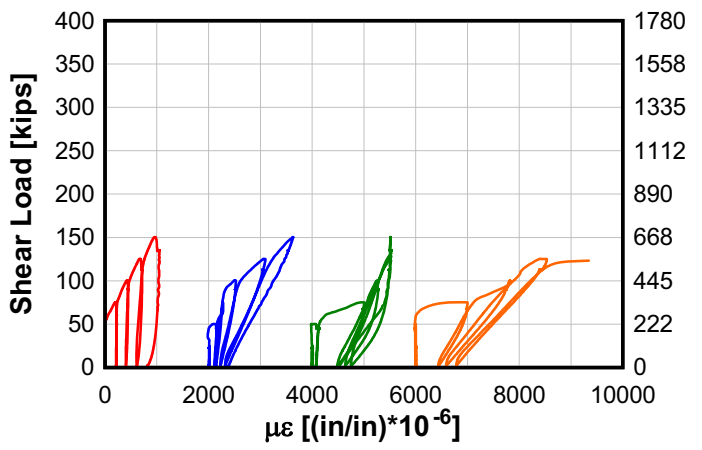

IT12MCK Recrack South CFRP Strains

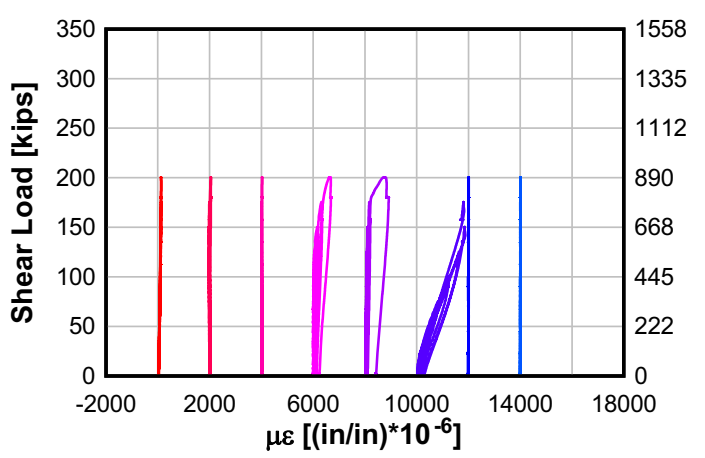

IT12MCK Failure Stirrup Strains (N1, N5)

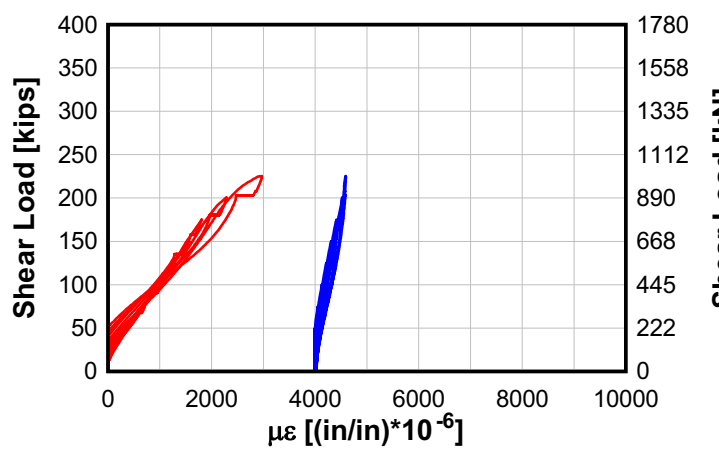

IT12MCK Failure North CFRP Strains

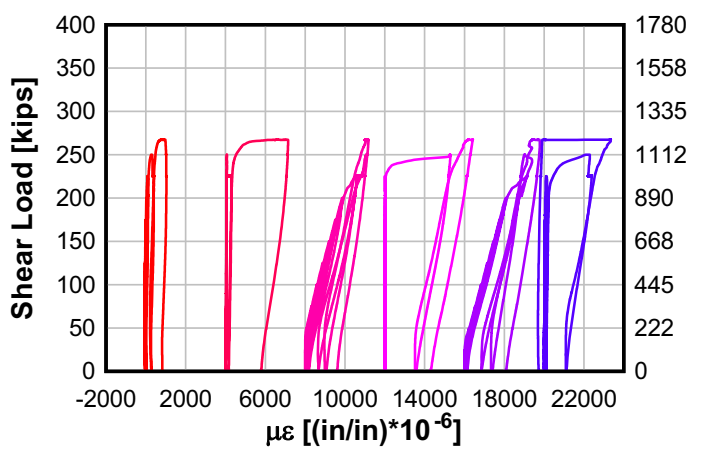

IT12MCK Recrack North CFRP Strains

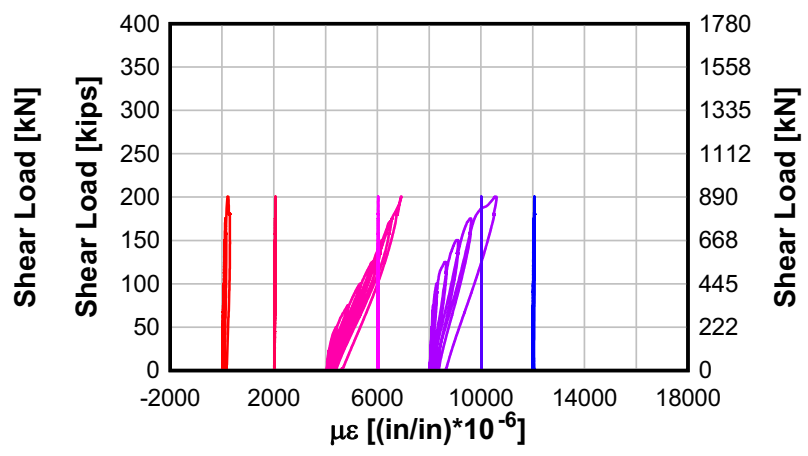

IT12MCK Failure Flexural Strains

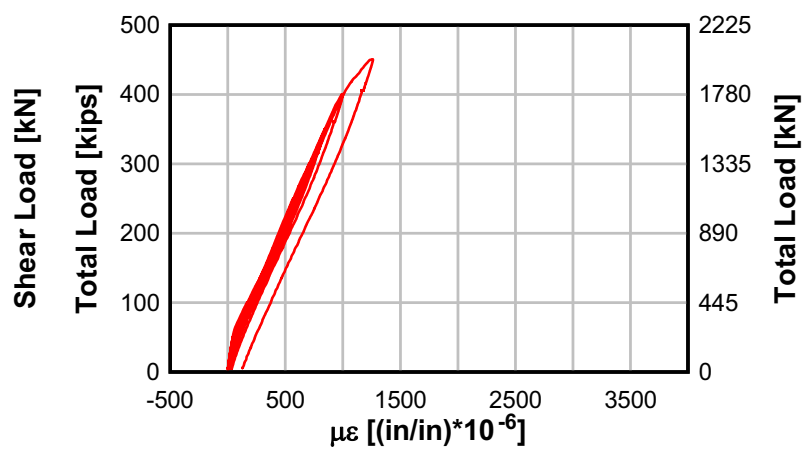

IT12MCK Failure Stirrup Strains (S1, S2, S3)

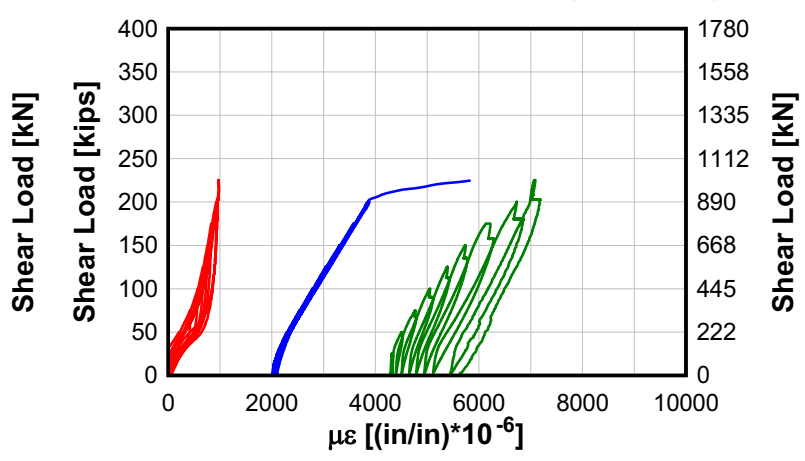

IT12MCK Failure South CFRP Strains

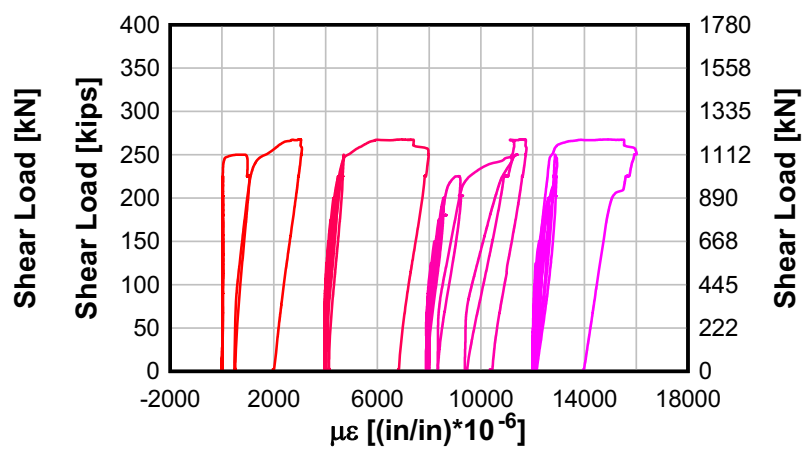




\section{Specimen ITT12FTCK}
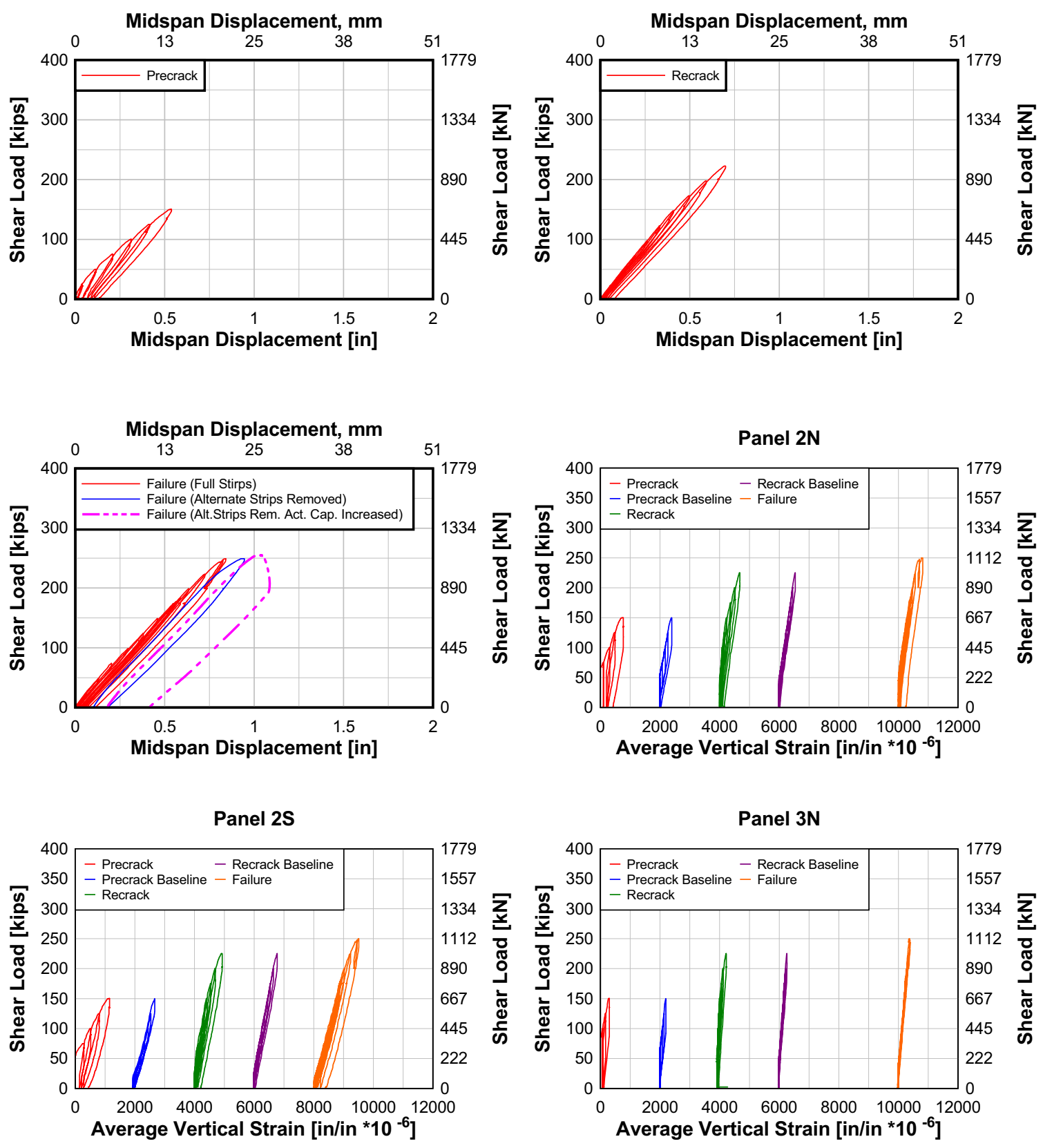
Panel 3S

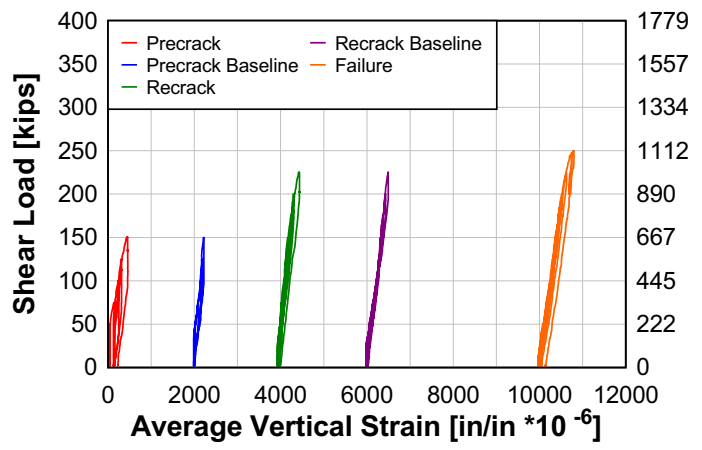

ITT12FTCK Recrack South CFRP Strains

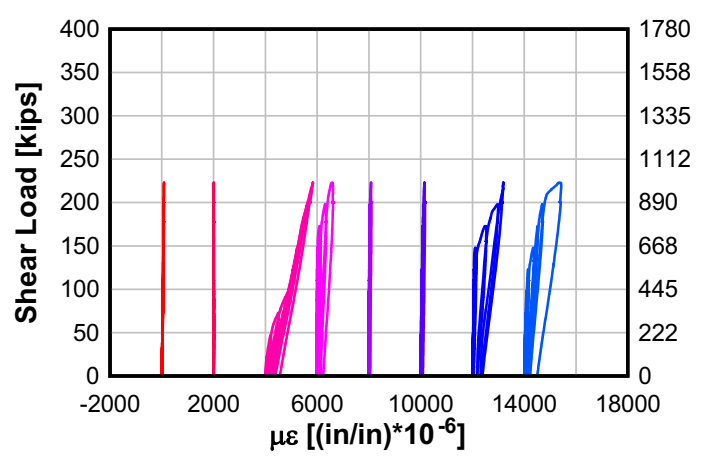

ITT12FTCK Failure South CFRP Strains

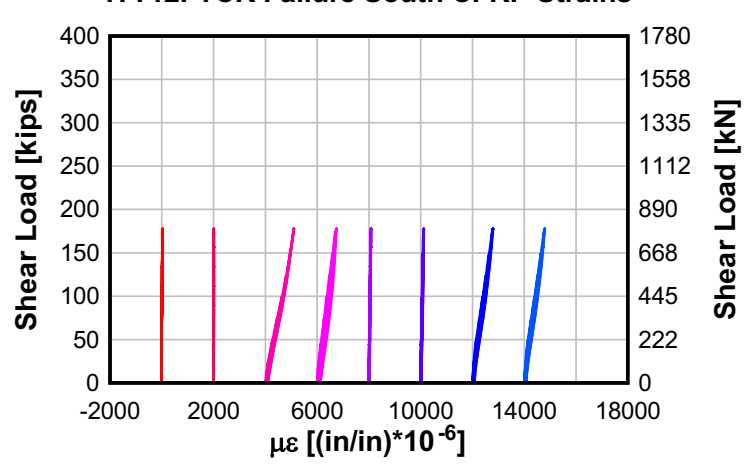

\section{Specimen T18Control}

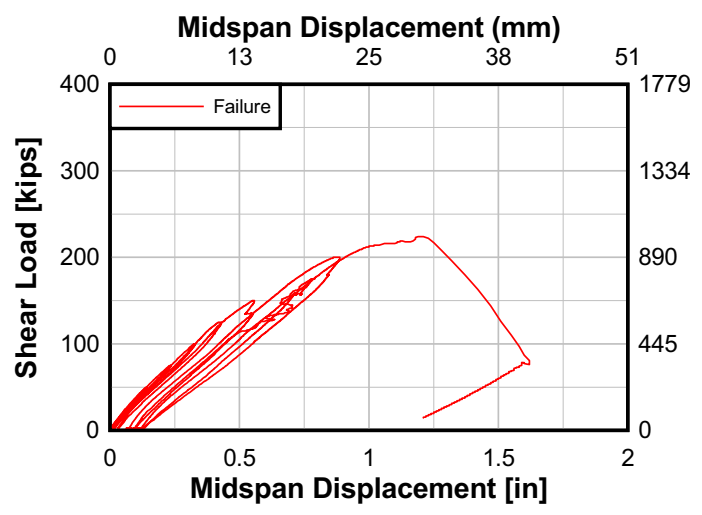

ITT12FTCK Recrack North CFRP Strains

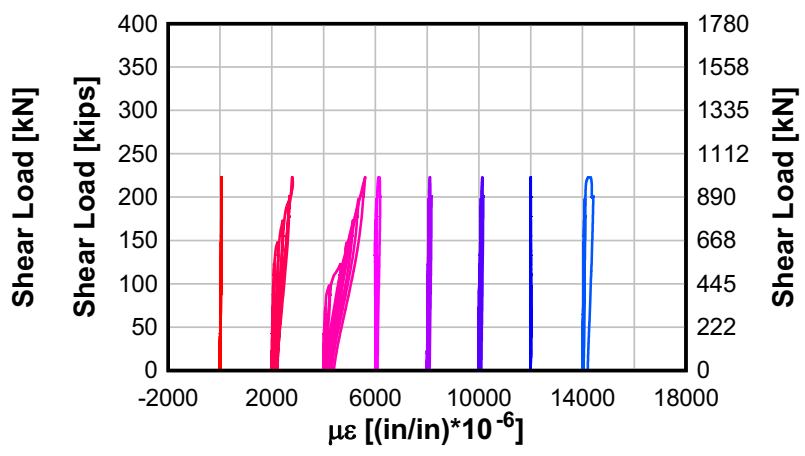

ITT12FTCK Failure North CFRP Strains

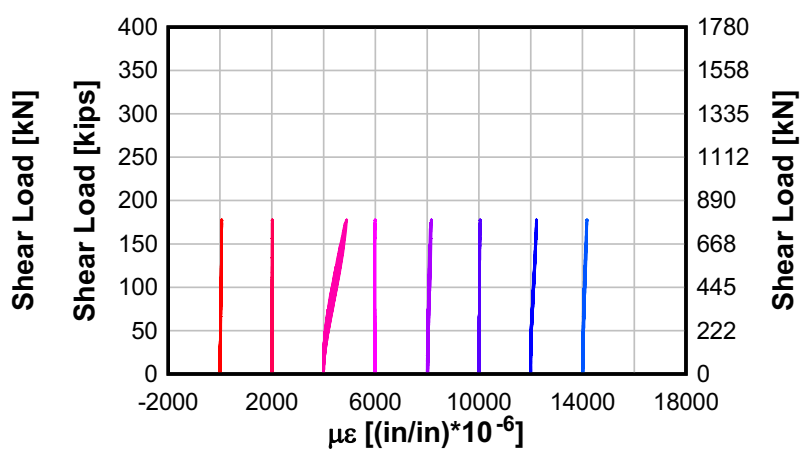

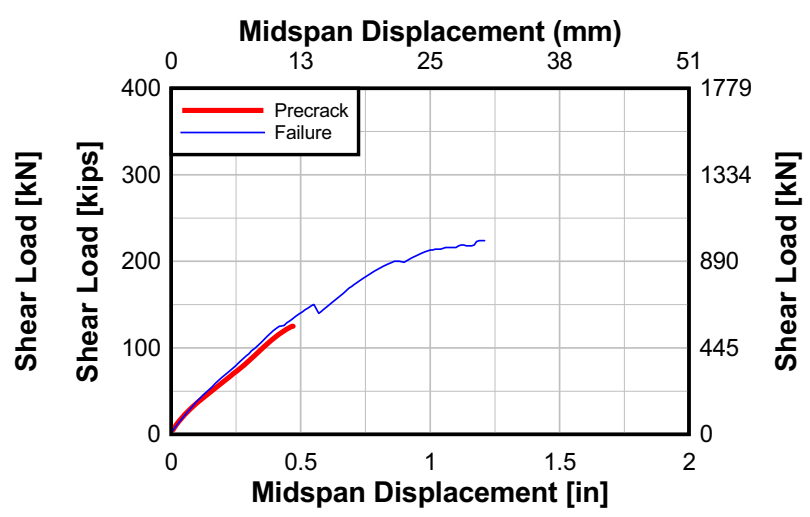


Panel 2N
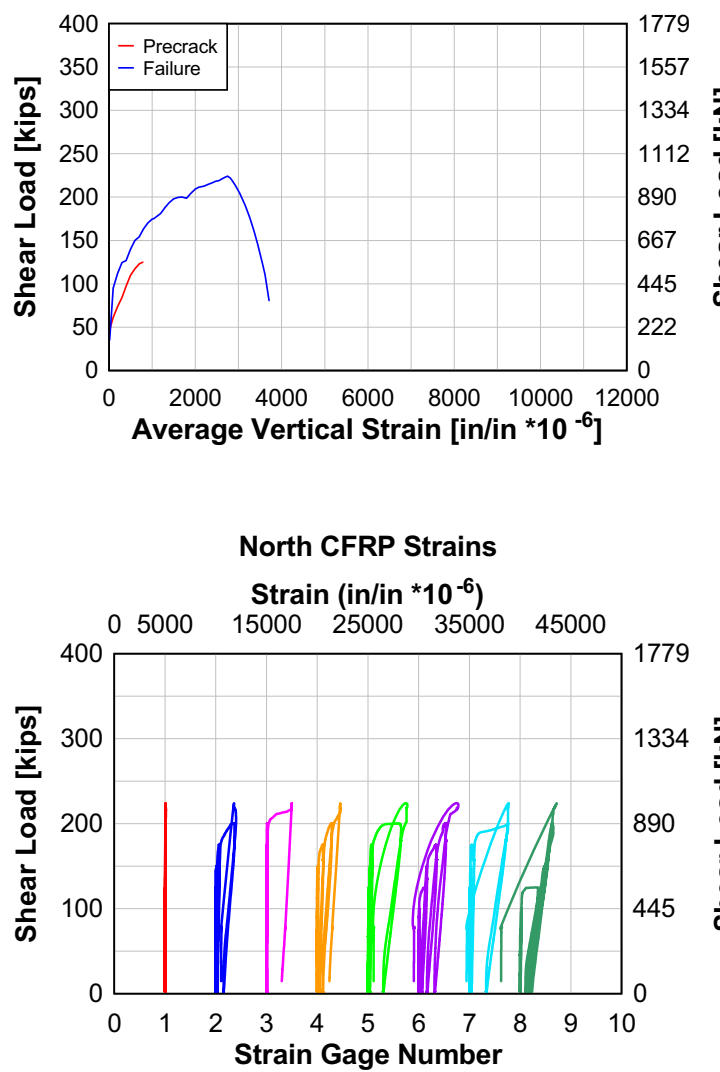

\section{Specimen T18FT}

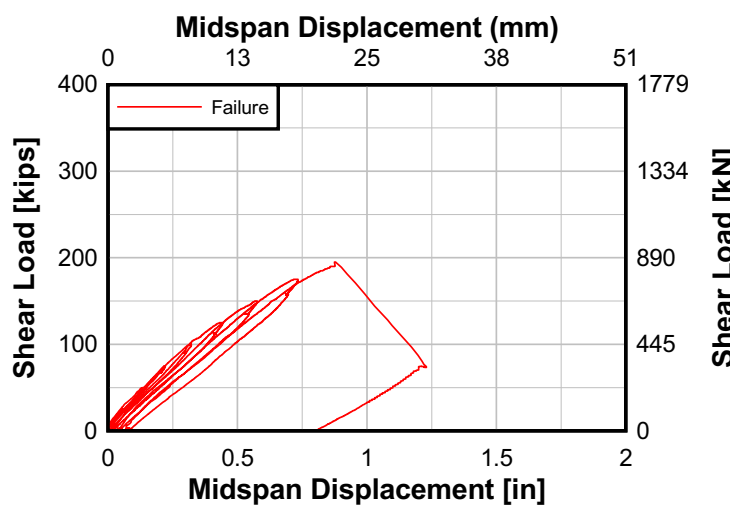

Panel 3N

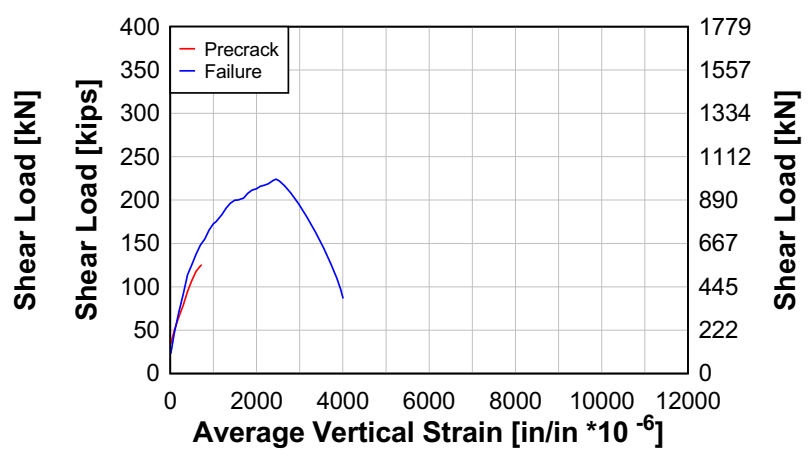

South CFRP Strains

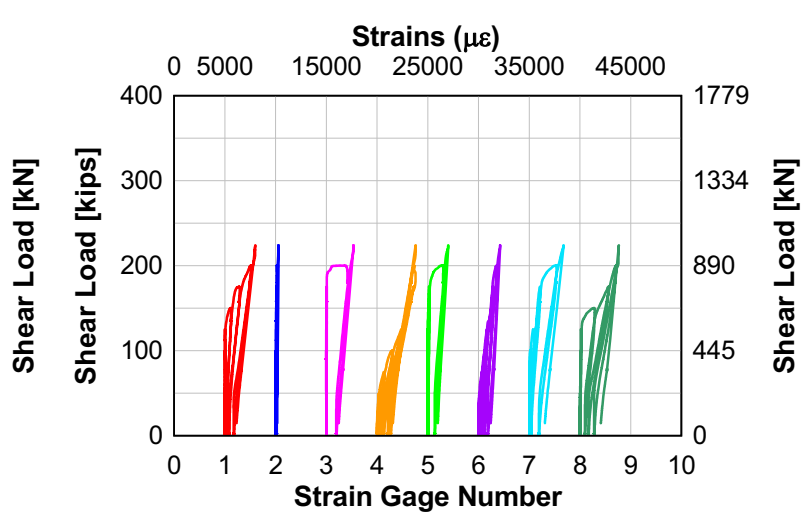

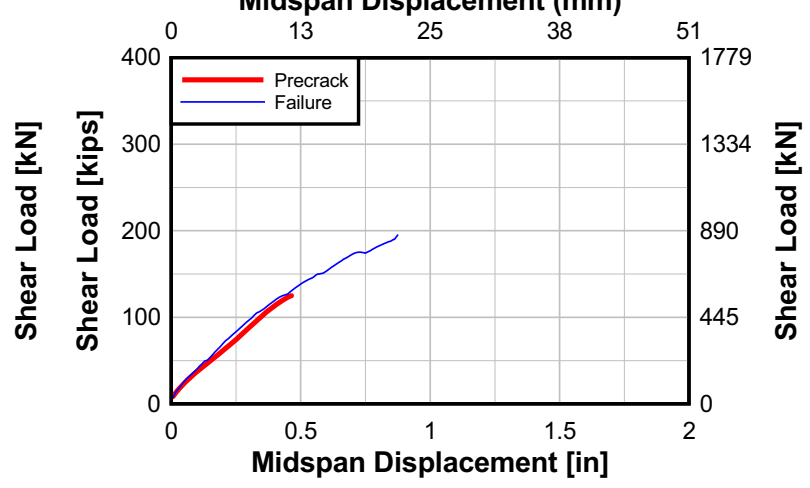


Panel 2N

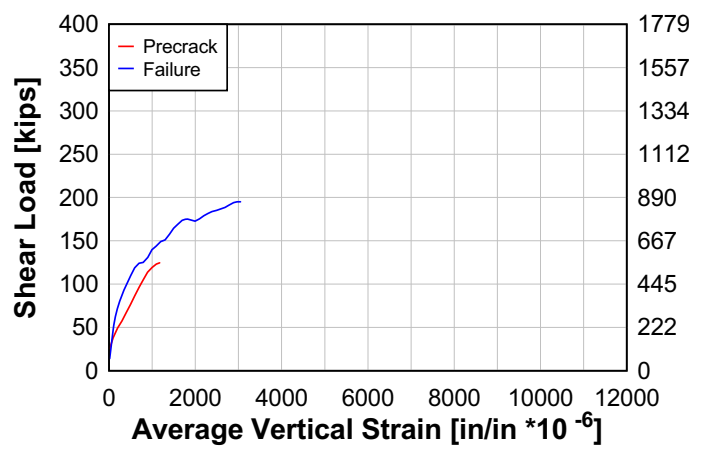

South CFRP Strains

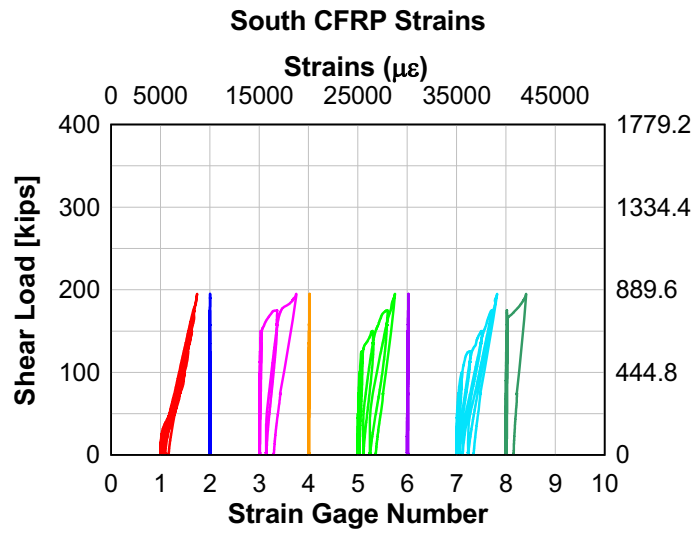

\section{Specimen T18FTCK}

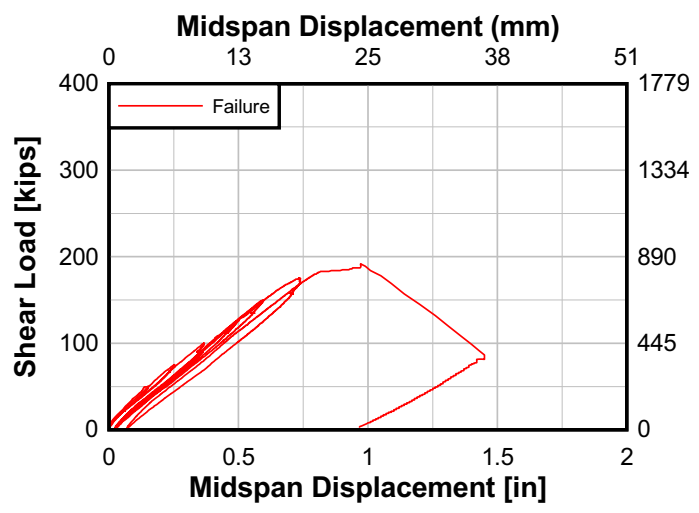

Panel 2S
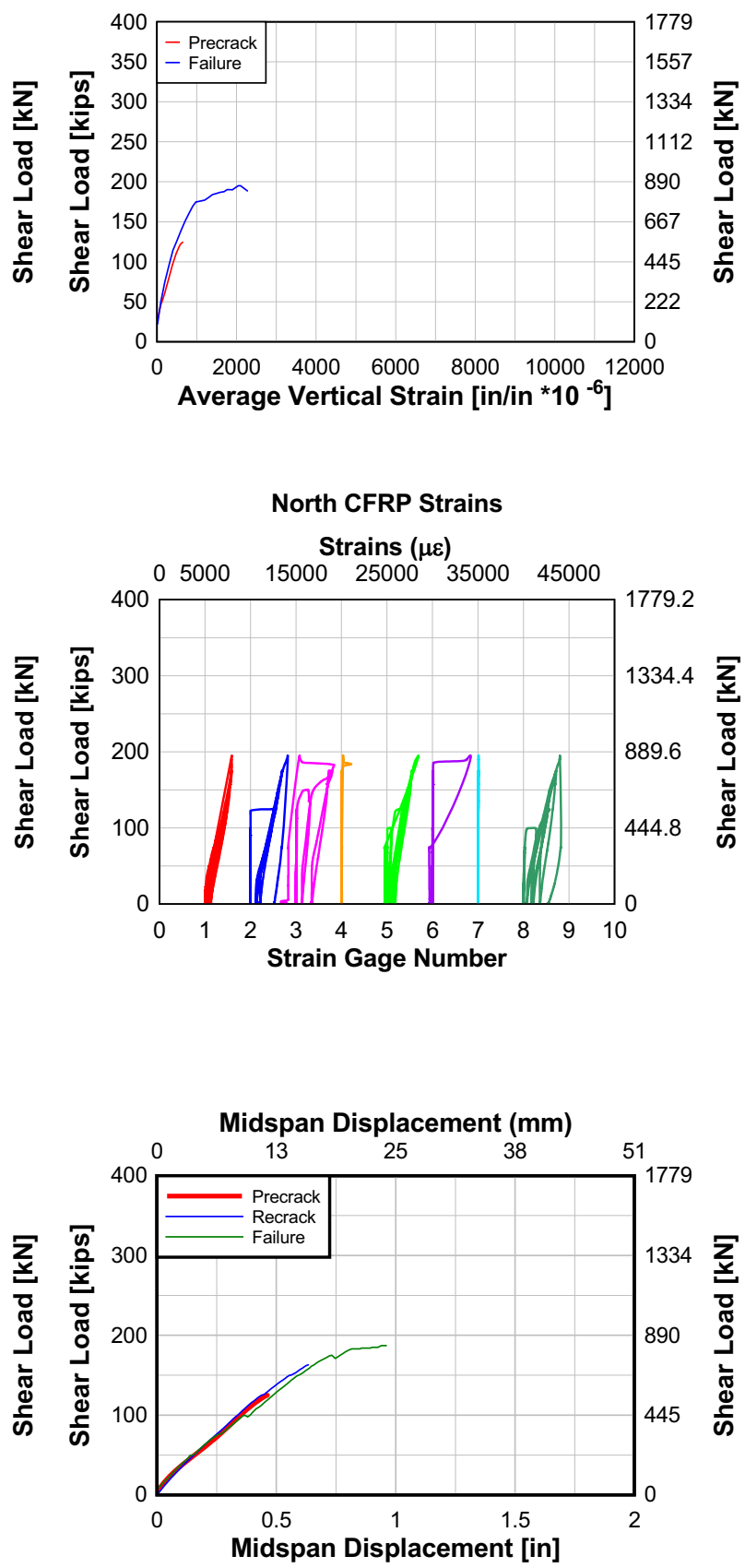
Panel 2N
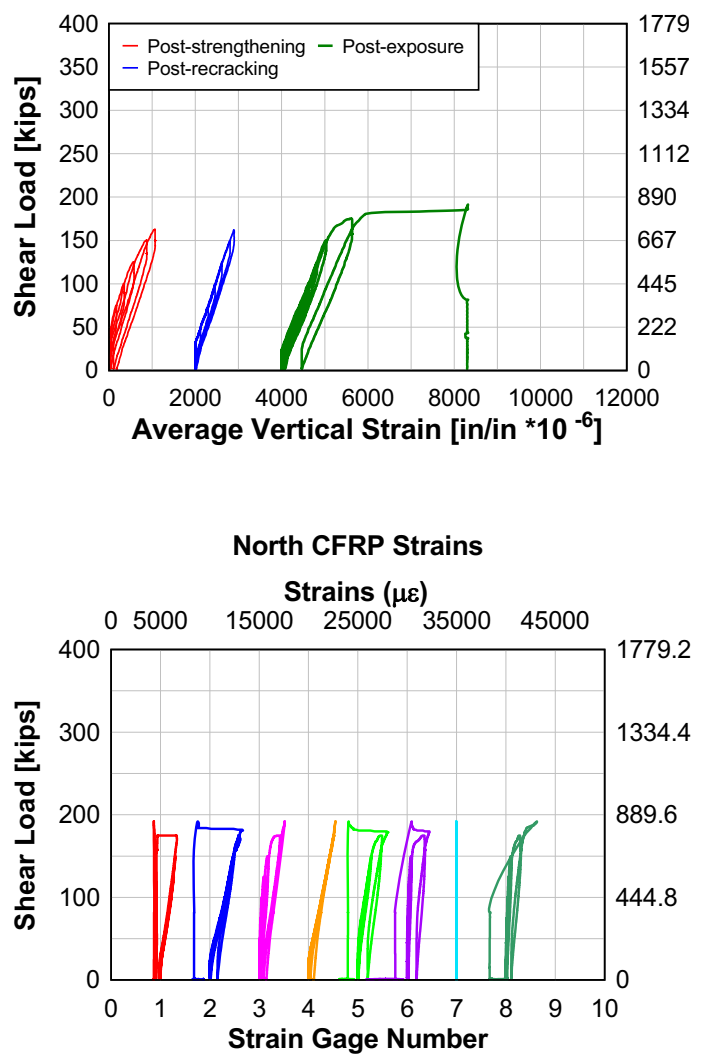

\section{Specimen T18FFTCK}

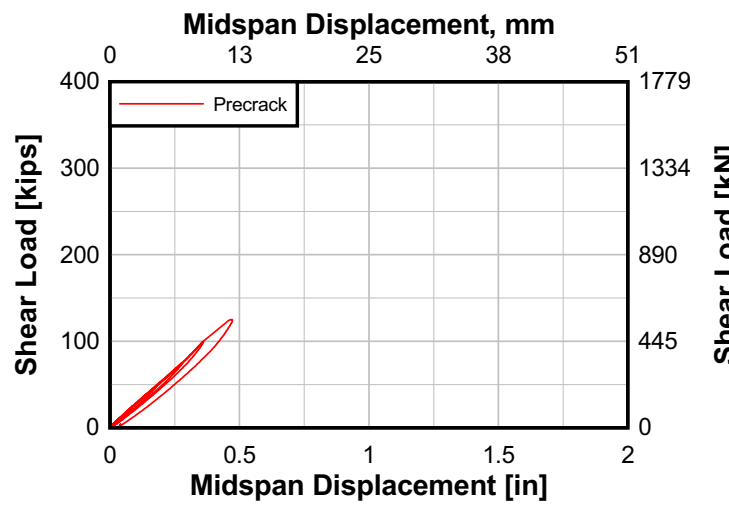

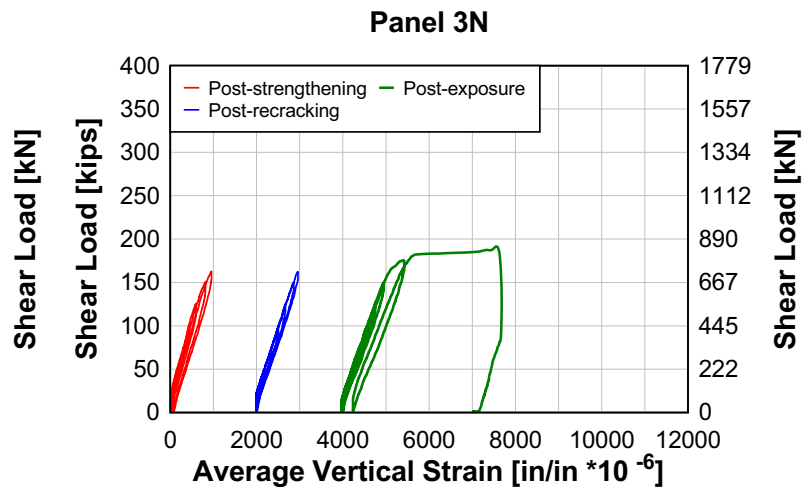
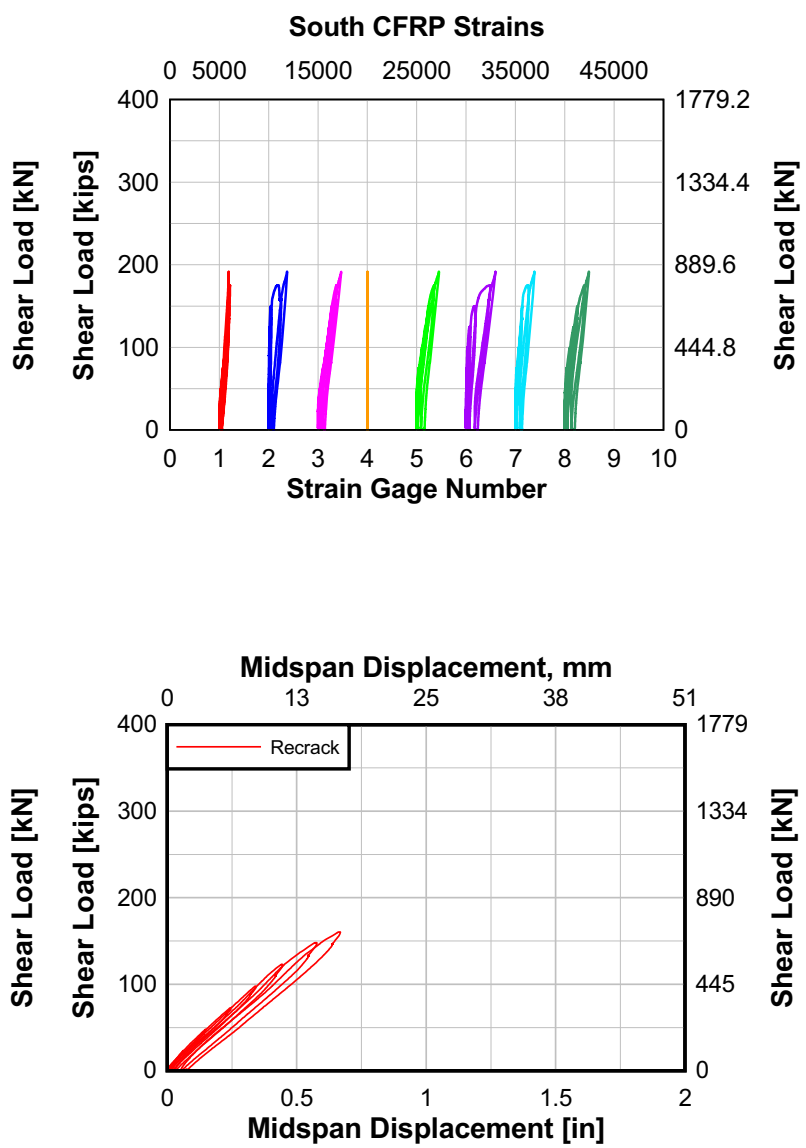


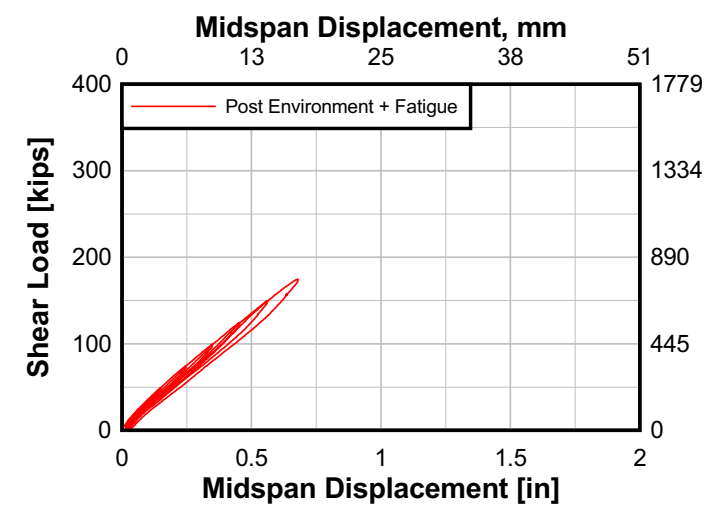

Panel 2N

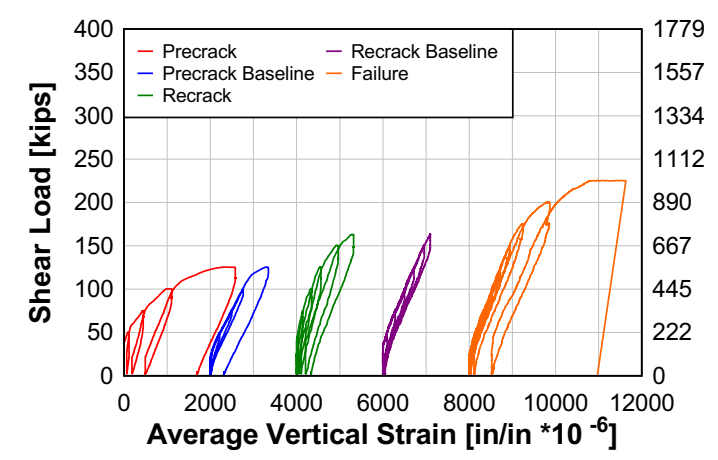

T18FFTCK Precrack Flexural Strains

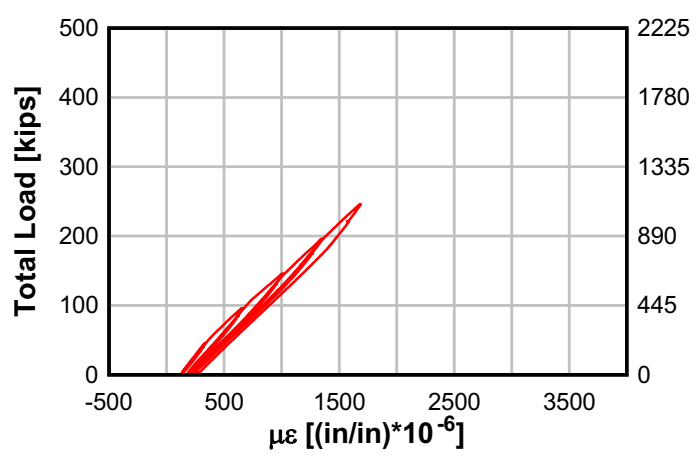

T18FFTCK Precrack Stirrup Strains (S1)

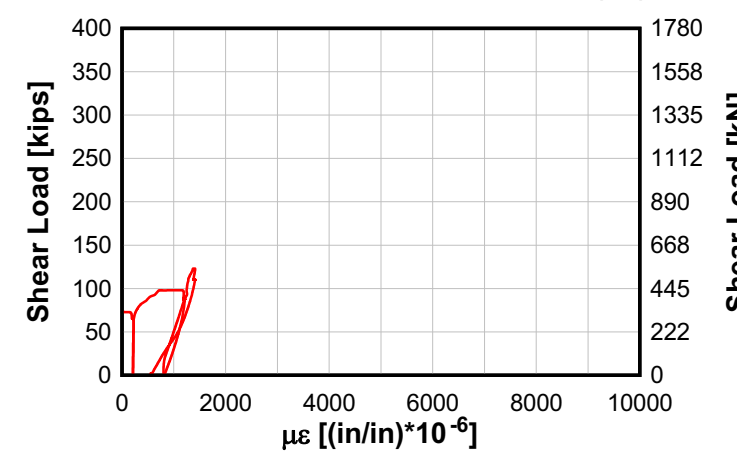

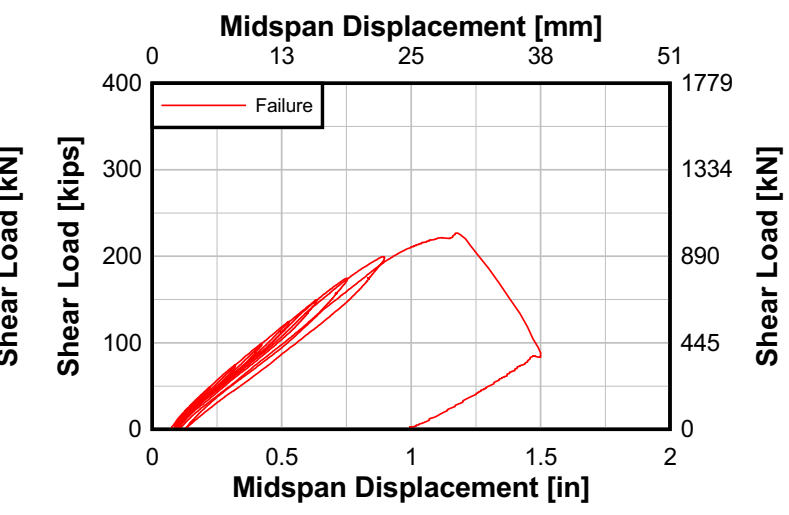
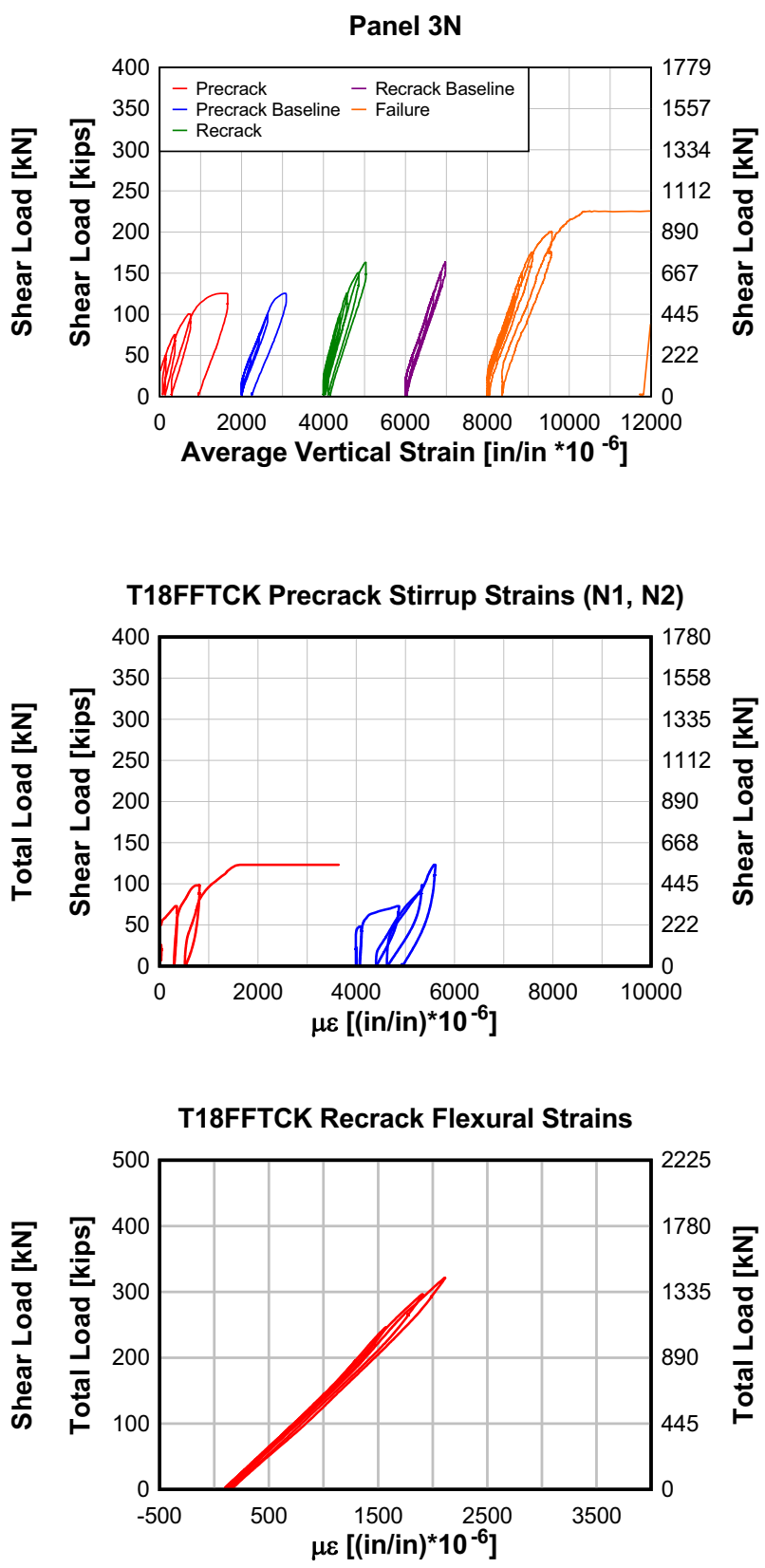
T18FFTCK Recrack Stirrup Strains (N1)

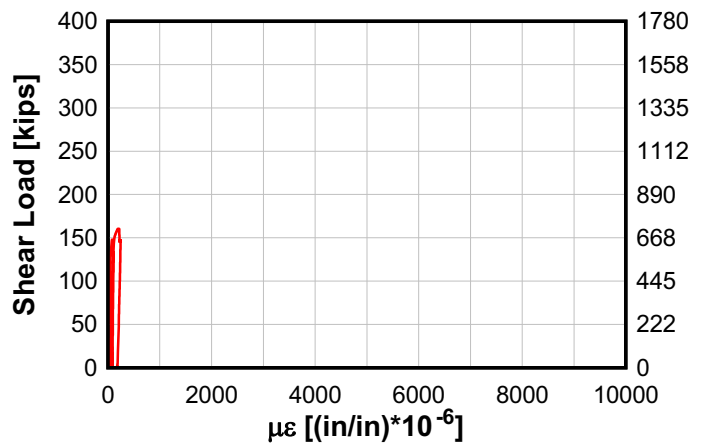

T18FFTCK Recrack North CFRP Strains

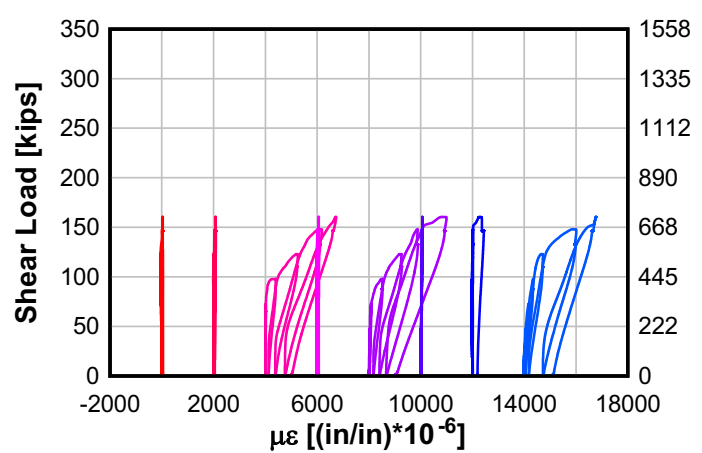

T18FFTCK Failure Flexural Strains

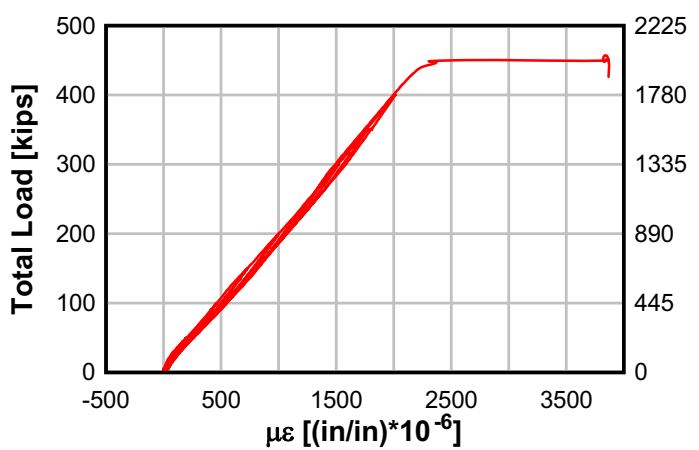

T18FFTCK Failure North CFRP Strains

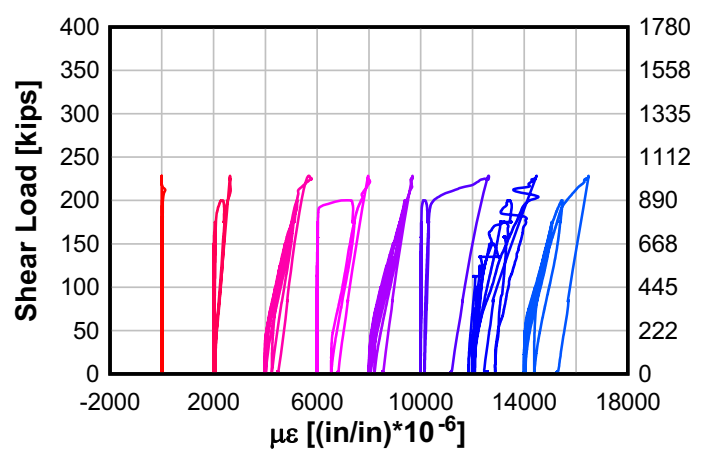

T18FFTCK Recrack Stirrup Strains (S2, S4)

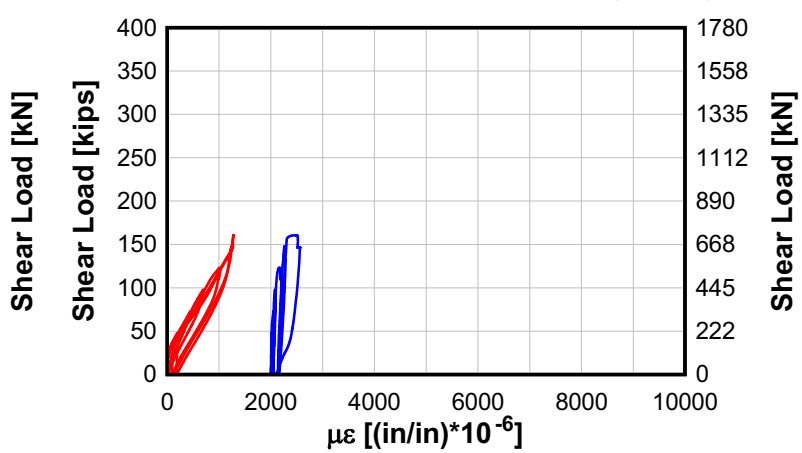

T18FFTCK Recrack South CFRP Strains

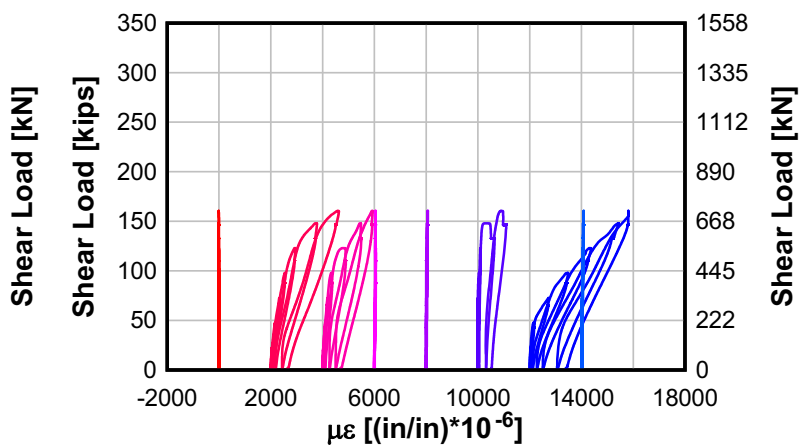

T18FFTCK Failure Stirrup Strains (N1)

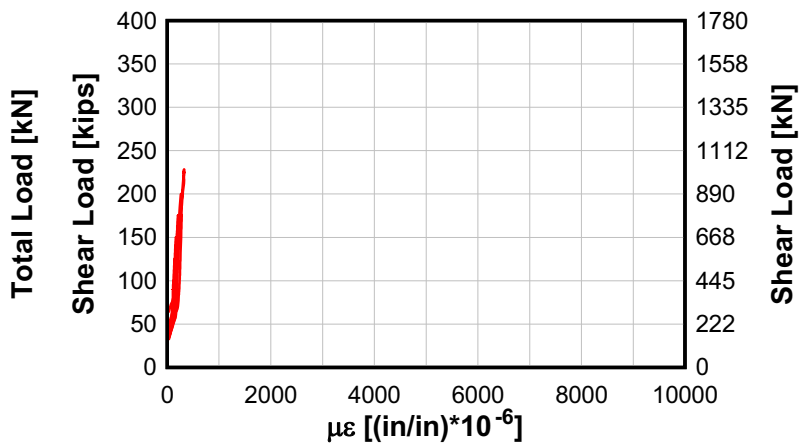

T18FFTCK Failure South CFRP Strains

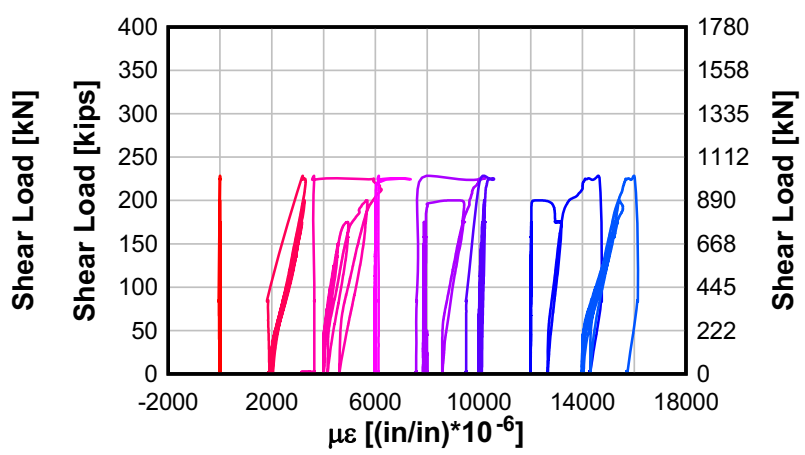


A-14 


\section{APPENDIX B: \\ SCALE EFFECTS ON REINFORCED CONCRETE BEAMS STRENGTHENED FOR SHEAR WITH DISCRETE EXTERNALLY BONDED CARBON FIBER-REINFORCED POLYMER U-WRAPS}





\section{SCALE EFFECTS ON REINFORCED CONCRETE BEAMS STRENGTHENED FOR SHEAR WITH DISCRETE EXTERNALLY BONDED CARBON FIBER-REINFORCED POLYMER U-WRAPS APPENDIX B: TABLE OF CONTENTS}

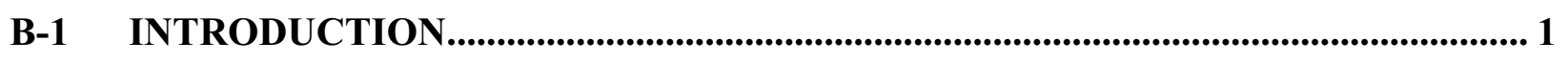

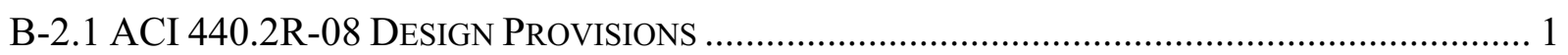

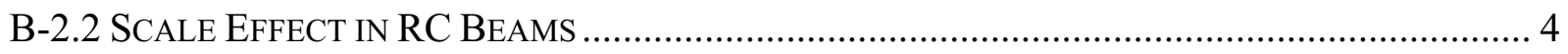

B-3 RESEARCH SIGNIFICANCE ....................................................................................... 5

B-4 EXPERIMENTAL PROGRAM.......................................................................... 6

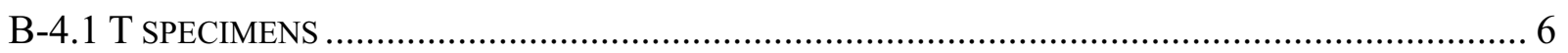

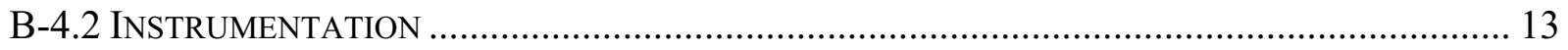

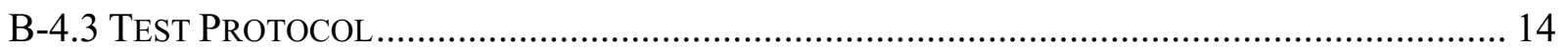

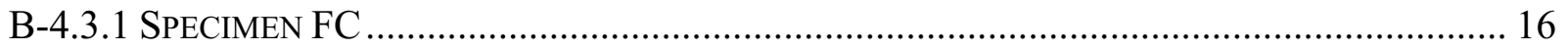

B-4.3.2 Specimen FT10 ................................................................................................................. 19

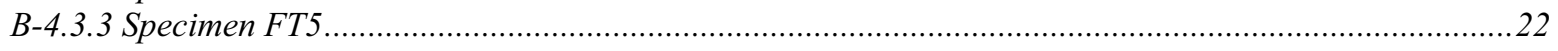

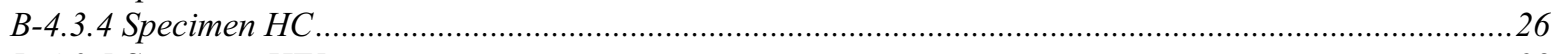

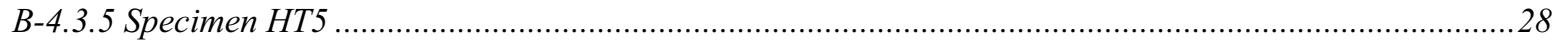

B-4.3.6 Specimen HT2.5 ……………………………………………………………... 31

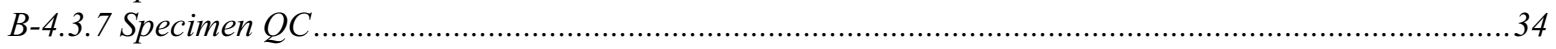

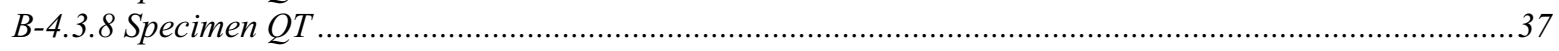

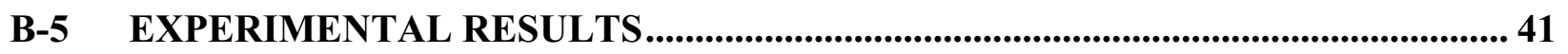

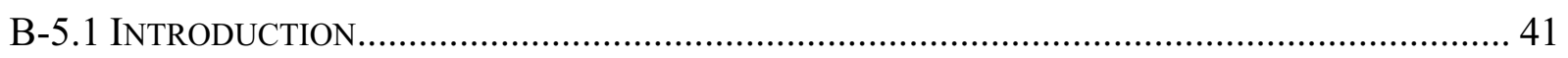

B-5.2 SURFACE STRAIN MEASUREMENTS IN CFRP STRIPS.................................................. 41

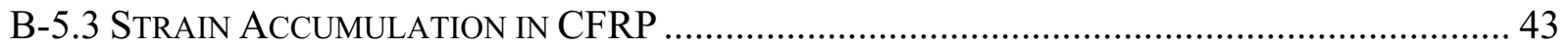

B-5.4 LOCAL STRAIN VARIATION ………………………........................................... 48

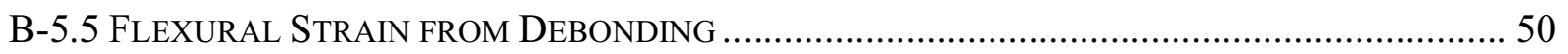

B-5.6 Redistribution OF STRAIN UPON MANUAL REMOVAL OF CFRP .................................. 54

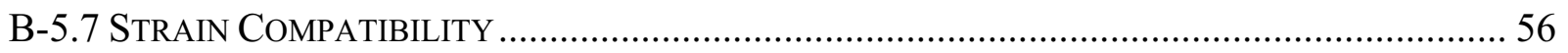

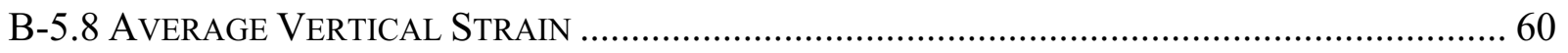

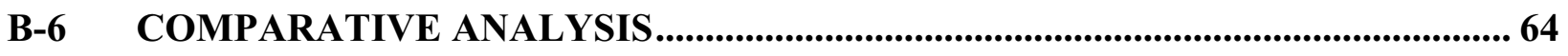

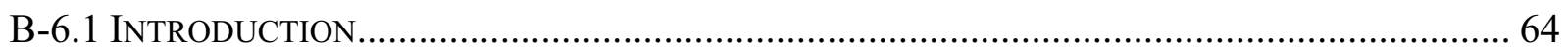

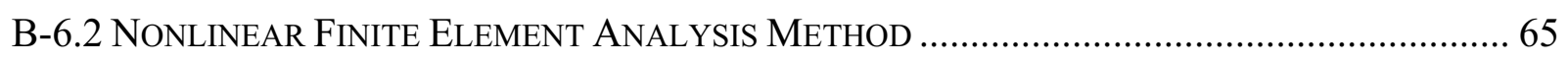

B-6.3 ShEAR ConTRIBUTION OF CFRP USING FinITE ElEMENT ANALYSIS................................. 68

B-6.4 CFRP SHEAR CONTRIBUTION USING EXPERIMENTAL RESULTS........................................ 70

B-6.5 CFRP SHEAR CONTRIBUTION USING ACI.................................................................. 70

B-6.6 COMPARISON OF BASE CAPACITY AND CFRP CONTRIBUTION......................................... 71

B-7 CONCLUSIONS ............................................................................................................... 72

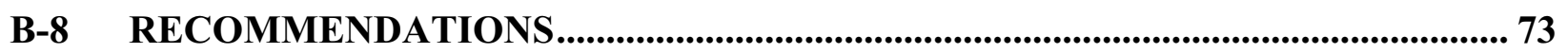


B-8.1 SCALING VARIABLES ……………………….................................................... 73

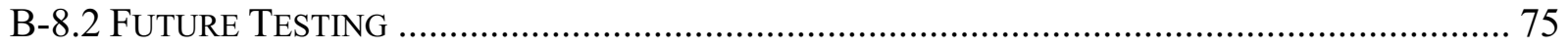

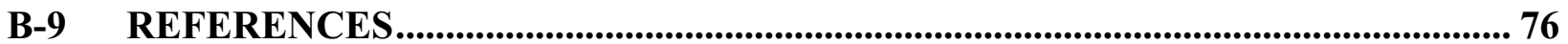

\section{APPENDIX B: LIST OF TABLES}

Table B-4.1: Specimen dimensions, effective depths and steel reinforcement ratios.............................................6

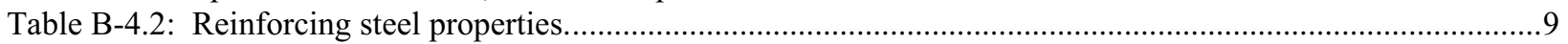

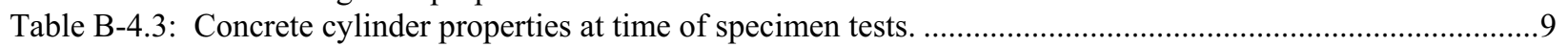

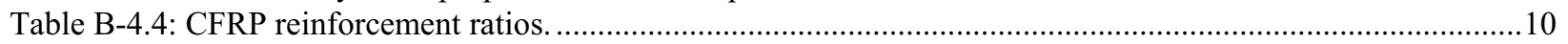

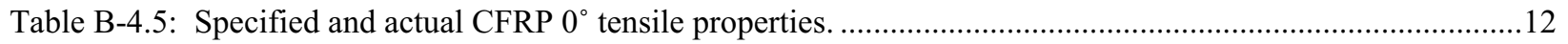

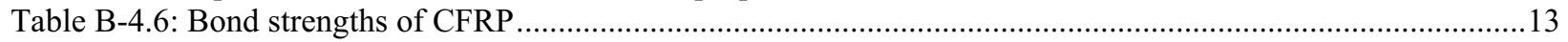

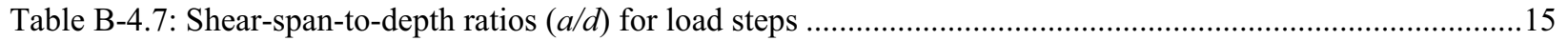

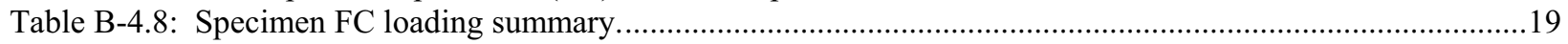

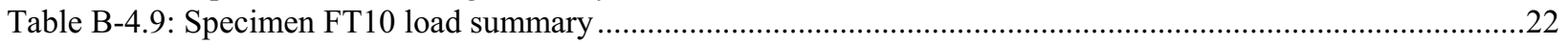

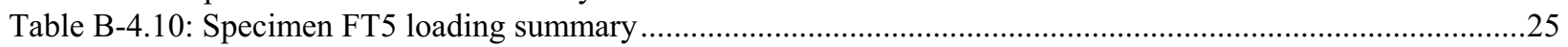

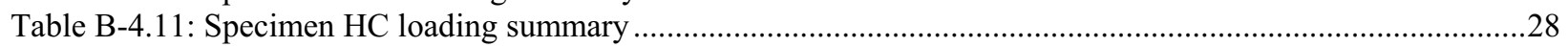

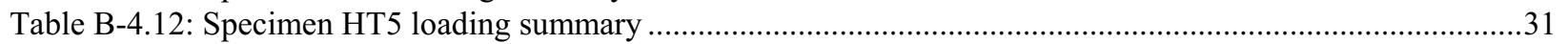

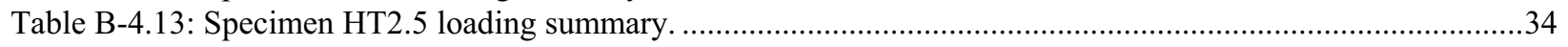

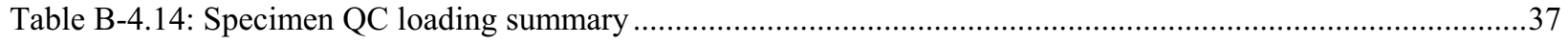

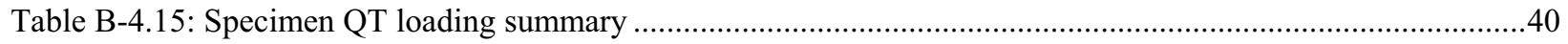

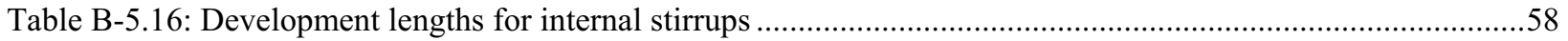

Table B-6.1: CFRP shear contributions from finite element model, experimental data and ACI ...........................68

Table B-6.2: Variation between shear contributions from finite element model and ACI .......................................70

Table B-8.1: Possible values for further scaled tests ........................................................................................... 74

\section{APPENDIX B: LIST OF FIGURES}

Figure B-4.1: Elevation views of specimens FT10, HT2.5 and QT ……........................................................

Figure B-4.2: Cross-sectional views of specimens FT10, HT2.5 and QT ............................................................

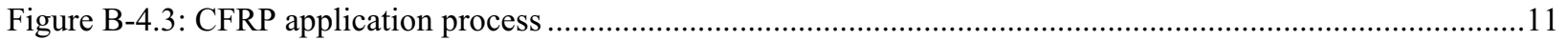

Figure B-4.4: Cohesive failure of concrete surface bonded to CFRP caused by direct-tension pull-off tests .............13

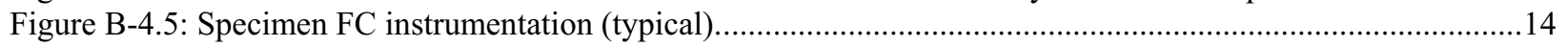

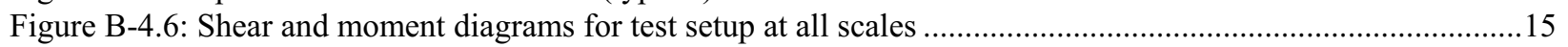

Figure B-4.7: Loading frames for full, half and quarter scale beams.................................................................16

Figure B-4.8: Shear versus displacement for Specimen FC ........................................................................... 17

Figure B-4.9: Specimen FC crack observations, support configurations and strain gage locations............................18

Figure B-4.10: Shear versus displacement for Specimen FT10 ........................................................................20

Figure B-4.11: Specimen FT10 crack maps and strain gages.........................................................................21

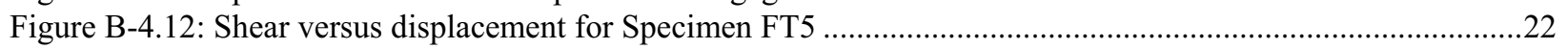

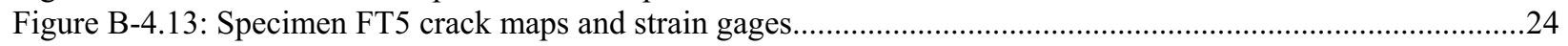

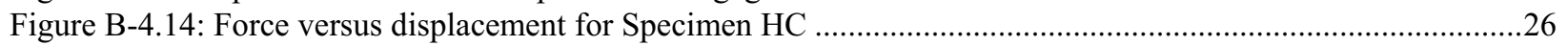

Figure B-4.15: Specimen HC crack propagation maps and strain gages...............................................................27

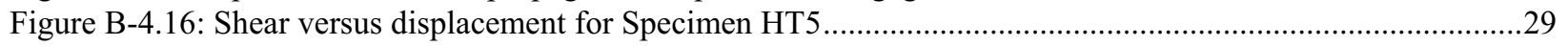

Figure B-4.17: Specimen HT5 crack propagation maps and strain gage locations ..................................................30

Figure B-4.18: Shear versus displacement for Specimen HT2.5 ...........................................................................32

Figure B-4.19: Specimen HT2.5 crack propagation maps and strain gage locations ................................................33

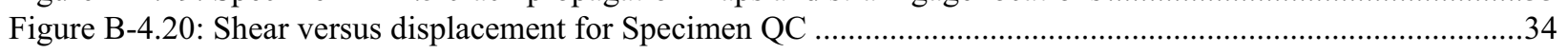

Figure B-4.21: Specimen QC crack propagation maps and strain gage locations ....................................................36

Figure B-4.22: Shear versus displacement for Specimen QT ........................................................................... 
Figure B-4.23: Specimen QT crack propagation maps and strain gage locations .....

Figure B-5.1: Strain gage length compared to CFRP strip heights. Gages represent 5\%, 10\% and 20\% of the CFRP strip length at the full, half and quarter scales, respectively

Figure B-5.2: Example applied shear versus (a) strain measured at CFRP gage 4S during load step 3b $(a / d=2.0)$ and (b) cumulative strain at CFRP gage $4 \mathrm{~S}$ from Specimen FC

Figure B-5.3: Applied shear versus measured (left column) and cumulative (right column) strain at CFRP gage 4S

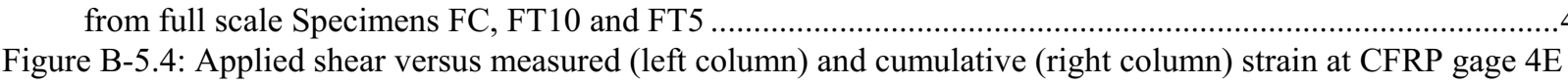

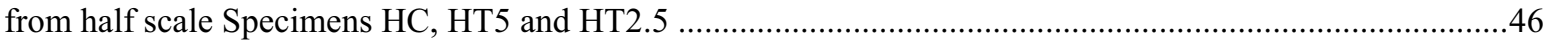

Figure B-5.5: Applied shear versus measured (left column) and cumulative (right column) strain at CFRP gage 4E from quarter scale Specimens QC and QT

Figure B-5.6: Applied shear versus cumulative strain at CFRP gages 3S, 4S and 5S from Specimen FC ..............49

Figure B-5.7: Photograph of a debonded CFRP strip that formerly crossed a diagonal crack (post-failure of Specimen FC).

Figure B-5.8: Illustrated section view of debonded CFRP at a diagonal crack ................................................52

Figure B-5.9: Assumed deflected shapes and boundary conditions for debonded portions of CFRP .....................53

Figure B-5.10: Modeled CFRP flexural-tension strains induced by debonding..............................................54

Figure B-5.11: Maximum measured strain in the internal stirrups and CFRP strips during load steps $2 \mathrm{~b}-2 \mathrm{~h}$ of

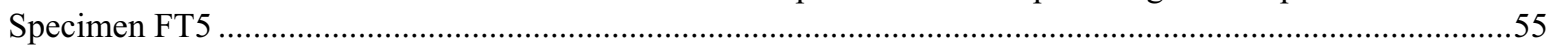

Figure B-5.12: Strain in adjacent internal stirrups and CFRP strips of Specimen FC........................................57

Figure B-5.13: Measured internal stirrup and CFRP strains for all specimens ..............................................59

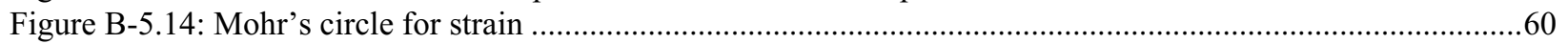

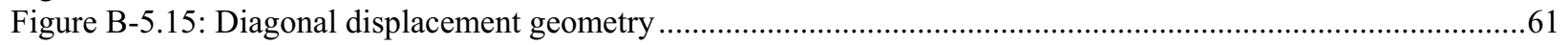

Figure B-5.16: Average panel strain in the vertical direction versus surface bonded strain gage strain for specimens

FC and FT5 during failure load steps (left column: internal stirrups, right column: CFRP) ........................62

Figure B-5.17: Applied shear versus average vertical strain for specimen FC during load step 3b......................63

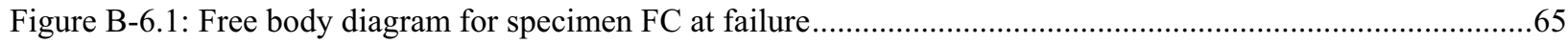

Figure B-6.2: Comparison of VecTor2 and Response-2000 analysis programs at $a / d=3.3$ for all $\mathrm{t}$ specimens (note: axis scales vary)

Figure B-6.3: Comparison of test curves and VecTor2 modeled base capacity at failure. 



\section{EXECUTIVE SUMMARY}

To investigate the possibility of conducting environmental exposure tests on reduced scale specimens with CFRP stirrups for shear, a separate experimental study was performed. Six specimens with rectangular cross-sections at three scales (full, half, and quarter scale) were constructed and tested. The prototype full-scale specimens were intended to reflect reasonable geometric proportions for cross-section as well as both flexural and transverse steel reinforcing ratios. The overall dimensions of the full-scale specimens were based on dimensions commonly seen at field-scale for conventionally reinforced concrete bridge girders. Half- and quarter-scale specimens were designed by geometrically scaling down the full-scale specimen. The applied structural forces, including moment and shear (and their interaction), were geometrically scaled very closely due to the approximately similar specimen depths, span lengths and geometrically scaled support and loading systems.

Although the geometric dimensions of the specimens were scaled accurately, material properties could not be ideally scaled, including concrete, steel, and CFRP. It was not possible to precisely scale the concrete materials and instead, the same batch of concrete was used in all specimen to reduce variability in concrete material properties. The concrete mix was modified based on the smallest specimen in selection of aggregate size to permit placement around the bars and cover. Longitudinal and transverse reinforcement ratios were kept the same in all specimens. For longitudinal reinforcement, the same bar size was used in all specimens and the longitudinal reinforcement ratio was adjusted by using the bars in a bundle to represent bars with larger areas in the larger scale specimens. However, due to the selection of the same material and bar size, it was not possible to geometrically scale the development lengths. For transverse reinforcement, use of different stirrup sizes at the different scales produced different scales of development lengths relative to the beam depths. Furthermore, single leg stirrups were used at the quarterscale instead of a closed stirrup, due to the limitation in width, and the single leg stirrups may not provide the same degree of confinement to the compression zone compared with the double-leg stirrups used at half- and full-scales. Because CFRP is produced in discrete thickness, the CFRP reinforcement was geometrically scaled by adjusting strip width and spacing. This produces differences between specimens in terms of crack control across the web, inconsistent CFRPconcrete bond stresses, as well as different proportions of exposed concrete surface areas relative to CFRP areas in terms of possible environmental exposure. Further, as testing progressed the specimens were observed to fail at different shear-moment interactions than anticipated and the amount of CFRP reinforcement and the a/d ratio had to be reduced (by moving the supports) to produce shear-dominant failures. Ultimately, the failed specimens did not have matching reinforcement CFRP ratios or similar shear-moment interactions.

In this appendix, the tests of scaled CFRP specimens are described in detail, and a comparative analysis to estimate CFRP shear contributions from experimental results, non-linear finite element analysis, and ACI 440.2R-08 is presented. Results indicate it was not practical to geometrically scale specimens such that all the important characteristics are preserved at reduced scales for environmental durability testing. 



\section{B-1 INTRODUCTION}

Many 1950s-vintage conventionally reinforced concrete (RC) deck girder bridges remain in the national inventory and are nearing the end of their originally intended design life. Field inspections in Oregon revealed large numbers of these bridges exhibit significant diagonal cracks in the girders and bent caps (Higgins et al. 2004). Over-estimation of the concrete contribution to shear resistance during design, reduced anchorage requirements for flexural steel, increasing service load magnitudes and volumes, as well as shrinkage and temperature effects, may contribute to diagonal cracking of bridge members. With the large population of cracked bridges and limited resources available for replacement, effective repair methods are needed. Many strengthening techniques for RC elements have been studied, including externally bonded steel plates, post-tensioning, internal and external stirrups as well as many others. Externally bonded carbon fiber-reinforced polymers (CFRP) are becoming more widely accepted for the repair and strengthening of RC members. CFRP materials possess many unique properties: they offer high strength for low weight, are relatively simple to apply, can be installed quickly and tend to have lower labor costs (Bakis et al. 2002).

\section{B-2 BACKGROUND}

Research on the use of externally bonded CFRP for RC beam strengthening began at the Swiss Federal Laboratories for Materials Testing and Research (EMPA) in 1984 (Meier et al. 1993). This research focused mainly on the flexural strengthening of RC beams, although several findings pertinent to shear strengthening were made. CFRP debonding from concrete was first observed and U-wraps were developed for shear. This research was conducted on moderately scaled laboratory beams and in-service structures.

In North America, externally bonded CFRP U-wraps are commonly designed with the ACI 440.2R-08 (2008) design code. A survey of transportation officials from 27 US states and Canadian provinces found that 10 states and 2 provinces had used FRP for shear strengthening (Higgins et al. 2006). Of those 12 states and provinces, 4 had used ACI 440.2R-08 for design.

\section{B-2.1 ACI 440.2R-08 DESIGN PROVISIONS}

The ACI design code for externally bonded CFRP for shear applications is based largely upon the results of small-scale tests. ACI 440.2R-08 references several researchers that have demonstrated RC beams partially-wrapped with CFRP possessed increased shear strengths 
(Malvar et al. 1995, Chajes et al. 1995, Sato et al. 1996, Norris et al. 1997, Kachlakev and McCurry 2000).

Malvar et al. (1995) tested a total of 6 rectangular beams without transverse steel reinforcement. Two of those beams were reinforced for shear by FRP jackets. These beams had effective depths, $d$, of $133 \mathrm{~mm}$ (5.25 in.), flexural-tension steel reinforcement ratios, $\rho_{s}$, of 0.00838 and overall lengths, $L$, of $1676 \mathrm{~mm}$ (66 in.). Chajes et al. (1995) developed an equation for FRP shear contribution based on tests of $12 \mathrm{~T}$-beams without transverse steel reinforcement. Eight of those beams were reinforced for shear with continuous FRP U-jackets. These beams had $d=152$ $\mathrm{mm}$ (6 in.), $\rho_{s}=0.0207$ and $L=1219 \mathrm{~mm}$ (48 in.). Sato et al. (1996) tested 6 rectangular beams without transverse steel reinforcement. Five of those beams were reinforced for shear with discrete or continuous side-bonded and U-jacketed FRP. These beams had $d=260 \mathrm{~mm}(10.2$ in.), $\rho_{s}=0.0328$ and $L=2200 \mathrm{~mm}$ ( $86 \mathrm{in}$.). Norris et al. (1997) tested 6 rectangular beams with transverse steel reinforcement that were precracked before 5 were strengthened for shear with FRP U-jackets. These beams had $d=163 \mathrm{~mm}$ (6.4 in.), $\rho_{s}=0.0193$ and $L=1219 \mathrm{~mm}$ (48 in.). Kachlakev and McCurry (2000) tested 4 rectangular beams without transverse steel reinforcement. Two of these beams were reinforced for shear by FRP U-jackets. These beams were designed to have the same capacity as a specific bridge that had been repaired with FRP in the field. These beams had $d=704 \mathrm{~mm}$ ( $27.7 \mathrm{in}$.), $\rho_{s}=0.00542$ and 0.00806 (tension steel was transitioned into the compression zone) and $L=6096 \mathrm{~mm}$ ( $240 \mathrm{in}$.).

Many different approaches were developed to predict FRP shear contribution during the late 1990s (Triantafillou 1998, Khalifa et al. 1998), and were calibrated with some of the ACI referenced research. These methods treated external FRP reinforcement analogously to internal steel reinforcement and assumed that the FRP contribution could be added to existing ACI concrete and steel contributions. Design equations were based upon strain in the FRP, which were limited to account for premature debonding failures. The total shear capacity was limited by the failure of a concrete strut in compression. The design methods presented by Triantafillou (1998) and Khalifa et al. (1998) were calibrated using t specimens with effective depths no greater than $0.36 \mathrm{~m}(14 \mathrm{in})$.

Khalifa et al. (1998) applied bond strength models based upon material tests (Horiguchi and Saeki 1997, Maeda et al. 1997) to limit the strain in the FRP at failure. Horiguchi and Saeki (1997) determined that different FRP-to-concrete bond tests provided different estimates of bond strength. Relationships between concrete compressive strength and bond strength were developed for each test. Maeda et al. (1997) determined through material tests that FRP bond strength was dependent on an effective bond length. The ultimate strength of FRP strips of varying bond lengths were the same as long as the actual bond length was longer than the effective bond length.

The ACI 440.2R-08 design code for externally bonded FRP adopted the approach of Triantafillou (1998), Khalifa et al. (1998) and others. The code acknowledges the strain limitations used to account for debonding, the use of moderate-scale specimens, the need for realistically scaled tests and an improved design approach. A brief summary of the ACI 440.2R-08 design method for U-wraps follows. 
ACI 440.2R-08 limits the ultimate strain of the FRP, $\varepsilon_{f u}$, to an effective strain, $\varepsilon_{f e}$, using a bondreduction coefficient, $\kappa_{v}$, which is based on the development length, $L_{e}(\mathrm{~mm})$ (in.), and other FRP properties:

$$
\begin{gathered}
L_{e}=\frac{416}{\left(n t_{f} E_{f}\right)^{0.58}} \\
L_{e}=\frac{2500}{\left(n t_{f} E_{f}\right)^{0.58}} \\
k_{1}=\left(\frac{f_{c}{ }^{\prime}}{254}\right)^{2 / 3} \\
k_{1}=\left(\frac{f_{c}{ }^{\prime}}{4000}\right)^{2 / 3} \\
k_{2}=\left(\frac{d_{f}-L_{e}}{d_{f}}\right) \\
\kappa_{v}=\frac{k_{1} k_{2} L_{e}}{468 \varepsilon_{f u}} \leq 0.75 \\
\varepsilon_{f e}=\kappa_{v} \varepsilon_{f u} \leq 0.004
\end{gathered}
$$

where $n=$ number of FRP layers, $t_{f}=$ FRP thickness (mm) (in.), $E_{f}=$ FRP elastic modulus (GPa) (ksi), $f_{c}{ }^{\prime}=$ concrete compression strength $(\mathrm{MPa})(\mathrm{psi})$ and $d_{f}=$ depth of FRP reinforcement $(\mathrm{mm})$ (in.).

ACI 440.2R-08 treats the FRP analogously to internal steel reinforcement to calculate its shear contribution, $V_{f}$, with the exception of the limited effective strain for debonding failure:

$$
\begin{gathered}
A_{f v}=2 n t_{f} w_{f} \\
f_{f e}=\varepsilon_{f e} E_{f} \\
V_{f}=\frac{A_{f v} f_{f e}(\sin \alpha+\cos \alpha) d_{f}}{s_{f}}
\end{gathered}
$$

where $w_{f}=$ FRP strip width (mm) (in.), $f_{f e}=$ effective FRP strength $(\mathrm{MPa})(\mathrm{ksi}), A_{f v}=$ area of FRP shear reinforcement $\left(\mathrm{mm}^{2}\right)\left(\right.$ in. $\left.^{2}\right), \alpha=$ FRP strip orientation from horizontal axis $\left({ }^{\circ}\right)$ and $s_{f}=$ FRP strip spacing (mm) (in.). 
ACI 440.2R-08 takes a reduced FRP shear contribution, $\psi_{f} V_{f}(\mathrm{~N})(\mathrm{lb})$, and combines it with the concrete, $V_{c}(\mathrm{~N})(\mathrm{lb})$, and steel, $V_{s}(\mathrm{~N})(\mathrm{lb})$, shear contributions from ACI 318-08 with reinforcement limits:

$$
\begin{gathered}
\phi V_{n}=\phi\left(V_{c}+V_{s}+\psi_{f} V_{f}\right) \\
V_{s}+V_{f} \leq 0.66 \sqrt{f_{c}{ }^{\prime}} b_{w} d \\
V_{s}+V_{f} \leq 8 \sqrt{f_{c}{ }^{\prime}} b_{w} d
\end{gathered}
$$

where $f_{c}{ }^{\prime}=$ concrete compression strength (MPa) (psi), $b_{w}=$ beam width (mm) (in.) and $d=$ effective depth (mm) (in.). The reduction factor for shear, $\phi$, is equal to 0.85 , as stated in ACI 318-08. The additional reduction factor for FRP, $\psi_{f}$, is equal to 0.85 for U-wrapping. The ACI 318-08 concrete shear contribution for members subjected to shear and flexure is expressed in Equation (11-3) US:

$$
V_{c}=2 \sqrt{f_{c}} b_{w} d
$$

The ACI 318-08 transverse steel shear contribution is expressed in Equation (11-15) US:

$$
V_{s}=\frac{A_{v} f_{y t} d}{s}
$$

where $A_{v}=$ area of transverse steel reinforcement $\left(\mathrm{mm}^{2}\right)\left(\right.$ in. $\left.^{2}\right), f_{y t}=$ transverse steel yield strength (MPa) (ksi) and $s=$ spacing (mm) (in.).

Testing of five full-scale beams repaired with CFRP indicated that the ACI approach provided conservative shear capacity predictions for T-beams and less conservative shear capacity predictions for inverted T-beams (Higgins et al. 2006). For a consistent level of reliability, Higgins et al. (2006) recommended a reduction factor of 2 when CFRP strips are anchored in flexural-tension zones. T-beams had $d=1115 \mathrm{~mm}$ (43.9 in.), $\rho_{s}=0.0152$ and $L=7925 \mathrm{~mm} \mathrm{(312}$ in.). Inverted T-beams had $d=1151 \mathrm{~mm}$ (45.3 in.), $\rho_{s}=0.0148$ and $L=7925 \mathrm{~mm}$ (312 in.). Higgins et al. (2006) cautioned that the effect of scale on RC beams was not well understood.

\section{B-2.2 SCALE EFFECT IN RC BEAMS}

Kani (1967) noted that then-current ACI shear design provisions were based upon beam tests with depths less than $380 \mathrm{~mm}$ (15 in.) and did not consider strength reduction at larger scales. Kani (1967) believed that increasing the effective depth would reduce beam capacity and he developed a series of tests using RC beams with no transverse steel reinforcement, regularly varying depths and consistent flexural reinforcement ratios to demonstrate this concept. Kani (1967) also observed that beam behavior depended heavily on the shear span-to-depth ratio, $a / d$, 
when all other properties remained constant, and that beam width had no significant effect on relative beam strength.

Kuchma et al. (1997) determined through RC beam tests found in the literature, mostly without transverse steel reinforcement, that the scale effect on shear capacity was related to the distance between layers of longitudinal reinforcement. Kuchma et al. (1997) stated that members of any height with equally spaced layers of longitudinal reinforcement failed at about the same shear stress. Increasing the longitudinal reinforcement ratio, $\rho_{s}$, was found to reduce crack widths and increase shear capacity.

Angelakos et al. (2001) described the results from 21 tests of large-scale, lightly reinforced concrete members. The tests indicated that concrete cylinder strength had little effect on shear capacity while increased longitudinal reinforcement ratios and the presence of transverse steel reinforcement increased capacity. Angelakos et al. (2001) stated that the ACI method overestimated the shear capacity of large beams when minimum stirrups were provided and recommended the use of AASHTO LRFD shear design provisions, which were developed using modified compression field theory (MCFT) and provided more consistent results.

Tompos and Frosch (2002) tested six full- and half-scale beams with effective depth, length and width scaled geometrically, having constant longitudinal steel reinforcement ratios and $d / s$, and constructed from a single batch of concrete and consistent heats of reinforcing steel. Tompos and Frosch (2002) used the results from these tests with additional results from the literature to draw conclusions about the effect of scale on RC beam shear capacity. It was concluded that ACI overestimated the concrete shear contribution, which is not influenced by shear reinforcement but longitudinal reinforcement. Tompos and Frosch (2002) stated that for values of $\rho_{s} \leq 1 \%$, which are common in design, the actual concrete contribution was less than that predicted by ACI Equation (11-3). They also concluded that stirrup shear contribution was determined by its location relative to the failure diagonal crack, the number of stirrups crossing the failure diagonal crack and the stirrup development length.

The literature on scale effects in RC beams emphasizes that the ACI shear contribution predictions are not consistent for beams with effective depths larger than those on which the code was based. Shear capacity in RC beams has been correlated to effective depth, $a / d$ ratio, and the amount of longitudinal reinforcement. Scaled beam tests from the literature were used to guide the design of CFRP strengthened specimens in this project.

\section{B-3 RESEARCH SIGNIFICANCE}

The provisions of ACI 440.2R-08 for shear strengthening were developed using experimental results from small-sized specimens. Small-scale reinforced concrete (RC) beams repaired with externally bonded carbon fiber-reinforced polymers (CFRP) would be preferable for experimental studies since more tests could be conducted than with full-scale beams given the same level of resources. Each small-scale beam would require less construction time, fewer 
materials and smaller load frames with lower capacities, which would facilitate testing at more laboratories. Conditioning time for environmental durability studies would be greatly reduced since more specimens could fit into a climatic chamber and it would take less time to cycle the temperature regime of the concrete.

Unfortunately, the effect of scale is not well understood for CFRP applications to RC beams. The results from small-scale testing may not be directly extrapolated to full-scale beams. This appendix describes an experimental program for six RC beams strengthened for shear with externally bonded CFRP at three geometric scales and offers recommendations for further research.

\section{B-4 EXPERIMENTAL PROGRAM}

\section{B-4.1 TEST SPECIMENS}

Six specimens at three scales $(\mathrm{F}=$ full, $\mathrm{H}=$ half, and $\mathrm{Q}=$ quarter scale) were used in a series of eight tests to characterize the behavior of CFRP shear strengthened RC beams. Overall height, width and length of the specimens were scaled geometrically, as shown in Table B-4.1

Schematics of specimen elevations and sections may be found in Figures B-4.1 and B-4.2.

Table B-4.1: Specimen dimensions, effective depths and steel reinforcement ratios.

\begin{tabular}{l|l|l|l|l|l|l}
\hline Scale & $\begin{array}{l}\boldsymbol{L} \\
(\mathbf{m m})(\mathbf{i n .})\end{array}$ & $\begin{array}{l}\boldsymbol{b}_{\boldsymbol{w}} \\
(\mathbf{m m})(\mathbf{i n .})\end{array}$ & $\begin{array}{l}\boldsymbol{h} \\
(\mathbf{m m})(\mathbf{i n} .)\end{array}$ & $\begin{array}{l}\boldsymbol{d} \\
(\mathbf{m m})(\mathbf{i n} .)\end{array}$ & $\boldsymbol{\rho}_{\boldsymbol{s}}$ & $\boldsymbol{\rho}_{\boldsymbol{v}}$ \\
\hline $\mathrm{F}$ & $\begin{array}{l}7920 \\
(312)\end{array}$ & $\begin{array}{l}356 \\
(14)\end{array}$ & $\begin{array}{l}1070 \\
(42)\end{array}$ & $\begin{array}{l}937 \\
(36.9)\end{array}$ & 0.0134 & 0.00238 \\
\hline $\mathrm{H}$ & $\begin{array}{l}3960 \\
(156)\end{array}$ & $\begin{array}{l}178 \\
(7)\end{array}$ & $\begin{array}{l}533 \\
(21)\end{array}$ & $\begin{array}{l}464 \\
(18.3)\end{array}$ & 0.0138 & 0.00238 \\
\hline $\mathrm{Q}$ & $\begin{array}{l}(780 \\
(78)\end{array}$ & $\begin{array}{l}88.9 \\
(3.5)\end{array}$ & $\begin{array}{l}267 \\
(10.5)\end{array}$ & $\begin{array}{l}238 \\
(9.38)\end{array}$ & 0.0136 & 0.00238 \\
\hline
\end{tabular}

The relatively small flexural reinforcing steel ratios were similar to RC bridge beams seen in practice and were approximately the same at each scale. Longitudinal flexural-tension steel reinforcement for all specimens consisted of \#19 ASTM A615 Grade 420 (\#6 Grade 60) bars. Longitudinal compression steel reinforcement for all specimens consisted of \#13 ASTM A615 Grade 420 (\#6 Grade 60) bars. Longitudinal bars in the full-scale specimens were bundled in four-bar groups. Transverse steel consisted of \#13 ASTM A615 Grade 280 (\#4 Grade 40) open stirrups for the full-scale specimens, undeformed $6 \mathrm{~mm}$ (\#2) ASTM A36 open stirrups for the half-scale and undeformed $6 \mathrm{~mm}$ (\#2) ASTM A36 alternating single leg stirrups for the quarterscale. Reinforcing steel was fabricated by a local rebar fabricator and the materials were from the same heats for all the different scales. 

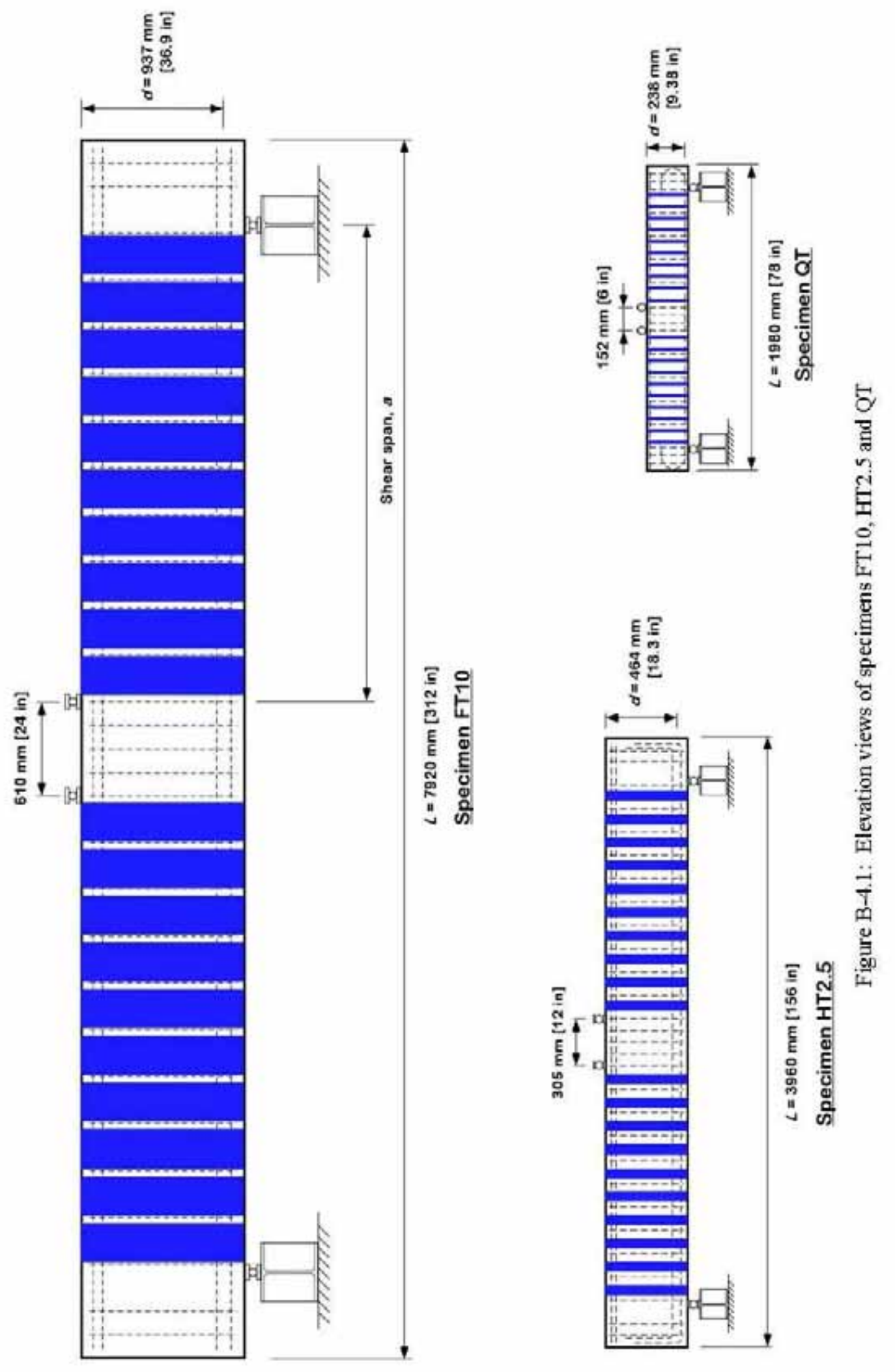


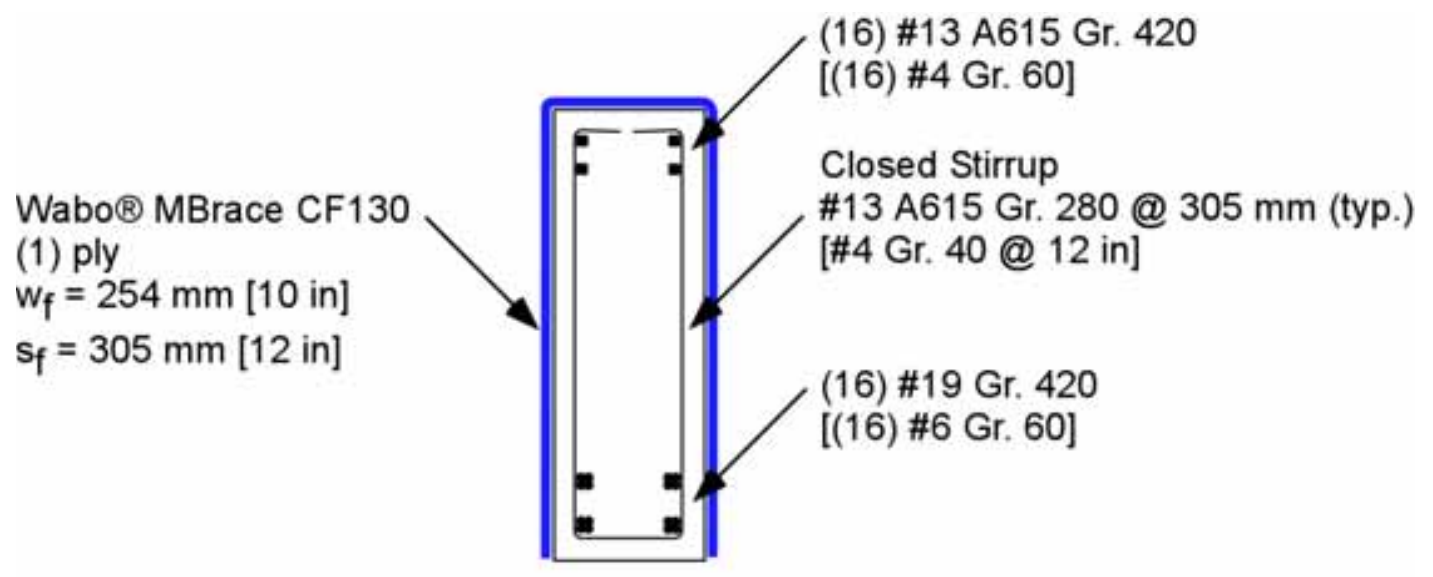

\section{Specimen FT10}

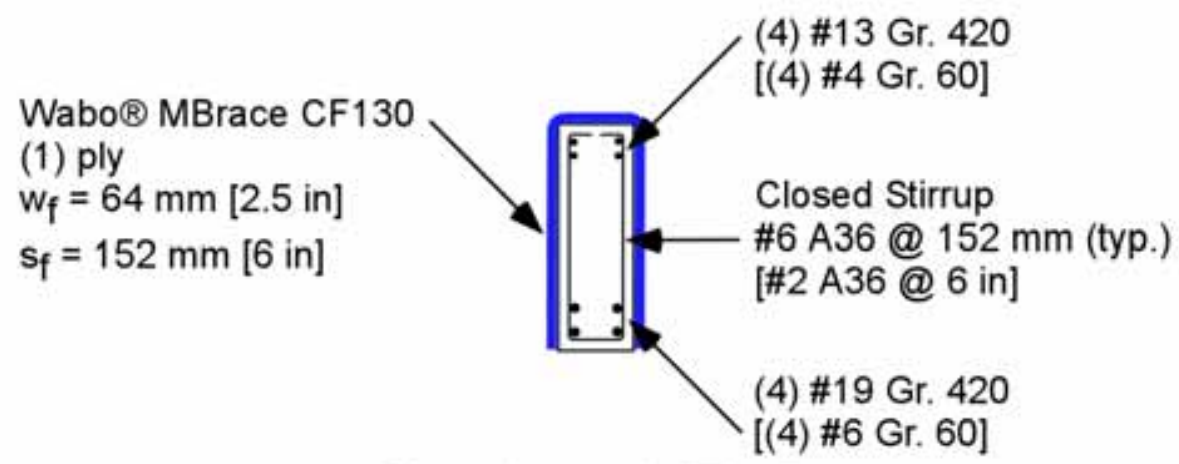

Specimen HT2.5

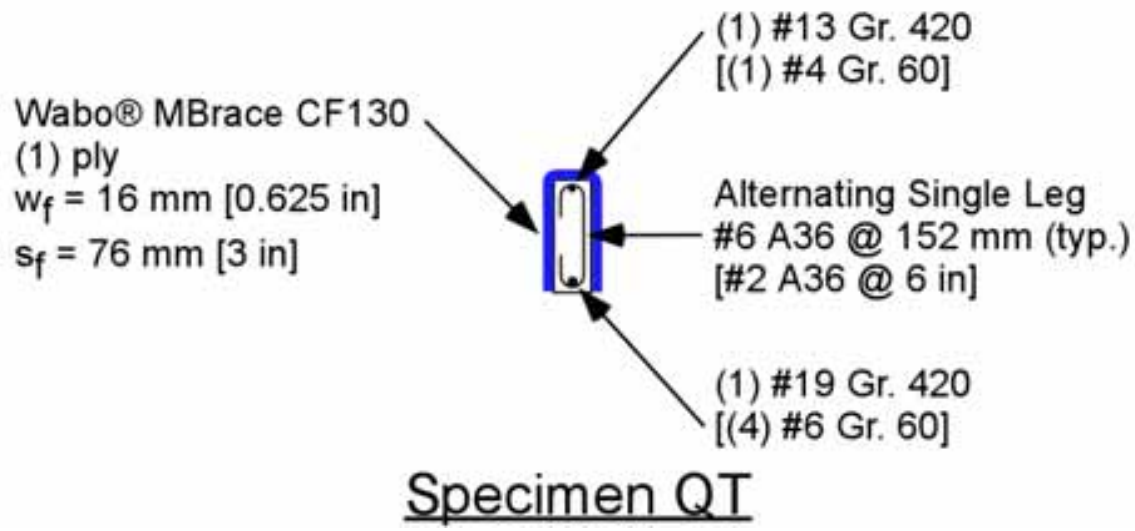

Figure B-4.2: Cross-sectional views of specimens FT10, HT2.5 and QT

Actual steel reinforcing properties were determined from tensile tests per ASTM A 370 and ASTM E 8. Three $406 \mathrm{~mm}$ (16 in.) long samples were cut from each material and tested with a $489 \mathrm{kN}$ (110 kip) universal testing machine. Tensile specimens were tested with constant head 
speeds of $0.0169 \mathrm{~mm} / \mathrm{sec}(0.000667 \mathrm{in} . / \mathrm{sec})$ for \#13 (\#4) and \#19 (\#6) bars and $0.0141 \mathrm{~mm} / \mathrm{sec}$ $(0.000556 \mathrm{in} . / \mathrm{sec})$ for \#6 (\#2) bars. Strain was measured using a class B1 extensometer with 50 $\mathrm{mm}$ (2 in.) gage length. Data were recorded at a frequency of $10 \mathrm{~Hz}$ using commercially available data acquisition software. Measured steel properties are given in Table B-4.2.

Table B-4.2: Reinforcing steel properties.

\begin{tabular}{|c|c|c|c|c|}
\hline Material & $\begin{array}{l}\begin{array}{l}\text { Bar Size } \\
(\mathrm{mm}) \text { (in.) }\end{array} \\
\end{array}$ & $\begin{array}{l}\text { Grade } \\
(\mathrm{MPa})(\mathrm{ksi})\end{array}$ & $\begin{array}{l}f_{y} \\
(\mathrm{MPa})(\mathrm{ksi})\end{array}$ & $\begin{array}{l}f_{\text {ult }} \\
(\mathrm{MPa})(\mathrm{ksi})\end{array}$ \\
\hline F Stirrups & $\begin{array}{l}\# 13 \\
(\# 4)\end{array}$ & $\begin{array}{l}\text { A615 Gr. } 280 \\
\text { (Gr. 40) }\end{array}$ & $\begin{array}{l}326 \\
(47.3)\end{array}$ & $\begin{array}{l}529 \\
(76.7)\end{array}$ \\
\hline $\begin{array}{l}\mathrm{H} \text { and } \mathrm{Q} \\
\text { Stirrups }\end{array}$ & $\begin{array}{l}\# 6 \\
(\# 2)\end{array}$ & A 36 & $\begin{array}{l}308 \\
(44.6)\end{array}$ & $\begin{array}{l}443 \\
(64.3)\end{array}$ \\
\hline Compr. Steel & $\begin{array}{l}\# 13 \\
(\# 4)\end{array}$ & $\begin{array}{l}\text { A615 Gr. } 420 \\
\text { (Gr. 60) }\end{array}$ & $\begin{array}{l}453 \\
(65.7)\end{array}$ & $\begin{array}{l}752 \\
(109)\end{array}$ \\
\hline Flexural Steel & $\begin{array}{l}\# 19 \\
(\# 6) \\
\end{array}$ & $\begin{array}{l}\text { A615 Gr. } 420 \\
\text { (Gr. 60) }\end{array}$ & $\begin{array}{l}402 \\
(58.3) \\
\end{array}$ & $\begin{array}{l}680 \\
(98.6) \\
\end{array}$ \\
\hline
\end{tabular}

Concrete was delivered to the laboratory by a local ready-mix supplier. A single concrete mix design was used for all test specimens, which were cast simultaneously. The concrete mix was designed to have properties similar to 1950 s vintage concrete, specifically a lower compression strength and lack of admixtures. Target 28-day compression strength was $20.7 \mathrm{MPa}$ (3000 psi) and the maximum aggregate size was $13 \mathrm{~mm}(0.5 \mathrm{in}$.). Actual 28-day cylinder compression strength was $27.8 \mathrm{MPa}(4030 \mathrm{psi})$. Results from cylinder compression and split tensile tests taken at the day of test for each specimen are shown in Table B-4.3.

Table B-4.3: Concrete cylinder properties at time of specimen tests.

\begin{tabular}{l|l|l}
\hline Specimen & $\begin{array}{l}\boldsymbol{f}^{\prime}{ }_{\boldsymbol{c}} \\
(\mathbf{M P a})(\mathbf{p s i})\end{array}$ & $\begin{array}{l}\boldsymbol{f}_{\boldsymbol{t}} \\
(\mathbf{M P a})(\mathbf{p s i})\end{array}$ \\
\hline $\mathrm{FC}$ & $32.1(4660)$ & $2.65(385)$ \\
\hline $\mathrm{FT}$ & $33.4(4850)$ & $2.86(415)$ \\
\hline $\mathrm{HC}$ & $32.8(4760)$ & $2.79(405)$ \\
\hline $\mathrm{HT}$ & $33.7(4890)$ & $2.79(405)$ \\
\hline $\mathrm{QC}$ & $34.6(5020)$ & $2.93(425)$ \\
\hline $\mathrm{QT}$ & $34.6(5020)$ & $2.93(425)$ \\
\hline
\end{tabular}

All specimens were strengthened with externally bonded CFRP strips in a U-wrap configuration. This configuration was chosen as it represents the most likely bridge retrofit condition, i.e. where full wrapping is prohibited by the deck. Specimens with labels ending in "T" had CFRP strips with the free edge in the tension zone ( $\mathrm{T}=$ tension zone), while labels ending in " $\mathrm{C}$ " had CFRP strips with the free edge in the compression zone $(\mathrm{C}=$ compression zone). The free edge terminating in the tension zone simulated an application in a negative moment region for a continuous bridge girder (i.e. span near continuous support). The free edge in the compression zone simulated an application in a positive moment region for a bridge girder (i.e. near an abutment or joint). 
A number following the two-letter designation indicates the width of fabric in inches for specimens tested twice (i.e. FT10, FT5, HT5, HT2.5). CFRP strip widths were reduced by manually removing portions. CFRP strip widths and reinforcement ratios for each specimen are provided in Table B-4.4.

Table B-4.4: CFRP reinforcement ratios.

\begin{tabular}{l|l|l}
\hline Specimen & $\begin{array}{l}\mathbf{w}_{\mathbf{f}} \\
(\mathbf{m m})(\mathbf{i n} .)\end{array}$ & $\boldsymbol{\rho}_{\mathbf{f}}$ \\
\hline FC & $254(10)$ & 0.00238 \\
\hline FT10 & $254(10)$ & 0.00476 \\
\hline FT5 & $127(5)$ & 0.00238 \\
\hline HC & $127(5)$ & 0.00952 \\
\hline HT5 & $127(5)$ & 0.00952 \\
\hline HT2.5 & $64(2.5)$ & 0.00476 \\
\hline QC & $16(0.625)$ & 0.00476 \\
\hline QT & $16(0.625)$ & 0.00476 \\
\hline
\end{tabular}

The RC beams were cured for three months before CFRP was applied. Application involved several steps, illustrated by Figure B-4.3(a) - (f), in accordance with the manufacturer's product specifications (Watson Bowman Acme 2002). All of the CFRP materials were provided by the Watson Bowman Acme Corporation (BASF) and consisted of the Wabo® MBrace CF130 unidirectional high strength carbon fiber fabric, low viscosity epoxy primer, high viscosity epoxy paste ("putty") and epoxy encapsulation resin ("saturant").

The RC beams were first ground to remove the surface layer of material (Figure B-4.3(a)). Heated tents were constructed around the specimens to raise their temperature before application. The CFRP primer coat was applied with $9.5 \mathrm{~mm}(3 / 8 \mathrm{in}$.) nap rollers to the clean, prepared surface (Figure B-4.3(b)). Before the primer cured, the putty was applied using drywall taping knives and trowels (Figure B-4.3(c)). The putty filled surface voids in the concrete. The first coat of saturant was then applied to the surface of the beam using fresh $9.5 \mathrm{~mm}(3 / 8 \mathrm{in}$.) nap rollers once the putty became viscous enough to remain in the concrete voids (Figure B-4.3(d)). Pre-cut fabric was then placed on the saturant and plastic putty knives were used to thoroughly work the saturant into the fibers (Figure B-4.3(e)). A final layer of saturant was applied, which helped to further saturate the fibers (Figure B-4.3(f)). 


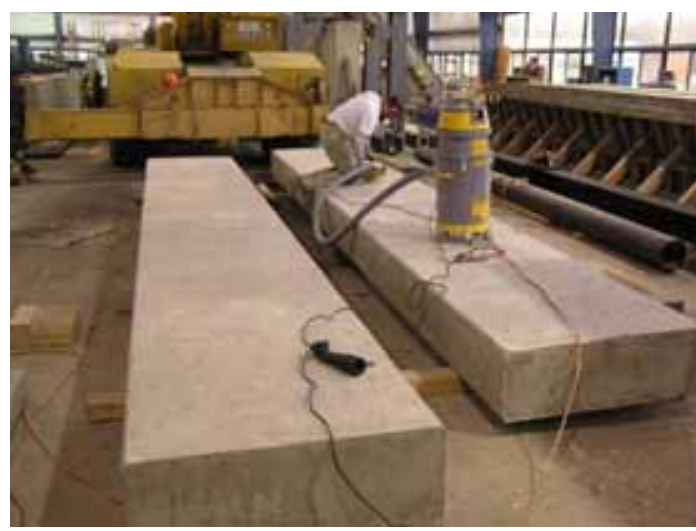

(a)

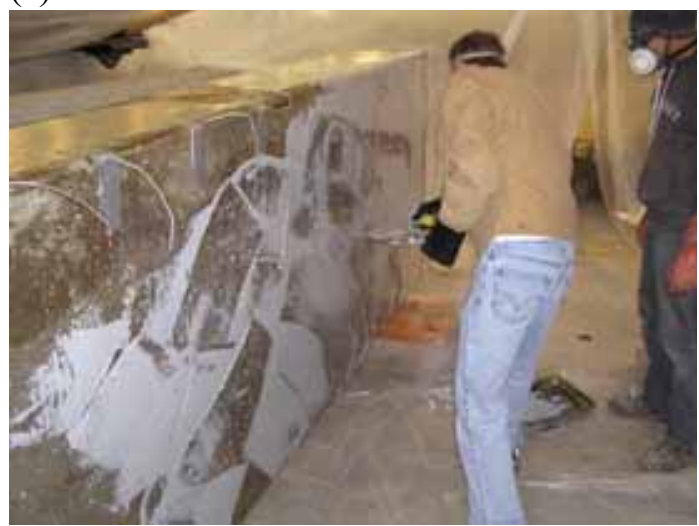

(c)

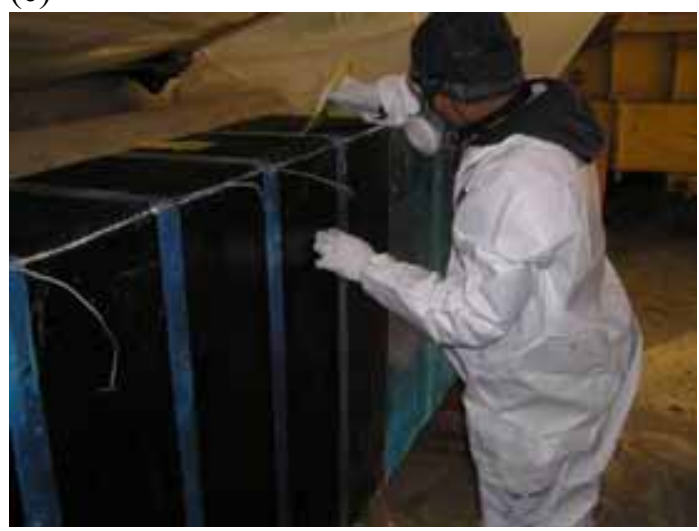

(e)

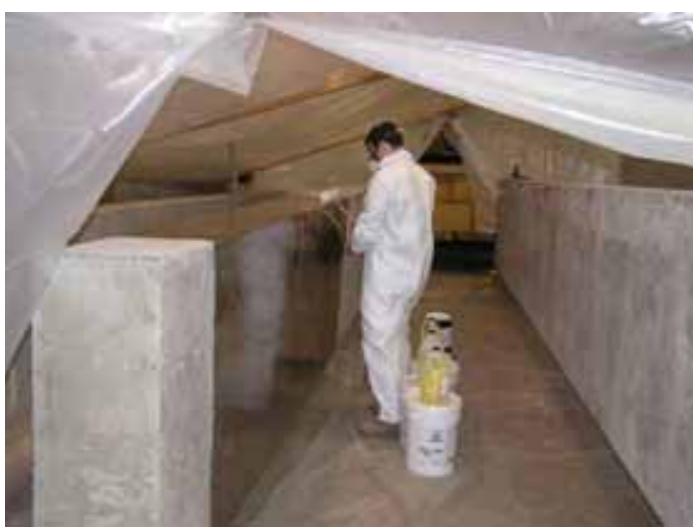

(b)

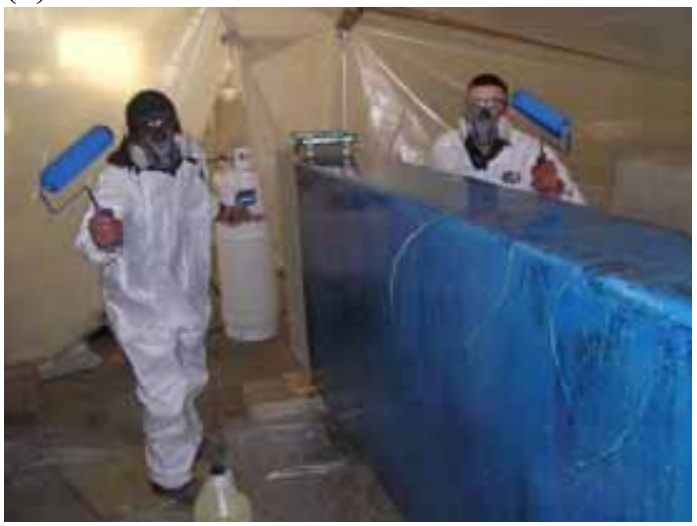

(d)

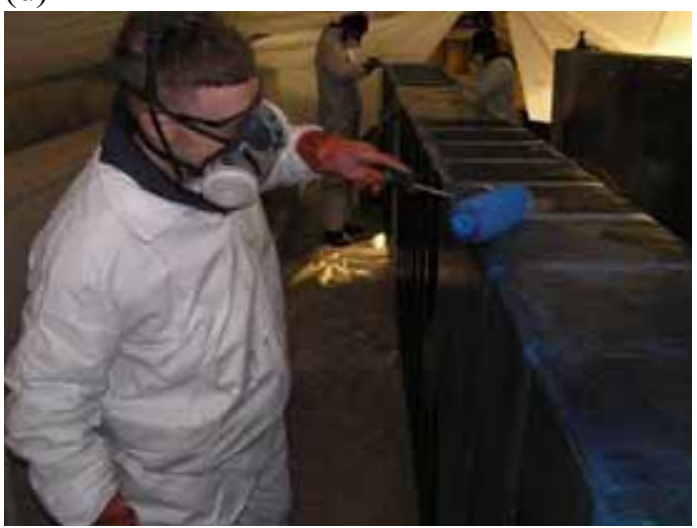

(f)

Figure B-4.3: CFRP application process

After CFRP application, specimens FC and FT were cured for 7 days between $5-15^{\circ} \mathrm{C}\left(41-59^{\circ} \mathrm{F}\right)$ with an average temperature of $12^{\circ} \mathrm{C}\left(53^{\circ} \mathrm{F}\right)$. Specimens HC, HT, QC and QT were cured for 7 days between $5-11^{\circ} \mathrm{C}\left(41-52^{\circ} \mathrm{F}\right)$ with an average temperature of $8^{\circ} \mathrm{C}\left(47^{\circ} \mathrm{F}\right)$. Curing temperatures were monitored with thermocouples to ensure that the application met installation specifications. 
The minimum specified curing temperature was $4^{\circ} \mathrm{C}\left(40^{\circ} \mathrm{F}\right)$. Specimens continued to cure for more than 30 days under ambient laboratory temperatures.

The manufacturer's product information reported an ultimate tensile strength, $f_{f u}$, of $3800 \mathrm{MPa}$ $(550 \mathrm{ksi})$, a tensile modulus, $E_{f u}$, of $227 \mathrm{GPa}(33,000 \mathrm{ksi})$ and an ultimate rupture strain, $\varepsilon_{f u}$, of 1.67\% per ASTM D 3039 (Watson Bowman Acme 2003). Actual CFRP properties were determined from 30 tensile coupon tests in accordance with ASTM D 3039. Two 457 x $508 \mathrm{~mm}$ (18 x 20 in.) CFRP panels were made on the day of CFRP application. These panels were cured under the same conditions as the half and quarter scale beams.

Three months after the CFRP application, the panels were cut into thirty $25 \times 357 \mathrm{~mm}(1 \times 14 \mathrm{in})$ tensile coupons with a wet tile saw and $25 \times 57 \mathrm{~mm}(1 \times 2.25$ in.) tabs cut from perforated programming board were attached with cyanoacrylate adhesive to make 30 tensile coupons. Coupons were tested with an $89 \mathrm{kN}$ (20 kip) universal testing machine at constant head speed of $2 \mathrm{~mm} / \mathrm{min}$ (0.05 in./min). Strain was measured via a class B1 extensometer with $25 \mathrm{~mm}$ (1 in.) gage length. Data were recorded at a frequency of $2 \mathrm{~Hz}$ using commercially available data acquisition software. Coupon test results are compared with the manufacturer's design values in Table B-4.5.

Table B-4.5: Specified and actual CFRP $0^{\circ}$ tensile properties.

\begin{tabular}{l|l|l|l}
\hline Property & Wabo® Design & Test Mean & Test St. Dev. \\
\hline $\begin{array}{l}\text { Coupon Thickness, } \\
\boldsymbol{t}_{f}(\mathbf{m m})(\mathrm{in} .)\end{array}$ & $\begin{array}{l}0.6-1.0 \\
(0.02-0.04)\end{array}$ & $1.16(0.0458)$ & $\begin{array}{l}0.314 \\
(0.0124)\end{array}$ \\
\hline $\begin{array}{l}\text { Tensile Strength, } \\
f_{f u}(\mathrm{MPa})(\mathrm{ksi})\end{array}$ & $\begin{array}{l}625-1042^{\mathbf{a}} \\
(89-179)\end{array}$ & $\begin{array}{l}725 \\
(105)\end{array}$ & $\begin{array}{l}218 \\
(31.6)\end{array}$ \\
\hline $\begin{array}{l}\text { Unit Stress, } \\
f_{\text {fu }} t_{f}(\mathrm{kN} / \mathrm{mm} / \mathrm{ply})(\mathrm{kip} / \mathrm{in} . / \mathrm{ply})\end{array}$ & $\begin{array}{l}0.625 \\
(3.57)\end{array}$ & $\begin{array}{l}0.777 \\
(4.44)\end{array}$ & $\begin{array}{l}0.0422 \\
(0.241)\end{array}$ \\
\hline $\begin{array}{l}\text { Elastic Modulus, } \\
E_{f}(\mathrm{GPa})(\mathrm{ksi})\end{array}$ & $\begin{array}{l}37.4-62.4^{\mathbf{a}} \\
(5300-10700)\end{array}$ & $\begin{array}{l}36.6 \\
(5300)\end{array}$ & $\begin{array}{l}9.34 \\
(1350)\end{array}$ \\
\hline $\begin{array}{l}\text { Rupture Strain, } \\
\varepsilon_{f u}(\%)\end{array}$ & 1.67 & 1.97 & 0.161 \\
\hline $\begin{array}{l}\text { Nom. Fabric } \\
\text { Thickness, } \boldsymbol{t}_{f}^{*}(\mathbf{m m})(\mathrm{in} .)\end{array}$ & $\begin{array}{l}0.165 \\
(0.0065)\end{array}$ & $\mathrm{n} / \mathrm{a}$ & $\mathrm{n} / \mathrm{a}$ \\
\hline $\begin{array}{l}\text { Tensile Strength, } \\
f_{f u} *(\mathrm{MPa})(\mathrm{ksi})\end{array}$ & $\begin{array}{l}3800 \\
(550)\end{array}$ & $\begin{array}{l}4720 \\
(684)\end{array}$ & $\begin{array}{l}253 \\
(36.7)\end{array}$ \\
\hline $\begin{array}{l}\text { Elastic Modulus, } \\
E_{f} *(\mathrm{GPa})(\mathrm{ksi})\end{array}$ & $\begin{array}{l}227 \\
(33000)\end{array}$ & $\begin{array}{l}241 \\
(35000)\end{array}$ & $(2390)$ \\
\hline
\end{tabular}

a: values not provided; calculated with other given values

*: values based on nominal fabric thickness

After structural testing of the specimens was completed, direct tension pull-off tests per ASTM D 4541 were performed on intact CFRP strips. A $16 \mathrm{kN}(3600 \mathrm{lb})$ capacity portable adhesive strength tester with digital manometer was employed. Square steel dollies with a surface area of $2580 \mathrm{~mm}^{2}\left(4 \mathrm{in}^{2}\right.$ ) were bonded to the clean, prepared CFRP surfaces and allowed to cure for 24 hours. The CFRP to be tested was cut flush to the edges of the dolly using a high-speed abrasive cutting wheel. The dolly was pulled with the portable tester and maximum load was recorded. Dimensions of the dolly were measured using calipers. Bond strengths were found by dividing the maximum load by the cross-sectional area of the dolly. 
Bond strengths for each specimen were averaged from at least three tests that resulted in cohesive failures in the surface layer of the concrete. Two cohesive failures in concrete bonded to CFRP are shown in Figure B-4.4. Pull-off test results are shown in Table B-4.6. Product specifications required a minimum bond strength of $1.4 \mathrm{MPa}(200 \mathrm{psi})$ (Watson Bowman Acme 2002).

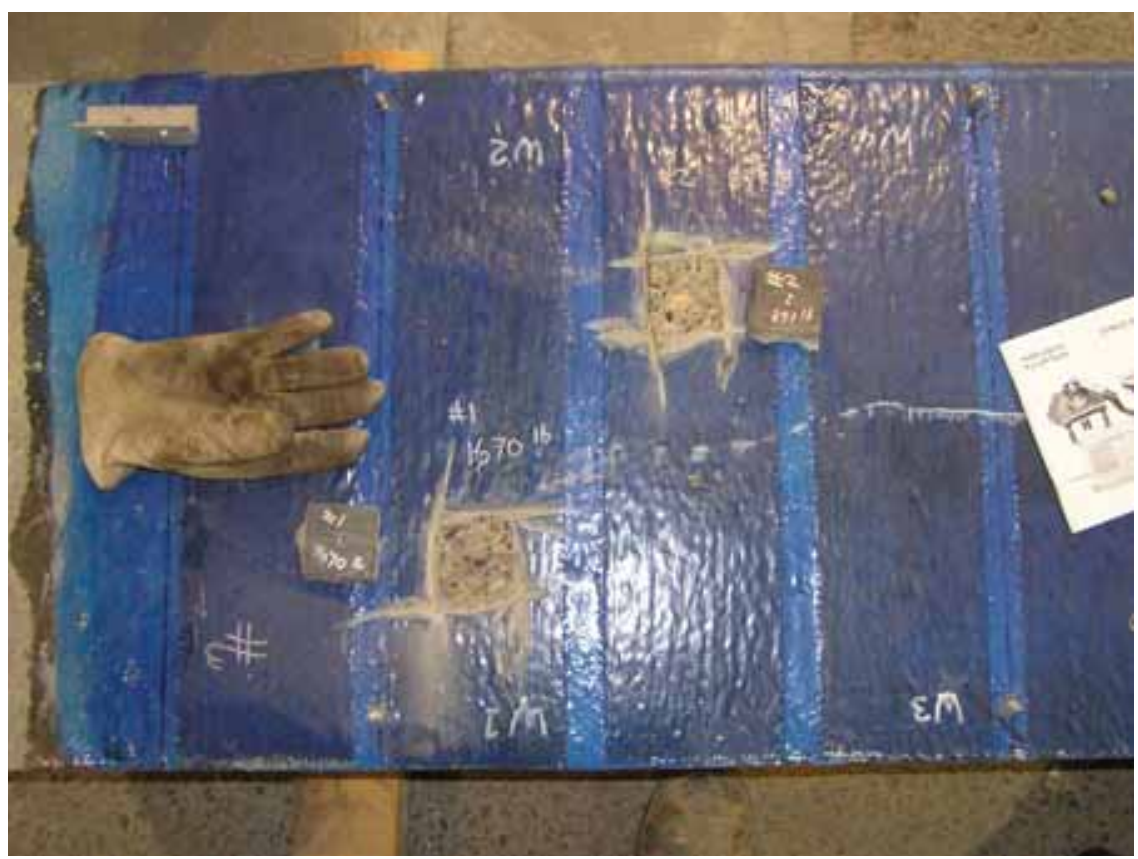

Figure B-4.4: Cohesive failure of concrete surface bonded to CFRP caused by direct-tension pull-off tests

Table B-4.6: Bond strengths of CFRP

\begin{tabular}{l|l|l}
\hline Specimen & $\begin{array}{l}\text { Mean f fond } \\
\text { (MPa) (psi) }\end{array}$ & St. Dev. \\
\hline FC & $3.46(503)$ & $0.593(86.1)$ \\
\hline FT & $4.37(634)$ & $0.646(93.7)$ \\
\hline HC & $2.26(328)$ & $1.01(147)$ \\
\hline HT & $3.91(567)$ & $0.397(57.5)$ \\
\hline QC & $3.27(474)$ & $0.0383(5.55)$ \\
\hline QT & $3.04(441)$ & $0.657(95.2)$ \\
\hline
\end{tabular}

\section{B-4.2 INSTRUMENTATION}

Typical instrumentation applied to the $\mathrm{t}$ specimens is shown schematically in Figure B-4.5. Reinforcing steel bars and CFRP strips were instrumented with general purpose strain gages. CEA-06-125UN-120 gages were affixed to the \#13 (\#4) and \#19 (\#6) bars. EA-06-015DJ120/LE gages were affixed to \#6 (\#2) stirrups. CFRP strips were instrumented with either N2A- 
06-20CBW-120 or EA-06-20CBW-120 gages. Gages on the CFRP strips had a $50 \mathrm{~mm}$ (2 in) length, which allowed for strain averaging.

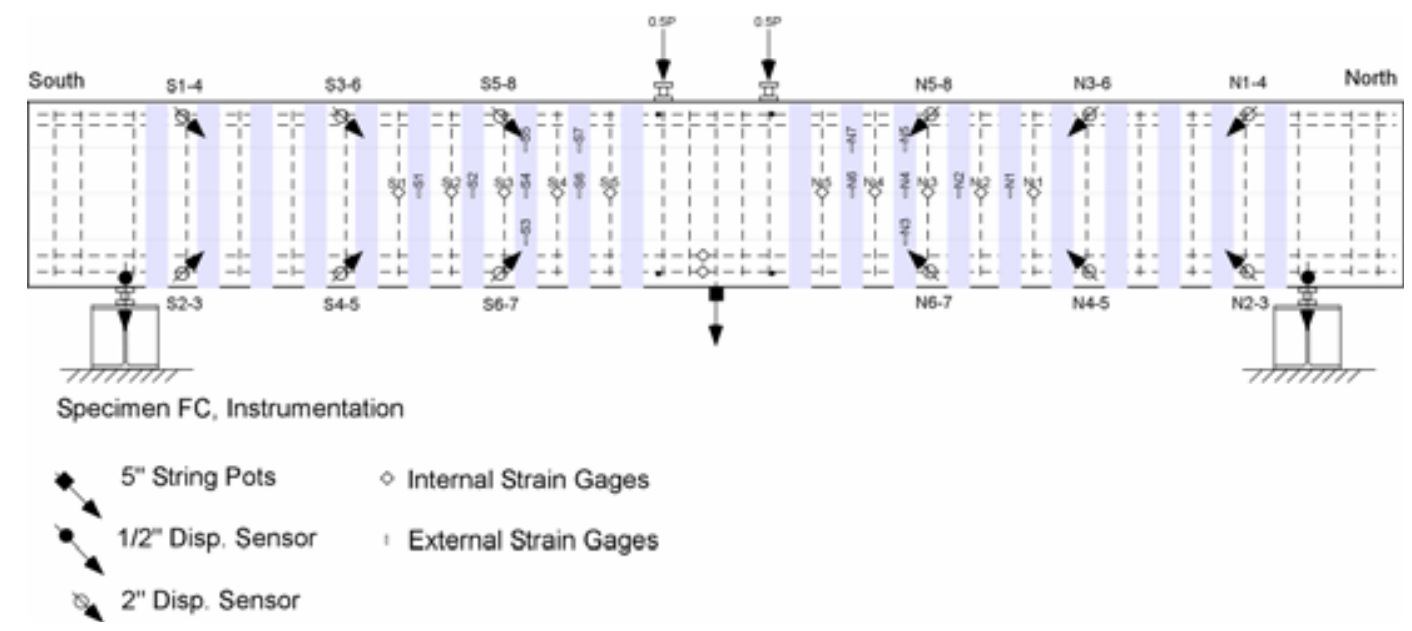

Figure B-4.5: Specimen FC instrumentation (typical).

Mid-span displacements were measured with $127 \mathrm{~mm}$ (5 in.) range string potentiometers, diagonal displacements were measured with $51 \mathrm{~mm}(2 \mathrm{in}$.) range string potentiometers and support settlements were measured with $13 \mathrm{~mm}(0.5 \mathrm{in}$.) range displacement sensors. Support settlements, which represent rigid body motion of the specimen at the supports, were averaged and subtracted from the mid-span displacement to reveal the specimen deformation.

Actuators were equipped with load cells rated for $2450 \mathrm{kN}$ (550 kips) and $1110 \mathrm{kN}$ (250 kips) at the full and smaller scales, respectively.

The actuator load cells, strain gages, string potentiometers and displacement sensors were connected to a high-speed, multi-channel, 16-bit data acquisition system. The system recorded sensor readings and converted signals into corresponding forces, strains and displacements. Data from sensors were archived for retrieval and post-processing.

The widths of diagonal cracks for specimens FC, QT and QC were measured visually with a crack comparator.

\section{B-4.3 TEST PROTOCOL}

Specimens were tested in a four-point bending setup using multiple load steps, which involved moving the supports inward at regular intervals of $a / d$, as described in Table B-4.7. Moving the supports allowed for greater shear-to-moment ratios, $V / M$, precluding flexural failure until the eventual failure in a shear dominant mode. Load points remained in the same position for all load steps, creating a small constant moment region with no shear. Shear and moment diagrams for this test setup are shown in Figure B-4.6. Load points were centered on the reinforcing steel 
at $610 \mathrm{~mm}$ (24 in.), $305 \mathrm{~mm}$ (12 in.) and $153 \mathrm{~mm}$ (6 in.) apart, respectively, for the full, half and quarter scale specimens.

Table B-4.7: Shear-span-to-depth ratios $(a / d)$ for load steps

\begin{tabular}{l|l|l|l|l|l|l}
\hline Load Step & $\mathbf{0}$ & $\mathbf{1}$ & $\mathbf{2}$ & $\mathbf{3}$ & $\mathbf{4}$ & $\mathbf{5}$ \\
\hline a/d & 3.3 & 3.0 & 2.5 & 2.0 & 1.5 & 1.0 \\
\hline
\end{tabular}
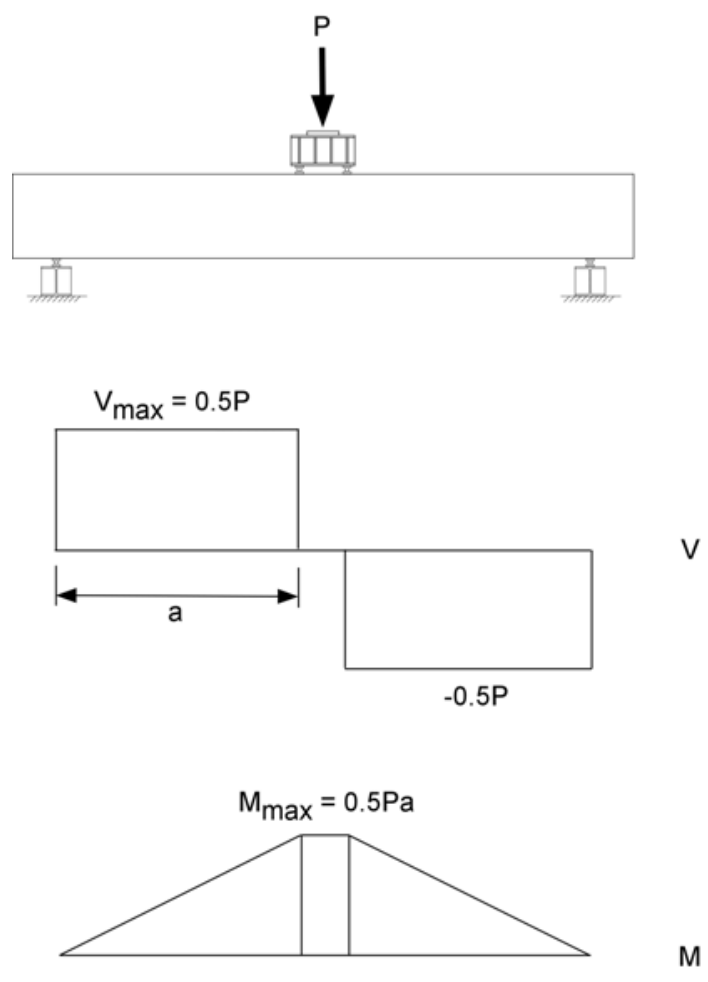

Figure B-4.6: Shear and moment diagrams for test setup at all scales

For each load step, the specimen was loaded to approximately $95 \%$ of the expected flexural capacity. Expected flexural capacities were found by increasing the calculated ACI nominal moment capacity by $20 \%$, as described by Equations 16 and 17 . A test of specimen HC well past flexural yielding and prior to concrete crushing indicated that the member capacity was approximately $20 \%$ greater than nominal capacity.

$$
\begin{gathered}
M_{\text {max }}=1.2 M_{n} \\
P_{\text {max }}=\frac{2 M_{\max }}{a}
\end{gathered}
$$

Due to the large differences in the sizes of $\mathrm{t}$ specimens, three loading frames were used for this research. The loading frames are shown schematically in Figure B-4.7. Full scale specimens 
were tested with a $2224 \mathrm{kN}$ (500 kip) capacity hydraulic actuator. Half and quarter scale specimens were tested with a $890 \mathrm{kN}$ (200 kip) capacity hydraulic actuator. The $2224 \mathrm{kN}$ (500 kip) actuator was operated under closed loop servo-hydraulic force control. The $890 \mathrm{kN}$ (200 kip) actuator was operated manually with a hand pump. Lateral bracing was provided at the support locations for the full and half scale specimens, but was not practical for the quarter scale because of the small specimen size.

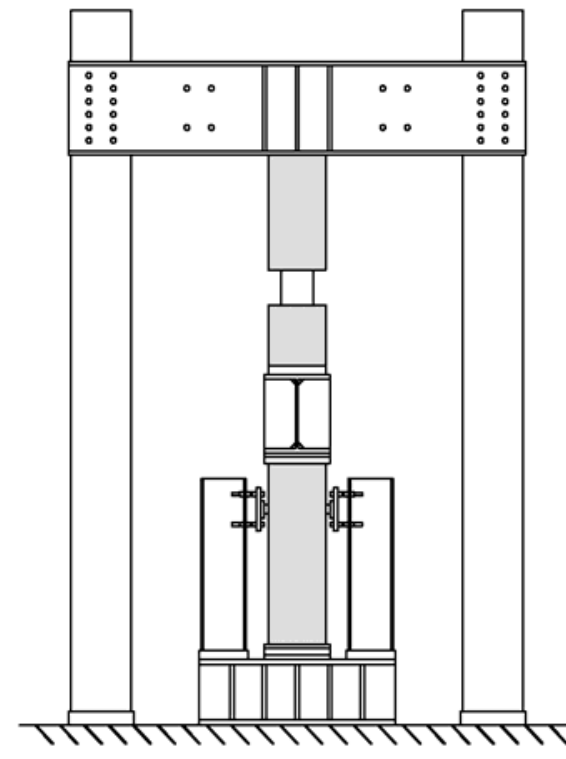

Full Scale

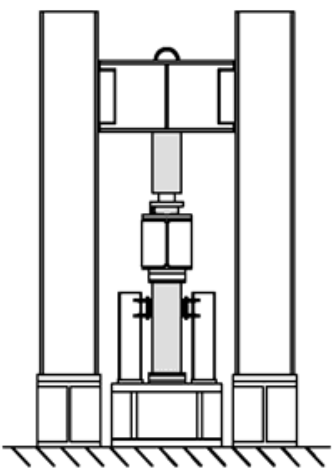

Half Scale

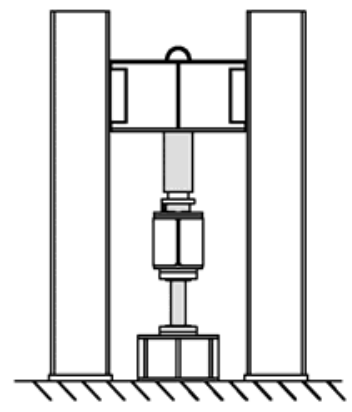

Quarter Scale

Figure B-4.7: Loading frames for full, half and quarter scale beams.

Detailed descriptions of the test protocol for each specimen, including values of applied shear, mid-span displacement as well as crack propagation and debonding observations, follow.

\section{B-4.3.1 SPECIMEN FC}

Specimen FC underwent a total of 8 load steps, as shown in Figure B-4.8 and Table B-4.8, with CFRP strip widths of $127 \mathrm{~mm}$ (5 in.) in the U-wrap configuration. 


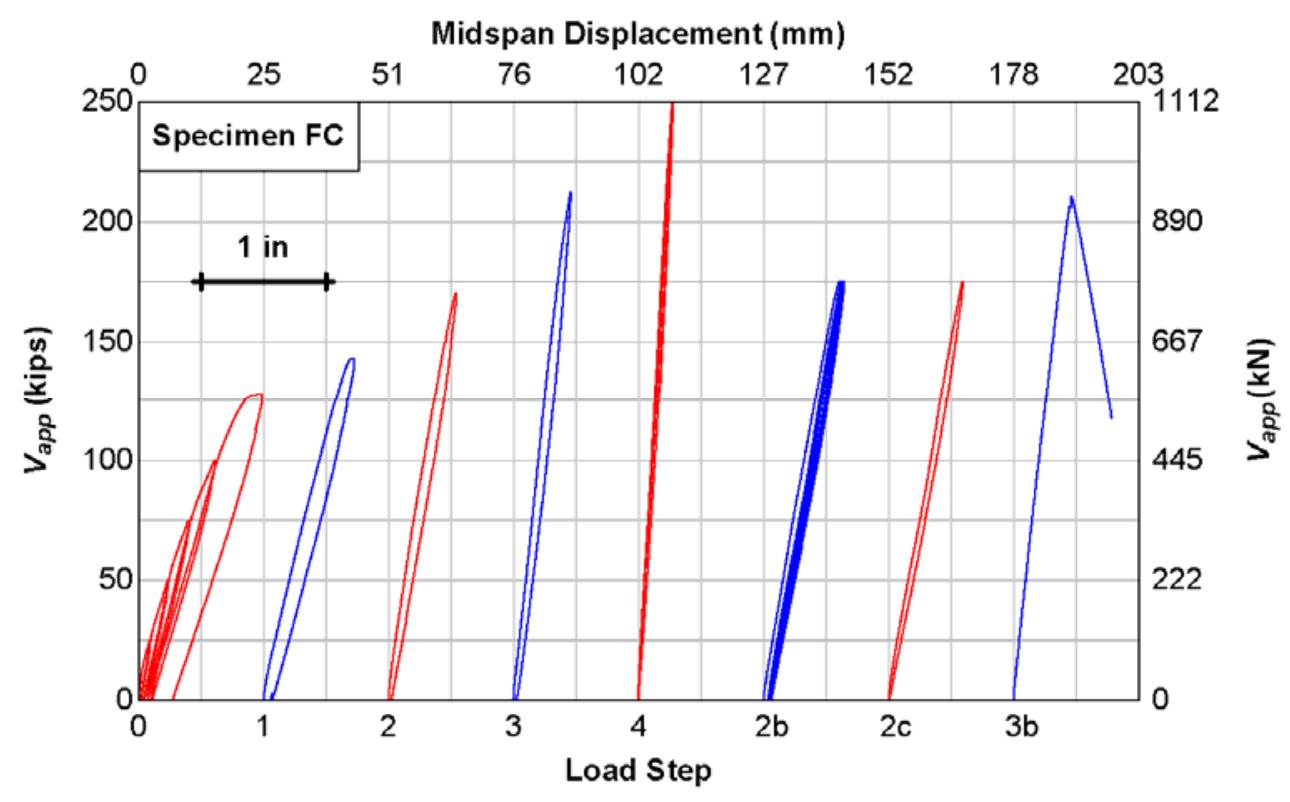

Figure B-4.8: Shear versus displacement for Specimen FC

During load step $0(a / d=3.3)$, the specimen was loaded cyclically to $222,445,667,890$ and $1139 \mathrm{kN}(50,100,150,200$ and $256 \mathrm{kips})$. The largest measured diagonal crack width during load step 0 was $0.51 \mathrm{~mm}$ (0.020 in.). The maximum applied force of $1139 \mathrm{kN}$ (256 kip) approached the flexural capacity of the specimen at this support configuration. Thus, the specimen was unloaded and the supports were moved inward to allow continued testing for shear. Instruments were zeroed for the new specimen configuration. Support locations and mapped crack observations for all Specimen FC load steps are shown in Figure B-4.9.

During load step $1(a / d=3.0)$, the specimen was loaded monotonically to $1272 \mathrm{kN}$ (286 kips). The largest measured diagonal crack width was $0.76 \mathrm{~mm}(0.030 \mathrm{in}$.). The maximum applied force approached the flexural capacity of the specimen at this support configuration. Thus, the specimen was unloaded and the supports were moved inward to allow continued testing for shear. Instruments were zeroed for the new specimen configuration.

During load step $2(a / d=2.5)$, the specimen was loaded monotonically to $1512 \mathrm{kN}$ (340 kips). Load step 2 saw no wider diagonal cracks than previously recorded. The maximum applied force approached the flexural capacity of the specimen at this support configuration. Thus, the specimen was unloaded and the supports were moved inward to allow continued testing for shear. Instruments were zeroed for the new specimen configuration.

During load step $3(a / d=2.0)$, the specimen was loaded monotonically to $1886 \mathrm{kN}$ (424 kips). The largest measured diagonal crack width was $1.02 \mathrm{~mm}(0.040 \mathrm{in}$.). The maximum applied force approached the flexural capacity of the specimen at this support configuration. Thus, the 
specimen was unloaded and the supports were moved inward to allow continued testing for shear. Instruments were zeroed for the new specimen configuration.

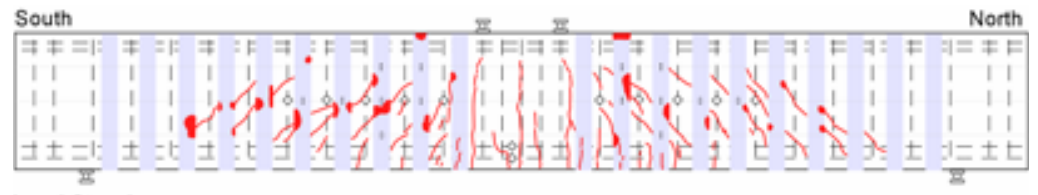

Load Step 0

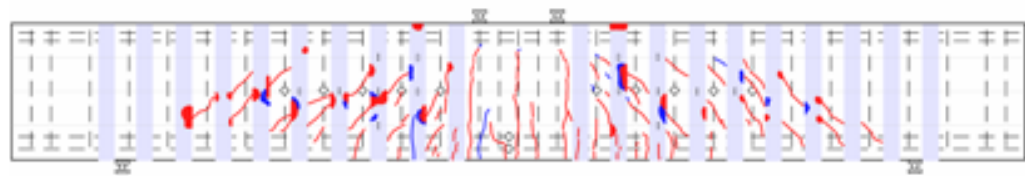

Load Step 1

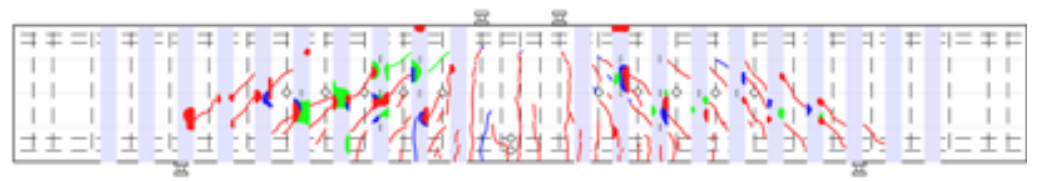

Load Step 2

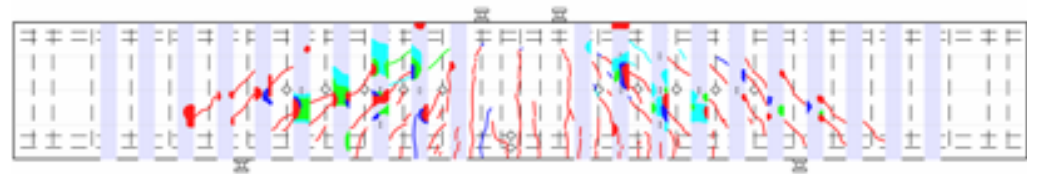

Load Step 3

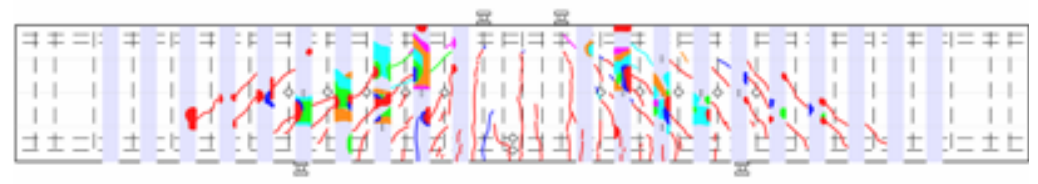

Load Step 4

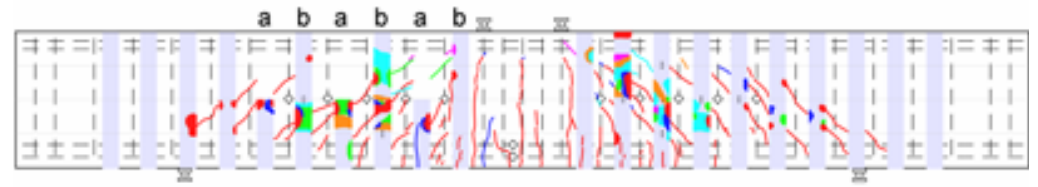

Load Step 2b

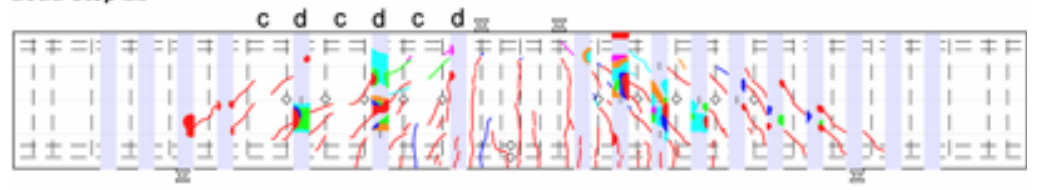

Load Step $2 \mathrm{c}$

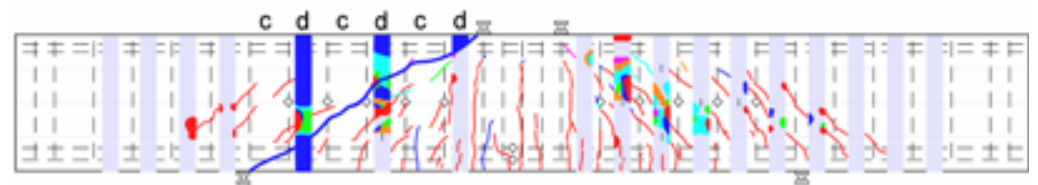

Load Step 3b

a: strip removed to mid-height on east face.

b: strip removed to mid-height on west face.

c: strip removed on east face.

d: strip removed on west face

Figure B-4.9: Specimen FC crack observations, support configurations and strain gage locations 
During load step $4(a / d=1.5)$, the specimen was loaded to the maximum actuator force of 2224 $\mathrm{kN}$ (500 kips) twice, in an effort to produce failure. The largest measured diagonal crack width during load step 4 was $1.27 \mathrm{~mm}$ (0.050 in.).

As the limit of the actuator was met during load step 4, the supports were moved back to an $a / d$ $=2.5$ and alternating strips in the south shear span were manually removed from the top of the beam down to mid-height. This test configuration is called load step $2 \mathrm{~b}$, which indicates the second loading at the load step 2 support location $(a / d=2.5)$.

Before load step $2 b$, the fifth, seventh, and ninth strips from the south end of the specimen were debonded to mid-height on the east face. The sixth, eighth and tenth strips were debonded to mid-height on the west face. During load step $2 \mathrm{~b}(a / d=2.5)$, the specimen was loaded to 1557 $\mathrm{kN}$ (350 kips) four times, in an effort to produce shear failure. This repeated loading did not succeed in producing failure.

For load step 2c $(a / d=2.5)$, strips that had been manually debonded to mid-height were then debonded over the full height of the beam and the specimen was loaded to $1557 \mathrm{kN}$ (350 kips). Failure did not occur during this load step.

Specimen FC was finally failed in shear during load step $3 b(a / d=2.0)$ with an applied force of $1868 \mathrm{kN}$ (420 kips). After failure, CFRP strips in the south span were observed to be debonded, a large diagonal crack extended through the compression zone and some stirrups were fractured.

Table B-4.8: Specimen FC loading summary.

\begin{tabular}{l|l|l|l|l|l}
\hline $\begin{array}{l}\text { Load } \\
\text { Step }\end{array}$ & $\boldsymbol{a} / \boldsymbol{d}$ & $\begin{array}{l}\text { Loading } \\
\text { Type }\end{array}$ & $\begin{array}{l}\boldsymbol{V}_{\text {app }} \\
\mathbf{( k N )}(\mathbf{k i p s )}\end{array}$ & $\begin{array}{l}\text { C.L. Disp. } \boldsymbol{a} \\
\boldsymbol{V}_{\text {app }} \\
(\mathbf{m m})(\mathbf{i n} .)\end{array}$ & $\begin{array}{l}\text { Max. Measured } \\
\text { Diagonal Crack } \\
\text { Width } \\
(\mathbf{m m})(\mathbf{i n} .)\end{array}$ \\
\hline 0 & 3.3 & 5 cycles & $569(128)$ & $25(0.98)$ & $0.51(0.020)$ \\
\hline 1 & 3.0 & monotonic & $636(143)$ & $18(0.72)$ & $0.76(0.030)$ \\
\hline 2 & 2.5 & monotonic & $756(170)$ & $14(0.54)$ & $0.76(0.030)$ \\
\hline 3 & 2.0 & monotonic & $943(212)$ & $11(0.45)$ & $1.02(0.040)$ \\
\hline 4 & 1.5 & 2 cycles & $1112(250)$ & $6.9(0.27)$ & $1.27(0.050)$ \\
\hline $2 \mathrm{~b}$ & 2.5 & 4 cycles & $778(175)$ & $16(0.64)$ & - \\
\hline 2c & 2.5 & monotonic & $778(175)$ & $15(0.59)$ & - \\
\hline $3 \mathrm{~b}$ & 2.0 & monotonic & $934(210)$ & $12(0.46)$ & - \\
\hline
\end{tabular}

\section{B-4.3.2 Specimen FT10}

Specimen FT underwent 5 load steps, as shown in Figures B-4.10 and B-4.11 and Table B-4.9, with CFRP strip widths of $254 \mathrm{~mm}$ (10 in) in the inverted U-wrap configuration. 


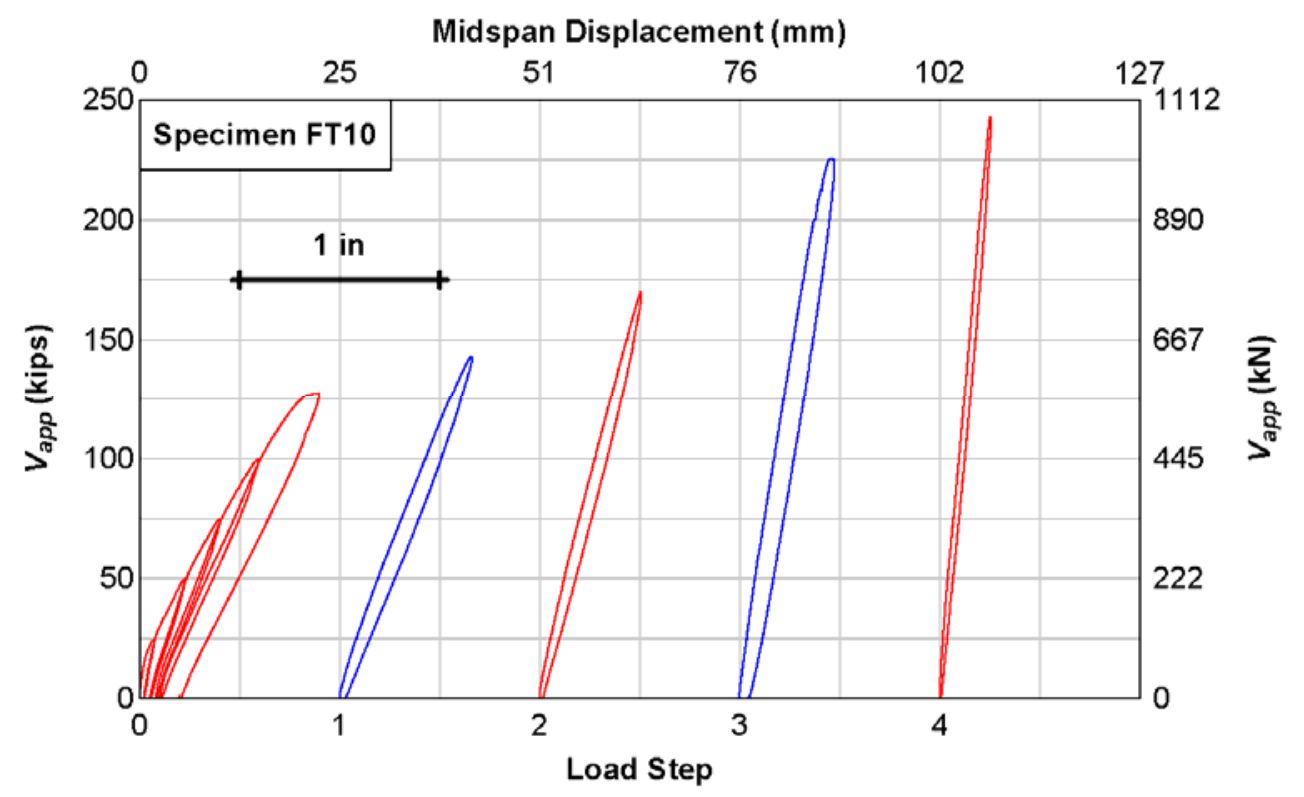

Figure B-4.10: Shear versus displacement for Specimen FT10 


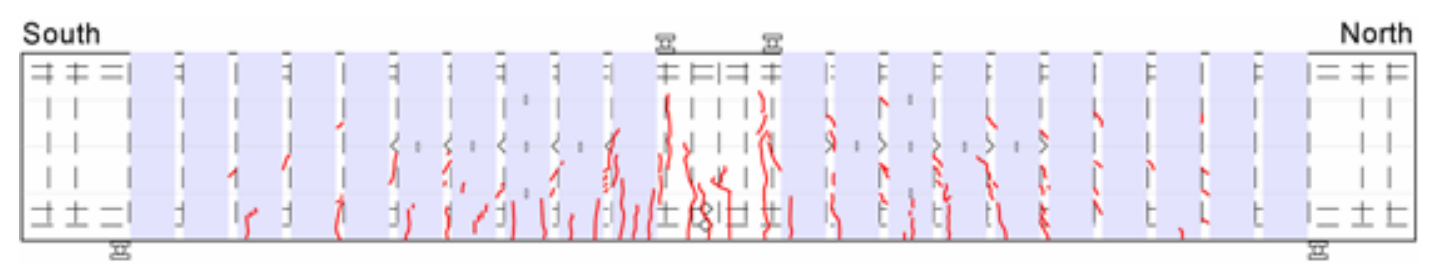

Load Step 0

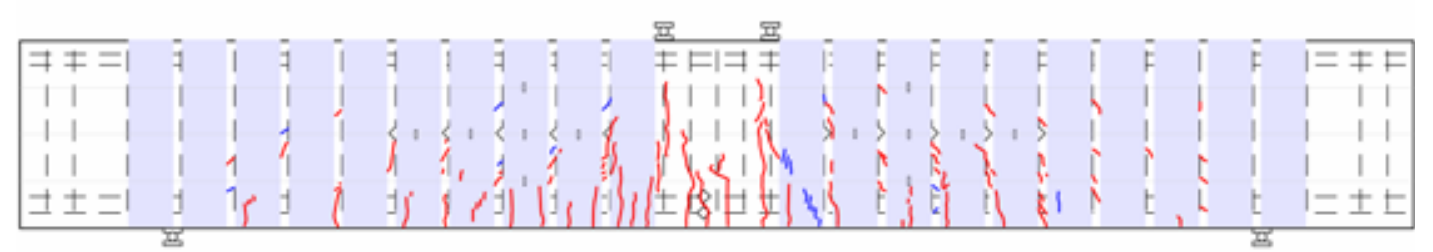

Load Step 1

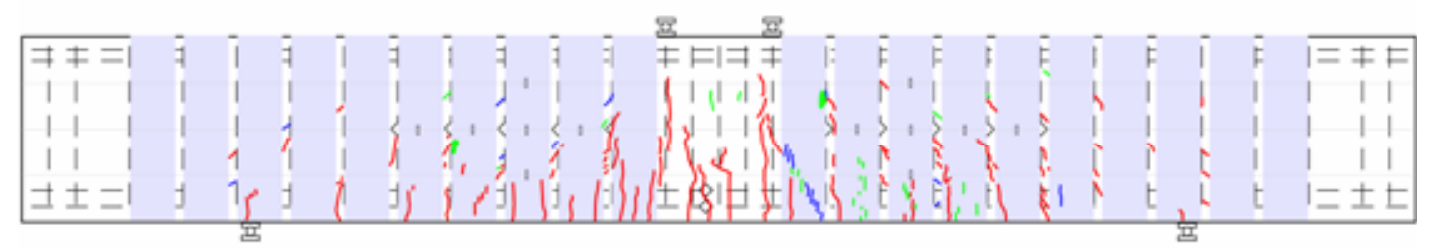

Load Step 2

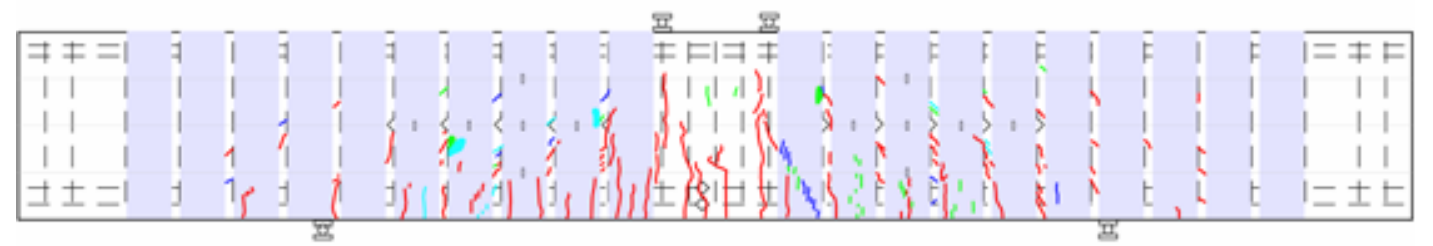

Load Step 3

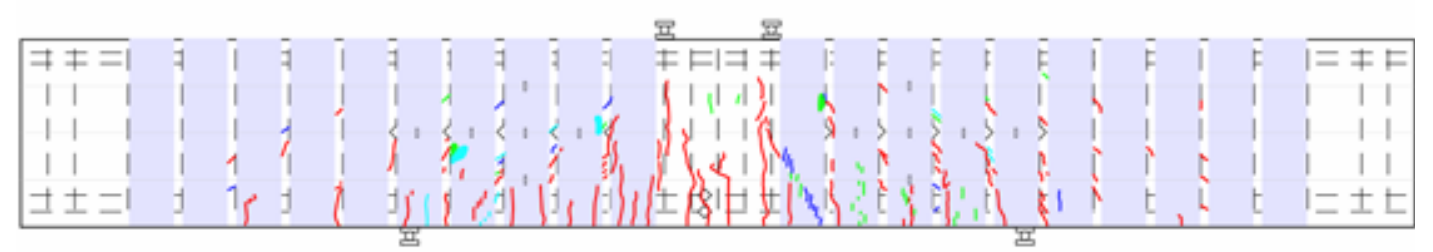

Load Step 4

Figure B-4.11: Specimen FT10 crack maps and strain gages

During load step $0(a / d=3.3)$, the specimen was loaded cyclically to $222,445,667,890$ and $1139 \mathrm{kN}(50,100,150,200$ and $256 \mathrm{kips})$. The maximum applied force of $1139 \mathrm{kN}$ (256 kip) approached the flexural capacity of the specimen at this support configuration. Thus, the specimen was unloaded and the supports were moved inward to allow continued testing for shear. Instruments were zeroed for the new specimen configuration.

After each load step that did not produce a shear failure, the supports were moved inward and instruments were zeroed. 
During load step $1(a / d=3.0)$, the specimen was loaded monotonically to $1272 \mathrm{kN}$ (286 kips). During load step $2(a / d=2.5)$, the specimen was loaded monotonically to $1512 \mathrm{kN}$ (340 kips). During load step $3(a / d=2.0)$, the specimen was loaded monotonically to $2002 \mathrm{kN}$ (450 kips). During load step $4(a / d=1.5)$, the specimen was loaded to $2162 \mathrm{kN}$ (486 kips). This was believed to be the maximum actuator force until the hydraulic line pressure was increased during a later test.

As the limit of the actuator was approached during load step 4, the supports were moved back to an $a / d=2.5$ and the CFRP strip widths were reduced to $127 \mathrm{~mm}(5 \mathrm{in})$. The specimen was retested as Specimen FT5.

Table B-4.9: Specimen FT10 load summary

\begin{tabular}{l|l|l|l|l}
\hline $\begin{array}{l}\text { Load } \\
\text { Step }\end{array}$ & $\boldsymbol{a} / \boldsymbol{d}$ & $\begin{array}{l}\text { Loading } \\
\text { Type }\end{array}$ & $\begin{array}{l}\boldsymbol{V}_{\text {app }} \\
(\mathbf{k N})(\mathbf{k i p s})\end{array}$ & $\begin{array}{l}\text { C.L. Disp. @ } \boldsymbol{V}_{\text {app }} \\
(\mathbf{m m})(\mathbf{i n .})\end{array}$ \\
\hline 0 & 3.3 & 5 cycles & $569(128)$ & $23(0.90)$ \\
\hline 1 & 3.0 & monotonic & $636(143)$ & $17(0.66)$ \\
\hline 2 & 2.5 & monotonic & $756(170)$ & $13(0.51)$ \\
\hline 3 & 2.0 & monotonic & $1001(225)$ & $12(0.46)$ \\
\hline 4 & 1.5 & monotonic & $1081(243)$ & $6.4(0.25)$ \\
\hline
\end{tabular}

\section{B-4.3.3 Specimen FT5}

Specimen FT5 underwent 10 load steps, as shown in Figures B-4.12 and B-4.13 and Table B-4.10.

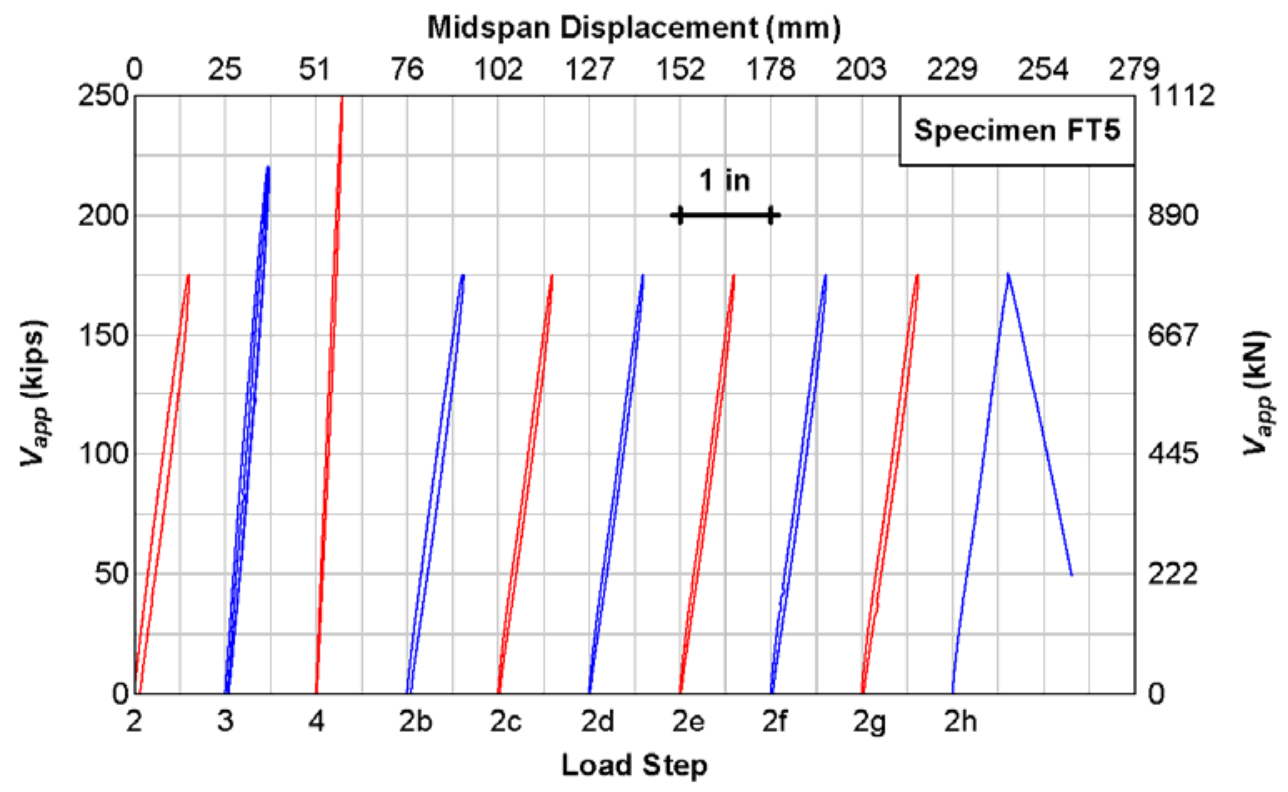

Figure B-4.12: Shear versus displacement for Specimen FT5 
During load step $2(a / d=2.5)$, the specimen was loaded monotonically to $1557 \mathrm{kN}$ (350 kips). The maximum applied force of $1557 \mathrm{kN}$ (350 kips) approached the flexural capacity of the specimen at this support configuration. Thus, the specimen was unloaded and the supports were moved inward to allow continued testing for shear. Instruments were zeroed for the new specimen configuration.

After each load step that did not produce a shear failure, the supports were moved inward and instruments were zeroed. 


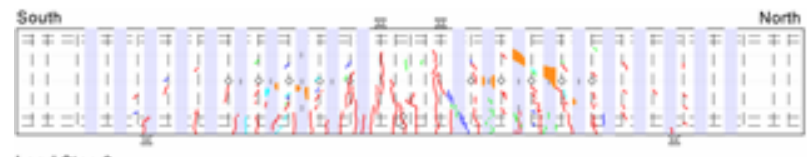

Load Step 2

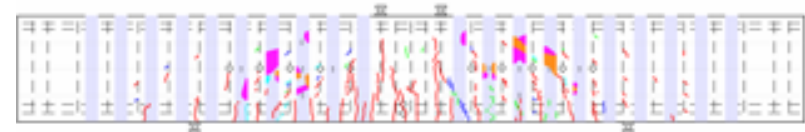

Loed Step 3

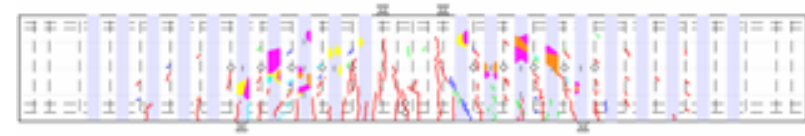

Load Step 4

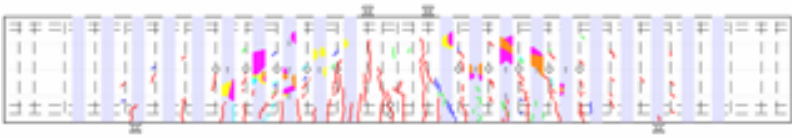

Load Step 2b

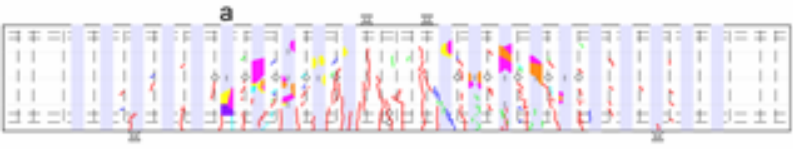

Load Step $2 \mathrm{c}$

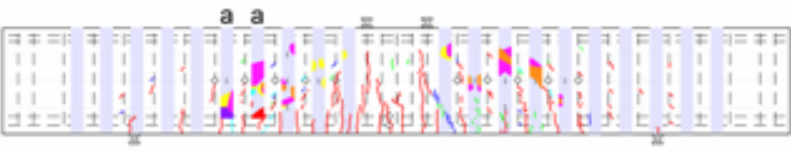

Load Step 2d
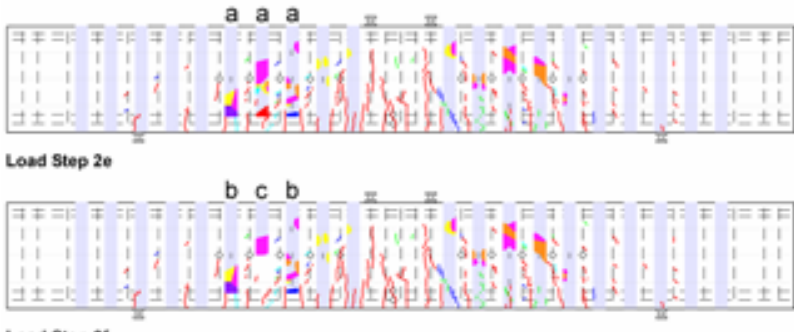

Load Step $2 t$

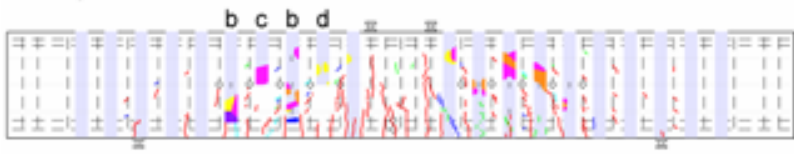

Load Step 29

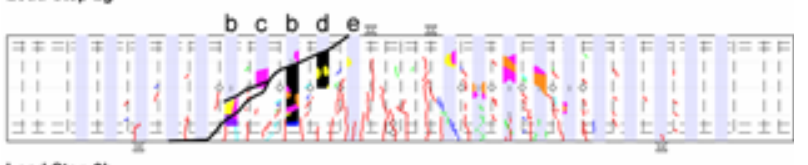

Lad Step $2 h$

a: $152 \mathrm{~mm}$ (6 in) of strip removed from bottom on both faces.

b: strip removed to mid-height on west face, no further removal on east face.

c: strip removed to mid-height on east face, no further removal on west face.

d: strip removed to mid-height on east face, full strip intact on west face.

e: strip removed to mid-height on west face, full strip intact on east face.

Figure B-4.13: Specimen FT5 crack maps and strain gages 
During load step $3(a / d=2.0)$, the specimen was loaded to $1957 \mathrm{kN}$ (440 kips) twice in an attempt to cause failure. This was unsuccessful and testing continued at load step 4. During load step $4(a / d=1.5)$, the specimen was loaded to the maximum actuator force of $2224 \mathrm{kN}$ (500 kips).

As the limit of the actuator was met during load step 4, the supports were moved back to an a/d $=2.5$ with the intent to remove CFRP strips gradually over the course of multiple load steps.

No CFRP strips were removed for load step $2 b$. This test configuration is called load step $2 b$ because it indicates the second loading at the load step 2 support location $(a / d=2.5)$. During this load step, the specimen was loaded to $1557 \mathrm{kN}$ (350 kips).

For load step $2 \mathrm{c}(\mathrm{a} / \mathrm{d}=2.5), 152 \mathrm{~mm}$ (6 in.) were removed from the bottom of the sixth strip from the south end and the specimen was loaded to $1557 \mathrm{kN}$ (350 kips). For load step $2 \mathrm{~d}$ ( $a / d=$ 2.5), $152 \mathrm{~mm}$ (6 in.) were removed from the bottom of the seventh strip from the south end and the specimen was loaded to $1557 \mathrm{kN}$ (350 kips). For load step $2 \mathrm{e}(a / d=2.5), 152 \mathrm{~mm}(6 \mathrm{in}$.) were removed from the bottom of the eighth strip from the south end and the specimen was loaded to $1557 \mathrm{kN}$ (350 kips).

For load step $2 \mathrm{f}(a / d=2.5)$, the CFRP strip was removed to mid-height on the west face for the sixth and eighth strips from the south end of the specimen and on the east face for the seventh strip. During this load step the specimen was loaded to $1557 \mathrm{kN}$ (350 kips).

For load step $2 \mathrm{~g}(a / d=2.5)$, the CFRP strip was removed to mid-height on the east face for the ninth strip from the south end of the specimen. During this load step the specimen was loaded to $1557 \mathrm{kN}$ (350 kips).

For load step $2 \mathrm{~h}(\mathrm{a} / \mathrm{d}=2.5)$, the CFRP strip was removed to mid-height on the west face for the tenth strip from the south end of the specimen. During this load step the specimen was loaded to $1557 \mathrm{kN}$ (350 kips). Specimen FT5 was finally failed in shear during this load step. After failure, CFRP strips in the south span were observed to be debonded, a large diagonal crack extended through the compression zone and some stirrups were fractured.

Table B-4.10: Specimen FT5 loading summary

\begin{tabular}{l|l|l|l|l}
\hline $\begin{array}{l}\text { Load } \\
\text { Step }\end{array}$ & $\boldsymbol{a} / \boldsymbol{d}$ & $\begin{array}{l}\text { Loading } \\
\text { Type }\end{array}$ & $\begin{array}{l}\boldsymbol{V}_{a p p} \\
(\mathbf{k N})(\mathbf{k i p s})\end{array}$ & $\begin{array}{l}\text { C.L. Disp. } \\
(\mathbf{m m})(\mathbf{i n} .)\end{array}$ \\
\hline 2 & 2.5 & monotonic & $778(175)$ & $15(0.60)$ \\
\hline 3 & 2.0 & 2 cycles & $979(220)$ & $12(0.47)$ \\
\hline 4 & 1.5 & monotonic & $1112(250)$ & $7.1(0.28)$ \\
\hline $2 \mathrm{~b}$ & 2.5 & monotonic & $778(175)$ & $16(0.62)$ \\
\hline $2 \mathrm{c}$ & 2.5 & monotonic & $778(175)$ & $15(0.59)$ \\
\hline $2 \mathrm{~d}$ & 2.5 & monotonic & $778(175)$ & $15(0.59)$ \\
\hline $2 \mathrm{e}$ & 2.5 & monotonic & $778(175)$ & $15(0.59)$ \\
\hline $2 \mathrm{f}$ & 2.5 & monotonic & $778(175)$ & $15(0.61)$ \\
\hline $2 \mathrm{~g}$ & 2.5 & monotonic & $778(175)$ & $15(0.61)$ \\
\hline $2 \mathrm{~h}$ & 2.5 & monotonic & $783(176)$ & $15(0.61)$ \\
\hline
\end{tabular}




\section{B-4.3.4 Specimen HC}

Specimen HC underwent 8 load steps, as shown in Figures B-4.14 and B-4.15 and Table B-4.11, with CFRP strip widths of $127 \mathrm{~mm}$ (5 in.) in the U-wrap configuration.

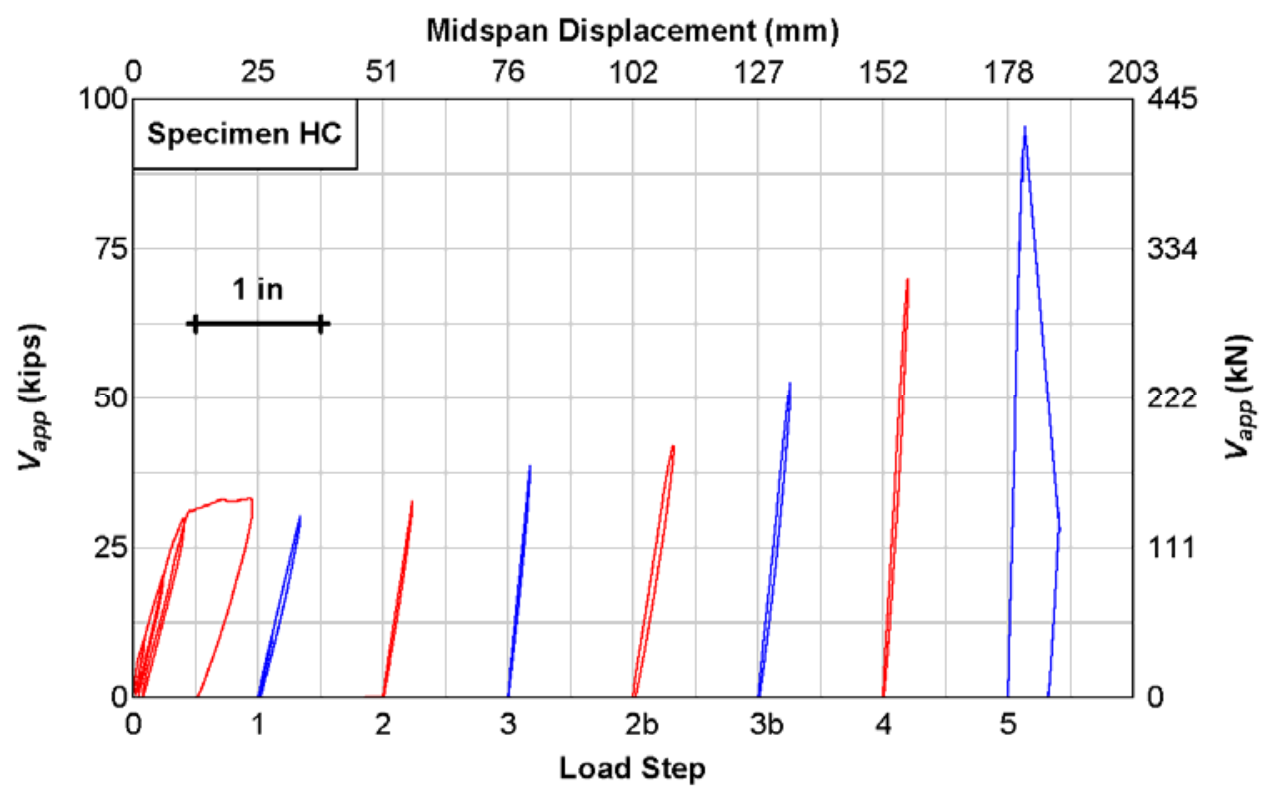

Figure B-4.14: Force versus displacement for Specimen HC

During load step 0 , the specimen was taken to its flexural capacity, which was indicated by yielding of the flexural reinforcing steel and excessive mid-span displacement. From this step, it was determined that the actual moment capacities of these rectangular specimens were about $20 \%$ greater than the calculated ACI nominal moment capacities. 


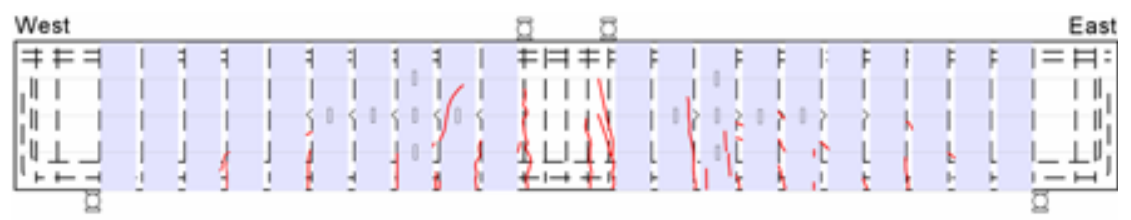

Load Step 0

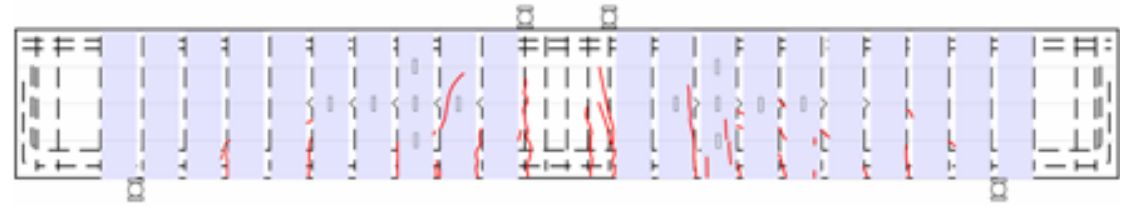

Load Step 1

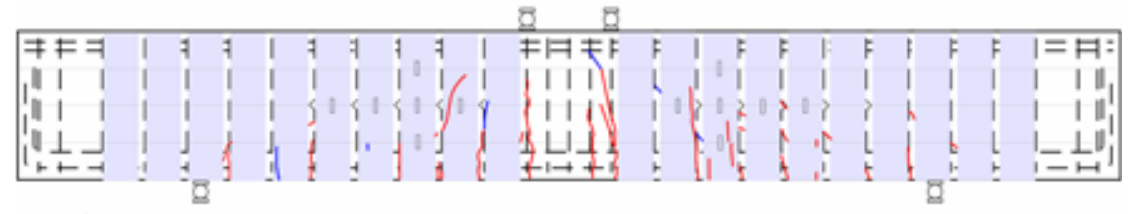

Load Step 2

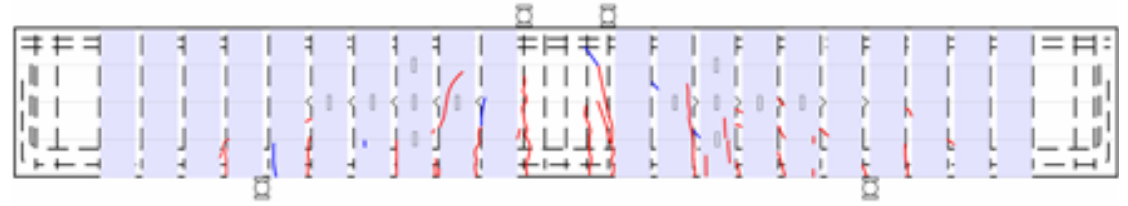

Load Step 3

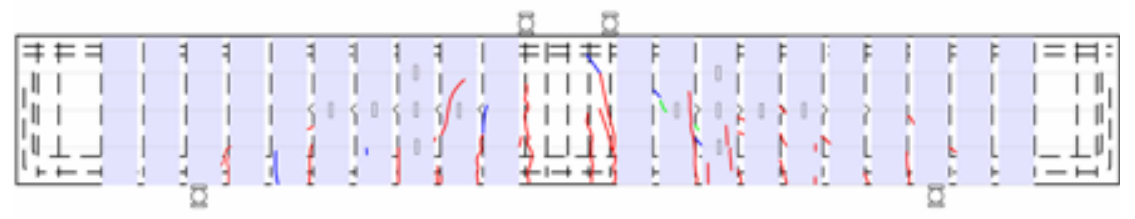

Load Step 2b

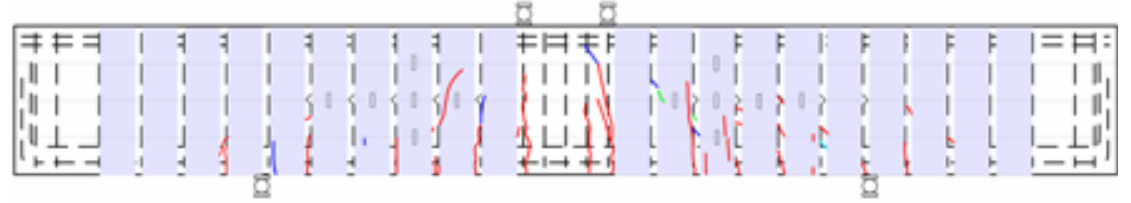

Load Step 3b

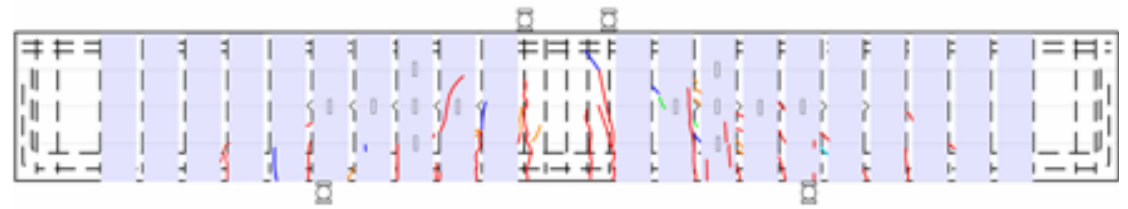

Load Step 4

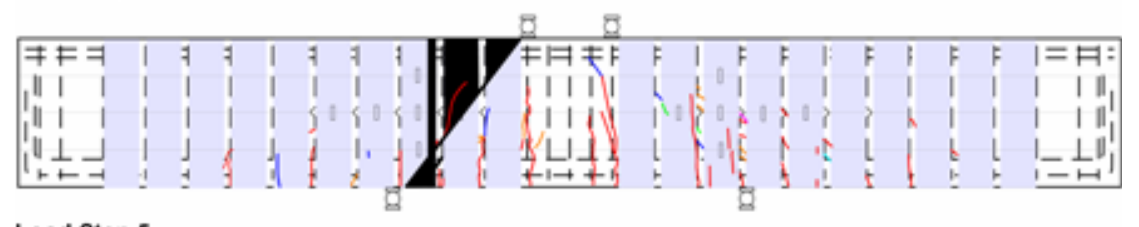

Load Step 5

Figure B-4.15: Specimen HC crack propagation maps and strain gages 
During load step $0(a / d=3.3)$, the specimen was loaded cyclically to $89,178,267$ and $294 \mathrm{kN}$ (20, 40, 60 and 66 kips). The maximum applied force of $294 \mathrm{kN}$ (66 kips) reached the flexural capacity of the specimen at this support configuration. Thus, the specimen was unloaded and the supports were moved inward to allow continued testing for shear. Instruments were zeroed for the new specimen configuration.

After each subsequent load step that did not produce a shear failure, the supports were moved inward and instruments were zeroed.

During load step $1(a / d=3.0)$, the specimen was loaded monotonically to $267 \mathrm{kN}$ (60 kips). During load step $2(a / d=2.5)$, the specimen was loaded monotonically to $294 \mathrm{kN}$ (66 kips). During load step $3(a / d=2.0)$, the specimen was loaded monotonically to $342 \mathrm{kN}$ (77 kips).

The applied forces in load steps $1-3$ were based upon the nominal moment capacity. Steps 2 and 3 were repeated as $2 b$ and $3 b$ with higher applied forces, which were based upon the $20 \%$ increase in moment capacity. During load step $2 \mathrm{~b}(a / d=2.5)$, the specimen was loaded monotonically to $365 \mathrm{kN}$ (82 kips). During load step $3 \mathrm{~b}(a / d=2.0)$, the specimen was loaded monotonically to $467 \mathrm{kN}$ (105 kips).

During load step $4(a / d=1.5)$, the specimen was loaded to $618 \mathrm{kN}$ (139 kips). During load step $5(a / d=1.0)$, the specimen was loaded to $845 \mathrm{kN}$ (190 kips). Failure occurred during load step 5. After failure, CFRP strips in the west span were observed to be debonded, a large diagonal crack extended through the compression zone and some stirrups were fractured. At this value of $a / d$, the diagonal crack formed nearly a straight path from support to load point.

Table B-4.11: Specimen HC loading summary

\begin{tabular}{l|l|l|l|l}
\hline $\begin{array}{l}\text { Load } \\
\text { Step }\end{array}$ & $\boldsymbol{a} / \boldsymbol{d}$ & $\begin{array}{l}\text { Loading } \\
\text { Type }\end{array}$ & $\begin{array}{l}\boldsymbol{V}_{\text {app }} \\
(\mathbf{k N})(\mathbf{k i p s})\end{array}$ & $\begin{array}{l}\text { C.L. Disp. @ } \boldsymbol{V}_{a p p} \\
(\mathbf{m m})(\mathbf{i n})\end{array}$ \\
\hline 0 & 3.3 & 4 cycles & $147(33)$ & $24(0.93)$ \\
\hline 1 & 3.0 & monotonic & $133(30)$ & $8.6(0.34)$ \\
\hline 2 & 2.5 & monotonic & $147(33)$ & $5.8(0.23)$ \\
\hline 3 & 2.0 & monotonic & $173(39)$ & $4.6(0.18)$ \\
\hline $2 \mathrm{~b}$ & 2.5 & monotonic & $187(42)$ & $8.1(0.32)$ \\
\hline $3 \mathrm{~b}$ & 2.0 & monotonic & $236(53)$ & $6.6(0.26)$ \\
\hline 4 & 1.5 & monotonic & $311(70)$ & $5.1(0.20)$ \\
\hline 5 & 1.0 & monotonic & $423(95)$ & $3.3(0.13)$ \\
\hline
\end{tabular}

\section{B-4.3.5 Specimen HT5}

Specimen HT5 underwent six load steps, as shown in Figures B-4.16 and B-4.17 and Table B4.12, with CFRP strips widths of $127 \mathrm{~mm}$ (5 in) in the inverted U-wrap configuration. 


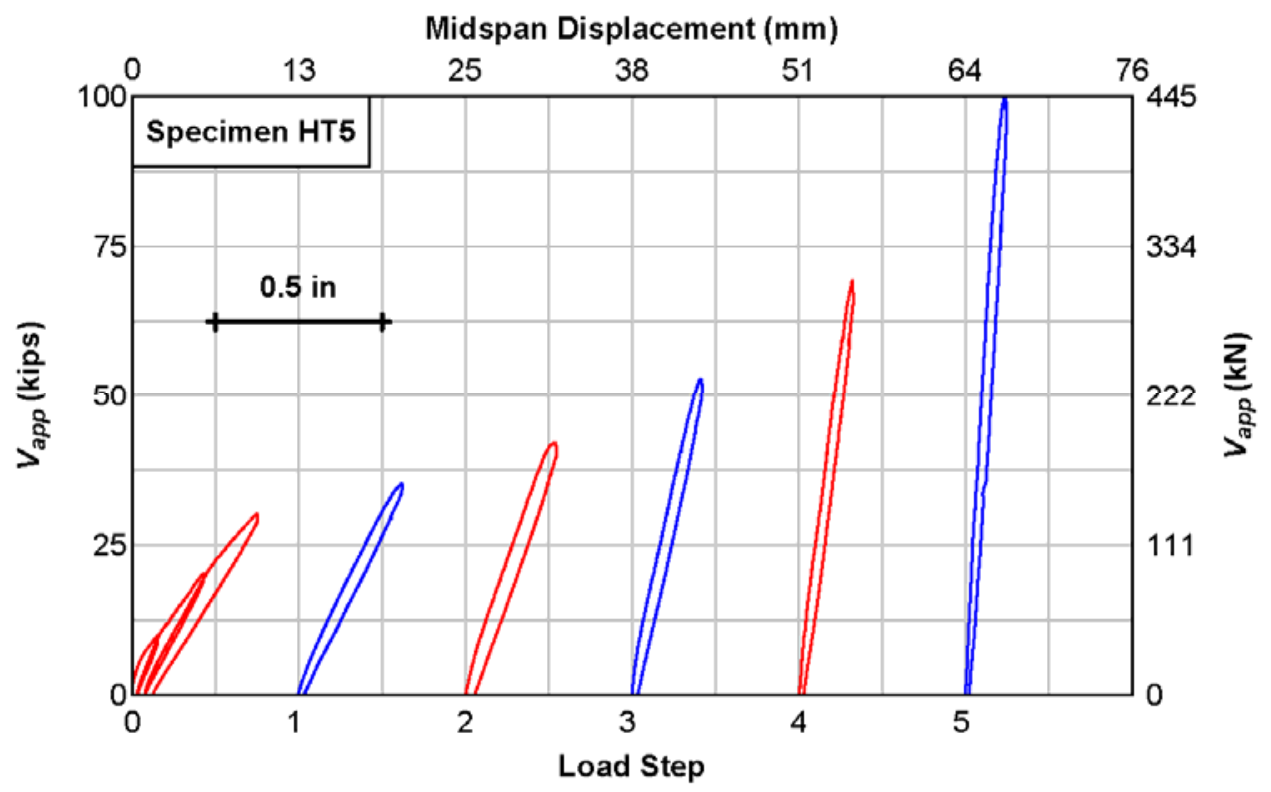

Figure B-4.16: Shear versus displacement for Specimen HT5 

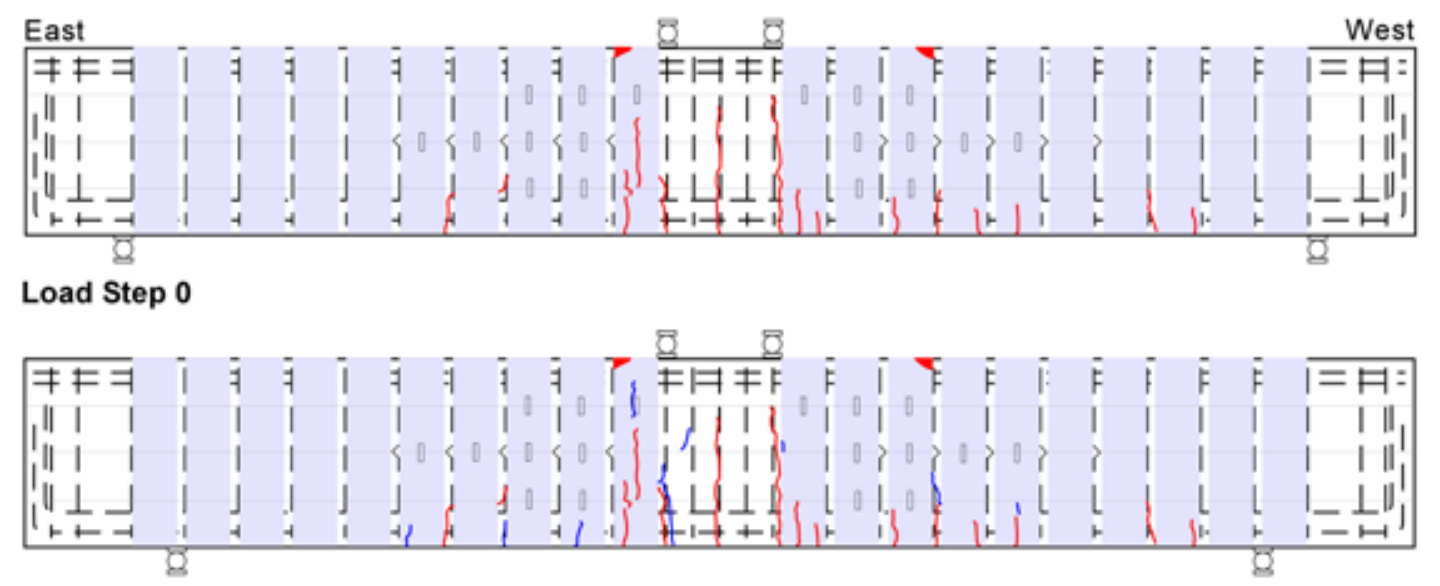

Load Step 1

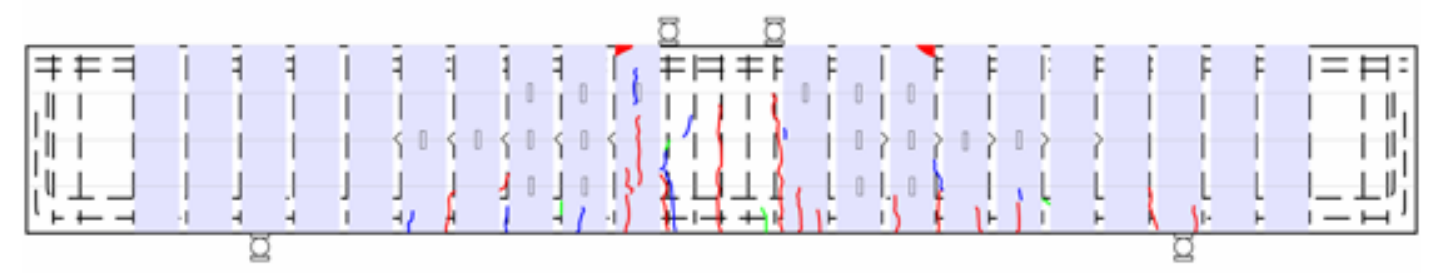

Load Step 2

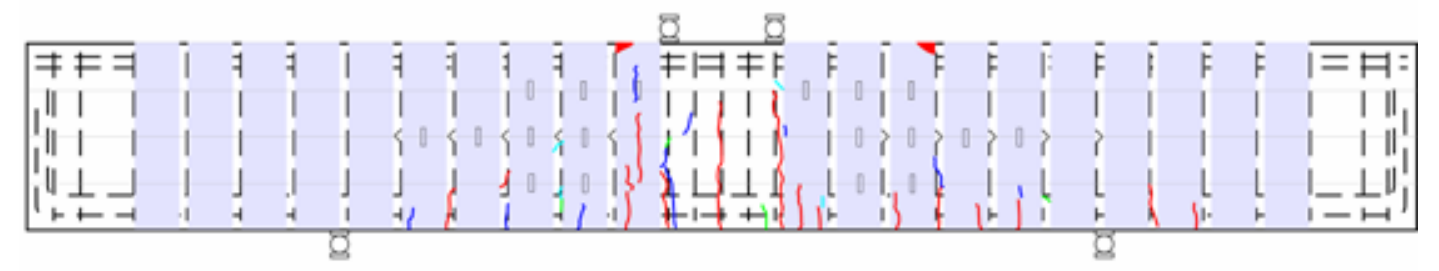

Load Step 3

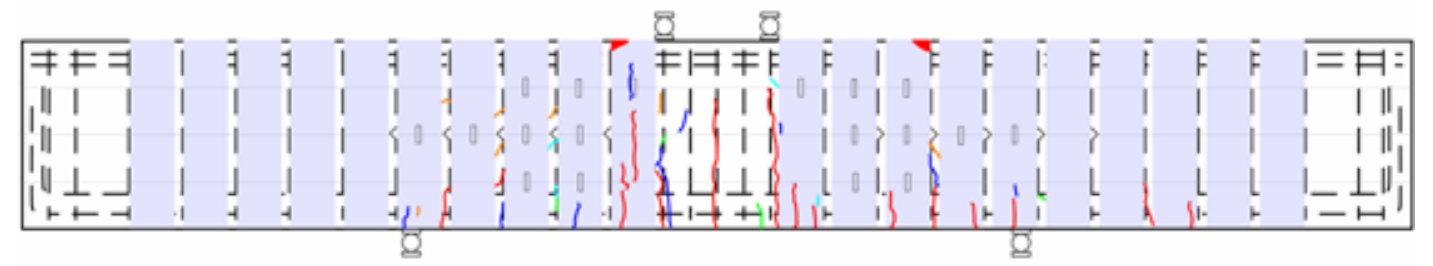

Load Step 4

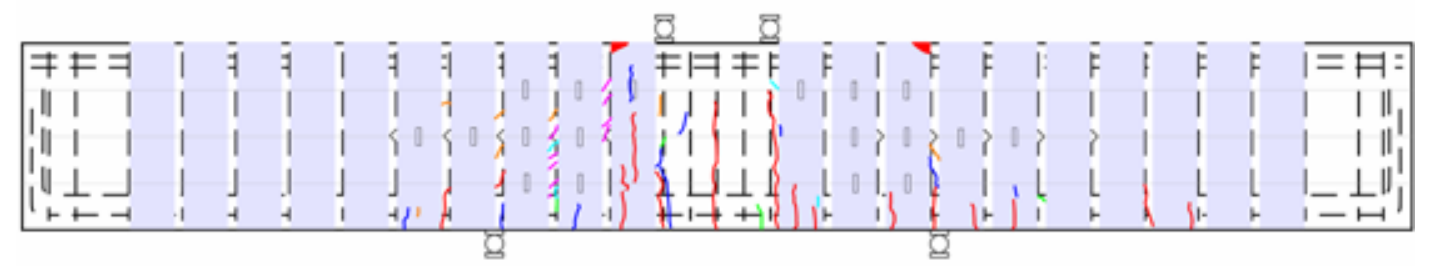

Load Step 5

Figure B-4.17: Specimen HT5 crack propagation maps and strain gage locations

During load step $0(a / d=3.3)$, the specimen was loaded cyclically to 89,178 and $267 \mathrm{kN}(20,40$ and $60 \mathrm{kips})$. The maximum applied force of $1139 \mathrm{kN}$ (256 kip) approached the flexural capacity of the specimen at this support configuration. Thus, the specimen was unloaded and the 
supports were moved inward to allow continued testing for shear. Instruments were zeroed for the new specimen configuration.

After each load step that did not produce a shear failure, the supports were moved inward and instruments were zeroed.

During load step $1(a / d=3.0)$, the specimen was loaded monotonically to $311 \mathrm{kN}$ (70 kips). During load step $2(a / d=2.5)$, the specimen was loaded monotonically to $374 \mathrm{kN}$ (84 kips). During load step $3(a / d=2.0)$, the specimen was loaded monotonically to $471 \mathrm{kN}$ (106 kips). During load step $4(a / d=1.5)$, the specimen was loaded to $614 \mathrm{kN}$ (138 kips). During load step $5(a / d=1.0)$, the specimen was loaded to $890 \mathrm{kN}$ (200 kips).

As the limit of the actuator was reached during load step 5, the supports were moved back to an $a / d=2.5$ and the CFRP strip widths were reduced to $64 \mathrm{~mm}(2.5 \mathrm{in})$. The specimen was retested as Specimen HT2.5.

Table B-4.12: Specimen HT5 loading summary

\begin{tabular}{l|l|l|l|l}
\hline $\begin{array}{l}\text { Load } \\
\text { Step }\end{array}$ & $\boldsymbol{a} / \boldsymbol{d}$ & $\begin{array}{l}\text { Loading } \\
\text { Type }\end{array}$ & $\begin{array}{l}\boldsymbol{V}_{\max } \\
(\mathbf{k N})(\mathbf{k i p s})\end{array}$ & $\begin{array}{l}\text { C.L. Disp. @ } \boldsymbol{V}_{\max } \\
(\mathbf{m m})(\mathbf{i n .})\end{array}$ \\
\hline 0 & 3.3 & 3 cycles & $133(30)$ & $9.7(0.38)$ \\
\hline 1 & 3.0 & monotonic & $156(35)$ & $7.9(0.31)$ \\
\hline 2 & 2.5 & monotonic & $187(42)$ & $6.9(0.27)$ \\
\hline 3 & 2.0 & monotonic & $236(53)$ & $5.3(0.21)$ \\
\hline 4 & 1.5 & monotonic & $307(69)$ & $4.1(0.16)$ \\
\hline 5 & 1.0 & monotonic & $445(100)$ & $3.0(0.12)$ \\
\hline
\end{tabular}

\section{B-4.3.6 Specimen HT2.5}

Specimen HT2.5 underwent six load steps, as shown in Figures B-4.18 and B-4.19 and Table B4.13, with strip widths of $64 \mathrm{~mm}$ (2.5 in.) in the inverted U-wrap configuration. 


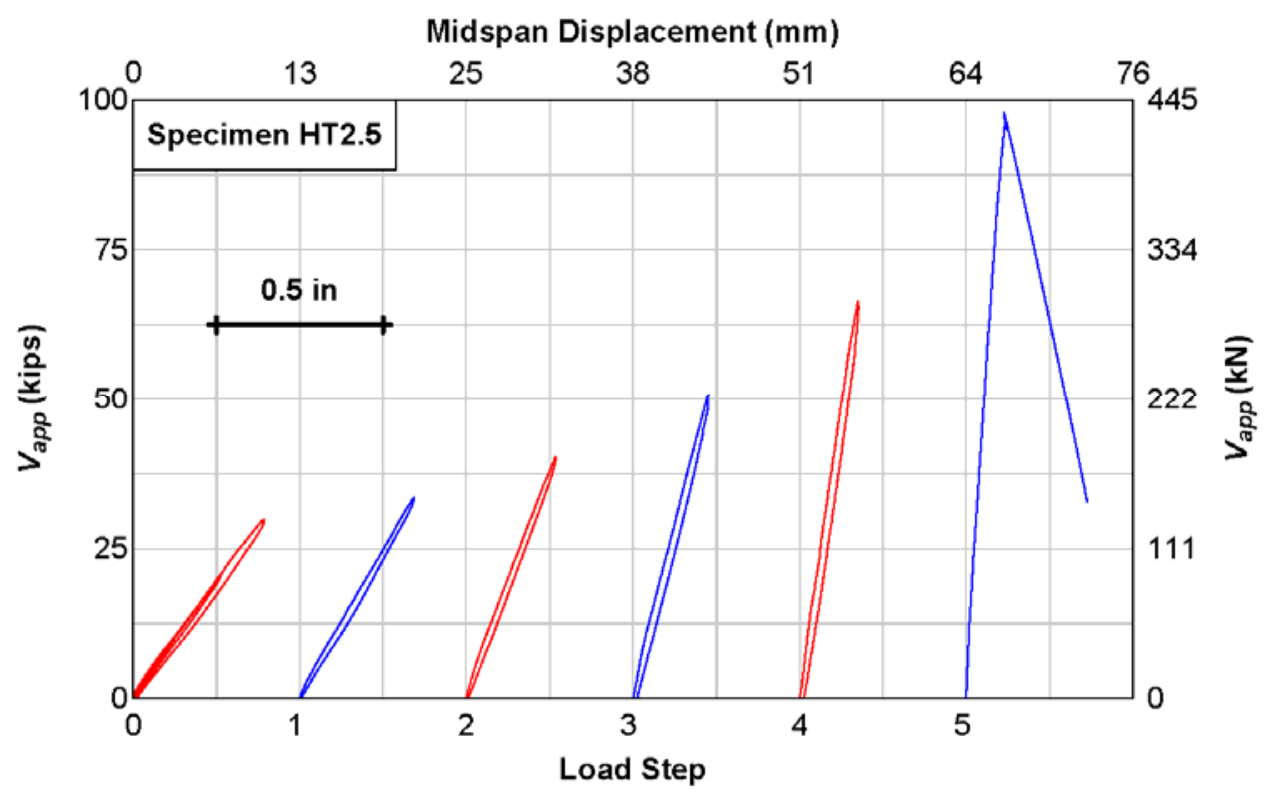

Figure B-4.18: Shear versus displacement for Specimen HT2.5

During load step $0(a / d=3.3)$, the specimen was loaded cyclically to 89,178 and $267 \mathrm{kN}(20,40$ and 60 kips). The maximum applied force of $178 \mathrm{kN}$ (60 kips) approached the flexural capacity of the specimen at this support configuration. Thus, the specimen was unloaded and the supports were moved inward to allow continued testing for shear. Instruments were zeroed for the new specimen configuration.

After each load step that did not produce a shear failure, the supports were moved inward and instruments were zeroed. 


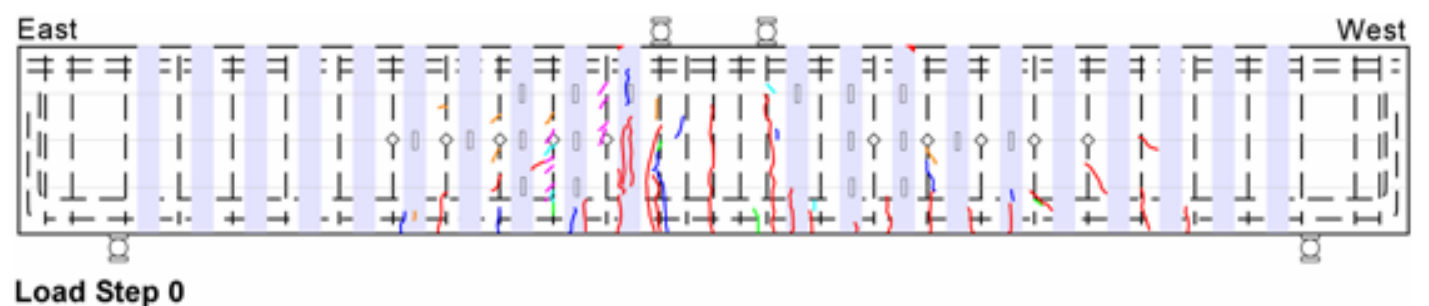

Load Step 0

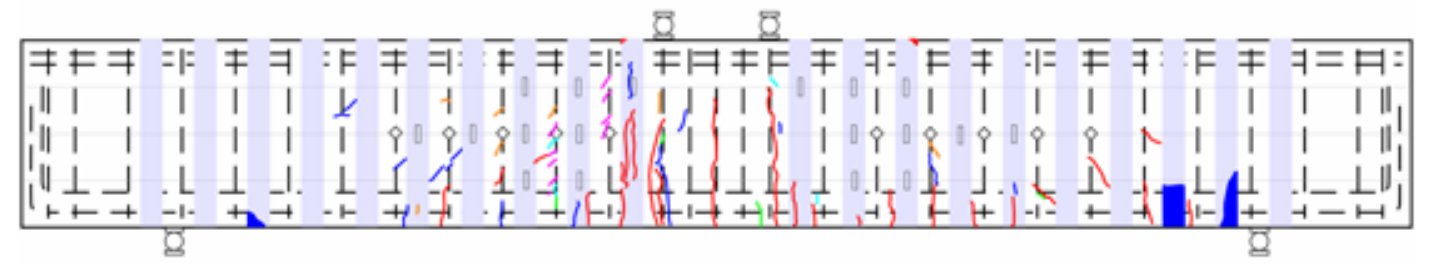

Load Step 1

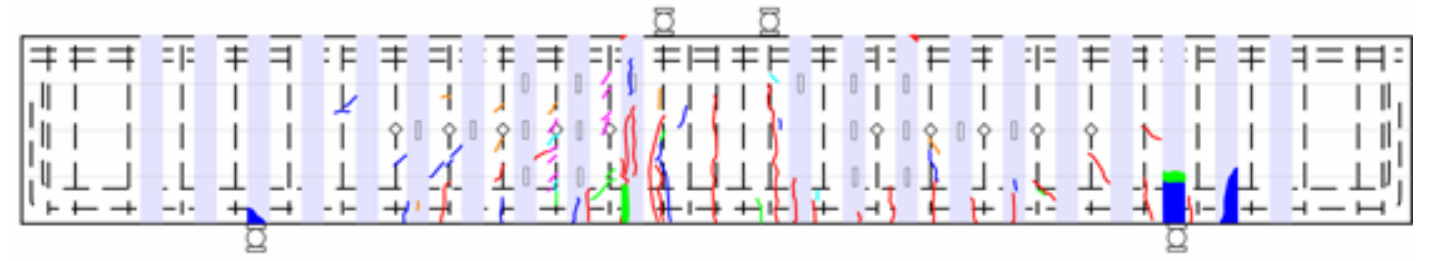

Load Step 2

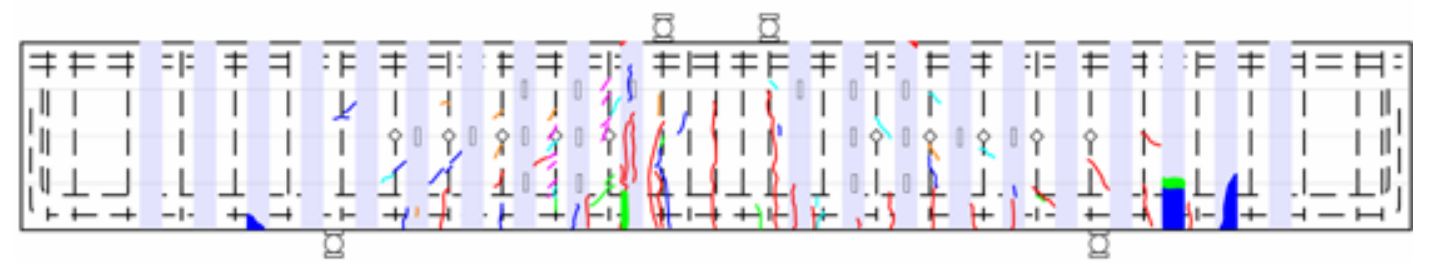

\section{Load Step 3}

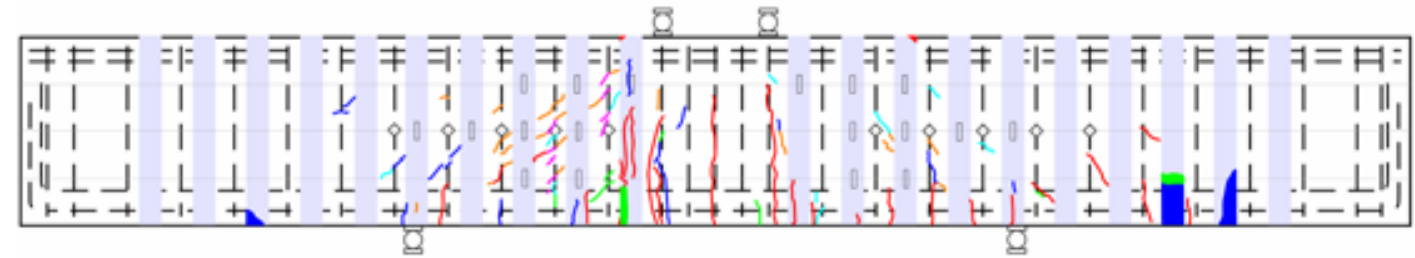

Load Step 4

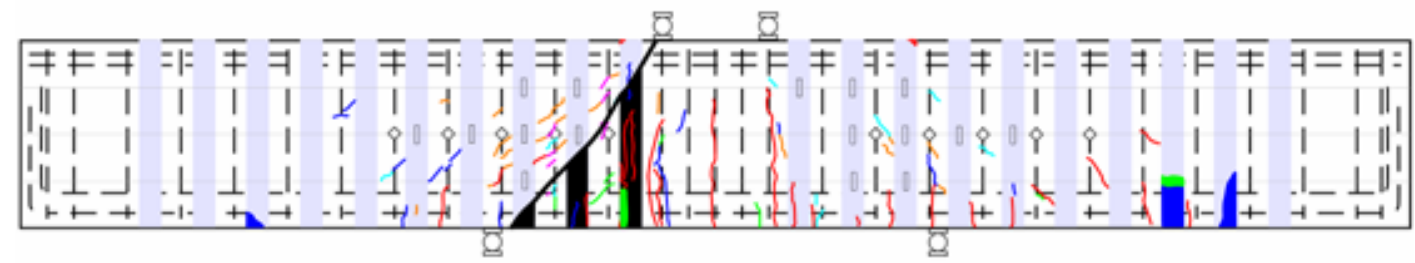

Load Step 5

Figure B-4.19: Specimen HT2.5 crack propagation maps and strain gage locations

During load step $1(a / d=3.0)$, the specimen was loaded monotonically to $294 \mathrm{kN}$ (66 kips). During load step $2(a / d=2.5)$, the specimen was loaded monotonically to $356 \mathrm{kN}$ ( $80 \mathrm{kips})$. During load step $3(a / d=2.0)$, the specimen was loaded monotonically to $454 \mathrm{kN}(102 \mathrm{kips})$. 
During load step $4(a / d=1.5)$, the specimen was loaded to $587 \mathrm{kN}$ (132 kips). During load step $5(a / d=1.0)$, the specimen was loaded to $867 \mathrm{kN}$ (195 kips).

Failure occurred during load step 5. At failure, CFRP strips in the east span were observed to be debonded, a large diagonal crack extended through the compression zone and some stirrups fractured.

Table B-4.13: Specimen HT2.5 loading summary.

\begin{tabular}{l|l|l|l|l}
\hline $\begin{array}{l}\text { Load } \\
\text { Step }\end{array}$ & $\boldsymbol{a} / \boldsymbol{d}$ & $\begin{array}{l}\text { Loading } \\
\text { Type }\end{array}$ & $\begin{array}{l}\boldsymbol{V}_{a p p} \\
(\mathbf{k N})(\mathbf{k i p s})\end{array}$ & $\begin{array}{l}\text { C.L. Disp. @ } \boldsymbol{V}_{\text {app }} \\
(\mathbf{m m})(\mathbf{i n .})\end{array}$ \\
\hline 0 & 3.3 & 3 cycles & $133(30)$ & $9.7(0.39)$ \\
\hline 1 & 3.0 & monotonic & $147(33)$ & $7.9(0.34)$ \\
\hline 2 & 2.5 & monotonic & $178(40)$ & $6.9(0.27)$ \\
\hline 3 & 2.0 & monotonic & $227(51)$ & $5.3(0.23)$ \\
\hline 4 & 1.5 & monotonic & $298(67)$ & $4.1(0.18)$ \\
\hline 5 & 1.0 & monotonic & $436(98)$ & $3.0(0.11)$ \\
\hline
\end{tabular}

\section{B-4.3.7 Specimen QC}

Specimen QC underwent seven load steps, as shown by Figures B-4.20 and B-4.221 and Table B-4.14, with strip widths of $16 \mathrm{~mm}$ (0.625 in.) in the U-wrap configuration.

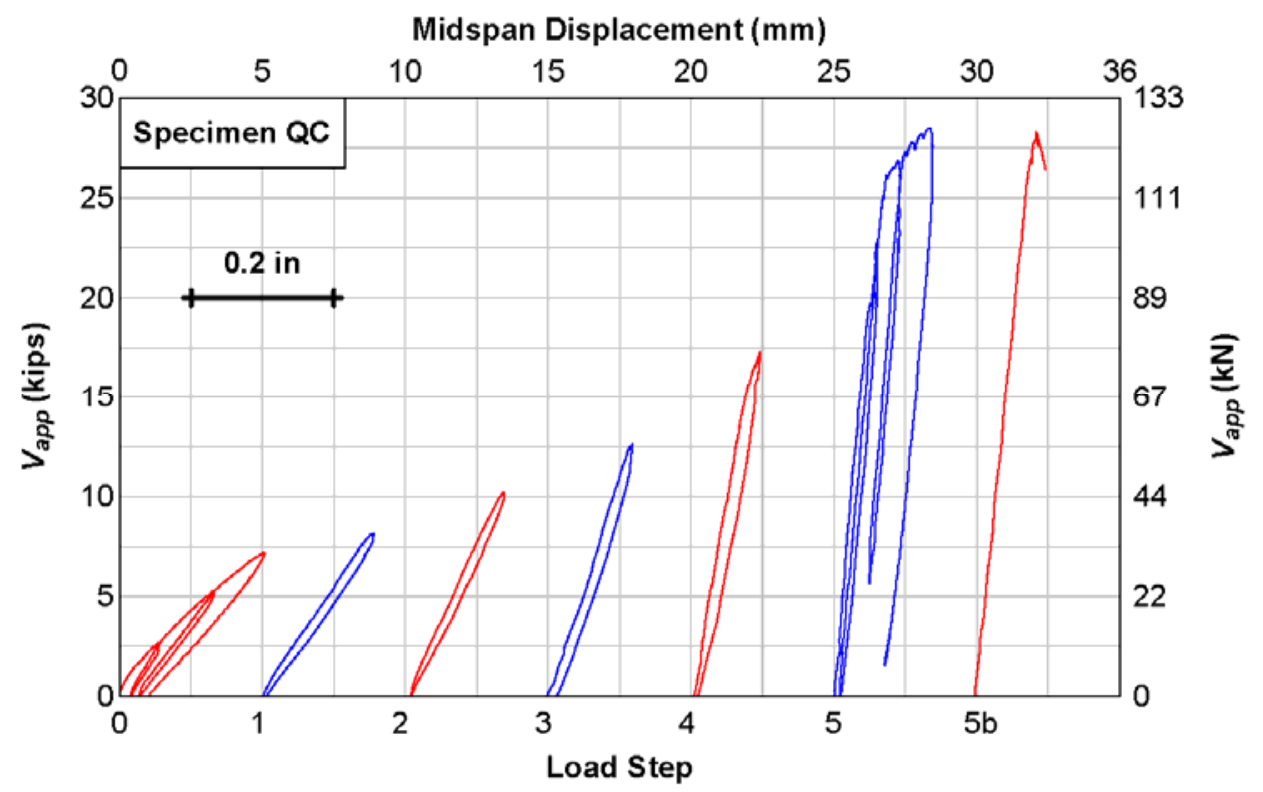

Figure B-4.20: Shear versus displacement for Specimen QC

During load step $0(a / d=3.3)$, the specimen was loaded cyclically to 24,49 and $62 \mathrm{kN}(5.4,11$ and 14 kips $)$. The largest measured diagonal crack width during load step 0 was $0.25 \mathrm{~mm}(0.010$ 
in.). The maximum applied force of $62 \mathrm{kN}$ (14 kips) approached the flexural capacity of the specimen at this support configuration. Thus, the specimen was unloaded and the supports were moved inward to allow continued testing for shear. Instruments were zeroed for the new specimen configuration.

After each load step that did not produce a shear failure, the supports were moved inward and instruments were zeroed. 


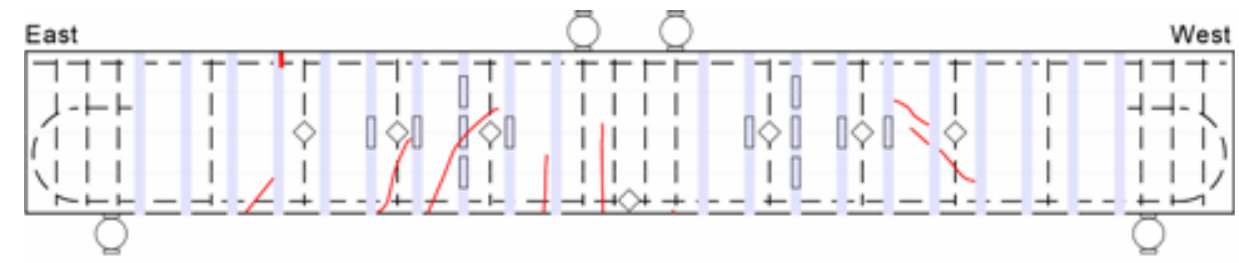

Load Step 0

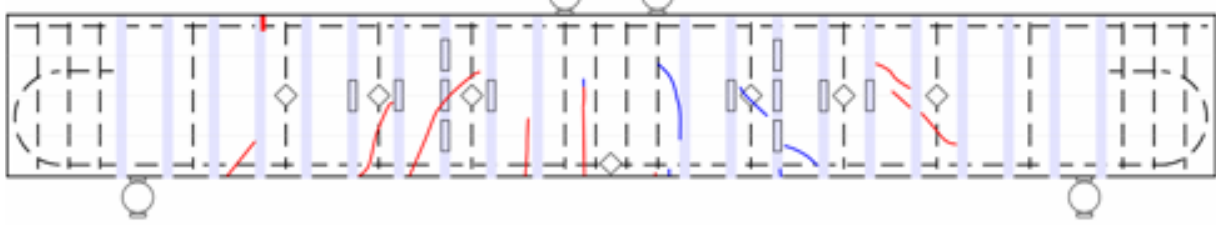

Load Step 1

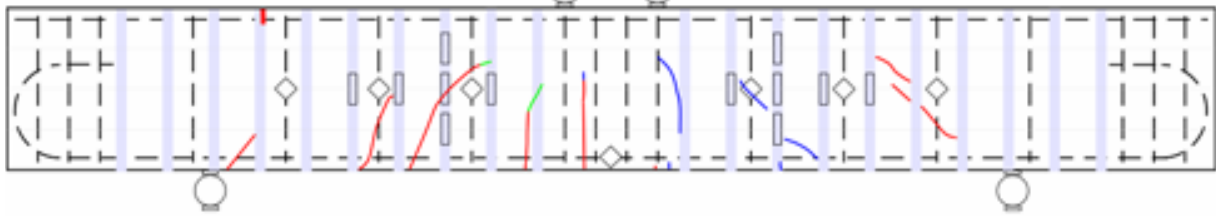

Load Step 2

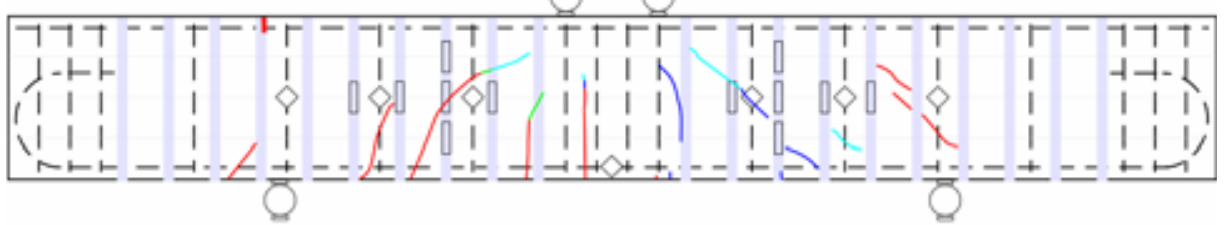

Load Step 3

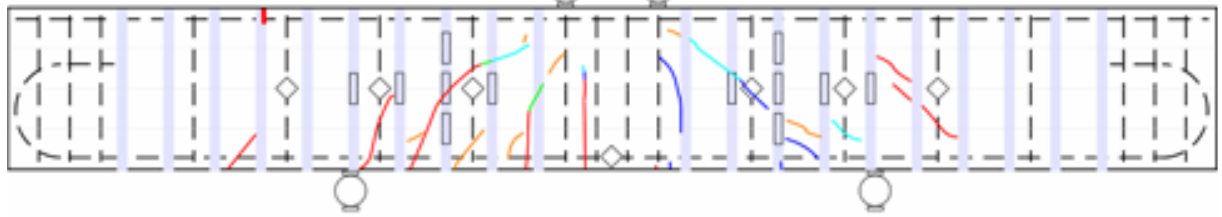

Load Step 4
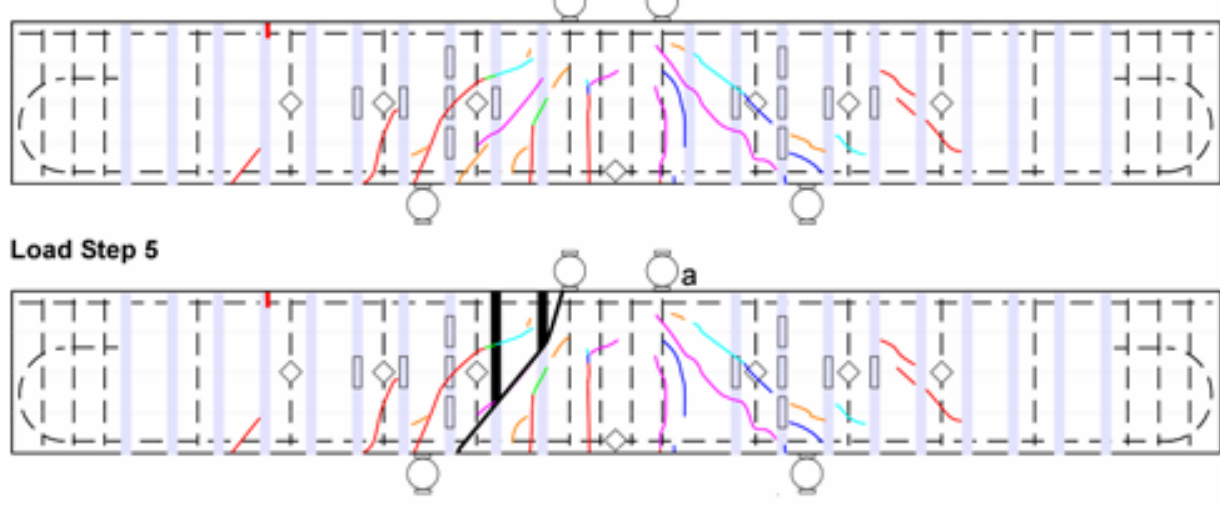

\section{Load Step 5b}

a: strip removed.

Figure B-4.21: Specimen QC crack propagation maps and strain gage locations 
During load step $1(a / d=3.0)$, the specimen was loaded monotonically to $71 \mathrm{kN}$ (16 kips).

Diagonal crack widths were not measured during this load step. During load step $2(a / d=2.5)$, the specimen was loaded monotonically to $89 \mathrm{kN}$ (20 kips). The largest measured diagonal crack width was $0.25 \mathrm{~mm}(0.010 \mathrm{in}$.). During load step $3(a / d=2.0)$, the specimen was loaded monotonically to $111 \mathrm{kN}$ (25 kips). The largest measured diagonal crack width was $0.41 \mathrm{~mm}$ (0.016 in.). During load step $4(a / d=1.5)$, the specimen was loaded to $156 \mathrm{kN}$ (35 kips). The largest measured diagonal crack width was $0.51 \mathrm{~mm}(0.020 \mathrm{in}$.). During load step $5(a / d=1.0)$, the specimen was loaded to $254 \mathrm{kN}$ (57 kips). The largest measured diagonal crack width was $0.33 \mathrm{~mm}(0.013 \mathrm{in}$.$) .$

During load step $5(a / d=1.0)$, the flexural steel reinforcement yielded. In an attempt to attain shear failure at this value of $a / d$, the strip closest to the load point on the west span was removed for load step $5 b$ (the west span appeared to have more extensive damage than the east span). During Step 5b, the specimen, somewhat unexpectedly, failed on the east span. After failure, strips in the shear span were observed to be debonded, a diagonal crack extended through the compression zone and some stirrups fractured.

Table B-4.14: Specimen QC loading summary

\begin{tabular}{l|l|l|l|l|l}
\hline $\begin{array}{l}\text { Load } \\
\text { Step }\end{array}$ & $\boldsymbol{a} / \boldsymbol{d}$ & $\begin{array}{l}\text { Loading } \\
\text { Type }\end{array}$ & $\begin{array}{l}\boldsymbol{V}_{\text {app }} \\
(\mathbf{k N}) \text { (kips) }\end{array}$ & $\begin{array}{l}\text { C.L. Disp. @ } \boldsymbol{V}_{\text {app }} \\
(\mathbf{m m})(\mathbf{i n )}\end{array}$ & $\begin{array}{l}\text { Max. Measured } \\
\text { Diagonal Crack Width } \\
(\mathbf{m m}) \text { (in.) }\end{array}$ \\
\hline 0 & 3.3 & 3 cycles & $32(7.2)$ & $5.1(0.20)$ & $0.25(0.010)$ \\
\hline 1 & 3.0 & monotonic & $36(8.2)$ & $4.1(0.16)$ & - \\
\hline 2 & 2.5 & monotonic & $44(10)$ & $3.6(0.14)$ & $0.25(0.010)$ \\
\hline 3 & 2.0 & monotonic & $58(13)$ & $3.0(0.12)$ & $0.41(0.016)$ \\
\hline 4 & 1.5 & monotonic & $76(17)$ & $2.5(0.10)$ & $0.51(0.020)$ \\
\hline 5 & 1.0 & monotonic & $129(29)$ & $3.3(0.13)$ & $0.33(0.013)$ \\
\hline $5 b$ & 1.0 & 3 cycles & $125(28)$ & $2.1(0.084)$ & - \\
\hline
\end{tabular}

\section{B-4.3.8 Specimen QT}

Specimen QT underwent six load steps, as shown in Figures B-4.22 and B-4.23 and Table B4.15 , with strip widths of $16 \mathrm{~mm}$ (0.625 in) in the inverted U-wrap configuration. 


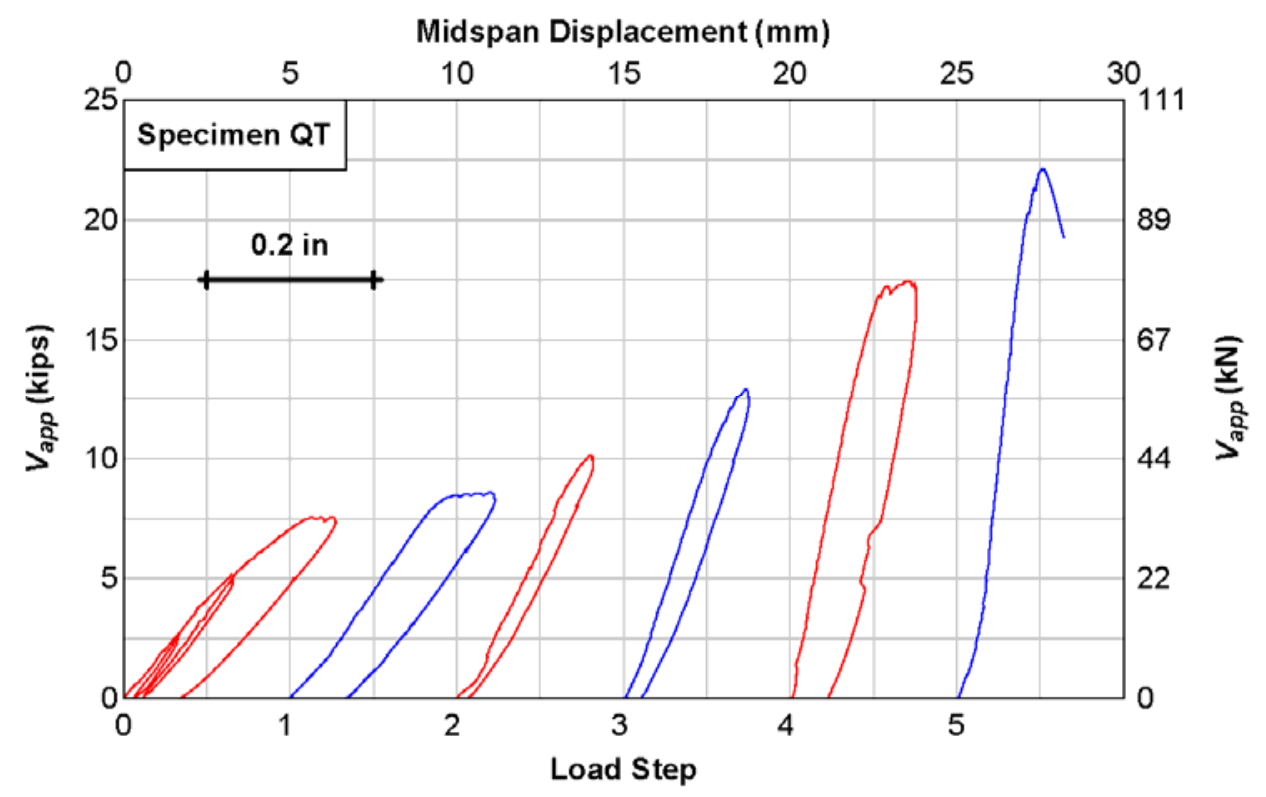

Figure B-4.22: Shear versus displacement for Specimen QT

Specimen QT displayed cracks in the concrete over its full height before any loads were applied. These cracks were incorporated into the map shown for load step 0 and may have been a result of handling. 


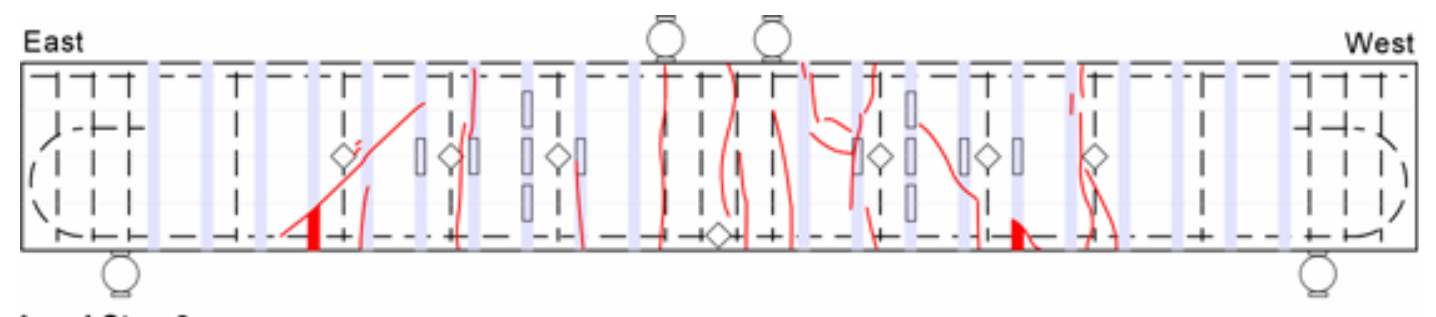

Load Step 0

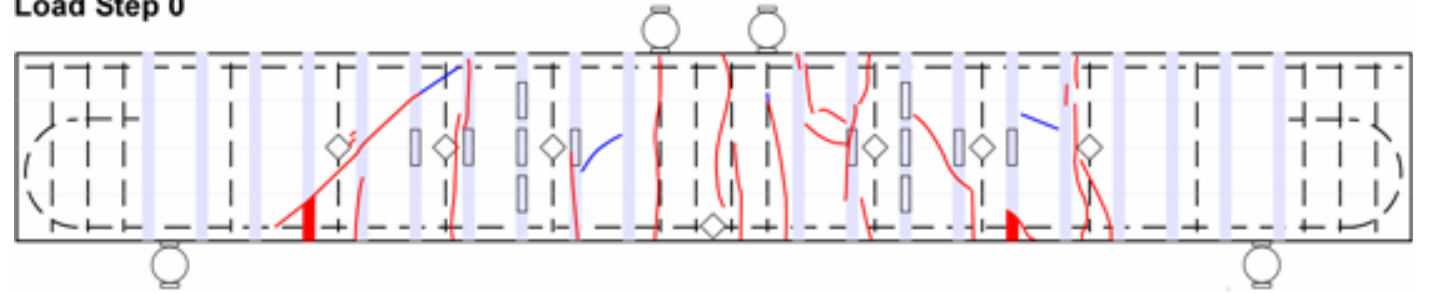

Load Step 1

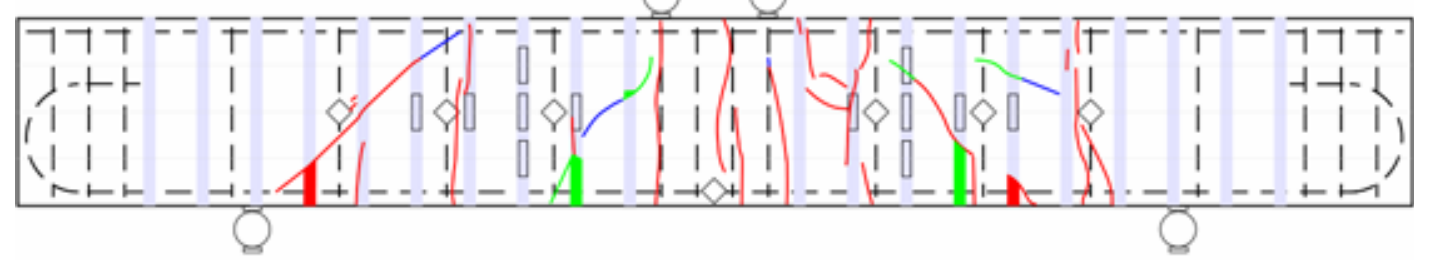

Load Step 2

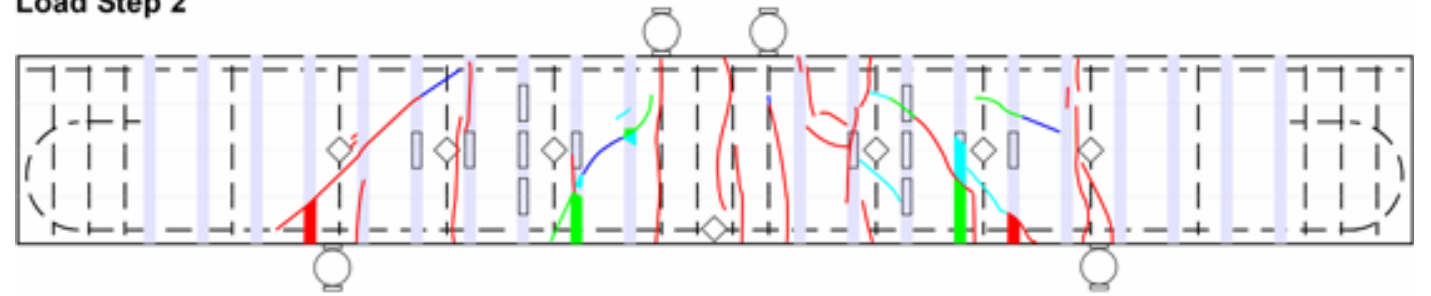

Load Step 3

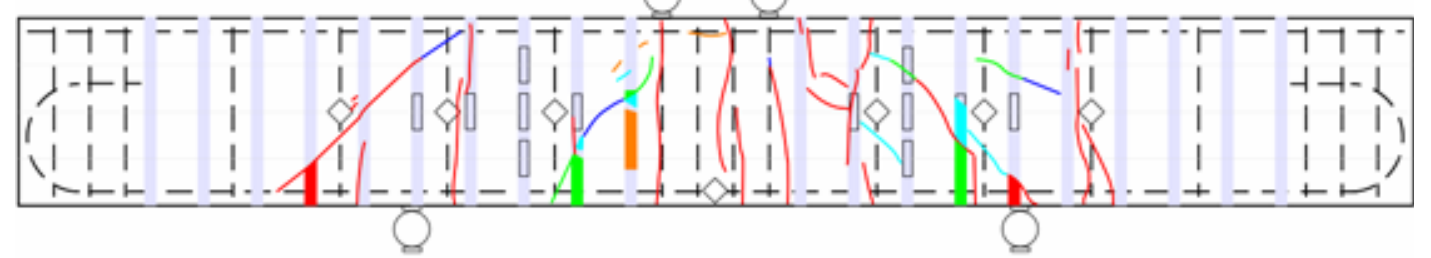

\section{Load Step 4}

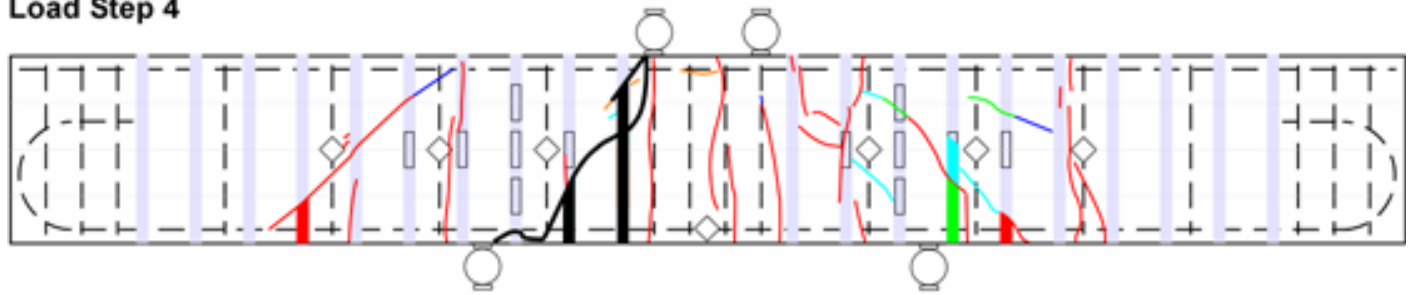

\section{Load Step 5}

Figure B-4.23: Specimen QT crack propagation maps and strain gage locations

During load step $0(a / d=3.3)$, the specimen was loaded cyclically to 24,44 and $67 \mathrm{kN}(5.4,10$ and 15 kips $)$. The largest measured diagonal crack width during load step 0 was $0.25 \mathrm{~mm}(0.010$ 
in.). The maximum applied force of $67 \mathrm{kN}$ (15 kips) approached the flexural capacity of the specimen at this support configuration. Thus, the specimen was unloaded and the supports were moved inward to allow continued testing for shear. Instruments were zeroed for the new specimen configuration.

After each load step that did not produce a shear failure, the supports were moved inward and instruments were zeroed.

During load step $1(a / d=3.0)$, the specimen was loaded monotonically to $76 \mathrm{kN}(17 \mathrm{kips})$. The largest measured diagonal crack width during load step 1 was $1.02 \mathrm{~mm}$ (0.040 in.). During load step $2(a / d=2.5)$, the specimen was loaded monotonically to $90 \mathrm{kN}$ (20 kips). The largest measured diagonal crack width was $0.25 \mathrm{~mm}(0.040 \mathrm{in}$.). During load step $3(a / d=2.0)$, the specimen was loaded monotonically to $116 \mathrm{kN}$ (26 kips). The largest measured diagonal crack width was $0.76 \mathrm{~mm}(0.030 \mathrm{in}$.).

During load step 4 ( $a / d=1.5$ ), the specimen was loaded to $156 \mathrm{kN}$ (35 kips). The largest measured diagonal crack width was $1.02 \mathrm{~mm}$ (0.040 in). During load step 4, the specimen developed a large crack in the west shear span and appeared to have significant damage in the compression zone. The force-displacement curve also appeared to soften, which seemed to indicate a flexural or interaction failure at this step. The specimen was used again, however, and failed in shear during load step 5 .

During load step $5(a / d=1.0)$, the specimen was loaded to $197 \mathrm{kN}$ (44 kips). CFRP strips in the west shear span were observed to be debonded, a large diagonal crack extended through the compression zone and some stirrups were fractured.

Table B-4.15: Specimen QT loading summary

\begin{tabular}{l|l|l|l|l|l}
\hline $\begin{array}{l}\text { Load } \\
\text { Step }\end{array}$ & $\boldsymbol{a} / \boldsymbol{d}$ & $\begin{array}{l}\text { Loading } \\
\text { Type }\end{array}$ & $\begin{array}{l}\boldsymbol{V}_{\max } \\
(\mathbf{k N})(\mathbf{k i p s})\end{array}$ & $\begin{array}{l}\text { Disp. @ } \boldsymbol{V}_{\max } \\
(\mathbf{m m})(\mathbf{i n .})\end{array}$ & $\begin{array}{l}\text { Max. Measured } \\
\text { Diagonal Crack Width } \\
(\mathbf{m m})(\mathbf{i n .})\end{array}$ \\
\hline 0 & 3.3 & 3 cycles & $33(7.5)$ & $6.4(0.25)$ & $0.25(0.010)$ \\
\hline 1 & 3.0 & monotonic & $38(8.6)$ & $6.1(0.24)$ & $1.02(0.040)$ \\
\hline 2 & 2.5 & monotonic & $44(10)$ & $4.1(0.16)$ & $1.02(0.040)$ \\
\hline 3 & 2.0 & monotonic & $58(13)$ & $3.8(0.15)$ & $0.76(0.030)$ \\
\hline 4 & 1.5 & monotonic & $80(18)$ & $3.6(0.14)$ & $1.02(0.040)$ \\
\hline 5 & 1.0 & monotonic & $98(22)$ & $2.5(0.10)$ & - \\
\hline
\end{tabular}




\section{B-5 EXPERIMENTAL RESULTS}

\section{B-5.1 INTRODUCTION}

Experimental measurements were reported in this section in detail for the $t$ specimens. These results included local and global response measurements and comparisons between different specimens, CFRP reinforcing patterns, and span length conditions. Some of the considerations for surface strain measurements in the CFRP strips are addressed compared with averaged strains from displacement sensor measurements.

\section{B-5.2 SURFACE STRAIN MEASUREMENTS IN CFRP STRIPS}

Strains in the CFRP were measured using a conventional uniaxial long-gage length bonded strain gage pattern for all specimens. This selected gage pattern had a fixed gage length of $51 \mathrm{~mm}(2$ in.) and is commonly used to measure strains in CFRP and other composite materials that require longer gage distances to allow strain averaging. The measured strain values are generally intended to represent a localized response quantity. However, due to the different scale lengths of the specimens, the proportion of the strain gage length to overall strip height increased when the specimen scale decreased, as illustrated in Figure B-5.1. Thus, for the large-scale specimens the strain gage measurements still represent a relatively localized response, while for the smallscale specimens, the strain gage measurements represent a more regional response for the CFRP strips. 


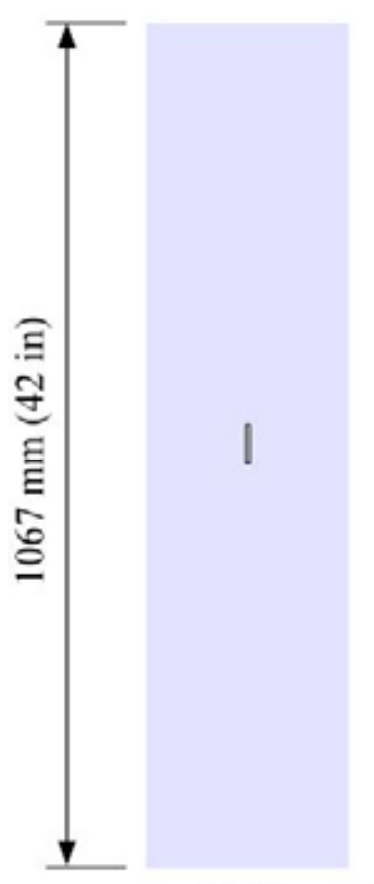

FT10 FC, FT5
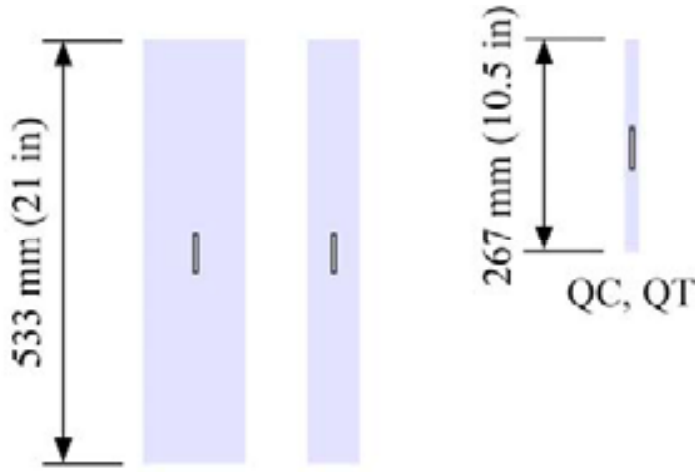

HC, HT5 HT2.5

Gage I.ength $=51 \mathrm{~mm}(2 \mathrm{in})$

Figure B-5.1: Strain gage length compared to CFRP strip heights. Gages represent 5\%, $10 \%$ and $20 \%$ of the CFRP strip length at the full, half and quarter scales, respectively

Large local strains may be expected in the CFRP, resulting from the material bridging across the cracked concrete combined with flexural-tension bending strains induced by localized debonding from the concrete surface. Due to the relatively short bond stress transfer length of the CFRP, the strains can change rapidly along the strip length and thus location of the strain gage relative to the concrete cracks and possible CFRP debonding will greatly affect the measurements. These possible sources of local strain variation will be discussed.

Strain in the section taken from diagonal displacement measurements may provide a more general perspective of the CFRP shear contribution then the local strain gage measurements as these tend to average out local variations at cracks and debonded regions. To permit these estimates, displacement measurements were taken along $45^{\circ}$ diagonals placed across the specimens in 3 panel sections within the shear span. For the failure load step, the diagonal displacement measurements were converted into average vertical strains using Mohr's circle. These average vertical strains will be compared with local strain measurements and used to estimate the CFRP contribution to shear strength. 


\section{B-5.3 STRAIN ACCUMULATION IN CFRP}

All of the specimens were loaded into the inelastic range over several different load cycles that produced concrete cracking, rebar yielding and CFRP debonding. As the $t$ specimens acquired damage, CFRP strains tended to exhibit a nonlinear loading and unloading response with plastic offset. This behavior was captured by linking measured CFRP strains from each load step to create a cumulative strain response curve. A brief description of this behavior using specimen FC as an example is provided, followed by descriptions for all the specimens.

Specimen FC was originally loaded up to $95 \%$ of the predicted flexural capacity with an $a / d=$ 3.3. Diagonal and flexural cracking of the concrete as well as localized debonding of the CFRP strips were observed at this load stage without failure. Had the test continued, the specimen would have failed in flexure. To preclude this failure mode, the supports were moved inward to the loading points for an $a / d=3.0$ and the specimen was loaded to $95 \%$ of the predicted flexural capacity for this new span length configuration. Additional diagonal and flexural cracking and CFRP debonding were observed without specimen failure. This process was repeated with the supports being moved to values of $a / d=2.5,2.0$ and 1.5 , then back out to values of $a / d=2.5$ and 2.0. Through this process the specimen acquired significant areas of CFRP debonding and concrete cracking prior to the final failure.

Measured CFRP strains were obtained from the strain gages after they were reset to zero prior to the start of each new load cycle. Measured strain from specimen FC during the failure load step, load step $3 \mathrm{~b}(a / d=2.0)$, is provided in Figure B-5.2(a).

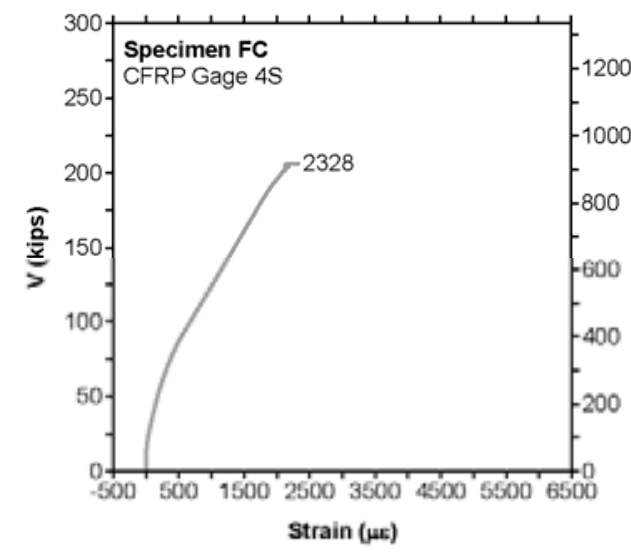

(a)

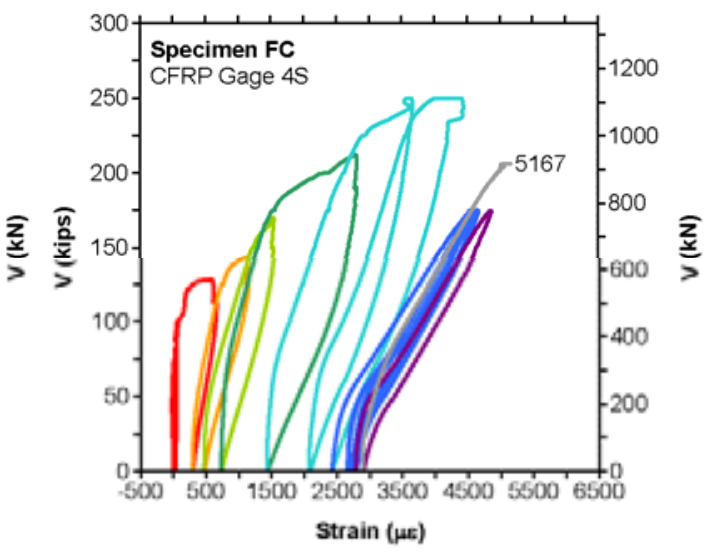

(b)

Figure B-5.2: Example applied shear versus (a) strain measured at CFRP gage 4S during load step 3b $(a / d=2.0)$ and (b) cumulative strain at CFRP gage 4S from Specimen FC 
The total accumulated strain for the strain gage during the complete test is shown in Figure B5.2(b). The accumulated CFRP strains were obtained by adding the measured strains, including the final offset values, from each of the load steps. The accumulated strain in the CFRP was much larger than that produced in the individual load steps. The accumulated strains are useful for tracking the onset and progression of diagonal cracks in the concrete.

Figures B-5.3-B-5.5 display the relationship between applied shear and CFRP strain at load step $4(a / d=1.5)$ for all specimens. CFRP strain was measured with gage $4 \mathrm{~S}$ in the full scale specimens and gage 4E in the half and quarter scale specimens. The location of CFRP gage 4 was scaled geometrically and is thus in relatively the same location for all specimens. 

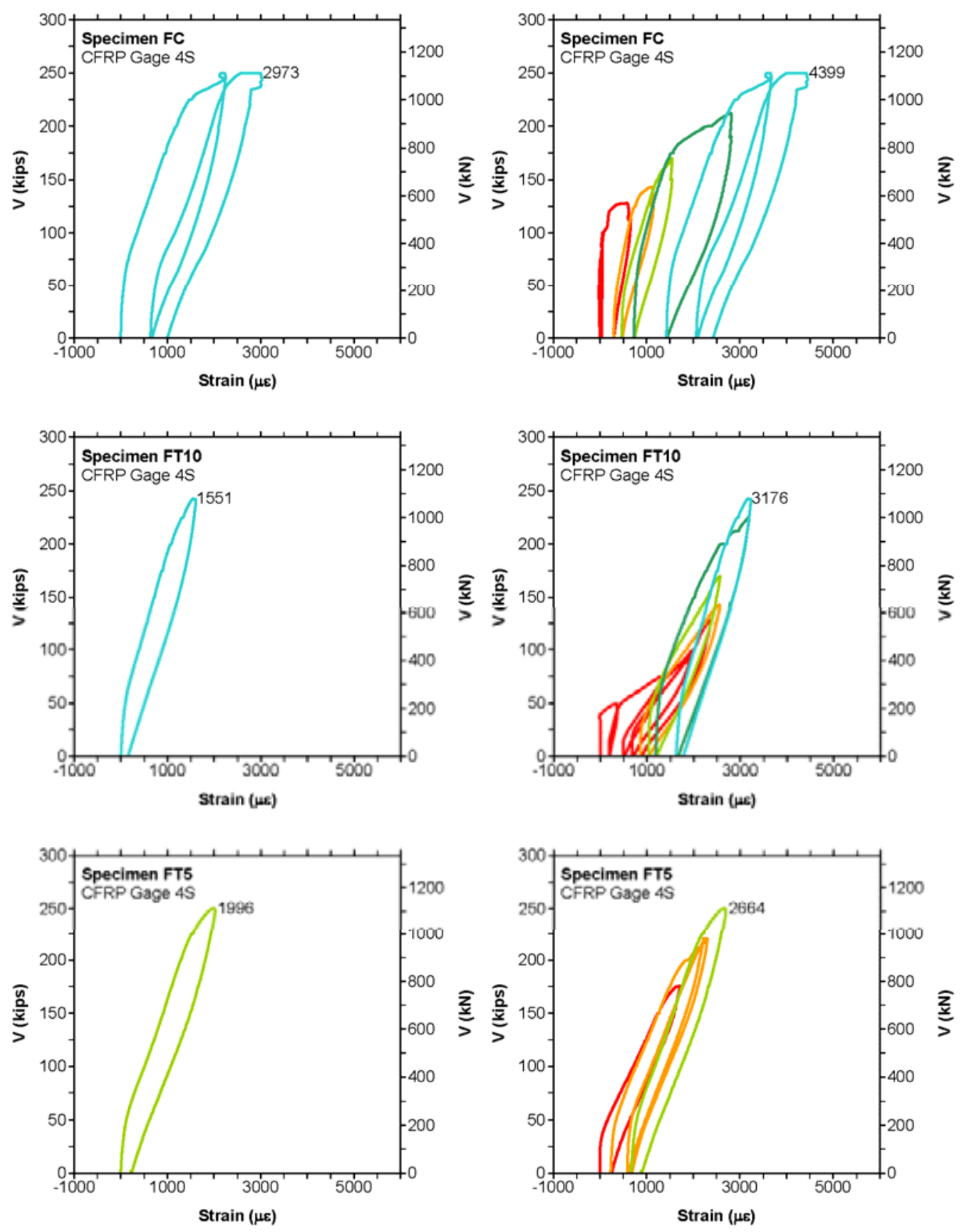

Figure B-5.3: Applied shear versus measured (left column) and cumulative (right column) strain at CFRP gage 4S from full scale Specimens FC, FT10 and FT5 

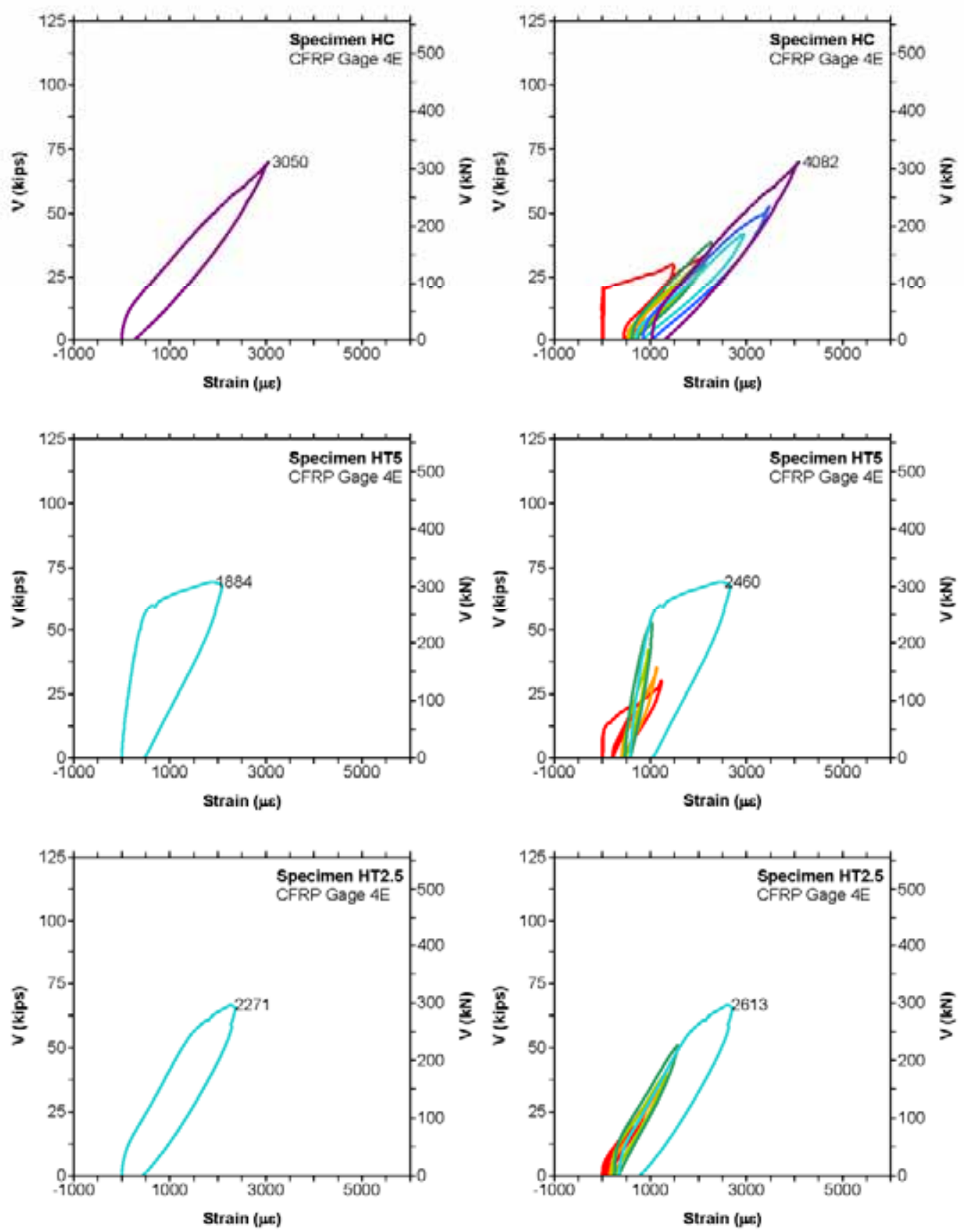

Figure B-5.4: Applied shear versus measured (left column) and cumulative (right column) strain at CFRP gage 4E from half scale Specimens HC, HT5 and HT2.5 

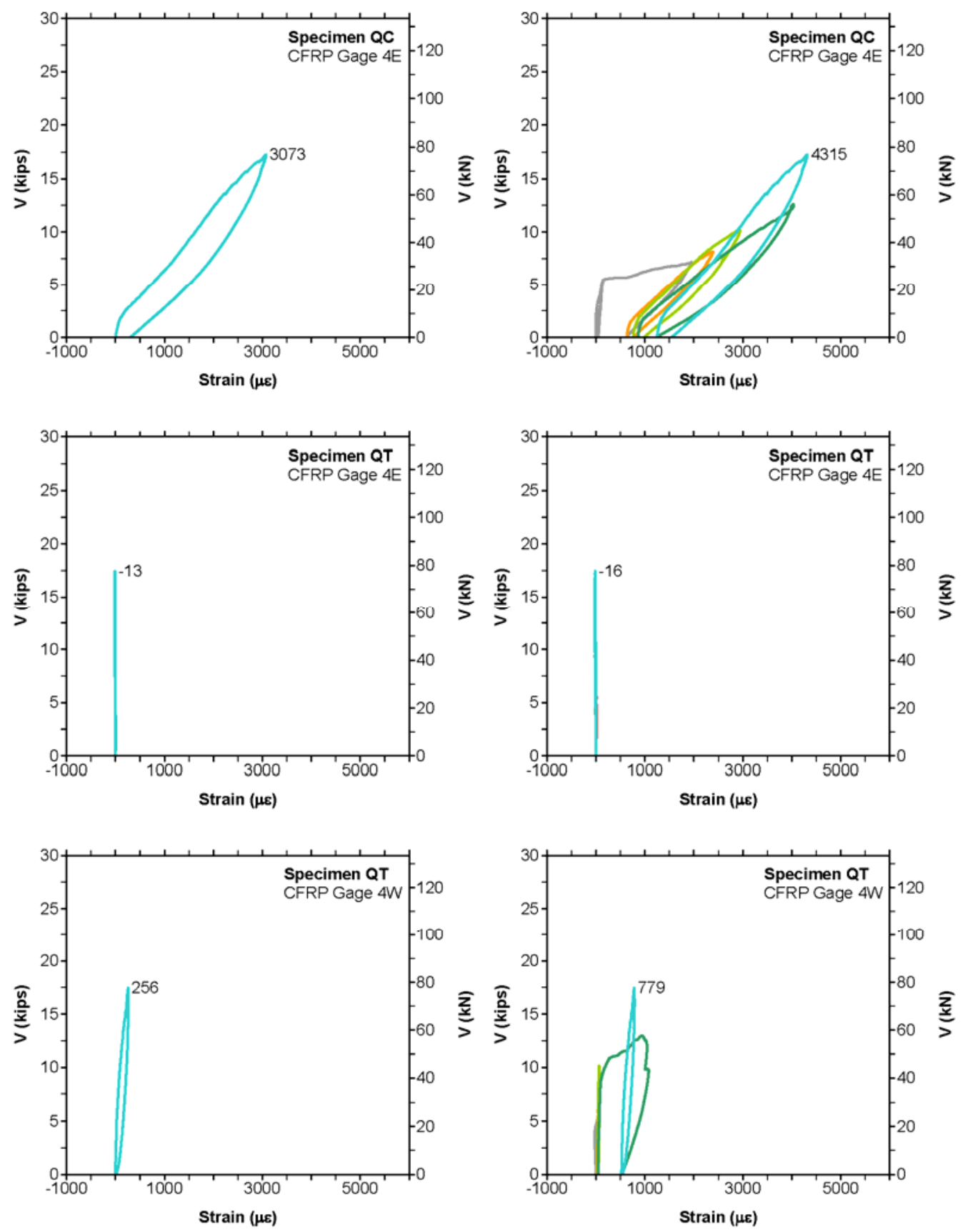

Figure B-5.5: Applied shear versus measured (left column) and cumulative (right column) strain at CFRP gage 4E from quarter scale Specimens QC and QT

From Figure B-5.3, Specimen FT5 exhibited the least amount of cumulative CFRP strain, followed by Specimens FT10 and FC. Specimen FT10 possessed the largest strip width. Specimens FT10 and FT5, which were strengthened by inverted U-wraps, had lower cumulative 
strains than Specimen FC. Specimen FT5 was first tested as Specimen FT10 before portions of CFRP were manually removed.

From Figure B-5.4, Specimen HT5 exhibited the least cumulative CFRP strain, followed by Specimens HT2.5 and HC. Specimen HT2.5 had the narrowest strip width, while HC and HT5 had the same strip width. Specimens HT5 and HT2.5, which were strengthened by inverted Uwraps, had lower cumulative strains than specimen HC. Specimen HT2.5 was first tested as Specimen HT5 before portions of CFRP were manually removed.

From Figure B-5.5, Specimen QT accumulated almost no strain in CFRP gage 4E during testing. Review of the crack map shows no diagonal cracks crossing the strip on which gage 4E was affixed. Other gages on this strip ( $3 \mathrm{E}$ and $5 \mathrm{E}$ ) also accumulated almost no strain. CFRP gage $4 \mathrm{~W}$, which was in the same relative location but on the west span, was used for comparison instead. Specimen QT appears to have accumulated less CFRP strain than Specimen QC. Specimen QT was strengthened with an inverted U-wrap. Both specimens had the same strip width.

It appeared that for all scales, cumulative CFRP strains tended to be less in the inverted U-wraps. The accumulation of almost no strain in the CFRP strip on which gage 4E from specimen QT was affixed indicates that local strain measurements are dependent on relative location of the sensor to diagonal cracks.

\section{B-5.4 LOCAL STRAIN VARIATION}

Local strain variations in CFRP exist around regions of debonding, which commonly occur where diagonal cracks cross CFRP strips. Maeda et al. (1997) demonstrated this through testing and nonlinear finite element modeling of CFRP bonded to concrete across a crack. Maeda et al. (1997) developed a strain distribution model and concluded that an effective bond length resists shear stresses. The effective bond length, $L_{e}$, was calculated for all the $\mathrm{t}$ specimens according to ACI 440.2R-08 Equation (10-7), which is provided in Equations 1 and 2 in Section B-2.1. The resulting bond length was $48 \mathrm{~mm}$ (1.9 in.) for all specimens, regardless of scale. To identify the local strain variations along the strip length, three gages were affixed to a single strip in specimen FC and measurements were compared.

CFRP gages $3 \mathrm{~S}, 4 \mathrm{~S}$ and $5 \mathrm{~S}$ were aligned vertically in the same CFRP strip on specimen FC. Gage $3 \mathrm{~S}$ was located at $1 / 4$ of the height of the specimen, gage $4 \mathrm{~S}$ was at mid-height and gage $5 \mathrm{~S}$ was located at $3 / 4$ of the height of the specimen. Cumulative strains through load step $3 \mathrm{~b}(\mathrm{a} / \mathrm{d}=$ 2.0), the failure load step, are shown in Figure B-5.6. As seen in Figure B-5.6, the CFRP strain was not uniformly distributed along the height of the strip. The eventual failure diagonal crack crossed the strip between gages $4 \mathrm{~S}$ and $5 \mathrm{~S}$. 

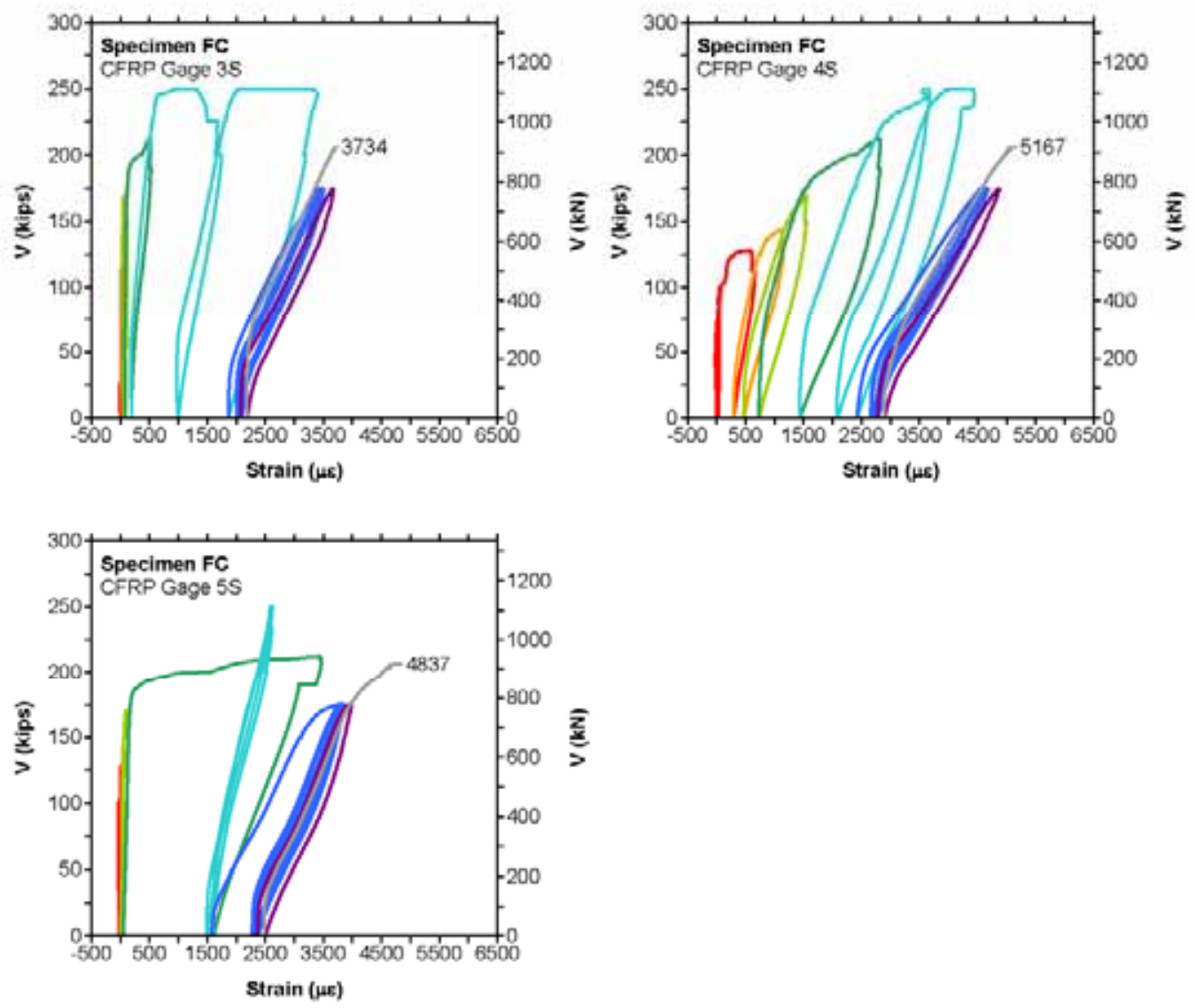

Figure B-5.6: Applied shear versus cumulative strain at CFRP gages 3S, 4S and 5S from Specimen FC

According to Figure B-5.6, gage 3S first experienced a rapid increase in strain during load step 3 $(a / d=2.0)$ with additional significant strain proceeding in load step $4(a / d=1.5)$. This was due to concrete cracking followed by CFRP strip localized debonding which produced the large strains and inelastic unloading, A small debonded region above gage $3 \mathrm{~S}$ was first observed during load step $1(a / d=3.0)$. During testing, the specimens were inspected to detect debonding by tapping on the CFRP surface after the applied shear had been reduced to $90 \%$ of the maximum applied shear and held constant. While this load was held, the extent of concrete cracking and CFRP debonding were documented. Debonded CFRP was associated with a hollow sound when the surface was tapped. The debonded region above the strain gage progressed upwards away from the gage during load step $2(a / d=2.5)$. Growth downward toward the gage was observed during load step $4(a / d=1.5)$.

As seen in Figure B-5.6, gage 4S first experienced large strains during load step $0(a / d=3.3)$ with significant additional strains during load steps 1-4. CFRP gage 4S was just above a debonded region that was first recorded during load step 0 . The debonded region was oriented 
along a diagonal crack and was approximately $50 \mathrm{~mm}(2 \mathrm{in}$.) high across the entire strip width. The debonded region expanded vertically during load steps $1(a / d=3.0)$ and $4(a / d=1.5)$.

According to Figure B-5.6, gage 5S first experienced large strains during load step $3(a / d=2.0)$. CFRP gage $5 \mathrm{~S}$ was centered over an eventually debonded region that was first recorded during load step 3. The debonded region was approximately $250 \mathrm{~mm}$ (10 in.) high across the entire strip width.

It appeared that larger cumulative CFRP strains were present closer to the failure diagonal crack as compared to the strains at gages located away from the crack. This indicated that even with significant observed debonding over the strip length, there is still sufficient bond stress transfer between the CFRP and concrete to result in strain gradients in the strips.

Prior to the onset of diagonal cracking and CFRP debonding, the CFRP strain response was linear elastic. It appears that diagonal cracking of the base concrete followed by CFRP debonding correlated to the observed decreased slope, large strains, nonlinear unloading and plastic offset when CFRP strain is plotted against applied shear. The very large CFRP strains, generally considered as the uniaxial strain in the material, that first occur upon concrete cracking and initial localized debonding, may be artificially inflated due to flexural-tension strains induced by debonding in the following sections.

\section{B-5.5 FLEXURAL STRAIN FROM DEBONDING}

Debonding of the CFRP was observed locally around the diagonal cracks that crossed the CFRP strips. After Specimen FC failed in shear, several CFRP-concrete failure surfaces were observable, as shown in Figure B-5.7. In some cases, the CFRP strips were able to pull away shallow concrete wedges at the diagonal crack locations, as shown schematically in Figure B5.8, which were still bonded to the CFRP strip. Away from diagonal cracks, the strips lost load capacity when the adhesive bond failed along the concrete substrate just under the CFRPconcrete interface. 


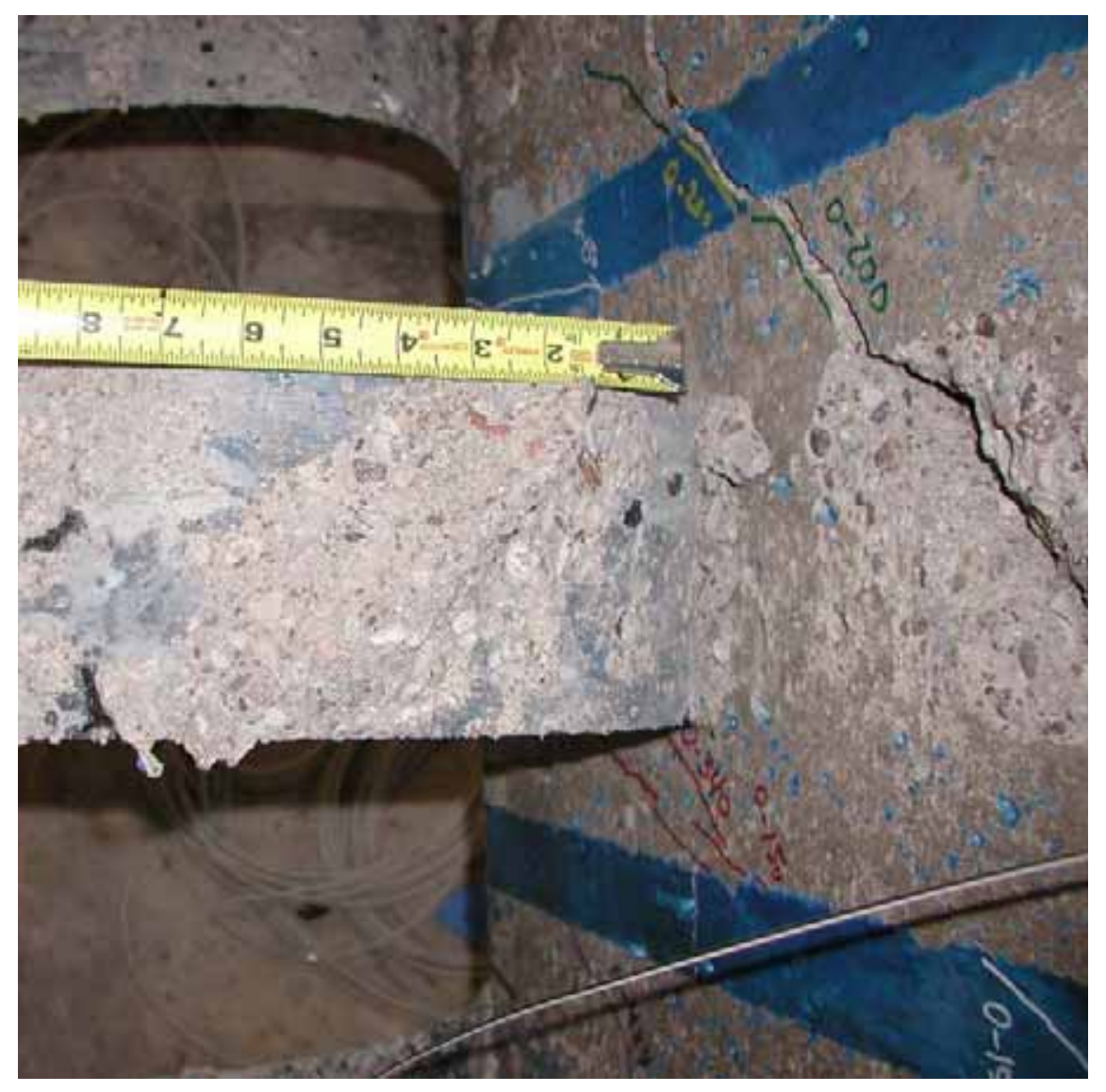

Figure B-5.7: Photograph of a debonded CFRP strip that formerly crossed a diagonal crack (post-failure of Specimen FC) 


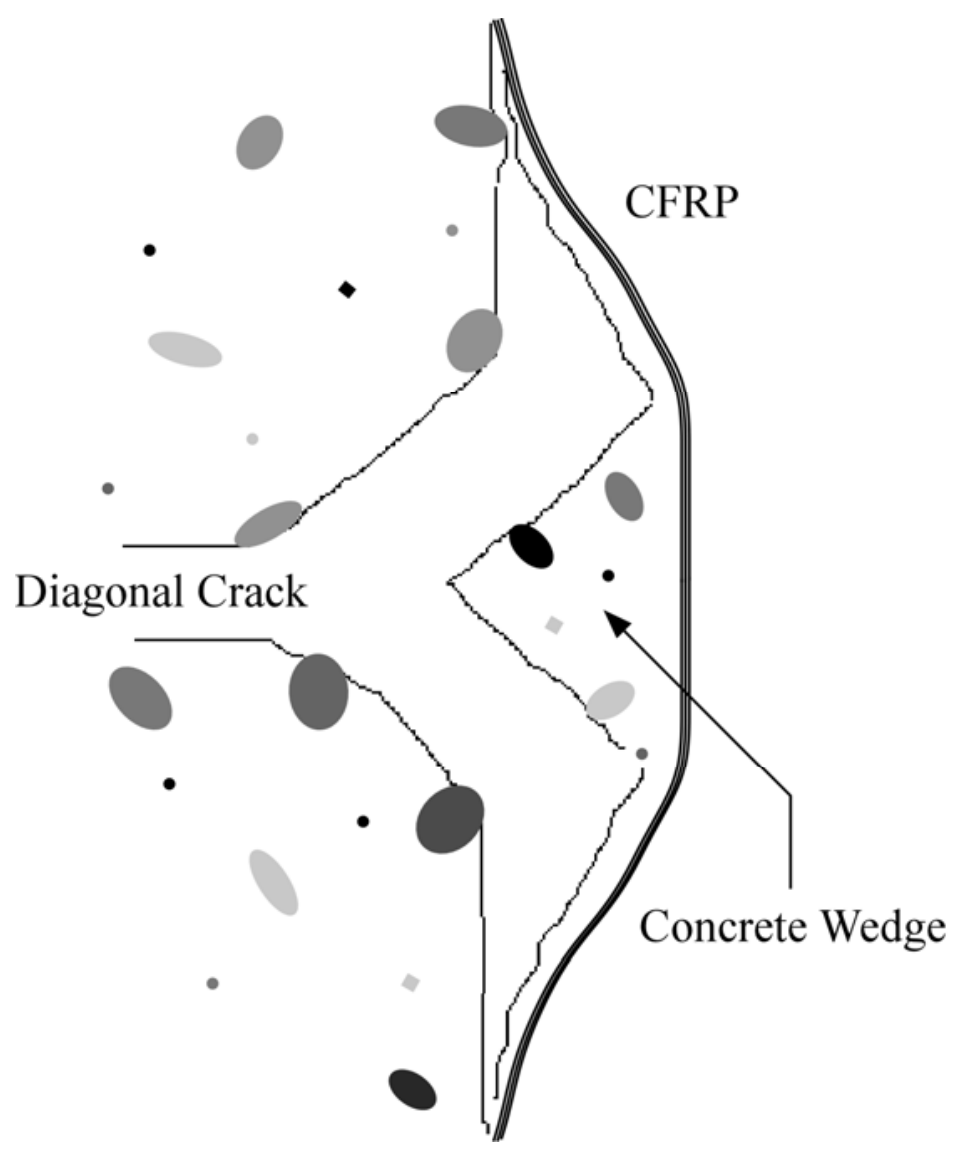

Figure B-5.8: Illustrated section view of debonded CFRP at a diagonal crack

Test observations indicated that the debonded CFRP deflected outward from the specimen and that adjacent bonded regions provided some restraint to the out-of-plane deformations. Two idealized deflected shapes of debonded CFRP are shown in Figure B-5.9. 


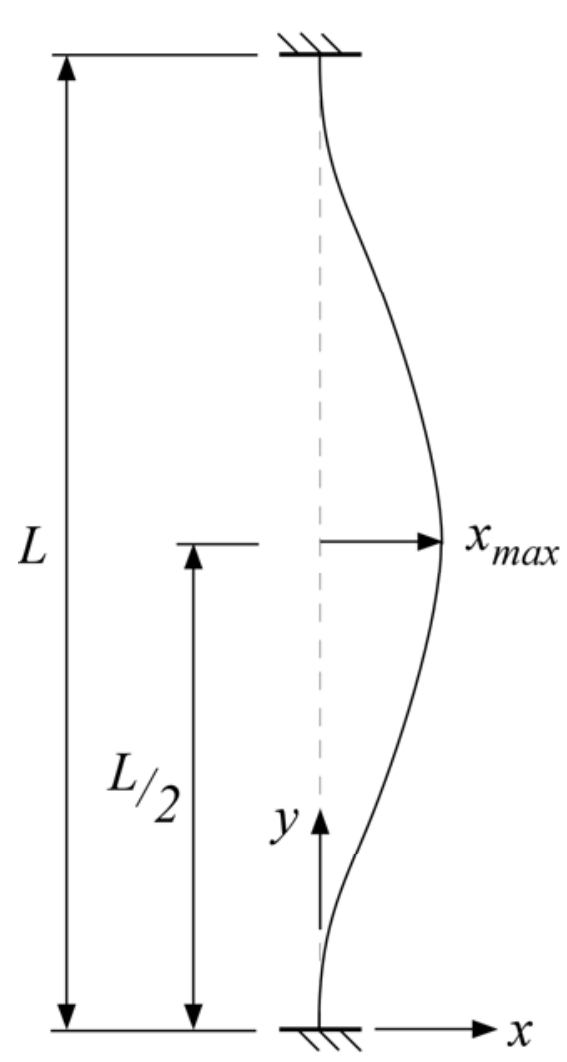

(a)

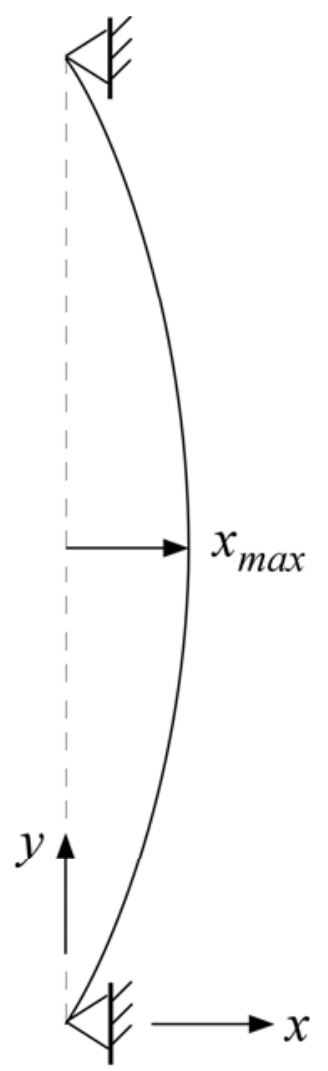

(b)

Figure B-5.9: Assumed deflected shapes and boundary conditions for debonded portions of CFRP

Assuming the boundary conditions and deflected shapes shown in Figure B-5.9, flexural-tension strains from debonding at the instrumented surface of the CFRP, $\varepsilon_{f d}$, at mid-length of the debonded region were calculated. For the fixed supports shown in Figure B-5.9(a), this strain may be expressed as:

$$
\varepsilon_{f d}=\frac{16 x_{\max } t_{f}}{L^{2}}
$$

where $t_{f}$ is the thickness of the CFRP, $x_{\max }$ is the maximum out-of-plane deformation, and $L$ is the unbonded length. For the pinned supports shown in Figure B-5.9(b), this strain may be expressed as:

$$
\varepsilon_{f d}=\frac{4 x_{\max } t_{f}}{L^{2}}
$$


These expressions for bending induced strains are presented graphically in Figure B-10 for ranges of $x_{\max }$ and $L$. As seen in Figure B-5.10, very large flexural-tension strains may be expected at short debonded lengths. As the debonded length increases, CFRP flexural-tension strains decrease nonlinearly. For this test configuration, the debonded length was limited by the height of the specimen. While flexural-tension strains appear to become negligible when the debonded length approaches the height of the full-scale specimens, significant bending induced surface tensile strains may still be present when the debonded length approaches the height of the half- and quarter-scale specimens.
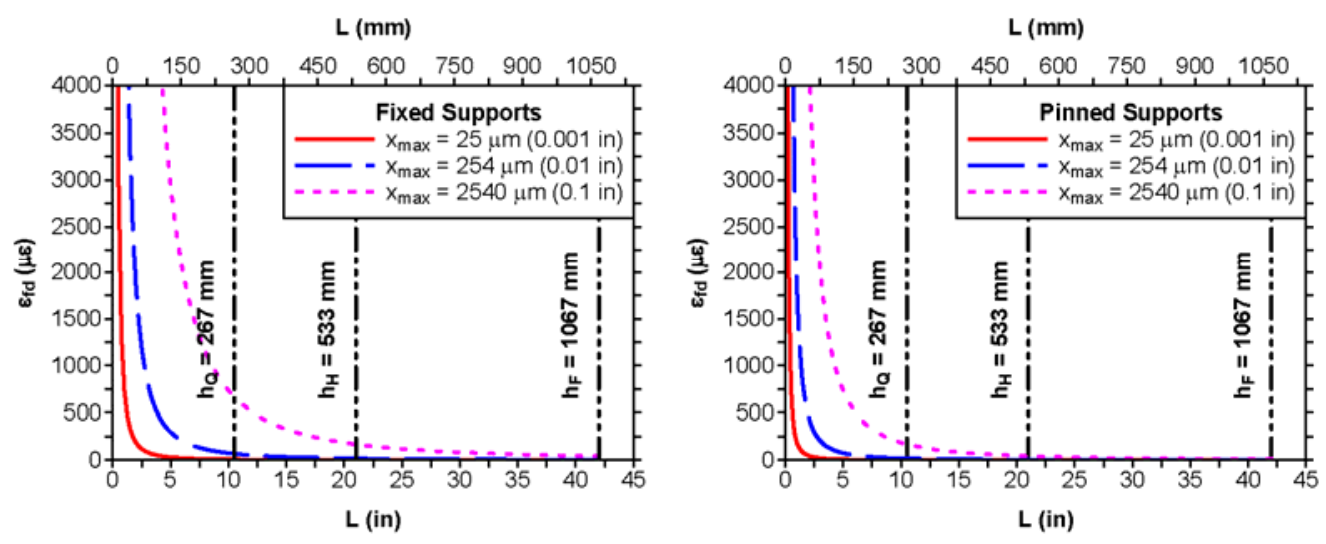

Figure B-5.10: Modeled CFRP flexural-tension strains induced by debonding.

Considering actual strain gages located in the specimens, CFRP gage 5S from specimen FC was identified as centered over a debonded strip region with $L=250 \mathrm{~mm}$ (10 in.) during load step 3 $(a / d=2.0)$. The difference between the initial and final measured strains at CFRP gage 5S was approximately $1540 \mu \varepsilon$, as shown in Figure B-5.6. With $t_{f}=1.16 \mathrm{~mm}$ (0.0458 in), Equations 18 and 19 yield maximum displacements of $5 \mathrm{~mm}(0.21 \mathrm{in})$ and $21 \mathrm{~mm}(0.84 \mathrm{in})$, respectively. While Equation 18 provides a feasible maximum displacement, actual measurements would be required to verify this model.

\section{B-5.6 REDISTRIBUTION OF STRAIN UPON MANUAL REMOVAL OF CFRP}

When a RC beam shear strengthened with CFRP U-wraps fails, a sudden progressive debonding of the strips is typically observed. To study the effect of bond loss along portions of adjacent CFRP strips on the remaining shear resisting components, some CFRP strips bonded to specimen FT5 were systematically removed while repeating the same load conditions during steps $2 \mathrm{~b}-2 \mathrm{~h}$. 
Support locations remained in one location $(a / d=2.5)$ and the same maximum value of shear was applied during each load step $(778 \mathrm{kN})$. A detailed description of the manual removal of strips with corresponding cracking and debonding diagrams may be found in Chapter 5.0. Measured strains in the internal stirrups and CFRP strips in the south span during these load steps are shown in Figure B-5.11.

Measured strain was studied as opposed to cumulative strain to mitigate the influence of the combined effects over the duration of the test, such as crack propagation and debonding, which were discussed previously. No strips were altered for load step $2 b$, which was used for the baseline to compare responses. Specimen FT5 eventually failed during load step $2 \mathrm{~h}$.

Internal stirrups gages $3 \mathrm{~S}$ and $4 \mathrm{~S}$ indicated yielding after the maximum applied shear was reached during load step $2 \mathrm{~g}$. CFRP gage $2 \mathrm{~S}$ was deactivated before load step $2 \mathrm{f}$ since the strip it was attached to was removed up to the gage location. Likewise, CFRP gage $6 \mathrm{~S}$ was removed before load step $2 \mathrm{~g}$.

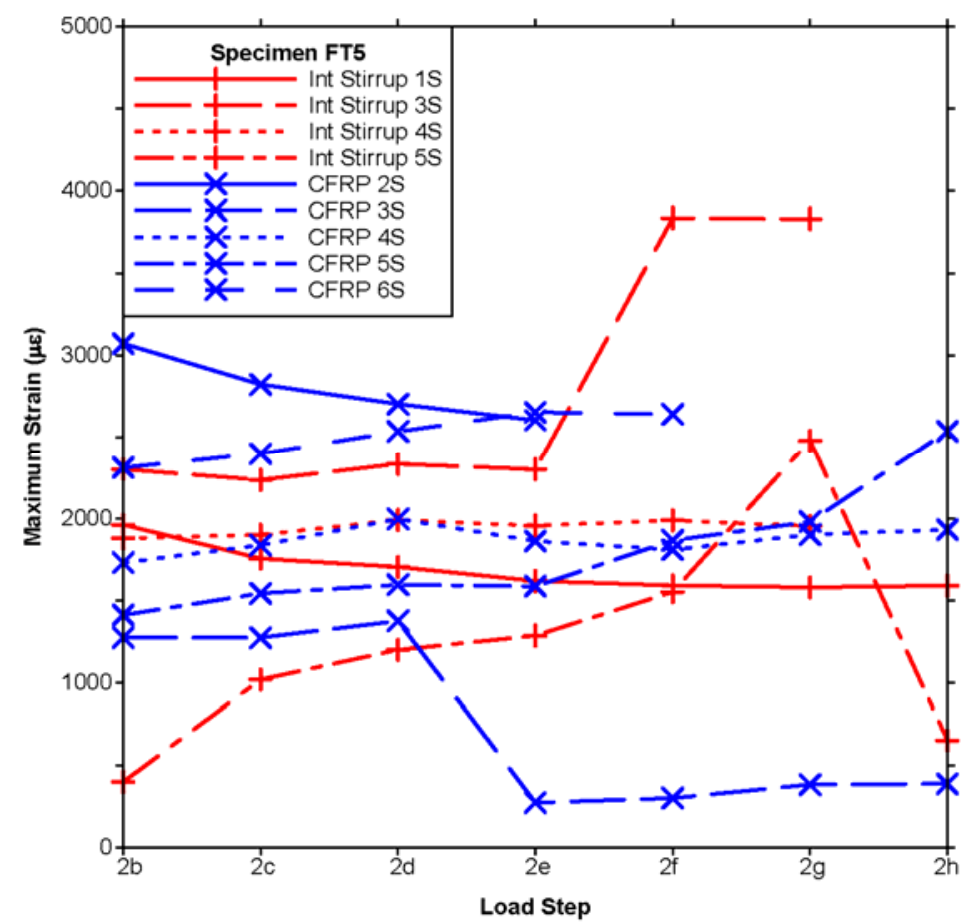

Figure B-5.11: Maximum measured strain in the internal stirrups and CFRP strips during load steps $2 \mathrm{~b}-2 \mathrm{~h}$ of Specimen FT5

Internal stirrup gage $3 \mathrm{~S}$ exhibited a significant increase in strain at load step $2 \mathrm{f}$. Prior to load step 2f, the sixth seventh and eighth CFRP strips from the south end of the specimen were removed to mid-height on alternating faces. Internal stirrup gage $3 \mathrm{~S}$ was located between the 
seventh and eighth strips. Figure B-5.11 indicates that the reduction of CFRP bonded area in strips directly adjacent to internal stirrup gage $3 \mathrm{~S}$ resulted in a significant strain increase in the stirrup.

Likewise, internal stirrup gage 5S exhibited a significant increase in strain at load step 2g. Prior to load step $2 \mathrm{~g}$, the ninth CFRP strip from the south end of the specimen was removed to midheight. Internal stirrup gage $5 \mathrm{~S}$ was located between the ninth and tenth strips.

Stirrup gage $1 \mathrm{~S}$ and CFRP gage $2 \mathrm{~S}$ showed about the same relative decrease in strain between load steps $2 \mathrm{~b}$ and $2 \mathrm{e}$. During load steps $2 \mathrm{c}, 2 \mathrm{~d}$ and $2 \mathrm{e}, 152 \mathrm{~mm}$ (6 in.) was removed from the bottom of the sixth, seventh and eighth strips, respectively. Figure B-5.11 indicates that these removals did not significantly affect the other gages in the vicinity. Diagonal cracks and debonded CFRP were not observed to expand significantly during these load steps, which may account for the reduction in strain measurements.

\section{B-5.7 STRAIN COMPATIBILITY}

To determine whether the CFRP and internal stirrup strains were compatible, strain gage measurements were compared for adjacent components located along the same diagonal crack. Strain values from adjacent internal stirrups and CFRP strips along diagonal cracks in specimen FC are shown in Figure B-5.12. Load steps are presented in order $(0,1,2,3,4,2 \mathrm{~b}, 2 \mathrm{c}$ and $3 \mathrm{~b})$ with an imposed manual offset of $2000 \mu \varepsilon$ between the load steps. 

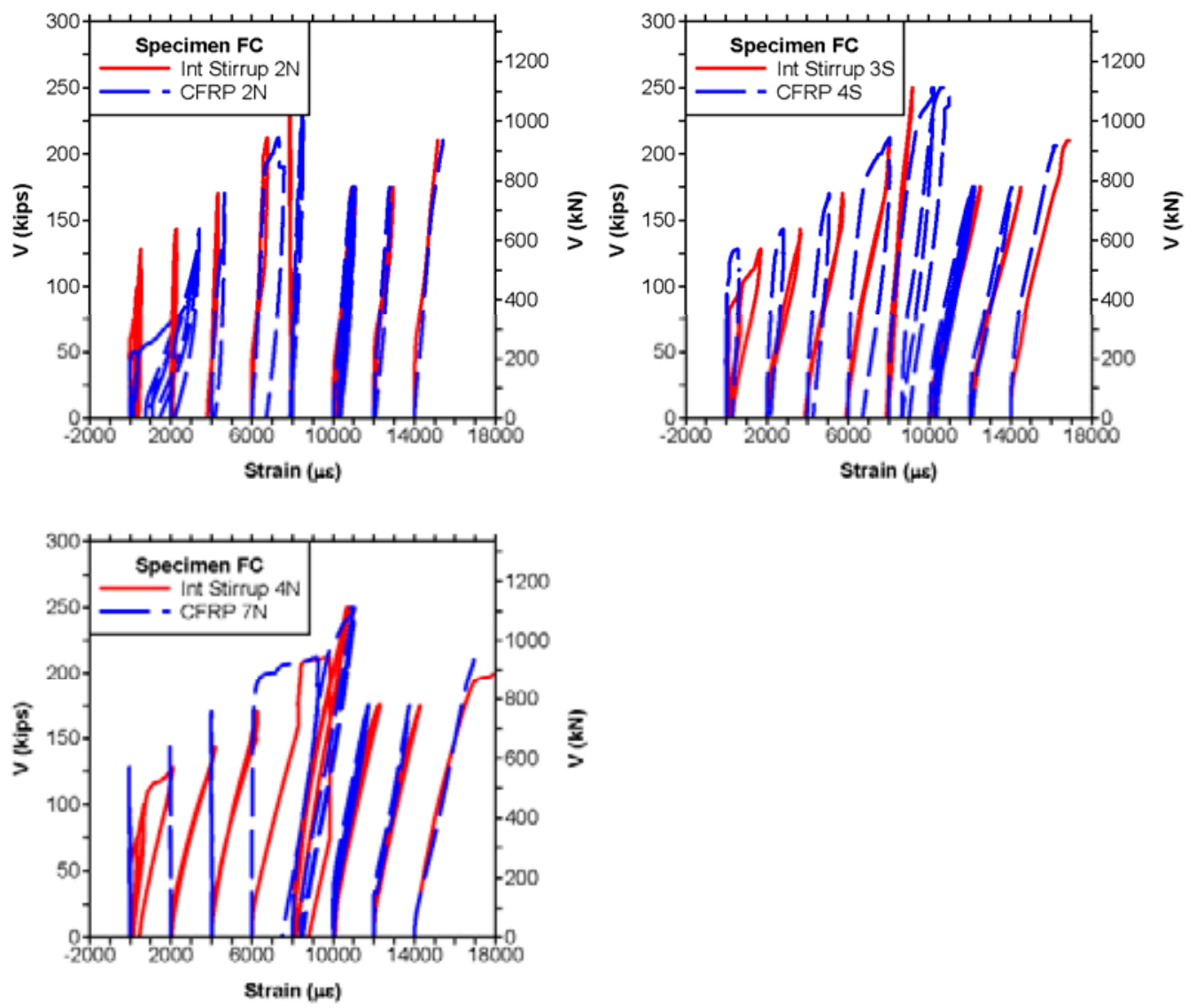

Figure B-5.12: Strain in adjacent internal stirrups and CFRP strips of Specimen FC

Strains in specimen FC were initially quite small during load step $0(a / d=3.3)$ prior to formation of diagonal cracking. After a diagonal crack forms, either the stirrup or strip will exhibit higher strain depending on the sensor location relative to the crack location. The strains did not appear to be compatible at these early cracking stages (through load steps 1-4). Internal stirrup strains would tend to be highest at the diagonal crack and then decrease over the development length. Development lengths, $\ell_{d}$, for internal stirrups were calculated according to ACI 318-08 Section 12.2.2 (Equation 20) and are given in Table B-5.16. Strain gages on internal stirrups were located at mid-height of the specimens.

$$
\ell_{d}=\left(\frac{f_{y} \psi_{t} \psi_{e} \lambda}{25 \sqrt{f_{c}{ }^{\prime}}}\right) d_{b}
$$

where $f_{y}=$ yield strength, $\psi_{t}=$ modification for reinforcement location, $\psi_{e}=$ modification for coating, $\lambda=$ modification for concrete unit weight, $f_{c}{ }^{\prime}=$ concrete compression strength and $d_{b}=$ reinforcement diameter. 
Table B-5.16: Development lengths for internal stirrups

\begin{tabular}{l|l|l|l|l|l}
\hline Specimen & FC & FT & HC & HT & QC \& QT \\
\hline$\ell_{d}(\mathrm{~mm})(\mathrm{in})$ & $353(13.9)$ & $345(13.6)$ & $164(6.46)$ & $162(6.38)$ & $160(6.29)$ \\
\hline $\mathrm{h} / 2(\mathrm{~mm})(\mathrm{in})$ & $533(21)$ & $533(21)$ & $267(10.5)$ & $267(10.5)$ & $133(5.25)$ \\
\hline
\end{tabular}

CFRP strains would likely be highest over the diagonal cracks and locally debonded areas because of the combined uniaxial and flexural-tension induced strains. CFRP strains would decrease away from debonded areas, along the effective bond length, and as debonded lengths grew. CFRP effective bond length was $48 \mathrm{~mm}$ (1.9 in.) for all specimens, which was much shorter than the internal steel stirrup development length.

Strains appear to be compatible during load steps $2 b, 2 c$ and $3 b$. Specimen FC underwent its highest applied shear and experienced widespread debonding during load step 4. After load step 4 , debonded lengths may have become large enough for flexural-tension strains to become greatly reduced and for debonded regions to have reached the CFRP gages and effectively allow for average strain conditions in the components.

The strain compatibilities observed for all specimens are shown in Figure B-5.13. Load steps are shown in order for each specimen with an imposed manual offset of $2000 \mu \varepsilon$ for each subsequent load step. Later load steps were not included if gage failure occurred previously or if the support location caused vastly different behavior (i.e. when the support was placed in between two gages, causing one gage to report zero strain while the other reported a non-zero strain). As seen in these figures, the other specimens exhibited similar stirrup and CFRP strip strain compatibility conditions to those described for Specimen FC. 

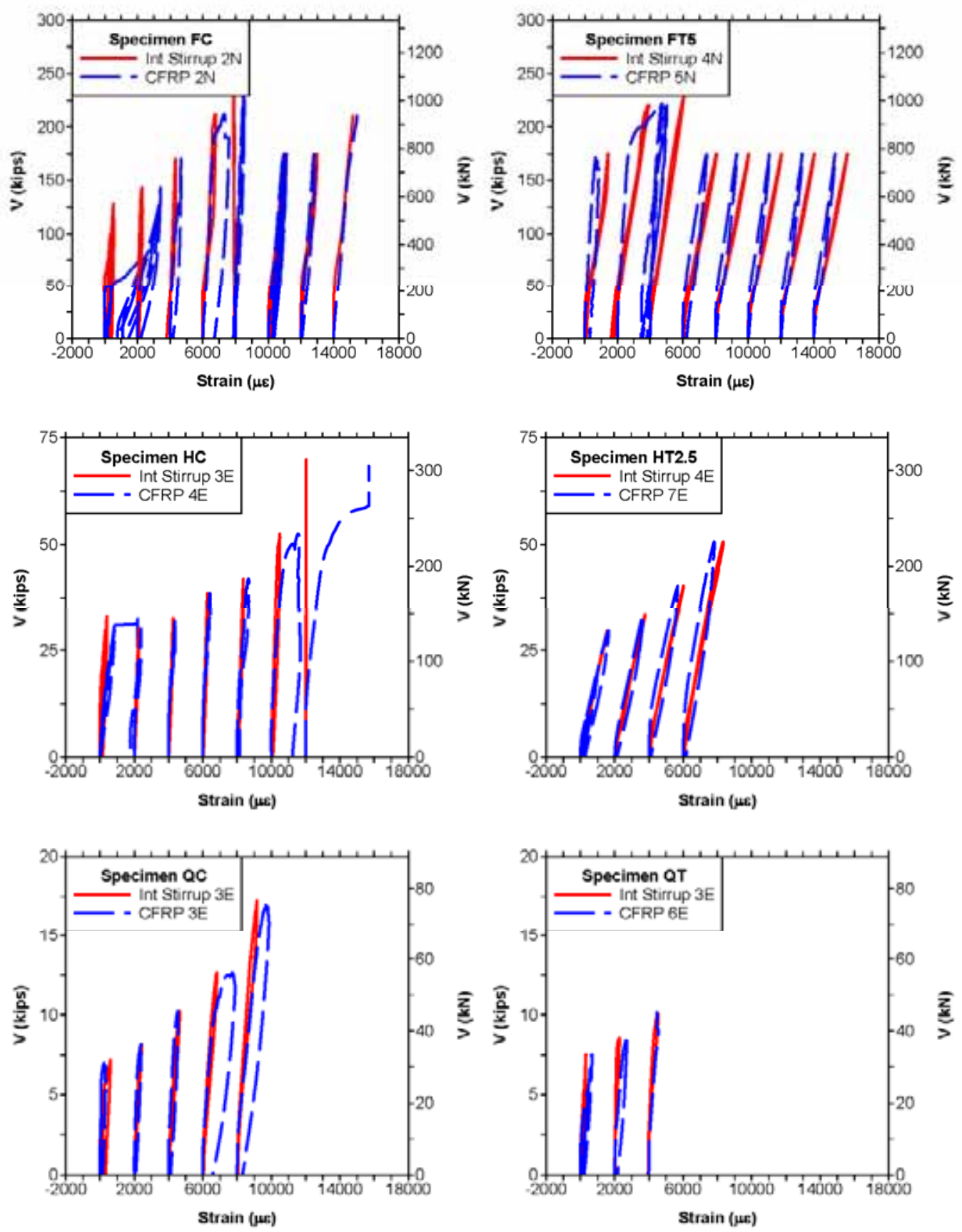

Figure B-5.13: Measured internal stirrup and CFRP strains for all specimens 


\section{B-5.8 AVERAGE VERTICAL STRAIN}

Average vertical strains were used to estimate the CFRP shear contribution at the final loading step when failure occurred. As discussed previously, surface bonded strain gage measurements can contain large local variations, which may be sensitive to the scale of the specimen relative to the instrument gage length (e.g. where the strain gage covers a very small portion of CFRP strips).

The diagonal displacement measurements from the failure load step were converted into average vertical strains using Mohr's circle, shown in Figure B-5.14. This conversion was based upon five known quantities, as shown in Figure B-5.15: diagonal tension displacement $\left(L_{t}\right)$, diagonal compression displacement $\left(L_{c}\right)$, diagonal displacement gage length $\left(L_{o}\right)$, diagonal displacement gage orientation $\left(\theta_{\text {diagonal }}\right)$ and failure crack angle $\left(\theta_{\text {crack }}\right)$. Changes in the diagonal displacement orientation were assumed to be negligible. This method was not used for non-failure load steps since the failure crack had not evolved during the earlier load steps.

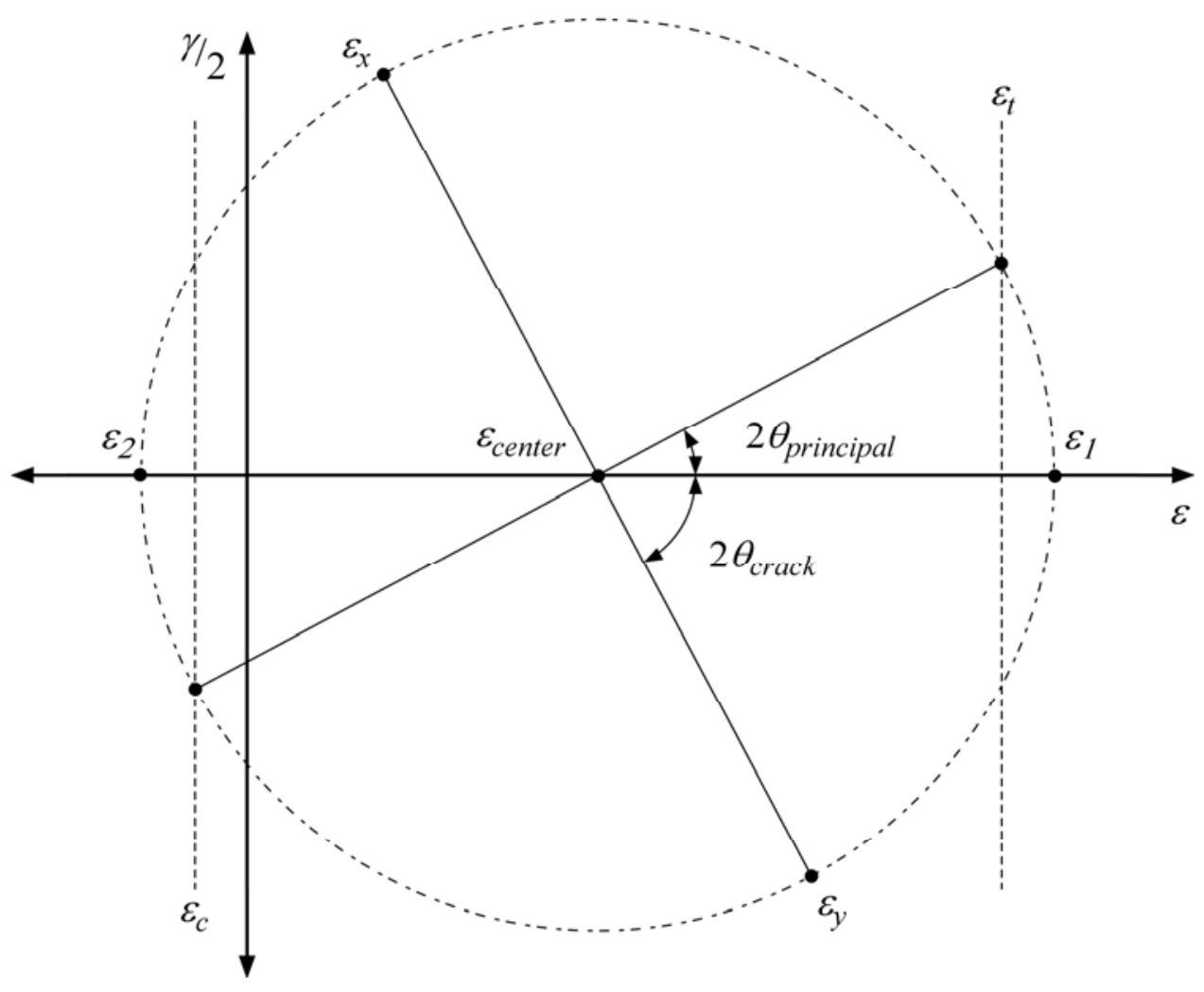

Figure B-5.14: Mohr's circle for strain 


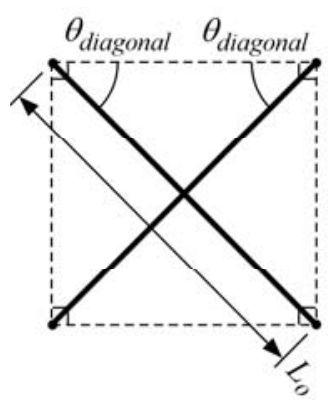

Initial Panel Configuration
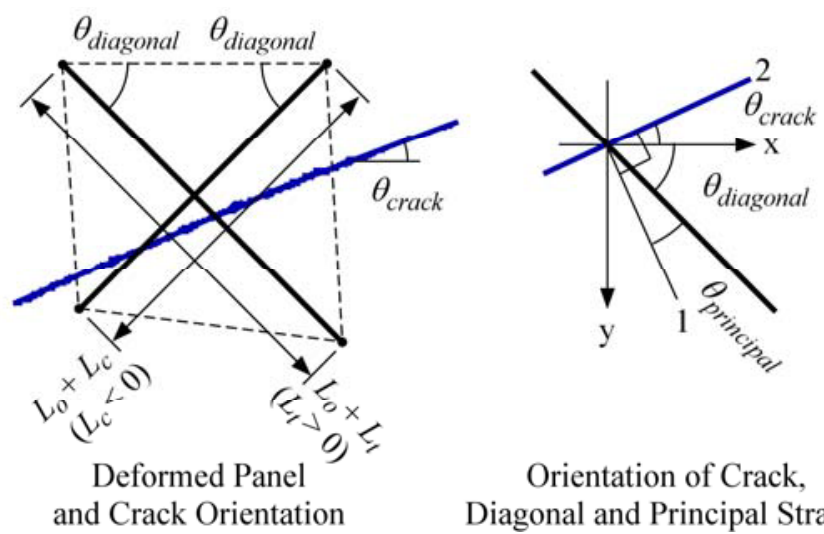

Orientation of Crack, Diagonal and Principal Strains

Figure B-5.15: Diagonal displacement geometry

The following describes the process of converting the diagonal displacement measurements into strains using Mohr's circle. First, the diagonal displacement measurements were converted into strains, $\varepsilon_{t}$ and $\varepsilon_{c}$, using Equations. 21 and 22. These tension and compression strains were then used to find the center of Mohr's circle, $\varepsilon_{\text {center }}$, using Equation 23. The orientation of the principal strain, $\theta_{\text {principal }}$, was assumed to be orthogonal to the failure diagonal crack orientation and was calculated using the diagonal displacement gage orientation and crack angle using Equation 24. The radius of Mohr's circle, $R$, was calculated using Equation 25. Principal strains, $\varepsilon_{1}$ and $\varepsilon_{2}$, as well as vertical and horizontal strains, $\varepsilon_{x}$ and $\varepsilon_{y}$, could then be resolved, as shown in Equations 26-29.

$$
\begin{gathered}
\varepsilon_{t}=\frac{L_{t}}{L_{o}} \\
\varepsilon_{c}=\frac{L_{c}}{L_{o}} \\
\varepsilon_{\text {center }}=\frac{\varepsilon_{t}+\varepsilon_{c}}{2} \\
\theta_{\text {principal }}=90^{\circ}-\theta_{\text {diagonal }}-\theta_{\text {crack }} \\
R=\frac{\varepsilon_{t}-\varepsilon_{\text {center }}}{\cos 2 \theta_{\text {principal }}} \\
\varepsilon_{1}=\varepsilon_{\text {center }}+R
\end{gathered}
$$




$$
\begin{gathered}
\varepsilon_{2}=\varepsilon_{\text {center }}-R \\
\varepsilon_{x}=\varepsilon_{\text {center }}-R \cos 2 \theta_{\text {crack }} \\
\varepsilon_{y}=\varepsilon_{\text {center }}+R \cos 2 \theta_{\text {crack }}
\end{gathered}
$$

Average vertical strains, $\varepsilon_{y}$, during the failure load step were compared with measured surface bonded strain gage strains in the CFRP and internal stirrups for specimens FC and FT5, as shown in Figure B-5.16. It appears that the average vertical strains correlate fairly well to the average of the bonded strain gage strains. Average strains from the diagonal deformation measurements for all specimens are shown in Figure B-5.17. Surface bonded strain gage strains from components crossing the failure crack are provided for comparison at the half and quarter scales.
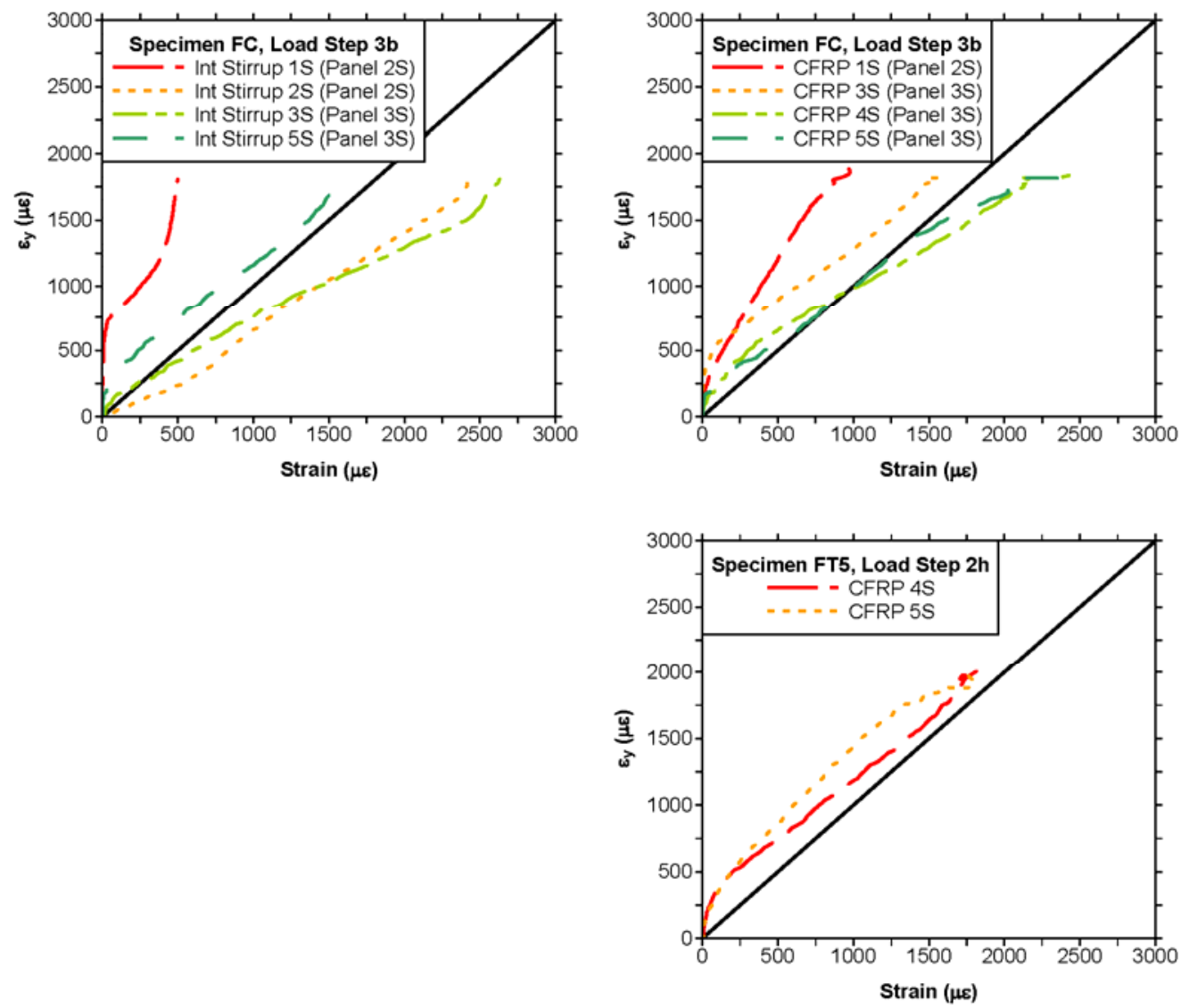

Figure B-5.16: Average panel strain in the vertical direction versus surface bonded strain gage strain for specimens FC and FT5 during failure load steps (left column: internal stirrups, right column: CFRP) 

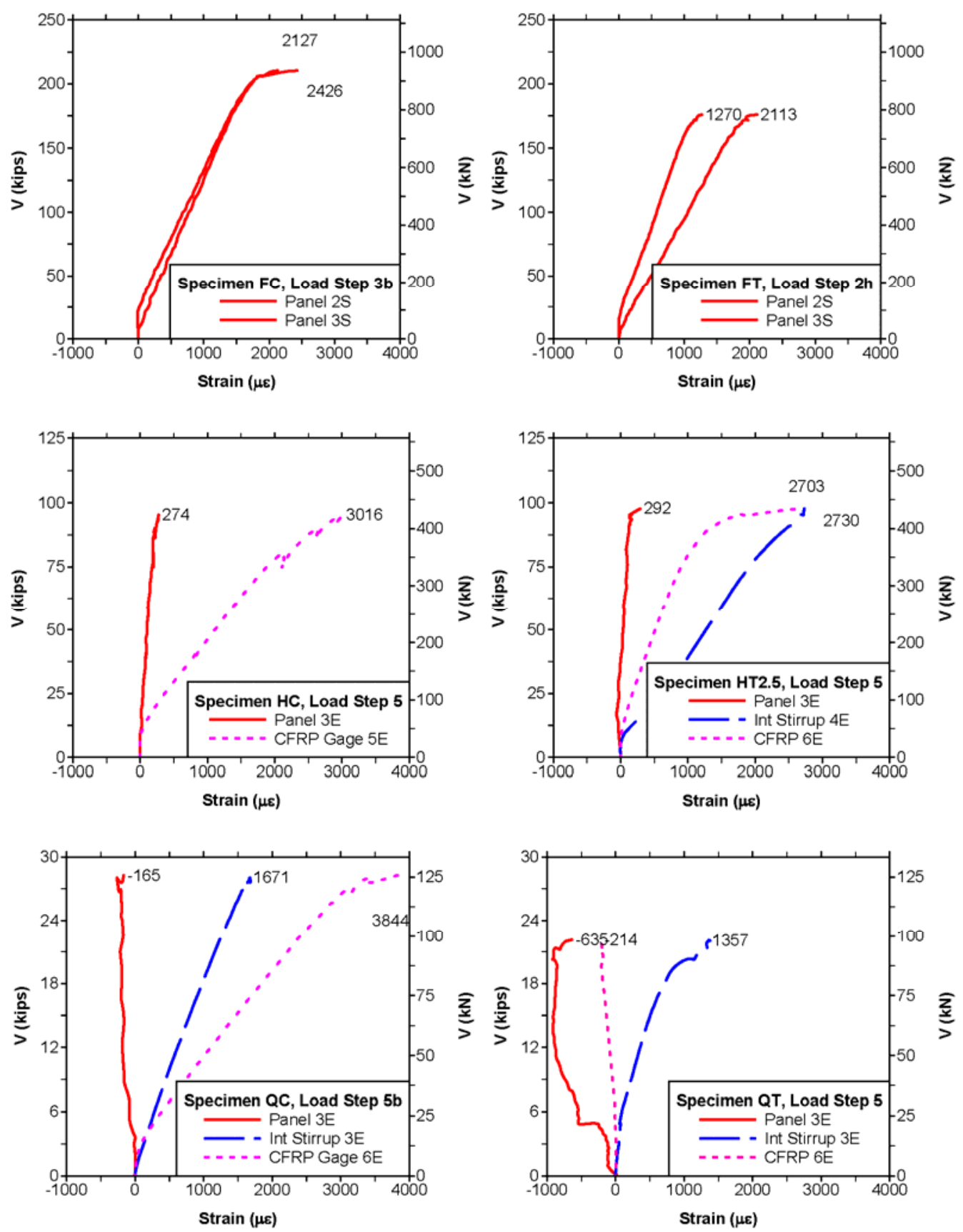

Figure B-5.17: Applied shear versus average vertical strain for specimen FC during load step 3b

Average vertical strains and surface bonded strain gage strains appeared to become less correlated as the scale decreases and at the low a/d ratios. To estimate the CFRP contribution, average strains were used for the full-scale specimens while internal stirrup strain measurements were used for the half- and quarter-scale specimens. As shown by Table B-5.16, stirrup 
development lengths make up a significant portion of the beam height for the half- and quarterscale specimens and may better average strains in the section compared with the CFRP, which has an effective bond length that makes up a much smaller proportion of the beam height. In addition, the relatively large strain gage relative to the strip length and possible flexural-tension induced by local CFRP strip debonding may have larger effects on the smaller specimens.

\section{B-6 COMPARATIVE ANALYSIS}

\section{B-6.1 INTRODUCTION}

Since there were no control specimens, a nonlinear finite element analysis package for reinforced concrete, VecTor2C, was employed to model specimen capacity without CFRP strengthening. The CFRP shear contribution was calculated as the difference between the strengthened specimen capacity, $V_{a p p}$, and the modeled unstrengthened capacity, $\left(V_{c}+V_{s}\right)_{\text {FEM. }}$.

The CFRP shear contribution calculated using finite element analysis results was compared with experimental data. For the full-scale specimens, average strains were transformed from diagonal displacements to estimate CFRP strain at capacity. For the half- and quarter-scale specimens, internal stirrup strains were used to estimate CFRP strain at capacity. CFRP strains were used to calculate the experimental CFRP contribution, $\left(V_{f}\right)_{\exp }$.

CFRP shear contributions from finite element modeling and experimental data were compared to the ACI 440.2R-08 shear contribution, $\left(V_{f}\right)_{\mathrm{ACI}}$, as described in the literature review.

All estimates of CFRP shear contribution assumed that the nominal shear capacity, $V_{n}$, was equal to the sum of the shear contributions from the concrete, $V_{c}$, steel, $V_{s}$, and CFRP, $V_{f}$, as illustrated by Figure B-6.1. 


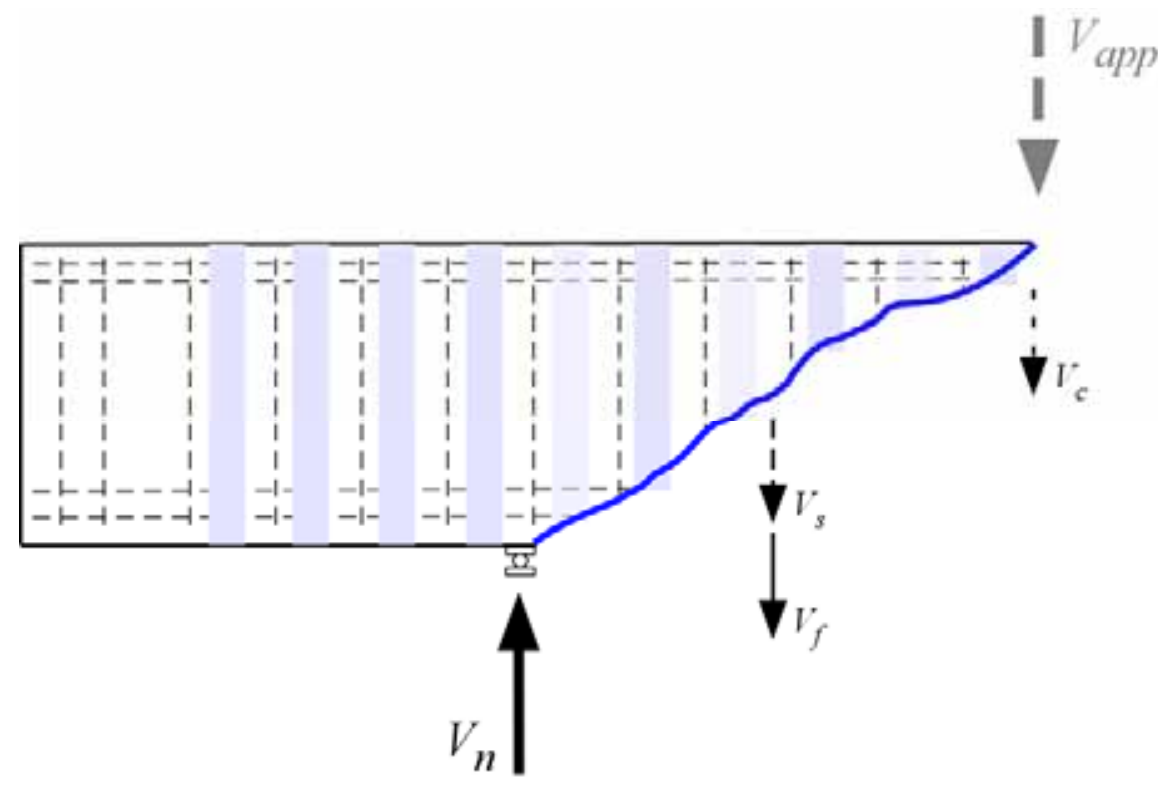

Figure B-6.1: Free body diagram for specimen FC at failure

\section{B-6.2 NONLINEAR FINITE ELEMENT ANALYSIS METHOD}

VecTor2 was developed at the University of Toronto based on modified compression field theory (MCFT) and the disturbed stress field model (Wong and Vecchio 2002). The package includes a graphical preprocessor, FormWorks $\mathbb{C}$, and a graphical post-processor, Augustus $\subseteq$.

The following constitutive models were assumed for the concrete and steel reinforcement using the FormWorks program default settings. Referenced models may be found in the VecTor2 user manual (Wong and Vecchio 2002).

The following models were applied to concrete. A Hognestad parabola was applied to pre-peak compression response, with the modified Park-Kent model applied to post-peak response, which allows enhanced strength and ductility from confinement. Compression softening was modeled by Vecchio (1992-A), which is based on the ratio of principal strains. The tension stiffening model was modified from Sato and Vecchio (2003). Post-cracking tensile stresses were assumed to descend linearly. Splitting cracks parallel to tension reinforcement were not considered. Enhanced strength from confinement was modeled by the Kupfer/Richart model. The cracking strength of concrete was calculated from the cylinder compression strength using the MohrCoulomb criterion and assuming an angle of internal friction of 37 degrees. The local shear stresses of elements were limited by Vecchio-Collins (1986) to avoid crack slip. Crack widths were limited to one-fifth of the maximum aggregate size. Strain from element slip was accounted for with the Vecchio-Lai (2002) stress model. A nonlinear hysteretic response with 
plastic offsets was selected, but not necessary since the analysis package was used as a strength capacity check for a particular load step and did not use previous damage or cyclic loading.

The following models were applied to steel reinforcement. Hysteretic response of reinforcement was governed by the Seckin model with the Bauschinger effect, which permits premature yielding upon load reversal after plastic prestraining. Dowel action was modeled as elasticplastic according to Tassios model. The Asatsu buckling model was selected for discrete reinforcement, but not applicable since perfect bond was assumed. The Eligehausen bond stressslip model was selected, but not applicable since perfect bond was assumed.

Specimens were modeled as plane members using the measured material properties, which were provided in the experimental program.

Concrete compression strength and maximum aggregate size were taken from cylinder tests and mix design submittals, respectively. The full scale desired rectangular element size was $80 \mathrm{~mm}$ (3.1 in.) square, which is approximately equal to the cover from the centroid of steel. Half and quarter scale meshes were 40 and $20 \mathrm{~mm}$ (1.6 and 0.79 in.), respectively. The mesh size was determined by convergence.

Reinforcing steel was modeled discretely using the measured yield and ultimate strengths from tensile tests. The elastic modulus, $E_{s}$, was taken as $200000 \mathrm{MPa}(29000 \mathrm{ksi})$, the strain hardening modulus, $E_{s h}$, was taken as $20000 \mathrm{MPa}(2900 \mathrm{ksi})$ and the strain hardening strain, $\varepsilon_{s h}$, was taken as $10000 \mu \varepsilon$.

Since statistical data were not available for the VecTor2 program, Response-2000C was used to compare behavior for $a / d \geq 2$. Response-2000, a nonlinear sectional analysis program based on MCFT, was developed at the University of Toronto (Bentz 2001). This program predicted the unrepaired member capacity to within $2 \%$ with a coefficient of variation of $7 \%$ for a series of 44 similar full-scale RC specimens tested at Oregon State University (Higgins et al. 2004).

To evaluate VecTor2, test data were used for the initial load steps of each specimen $(a / d=3.3)$. For this value of $a / d$, it was assumed that the behavior would be dominated by flexure, with the CFRP having little influence. In addition, the specimens were undamaged before this load step. As shown by Figure B-6.2, the VecTor2 program models the behavior of these specimens at all scales fairly well. 

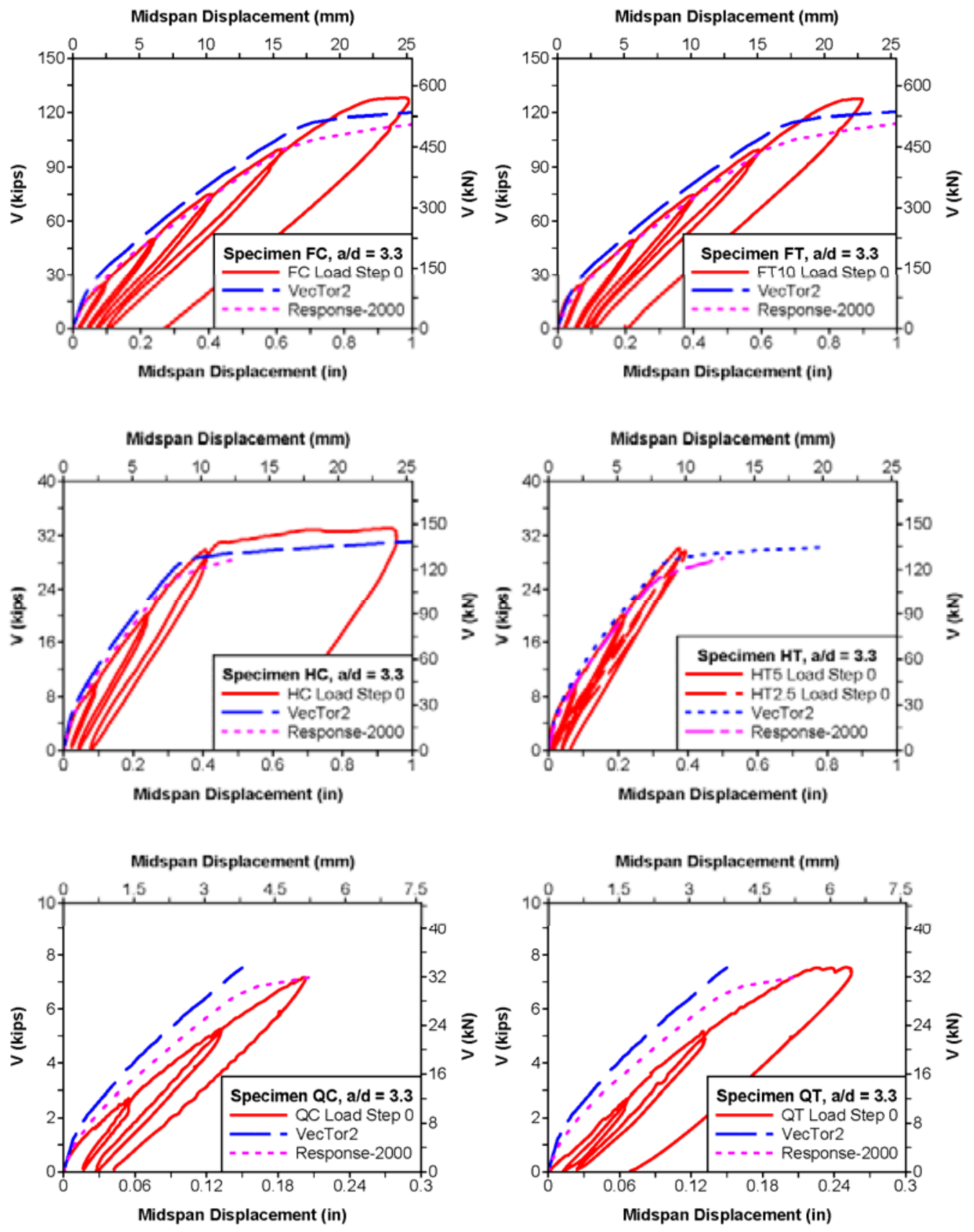

Figure B-6.2: Comparison of VecTor2 and Response-2000 analysis programs at $a / d=3.3$ for all $\mathrm{t}$ specimens (note: axis scales vary) 


\section{B-6.3 SHEAR CONTRIBUTION OF CFRP USING FINITE ELEMENT ANALYSIS}

Shear-displacement curves at the failure load step for each specimen are shown in Figure B-6.3. VecTor2 and Response-2000 appear to provide similar models of behavior for $a / d \geq 2$ (full scale specimens only). Test curves are generally more linear than the curves produced from finite element analysis because of damage acquired over multiple load steps.

CFRP capacity was taken as the difference between the test capacity and the modeled unstrengthened capacity:

$$
\left(V_{f}\right)_{F E M}=V_{a p p}-\left(V_{c}+V_{s}\right)_{F E M}
$$

where $\left(V_{f}\right)_{\mathrm{FEM}}=\mathrm{CFRP}$ shear contribution $(\mathrm{kN})(\mathrm{kips}), V_{a p p}=$ tested capacity $(\mathrm{kN})(\mathrm{kips})$, $\left(V_{c}+V_{s}\right)_{F E M}=$ modeled unstrengthened capacity $(\mathrm{kN})$ (kips). Base capacities from FEM are shown in Table B-6.1, column (4). CFRP shear contributions calculated using the FEM base capacity are shown in Table B-6.1, column (5).

Table B-6.1: CFRP shear contributions from finite element model, experimental data, and ACI

\begin{tabular}{|c|c|c|c|c|c|c|c|c|c|}
\hline $\begin{array}{l}\text { Speci } \\
\text {-men }\end{array}$ & $\begin{array}{c}a / d \\
\text { at } \\
\text { Failure }\end{array}$ & $\begin{array}{c}V_{a p p} \\
(\mathbf{k N}) \\
\text { (kips) } \\
\end{array}$ & $\begin{array}{c}\left(V_{c}+V_{s}\right)_{\text {FEM }} \\
(\mathrm{kN}) \\
(\mathrm{kips}) \\
\end{array}$ & $\begin{array}{c}\left(V_{f}\right)_{\mathrm{FEM}} \\
(\mathbf{k N}) \\
(\mathbf{k i p s}) \\
\end{array}$ & $\begin{array}{c}\varepsilon_{y i}(\mu \varepsilon) \\
\left(n_{i}\right)\end{array}$ & $\begin{array}{c}\left(V_{f}\right)_{\text {exp }} \\
(\mathbf{k N}) \\
(\mathbf{k i p s}) \\
\end{array}$ & $\begin{array}{c}\left(V_{c}+V_{s}\right)_{\mathrm{ACI}} \\
(\mathbf{k N}) \\
(\mathrm{kips}) \\
\end{array}$ & $\begin{array}{c}\left(V_{f}\right)_{\mathrm{ACI}} \\
(\mathbf{k N}) \\
(\mathbf{k i p s}) \\
\end{array}$ & $\begin{array}{c}\left(V_{n}\right)_{\mathrm{ACI}} \\
(\mathbf{k N}) \\
(\mathrm{kips}) \\
\end{array}$ \\
\hline (1) & (2) & (3) & (4) & (5) & (6) & (7) & (8) & (9) & $(\mathbf{1 0})$ \\
\hline $\mathrm{FC}$ & 2.0 & $934(210)$ & $940(211)$ & $0^{\mathrm{a}}$ & $\begin{array}{l}2127(3)^{b} \\
2426(3)^{b}\end{array}$ & 74 (16.6) & $574(129)$ & $66(14.9)$ & $641(144)$ \\
\hline FT5 & 2.5 & $783(176)$ & $778(175)$ & $4(1)$ & $\begin{array}{l}1270(2)^{b} \\
2113(4)^{b}\end{array}$ & $59(13.3)$ & $578(130)$ & $66(14.9)$ & $645(145)$ \\
\hline $\mathrm{HC}$ & 1.0 & $424(95.3)$ & $307(69.1)$ & $117(26.2)$ & (c) & (c) & $139(31.2)$ & $131(29.5)$ & $270(60.7)$ \\
\hline HT2.5 & 1.0 & $435(97.7)$ & $318(71.5)$ & $117(26.2)$ & $2730(6)^{\mathrm{d}}$ & $89(19.9)$ & $140(31.5)$ & $66(14.8)$ & $206(46.3)$ \\
\hline $\mathrm{QC}$ & 1.0 & $126(28.3)$ & $105(23.5)$ & $21(4.8)$ & $1671(4)^{d}$ & $36(8.1)$ & $36(8.1)$ & $16(3.6)$ & $52(11.7)$ \\
\hline QT & 1.0 & $98(22.1)$ & $105(23.5)$ & $0^{\mathrm{a}}$ & $1357(4)^{d}$ & $29(6.6)$ & $36(8.1)$ & $16(3.6)$ & $52(11.7)$ \\
\hline
\end{tabular}

a: the addition of CFRP likely did not reduce the capacity of specimens FC and QT

b: CFRP strain estimated from average vertical strains

c: no reliable strain measurements available

d: CFRP strain estimated from internal stirrup strains 

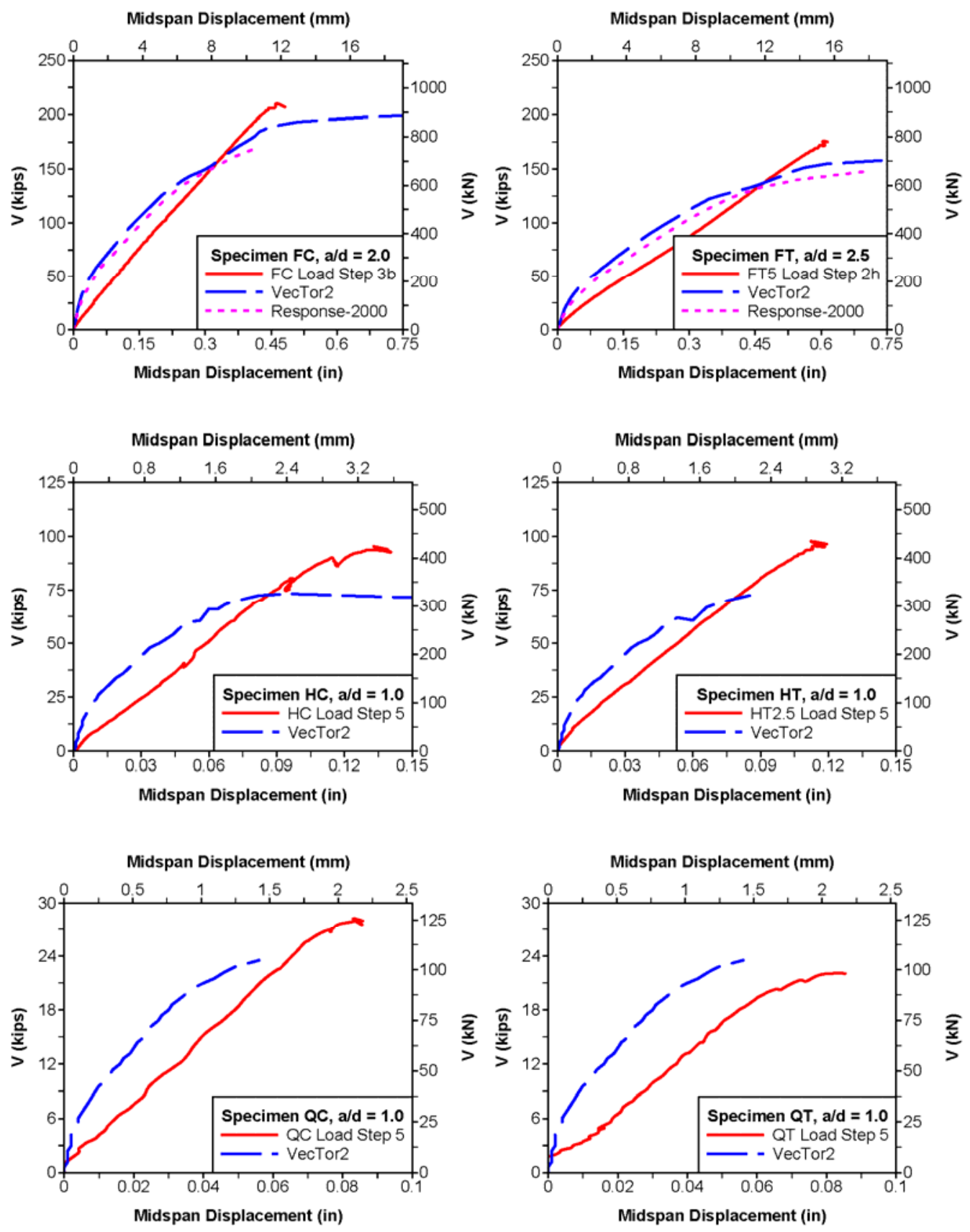

Figure B-6.3: Comparison of test curves and VecTor2 modeled base capacity at failure 


\section{B-6.4 CFRP SHEAR CONTRIBUTION USING EXPERIMENTAL RESULTS}

The experimental CFRP shear contribution, $\left(V_{f}\right)_{\text {exp }}$, was calculated from maximum average vertical strains or maximum internal stirrup strains using the following equation:

$$
\left(V_{f}\right)_{\exp }=w_{f} t_{f} E_{f} \sum_{i=1}^{m} n_{f i} \varepsilon_{y i}
$$

where $w_{f}=$ CFRP strip width (mm) (in.), $t_{f}=$ CFRP coupon thickness (mm) (in.), $E_{f}=$ CFRP tensile modulus (GPa) (ksi), $m=$ number of different average strain values, $n_{f i}=$ number of strips corresponding to a particular value of strain (each U-wrap was counted as two strips), $\varepsilon_{y i}=\mathrm{a}$ particular average value of CFRP strain. Estimated CFRP strain values are shown in Table B6.1 , column (6), along with the number of strips corresponding to those values. Calculated experimental CFRP shear contributions are shown in Table B-6.1, column (7).

\section{B-6.5 CFRP SHEAR CONTRIBUTION USING ACI}

The CFRP shear contribution was also calculated according to the provisions of ACI 440.2R-08 and ACI 318-08, as described in the literature review. ACI 440.2R-08 is commonly used to design CFRP repairs in practice.

Given the removed strips on alternating faces of specimens FC and FT5, it was unclear how to define the CFRP reinforcement. Since the CFRP remained bonded to the bottom or top soffit (forming an L-shape) for specimens FC and FT5, respectively, the strips were treated as U-wraps at twice the original spacing. All other specimens possessed intact U-wraps.

ACI shear contributions from concrete and steel components are shown in Table B-6.1.column (8). The CFRP shear contribution calculated according to ACI is shown in Table B-6.1 column (9).

Table B-6.2: Variation between shear contributions from finite element model and ACI

\begin{tabular}{l|l|l|l|l|l|l}
\hline Specimen & $\begin{array}{l}\text { a/d } \\
\text { at } \\
\text { Failure }\end{array}$ & $\frac{\left(V_{c}+V_{s}\right)_{A C I}}{\left(V_{c}+V_{s}\right)_{F E M}}$ & $\frac{\left(V_{f}\right)_{A C I}}{\left(V_{f}\right)_{F E M}}$ & $\frac{\left(V_{f}\right)_{A C I}}{\left(V_{f}\right)_{\exp }}$ & $\frac{\left(V_{f}\right)_{F E M}}{\left(V_{f}\right)_{\exp }}$ & $\frac{\left(V_{n}\right)_{A C I}}{V_{a p p}}$ \\
\hline$(1)$ & $(2)$ & $(3)$ & $(4)$ & $(5)$ & $(6)$ & $(7)$ \\
\hline FC & 2.0 & 0.61 & - & 0.90 & - & 0.69 \\
\hline FT5 & 2.5 & 0.74 & - & 1.12 & - & 0.82 \\
\hline HC & 1.0 & 0.45 & 1.13 & - & - & 0.64 \\
\hline HT2.5 & 1.0 & 0.44 & 0.56 & 0.74 & 1.32 & 0.47 \\
\hline QC & 1.0 & 0.35 & 0.75 & 0.44 & 0.59 & 0.41 \\
\hline QT & 1.0 & 0.35 & - & 0.55 & - & 0.53 \\
\hline
\end{tabular}




\section{B-6.6 COMPARISON OF BASE CAPACITY AND CFRP CONTRIBUTION}

Calculated values of base shear capacity and CFRP shear contribution are compared in Table B6.2 .

As shown in Table B-6.2, column (3), the ACI equations for concrete and steel shear contribution provide a base capacity lower than the finite element analysis. The ratio of ACI-toFEM base capacity appears to be affected by the scale of the specimen, with higher values at the full-scale and decreasing values at the half- and quarter-scale. The ratio may also be affected by the value of $a / d$ at failure, which is provided in column (2). Based on these observations, the level of conservatism for the ACI method appears to be greater for lower values of $a / d$ and $d$.

As shown in Table B-6.2, column (4), the ACI CFRP shear contribution was generally lower than the contribution calculated using finite element analysis, with the exception of specimen HC. Specimen HC had twice the strip width of specimen HT2.5, though both failed at approximately the same applied shear at an $a / d=1$. Specimens HC and HT2.5 should therefore have had nearly the same CFRP contribution since they had approximately the same base specimen capacity. The ACI approach may have overestimated capacity for larger strip widths, but that could not be confirmed with this data. The ratio of shear contributions from ACI and FEM analysis do not appear to be affected by the scale of the specimen or by the $a / d$ ratio.

As shown in Table B-6.2, column (5), the ACI CFRP shear contribution was unconservative for Specimen FT5, possibly unconservative for specimen HC and conservative for the other specimens. The ACI shear contribution appeared unconservative for Specimen HC, though this could was not definitive based upon the available data. The ACI prediction became more conservative as the specimen scale decreased. As the half- and quarter-scale specimens failed at a lower value of $a / d$, the ACI prediction also became more conservative for lower $a / d$ ratios. The ratio of ACI-to-experimental CFRP shear contribution appears to be affected by the scale of the specimen and possibly the $a / d$ ratio and U-wrap orientation.

As shown in Table B-6.2, column (6), the CFRP shear contribution calculated using finite element analysis is larger than the experimental value at the full-scale and for specimen HT2.5. The CFRP shear contribution using FEM was lower than the experimental value for the quarterscale specimens, with no contribution provided by the CFRP for specimen QT.

Because of variability in the test data, it is difficult to draw further conclusions about scale effect on shear capacity from Table B-6.1 and Table B-6.2. Variations in the test data include the following:

- CFRP reinforcement ratios were not the same across all scales.

- Specimens failed at different values of $a / d$.

- A large amount of CFRP material was removed from specimens FC and FT5 such that the specimens appeared to fail at their base capacities.

- Reliable average CFRP strain measurements were not available for specimen HC. 
- Specimen QT failed below its estimated base capacity from FEM analysis.

\section{B-7 CONCLUSIONS}

Experimental and analytical results indicated that it was not practical to geometrically scale specimens such that all the important characteristics are preserved at reduced scales for environmental durability testing.

Based upon the results of experimental testing:

- CFRP strains were small until crossed by a diagonal crack.

- CFRP debonding accumulated as increased loads were applied at progressively smaller $a / d$ ratios.

- Debonding was observed during testing by tapping on the CFRP surface; debonded CFRP sounded hollow when compared to adequately bonded CFRP. Debonding was observed as decreased slope, large strains, nonlinear loading and unloading behavior and plastic offset when CFRP strains were plotted against applied shear.

- Debonded CFRP was observed locally around diagonal cracks that crossed the strip. After failure, some debonded CFRP strips had pulled away shallow concrete wedges at the diagonal crack. Debonded CFRP was characterized by out-of-plane deformation, which was restrained by adjacent regions of CFRP with adequate bond.

- Large local strains were measured near diagonal cracks and were attributed to flexuraltension strains induced by bending of the debonded CFRP. Two simple expressions were presented to calculate additional tensile strains from debonding. These expressions indicated that flexural-tension strains dissipated nonlinearly as the debonded length increased. Beam height provided a limit on the debonded length and, subsequently, limited the dissipation of local strains.

- Based upon the systematic removal of portions of CFRP strips, strains from removed strips appeared to redistribute to adjacent internal transverse steel reinforcement.

- Inverted U-wraps accumulated less strain than the normal U-wrap configuration with nearly identical base specimens.

- As diagonal cracks initially grew, the measured strains in steel and CFRP components were not compatible. Internal stirrup and CFRP strains became compatible along diagonal cracks once debonded CFRP regions grew such that flexural-tension strains from bending dissipated and strain gages were not farther from the debonded region than the effective bond length. 
- Due to local variations from CFRP strain gage measurements, average vertical strains transformed from diagonal displacement measurements during the failure load step were used to estimate the CFRP shear contribution. This method provided reasonable average vertical strains for the full-scale specimens, but not the half- and quarter-scale specimens, which failed at smaller values of $a / d$. Internal stirrup strains were used to calculate the CFRP shear contribution at the half- and quarter-scales since the development length of transverse reinforcement took up a significant portion of the beam depth and contained the failure diagonal crack.

Based upon the comparative analysis:

- The ACI 318-08 concrete and steel shear contributions appeared to provide conservative estimates of base specimen capacity when compared to a finite element model. The ACI base capacity prediction appeared to become more conservative with decreased specimen scale and $a / d$ ratio.

- The ACI 440.2R-08 CFRP shear contribution appeared to provide a conservative estimate when compared with the contribution found using the finite element model for base capacity, except for specimen $\mathrm{HC}$, which had the largest CFRP reinforcement ratio of all the failed specimens due to relatively wide strips. This may imply that the ACI method overestimates the capacity of wide strips, though this could not be confirmed with the available data. Otherwise, the ACI prediction did not appear affected by scale or $a / d$ when compared to the prediction using finite element analysis to model the base capacity.

- The ACI 440.2R-08 CFRP shear contribution was unconservative for some of the specimens when compared to the experimental shear contribution. The ACI method overestimated the CFRP shear contribution of specimen FT5, which was strengthened by an inverted U-wrap. The ACI method appeared to overestimate the CFRP shear contribution of specimen $\mathrm{HC}$, which had the largest CFRP reinforcement ratio of all the failed specimens due to relatively wide strips, though this could not be adequately confirmed with the available test data.

\section{B-8 RECOMMENDATIONS}

\section{B-8.1 SCALING VARIABLES}

Before small-scale RC specimens with discrete CFRP U-wraps are used for environmental durability studies, the effects of scaling need to be modeled carefully using a large database of tested specimens. Several variables that may affect shear capacity were identified through this research. These variables include: 
- Effective depth $(d)$

- Shear span-to-depth ratio $(a / d)$

- Flexural-tension steel reinforcement ratio $\left(\rho_{s}\right)$

- Transverse steel reinforcement ratio $\left(\rho_{v}\right)$

- CFRP reinforcement ratio $\left(\rho_{f}\right)$

- U-wrap orientation (i.e. normal or inverted)

- CFRP strip width $\left(w_{f}\right)$

In addition, it was theorized that the number of CFRP layers, $n_{f}$, may influence shear capacity. Possible values of these variables for future testing are provided in Table B-8.1, with justifications for each value following the table. Values in Table B-8.1 should be viewed as an order of magnitude and not as explicit design values.

Table B-8.1: Possible values for further scaled tests

\begin{tabular}{l|l|l|l|l|l|l}
\hline $\begin{array}{l}\boldsymbol{d} \\
(\mathbf{m m})(\mathrm{in} .)\end{array}$ & $\boldsymbol{a} / \boldsymbol{d}$ & $\begin{array}{l}\boldsymbol{\rho}_{\boldsymbol{s}} \\
(\mathbf{\%})\end{array}$ & $\begin{array}{l}\boldsymbol{\rho}_{\boldsymbol{f}} \\
(\mathbf{\%})\end{array}$ & $\boldsymbol{n}_{\boldsymbol{f}}$ & $\begin{array}{l}\text { U-wrap } \\
\text { orientation }\end{array}$ & $\begin{array}{l}\boldsymbol{w}_{\boldsymbol{f}} \\
(\mathbf{m m})(\mathbf{i n} .)\end{array}$ \\
\hline $900(36)$ & 1.0 & 1.0 & 1.0 & 1 & normal & $100(4)$ \\
\hline $200(9)$ & 2.5 & 3.0 & 0.25 & multiple & inverted & $25(1)$ \\
\hline
\end{tabular}

Effective Depth: Laboratory scale effective depths in the literature are commonly on the order of $200 \mathrm{~mm}$ (9 in). Conventional RC deck girders often possess effective depths on the order of 900 $\mathrm{mm}$ (36 in) as this is approximately the limit on effective depth before skin steel is required. These sizes would constitute full- and quarter-scales. While intermediate scales would benefit the understanding of scale effects, the full- and quarter-scales represent common laboratory and field scales.

Shear Span-to-Depth Ratio: The two values of a/d are suggested to capture the behavior of deep and slender beams.

Flexural-tension Steel Reinforcement Ratio: Laboratory scaled specimens are typically overreinforced to avoid flexural failure. Older tests cited by the literature used lower grades of reinforcing steel and thus required higher reinforcement ratios. Actual structures commonly have lower reinforcement ratios, which this study emulated.

Transverse Steel Reinforcement Ratio: The majority of tests described in the literature used specimens without transverse steel reinforcement. To simulate field conditions, internal stirrups were included in this test series. The inclusion of internal stirrups may have made it more difficult to attain shear failures at larger values of $a / d$ in the CFRP strengthened specimens. For future testing, minimum or reduced stirrups should be used. 
CFRP Reinforcement Ratio: For the full- and half-scale inverted U-wrapped specimens, the CFRP reinforcement ratio had to be reduced in order to achieve shear failure.

Layers of CFRP: CFRP bond models, which include the number of layers, are commonly based on small-scale or materials tests. The effect of adding layers at the full-scale should be studied closely. Multiple layers were not considered in this study.

CFRP U-wrap Orientation: The ACI CFRP shear contribution appeared less conservative for the full-scale inverted U-wrap.

Width of CFRP: During testing, inverted and normal U-wrapped strips on the same half-scale base specimen produced about the same shear capacity at an $a / d=1.0$ despite the U-wrap having twice the strip width of the inverted U-wrap. As $d, a / d$ and U-wrap orientation are considered here, the CFRP strip width needs to be studied as well in order to determine what led to the similarity of shear capacities.

In order to investigate the effect of each of these properties on shear capacity as outlined, 128 specimens would be required, not including control specimens. However, not all of these specimens must be new. Though not as controlled, a review of the literature should provide some specimens having properties similar to those outlined in Table B-8.1. For future testing, design guidelines are provided.

\section{B-8.2 FUTURE TESTING}

T specimens should conform to the recommendations in ACI 440.2R-08. Before testing begins, all capacities should be predicted for shear and flexure according to the provisions of ACI 31808 and ACI 440.2R-08. This process should be relatively straightforward and could be completed with spreadsheets. If time and resources allow for more detailed analyses, Response2000 should be used for beam modeling where $a / d \geq 2$ and VecTor 2 (or another finite element program) should be used where $a / d \leq 2$. Specimens that conform to the properties in Table B8.1 , but are predicted to fail in flexure should be discarded from the study.

Materials should be provided by the same manufacturers and fabricators to reduce variation in material properties. Consistent concrete mix designs and reinforcing steel grades should be verified by inspection and testing.

Minimum or low amounts of internal stirrups should be used to simulate repair of an underreinforced girder. The same stirrup shape and reinforcement ratio should be used for all specimens, as is practical, to avoid differences in relative concrete confinement.

Specimens should be pre-cracked as that represents the most likely repair state. Pre-cracking may also enable a calibration for FEM analysis.

Only U-wraps should be considered as this represents the most common RC deck girder bridge shear strengthening application (i.e. where the deck prevents full wrapping). Inverted U-wraps 
should have their free ends terminated such that the flexural-tension steel reinforcement does not reduce the biaxial stress state that occurs when CFRP is terminated in a flexural-tension zone. In $\mathrm{RC}$ deck girder bridges, the flexural-tension steel is typically in the deck and thus inaccessible to the FRP strip end.

Given the significant amounts of time, materials and testing facilities required to conduct a full investigation, collaboration between research institutions is recommended. Besides providing an evaluation of FRP design methods for different scales, these specimens could be used to verify finite element analysis methods or check FRP bond models. Control specimens could also be used for deep beam research.

\section{B-9 REFERENCES}

American Concrete Institute. 440.2R-08: Design and construction of externally bonded FRP systems. ACI Manual of Concrete Practice. Farmington Hills, Michigan.2008,

American Concrete Institute. 318-08: Building code requirements for structural concrete and commentary. ACI Manual of Concrete Practice. Farmington Hills, Michigan.2008.

Angelakos, D., C. Bentz, and M.P. Collins. Effect of concrete strength and minimum stirrups on shear strength of large members. ACI Structural Journal, Vol. 290 No. 3, 2001, pp. 290-300.

ASTM A 370-97a, American Society of Testing and Materials. Standard Test Methods and Definitions for Mechanical Testing of Steel Products. ASTM, West Conshohocken, PA, 1997.

ASTM D 3039/D 3039M-00, American Society of Testing and Materials. Standard Test Method for Tensile Properties of Polymer Matrix Composite Materials. ASTM, West Conshohocken, PA, 2001.

ASTM D 4541-02, American Society of Testing and Materials. Standard Test Method for PullOff Strength of Coatings Using Portable Adhesion Testers. ASTM, West Conshohocken, PA, 2002.

ASTM E 8-00, American Society of Testing and Materials. Standard Test Methods for Tension Testing of Metallic Materials. ASTM, West Conshohocken, PA, 2000.

Bakis, C.E., L.C. Bank, V.L Brown, E. Cosenza, J.F. Davalos, J.J.Lesko, A.Machida, S.H. Rizkalla, T.C.Triantafillou. Fiber-reinforced polymer composites for construction - State-of-theart review. Journal of Composites for Construction, Vol.6 No.2, 2002, pp. 73-87.

Bentz, E.C.Membrane-2000, Response-2000, Triax-2000, Shell-2000 User Manual. University of Toronto. http://www.ecf.utoronto.ca/ bentz/manual.shtml. 
Chajes, M., T. Januska, D. Mertz, T. Thomson, and W. Finch. Shear strengthening of reinforced concrete beams using externally applied composite fabrics," ACI Structural Journal, Vol. 92, No. 3, May-June, 1995, pp. 295-303.

Higgins, C., T.H. Miller, D.V. Rosowsky, S.C.Yim, T.Potisuk, T.K. Daniels, B.S. Nicholas, M.J. Robelo, A-Y Lee, and R.W. Forrest. Assessment Methodology for Diagonally Cracked Reinforced Concrete Deck Girders. Publication FHWA-OR-RD-05-04. FHWA, U.S. Department of Transportation, 2004.

Higgins, C., G.Williams, and L. Elkins. Capabilities of Diagonally-Cracked Girders Repaired with CFRP. Publication FHWA-OR-RD-06-16. FHWA, U.S. Department of Transportation. 2006.

Horiguchi, T., and N.Saeki. Effect of test methods and quality of concrete on bond strength of CFRP sheet. Non-Metallic (FRP) Reinforcement for Concrete Structures, Proceedings, $3^{\text {rd }}$ Symposium, Vol. 1, Japan, 1997, pp. 265-270.

Kachlakev, D, and D. McCurry. Testing of full-size reinforced concrete beams strengthened with FRP composites: Experimental results and design methods verification. Publication FHWA-OR00-19, FHWA, U.S. Department of Transportation, 2000.

Kani, G.N.J. How safe are our large reinforced concrete beams. Journal of the American Concrete Institute, March, 1967, pp. 128-141.

Khalifa, A., W. Gold, A. Nanni, and M. Abel-Aziz. Contribution of externally bonded FRP to the shear capacity of RC flexural members. Journal of Composites in Construction, Vol. 2, No. 4, 1998, pp. 195-203.

Kuchma, D., P. Vegh, K. Simionopoulos, B. Stankik, and M.P. Collins. The influence of concrete strength, distribution of longitudinal reinforcement and member size on the shear strength of reinforced concrete beams. CEB Bulletin No. 237 -Concrete Tension and Size Effects, 1997, pp. 209-229.

Maeda, T., Y. Asano, Y. Sato, T. Ueda, and Y. Kakuta. A study on bond mechanism of carbon fiber sheets. Non-Metallic (FRP) Reinforcement for Concrete Structures, Proceedings, $3^{\text {rd }}$ Symposium, Vol. 1, Japan, 1997, pp. 279-286.

Malvar, L., G. Warren, and C. Inaba, Rehabilitation of navy pier beams with composite sheets. Second FRP International Symposium on Non-Metallic (FRP) Reinforcement for Concrete Structures, Aug., Get, Belgium, 1995, pp. 533-540.

Meier, U., M. Deuring, H. Meier, and G. Schwegler, CFRP bonded sheets, Fiber-ReinforcedPlastic (FRP) Reinforcement for Concrete Structures: Properties and Applications. A. Nanni, ed., Elsevier Science Publishers, New York, 1993, pp. 423-434.

T. Norris, H. Saadatmanesh, and M. Ehsani. Shear and flexural strengthening of R/C beams with carbon fiber sheets. Journal of Structural Engineering, Vol. 123, No. 7, 1997, pp. 903-911. 
Sato, Y., T. Ueda Y. Kakuta, and T. Tanaka. Shear reinforcing effect of carbon fiber sheet attached to side of reinforced concrete beams. Advanced Composite Materials in Bridges and Structures, M.M. El-Badry, ed., 1996, pp. 621-627.

Tompos, E.J., and R.J. Frosch, Influence of beam size, longitudinal reinforcement and stirrup effectiveness on concrete shear strength. ACI Structural Journal, September-October, 2002, pp. 559-567.

Triantafillou, T.C. Shear strengthening of reinforced concrete beams using epoxy-bonded FRP composites. ACI Structural Journal, V. 95, No. 2, Mar.-Apr., 1998, pp. 107-115.

Watson Bowman Acme Corporation. Specification: Wabo ${ }^{\circledR}$ MBrace Composite Strengthening System with Carbon Fiber Reinforcement. Amherst, NY, March 2002.

Watson Bowman Acme Corporation. Wabo ${ }^{\circledR}$ MBrace CF130. Amherst, NY, February 2003.

Wong, P.S., and F.J. Vecchio. VecTor2 and FormWorks User's Manual. University of Toronto, 2002. 


\section{APPENDIX C: CFRP SHEAR STRENGTHENING DESIGN OF A T-GIRDER}



In this appendix, a design example is presented for the shear strengthening of a bridge girder. Increased live loads in the last 50 years require the girder to carry a factored shear load of 107 kips $(476 \mathrm{kN})$. An analysis of the existing beam indicated that all the flexural bars were developed at the section, and the corresponding nominal moment capacity, $\left(M_{n}=1954 \mathrm{kip}-\mathrm{ft}\right.$ $(28.5 \mathrm{kN}-\mathrm{mm}))$ was still satisfactory for flexural strength when the resistance factor applied; however, the shear capacity was found to be insufficient to carry the increased live load. A Uwrap CFRP application was selected as the shear strengthening method. The shear span length of the girder was $11 \mathrm{ft}(3353 \mathrm{~mm})$. The critical section for design was determined as $7.54 \mathrm{ft}(2298$ $\mathrm{mm})$ away from the support location, and the $\mathrm{M} / \mathrm{V}$ ratio is determined as $7.54 \mathrm{ft}(2298 \mathrm{~mm})$. Dimensions and the material properties of the existing member are summarized in Table C-1.1. Manufacturer reported CFRP material properties are shown in Table C-1.2.

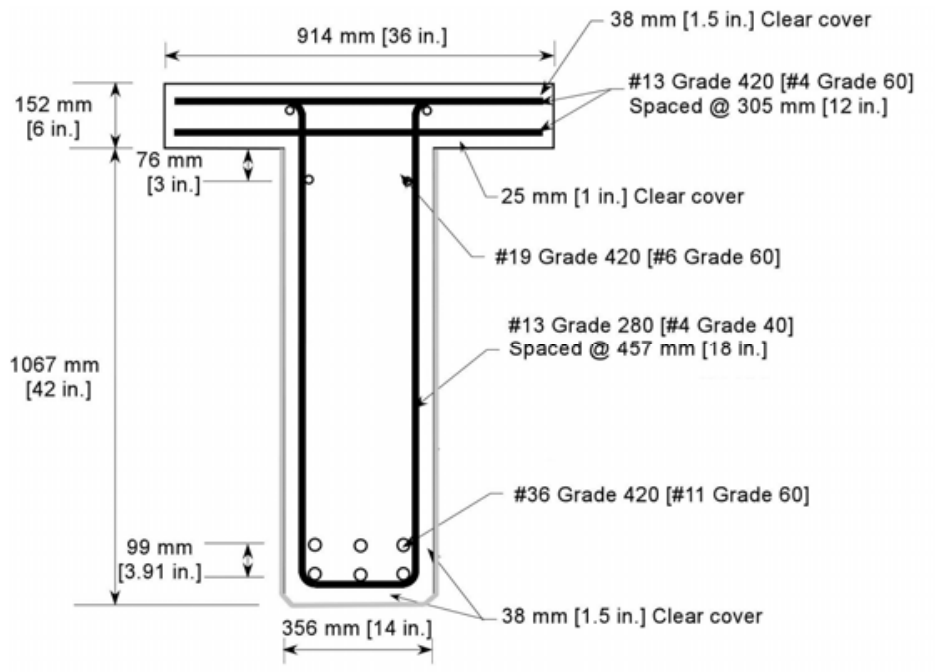

Figure C-1.1:T girder dimensions and reinforcement configuration

Table C.-1.1: Design Parameters

\begin{tabular}{l|l}
\hline $\boldsymbol{h}$ & 48 in. $(1219 \mathrm{~mm})$ \\
\hline $\boldsymbol{t}_{\boldsymbol{f}}$ & 6 in. $(152 \mathrm{~mm})$ \\
\hline $\boldsymbol{b}_{\boldsymbol{f}}$ & 36 in. $(914 \mathrm{~mm})$ \\
\hline $\boldsymbol{b}_{\boldsymbol{w}}$ & 14 in. $(356 \mathrm{~mm})$ \\
\hline $\boldsymbol{d}$ & $43.8 \mathrm{in} .(1114 \mathrm{~mm})$ \\
\hline $\boldsymbol{d}_{\boldsymbol{v}}$ & $39.5 \mathrm{in} .(1003 \mathrm{~mm})$ \\
\hline $\boldsymbol{f}_{\boldsymbol{c}}$ & $4000 \mathrm{psi}(27.6 \mathrm{MPa})$ \\
\hline $\boldsymbol{f}_{\boldsymbol{v}}$ & $60 \mathrm{ksi}(414 \mathrm{MPa})$ \\
\hline $\boldsymbol{A}_{\boldsymbol{v}}$ & $0.4 \mathrm{in}^{2}(258 \mathrm{~mm})$ \\
\hline $\boldsymbol{f}_{\boldsymbol{v} v}$ & $40 \mathrm{ksi}(276 \mathrm{MPa})$ \\
\hline $\boldsymbol{s}$ & 18 in. $(457 \mathrm{~mm})$ \\
\hline
\end{tabular}


Table C-1.2: CFRP system properties

\begin{tabular}{l|l}
\hline $\boldsymbol{d}_{\boldsymbol{f}}$ & $37.8 \mathrm{in} .(960 \mathrm{~mm})$ \\
\hline $\boldsymbol{w}_{f}$ & 10 in. $(254 \mathrm{~mm})$ \\
\hline $\boldsymbol{t}_{\boldsymbol{f}}$ & $0.0065 \mathrm{in} .(0.165 \mathrm{~mm})$ \\
\hline $\boldsymbol{f}_{f_{u}}{ }^{*}$ & $550 \mathrm{ksi}(3790 \mathrm{MPa})$ \\
\hline $\boldsymbol{\varepsilon}_{f u}{ }^{*}$ & $0.017 \mathrm{in} . / \mathrm{in} .(0.017 \mathrm{~mm} / \mathrm{mm})$ \\
\hline $\boldsymbol{E}_{f}$ & $33,000 \mathrm{ksi}(228 \mathrm{GPa})$ \\
\hline $\boldsymbol{C}_{\boldsymbol{E}}$ & 0.85 (bridges) \\
\hline
\end{tabular}

SOLUTION PROCEDURE (USING CURRENT ACI-440)

Step 1 - Calculation of the nominal base capacity via ACI 318-08:

$$
\begin{aligned}
& V_{n}=V_{c}+V_{s} \\
& V_{c}=2 \sqrt{f_{c}^{\prime}} b_{w} d=2(\sqrt{4000 \mathrm{psi}})(14 \mathrm{in} .)(43.8 \mathrm{in} .)=77.5 \mathrm{kips}(345 \mathrm{kN}) \\
& V_{s}=\frac{A_{v} f_{y v} d}{s}=\frac{A_{v} f_{y v} d}{s}=\frac{\left(0.4 \mathrm{in}^{2}\right)(40 \mathrm{ksi})(43.8 \mathrm{in} .)}{(18 \mathrm{in} .)}=38.9 \mathrm{kips}(173 \mathrm{kN}) \\
& V_{n}=77.5 \mathrm{kips}+38.9 \mathrm{kips}=116.4 \mathrm{kips}(518 \mathrm{kN})
\end{aligned}
$$

Step 2 - Determine required CFRP shear contribution:

$$
\begin{aligned}
& \phi V_{n} \geq V_{u} \\
& \phi\left(V_{c}+V_{s}+\psi V_{f}\right) \geq V_{u} \\
& \phi=0.75 \text { (shear) } ; \psi=0.85 \text { (U-wrap) } \\
& 0.75\left(77.5 \text { kips }+38.9 \text { kips }+0.85 V_{f}\right) \geq 107 \text { kips } \\
& V_{f} \geq 30.9 \text { kips }
\end{aligned}
$$


Step 3 - Design of the CFRP system:

Compute design material properties:

$f_{f u}=C_{E} f_{f u}^{*}=(0.85)(550 \mathrm{ksi})=467.5 \mathrm{ksi}(3.2 \mathrm{GPa})$

$\varepsilon_{f u}=C_{E} \varepsilon_{f u}^{*}=(0.85)(0.017$ in./in. $)=0.014$ in. $/$ in. $(0.014 \mathrm{~mm} / \mathrm{mm})$

$A_{f v}=2 n t_{f} w_{f}=(2)(1)(0.0065$ in. $)(10 \mathrm{in})=.0.13 \mathrm{in}^{2}$

Calculate the effective stress level in the FRP shear reinforcement:

$L_{e}=\frac{2500}{\left(n t_{f} E_{f}\right)^{0.58}}=\frac{2500}{\left[(1)(0.0065 \mathrm{in} .)\left(33 \times 10^{6} \mathrm{psi}\right)\right]^{0.58}}=2.0 \mathrm{in} .(51 \mathrm{~mm})$

$k_{1}=\left(\frac{f_{c}^{\prime}}{4000}\right)^{2 / 3}=\left(\frac{4000 \mathrm{psi}}{4000}\right)^{2 / 3}=1.000$

$k_{2}=\left(\frac{d_{f v}-L_{e}}{d_{f v}}\right)=\left(\frac{(37.8 \text { in. })-(2.0 \text { in. })}{(37.8 \text { in. })}\right)=0.947$

$f_{f e}=\min \left\{\begin{array}{c}\frac{k_{1} k_{2} L_{e}}{468} \\ 0.75 C_{E} \varepsilon_{f u}^{*} \\ 0.004\end{array}\right\} \times E_{f}=\min \left\{\begin{array}{c}\frac{(1.000)(0.947)(2.0 \text { in. })}{468} \\ (0.75)(0.85)(0.017 \text { in./in. }) \\ 0.004\end{array}\right\} \times 33 \times 10^{3} \mathrm{ksi}$

$f_{f e}=\min \left\{\begin{array}{c}0.0041 \\ 0.0110 \\ 0.0040\end{array}\right\} \times\left(33 \times 10^{3} \mathrm{ksi}\right)=132 \mathrm{ksi}(910 \mathrm{MPa})$

as seen in the above calculation, long-term environmental effects are not taken into account by ACI 440.2R-08. 


$$
\begin{aligned}
& V_{f}=\frac{A_{f v} f_{f e}(\sin \alpha+\cos \alpha) d_{f v}}{s_{f}} \\
& s_{f-\text { design }} \leq \frac{A_{f v} f_{f e}(\sin \alpha+\cos \alpha) d_{f v}}{V_{f}}=\frac{\left(0.13 \mathrm{in}^{2}\right)(132 \mathrm{ksi})(1)(37.8 \mathrm{in})}{(30.9 \mathrm{kips})} \\
& s_{f-\text { design }} \leq 20.9 \mathrm{in} .
\end{aligned}
$$

The CFRP strip spacing is selected as $20 \mathrm{in}$.

$$
\begin{aligned}
& V_{f}=\frac{A_{f v} f_{f e}(\sin \alpha+\cos \alpha) d_{f v}}{s_{f}}=\frac{\left(0.13 \mathrm{in}^{2}\right)(132 \mathrm{ksi})(1)(37.8 \mathrm{in} .)}{(20 \mathrm{in} .)}=32.4 \mathrm{kips} \\
& \phi\left(V_{c}+V_{s}+\psi V_{f}\right) \geq V_{u} \\
& 0.75[77.5 \text { kips }+38.9 \text { kips }+0.85(32.4 \mathrm{kips})] \geq 107 \text { kips } \\
& 108 \text { kips } \geq 107 \text { kips } \text { OK }
\end{aligned}
$$

\section{PROPOSED SOLUTION METHOD}

As demonstrated in the design example, ACI 440.2R-08 does not take into account the potentially deleterious long-term environmental exposure effects on shear strength provided by CFRP reinforcement for the given material type. To account for environmental exposure using the current ACI 440.2R-08 environmental reduction factors, a proposed modification is applied to the effective stress formula as:

$$
f_{f e}=\min \left\{\begin{array}{c}
\frac{k_{1} k_{2} L_{e}}{468} C_{E} \\
0.75 C_{E} \varepsilon_{f u}^{*} \\
0.004 C_{E}
\end{array}\right\} \times E_{f}=\min \left\{\begin{array}{c}
\frac{(1.000)(0.947)(2.0 \mathrm{in} .)}{468}(0.85) \\
(0.75)(0.85)(0.017 \mathrm{in} . / \mathrm{in} .) \\
0.004(0.85)
\end{array}\right\} \times 33 \times 10^{3} \mathrm{ksi}
$$


$f_{f e}=\min \left\{\begin{array}{l}0.0034 \\ 0.0110 \\ 0.0034\end{array}\right\} \times\left(33 \times 10^{3} \mathrm{ksi}\right)=112 \mathrm{ksi}(910 \mathrm{MPa})$

when long-term environmental effects are taken into account:

$$
\begin{aligned}
& V_{f}=\frac{A_{f v} f_{f e}(\sin \alpha+\cos \alpha) d_{f v}}{s_{f}} \\
& s_{f-\text { design }} \leq \frac{A_{f v} f_{f e}(\sin \alpha+\cos \alpha) d_{f v}}{V_{f}}=\frac{\left(0.13 \mathrm{in}^{2}\right)(112 \mathrm{ksi})(1)(37.8 \mathrm{in})}{(30.9 \mathrm{kips})} \\
& s_{f-\text { design }} \leq 17.8 \mathrm{in} .
\end{aligned}
$$

The CFRP strip spacing is selected as 17 in.

$V_{f}=\frac{A_{f v} f_{f e}(\sin \alpha+\cos \alpha) d_{f v}}{s_{f}}=\frac{\left(0.13 \mathrm{in}^{2}\right)(112 \mathrm{ksi})(1)(37.8 \mathrm{in} .)}{(17 \mathrm{in} .)}=32.4 \mathrm{kips}$

$\phi\left(V_{c}+V_{s}+\psi V_{f}\right) \geq V_{u}$

$0.75[77.5$ kips +38.9 kips $+0.85(32.4$ kips $)] \geq 107$ kips

108 kips $\geq 107$ kips $\quad$ OK

Alternatively, a different material thickness could be used with wider spacing.

Additionally, bond stresses need to be calculated by constructing the average shear stress vs. stirrup quantity curve based on MV interaction: 


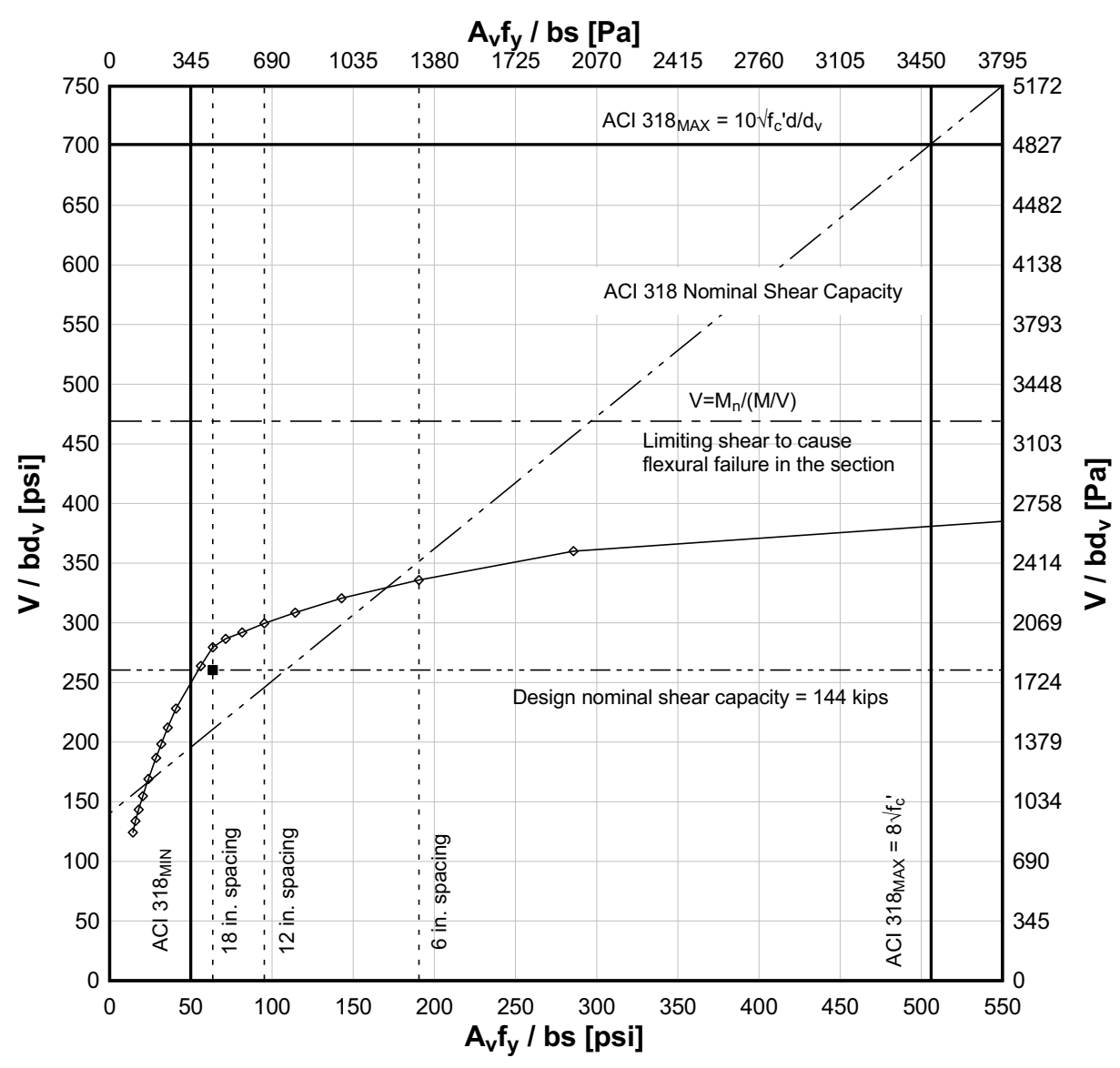

Figure C-1.2: Comparison of nominal shear capacity to MV interaction.

Since the nominal shear capacity is below the average shear stress vs. stirrup quantity curve based on MV interaction, effective bond stresses do not need to be checked. 